\title{
The Behavioural Sciences in Dialogue with the Theory and Practice of Analytical Psychology
}

\author{
Edited by \\ Lucy Huskinson
}

Printed Edition of the Special Issue Published in Behavioural Sciences

\section{MDPI}


Lucy Huskinson (Ed.)

\section{The Behavioural Sciences in Dialogue with the Theory and Practice of Analytical Psychology}


This book is a reprint of the special issue that appeared in the online open access journal Behavioral Sciences (ISSN 2076-328X) in 2013 (available at:

http://www.mdpi.com/journal/behavsci/special_issues/analytical-psychology).

Guest Editor

Lucy Huskinson

School of Philosophy and Religion, Bangor University

Bangor, Gwynedd, LL57 2DG, UK

Editorial Office

MDPI AG

Klybeckstrasse 64

Basel, Switzerland

Publisher

Shu-Kun Lin

Production Editor

Dr. Martyn Rittman

\section{Edition 2014}

MDPI • Basel • Beijing

ISBN 978-3-03842-003-3

(C) 2014 by the authors; licensee MDPI, Basel, Switzerland. All articles in this volume are Open Access distributed under the Creative Commons Attribution 3.0 license (http://creativecommons.org/licenses/by/3.0/), which allows users to download, copy and build upon published articles even for commercial purposes, as long as the author and publisher are properly credited, which ensures maximum dissemination and a wider impact of our publications. However, the dissemination and distribution of copies of this book as a whole is restricted to MDPI, Basel, Switzerland. 


\section{Table of Contents}

\section{Preface}

Guest Editor : Lucy Huskinson i

\section{Chapter 1}

\section{Raya A. Jones}

Jung's "Psychology with the Psyche" and the Behavioral Sciences

Reprinted from Behav. Sci. 2013, 3(3), 408-417; doi:10.3390/bs3030408 .1

http://www.mdpi.com/2076-328X/3/3/408

\section{Chapter 2}

\section{Robin McCoy Brooks}

Accounting for Material Reality in the Analytic Subject

Reprinted from Behav. Sci. 2013, 3(4), 619-633; doi:10.3390/bs3040619 11

http://www.mdpi.com/2076-328X/3/4/619

\section{Chapter 3}

\section{Steve Myers}

Normality in Analytical Psychology

Reprinted from Behav. Sci. 2013, 3(4), 647-661; doi:10.3390/bs3040647

http://www.mdpi.com/2076-328X/3/4/647

\section{Chapter 4}

\section{Maryann Barone-Chapman}

Gender Legacies of Jung and Freud as Epistemology in Emergent Feminist Research on

Late Motherhood

Reprinted from Behav. Sci. 2014, 4(1), 14-30; doi:10.3390/bs4010014 .41

http://www.mdpi.com/2076-328X/4/1/14

\section{Chapter 5}

\section{Jay Sherry}

Beatrice Hinkle and the Early History of Jungian Psychology in New York

Reprinted from Behav. Sci. 2013, 3(3), 492-500; doi:10.3390/bs3030492.

http://www.mdpi.com/2076-328X/3/3/492

\section{Chapter 6}

\section{William E. Smythe}

The Dialogical Jung: Otherness within the Self

Reprinted from Behav. Sci. 2013, 3(4), 634-646; doi:10.3390/bs3040634 69

http://www.mdpi.com/2076-328X/3/4/634 


\section{Chapter 7}

\section{Giovanni B. Caputo}

Archetypal-Imaging and Mirror-Gazing

Reprinted from Behav. Sci. 2014, 4(1), 1-13; doi:10.3390/bs4010001

http:/www.mdpi.com/2076-328X/4/1/1

\section{Chapter 8}

\section{Diogo Valadas Ponte and Lothar Schäfer}

Carl Gustav Jung, Quantum Physics and the Spiritual Mind: A Mystical Vision of the Twenty-First Century

Reprinted from Behav. Sci. 2013, 3(4), 601-618; doi:10.3390/bs3040601 .97 http://www.mdpi.com/2076-328X/3/4/601

\section{Chapter 9}

\section{Caifang Zhu}

Jung on the Nature and Interpretation of Dreams: A Developmental Delineation with

Cognitive Neuroscientific Responses

Reprinted from Behav. Sci. 2013, 3(4), 662-675; doi:10.3390/bs3040662.

http://www.mdpi.com/2076-328X/3/4/662

\section{Chapter 10}

Milena Sotirova-Kohli, Klaus Opwis, Christian Roesler, Steven M. Smith,

David H. Rosen, Jyotsna Vaid and Valentin Djonov

Symbol/Meaning Paired-Associate Recall: An “Archetypal Memory” Advantage?

Reprinted from Behav. Sci. 2013, 3(4), 541-561; doi:10.3390/bs3040541

http://www.mdpi.com/2076-328X/3/4/541

\section{Chapter 11}

\section{Christian Roesler}

Evidence for the Effectiveness of Jungian Psychotherapy: A Review of Empirical Studies

Reprinted from Behav. Sci. 2013, 3(4), 562-575; doi:10.3390/bs3040562 151

http://www.mdpi.com/2076-328X/3/4/562 


\section{Preface}

Just over one hundred years ago, Jung coined the term, "Analytical Psychology" to differentiate his theories about the nature and dynamics of the human psyche from the "psychoanalytic" theories of his compatriot, Sigmund Freud. Whilst Jung and his compatriots in related schools of "depth psychology" spoke of "the unconscious" as the driving instinctual force of the mind, scientists today refer principally to the "brain" and its neurological functions and processes.

Despite this change in focus, Analytical Psychology, as a recognized corpus of thought and therapeutic practice in its own right, continues to incite dialogue and debate with many other academic traditions, praxes, and fields of study, far beyond its own psychological and psychiatric disciplinary origins. Ideas of analytical psychology can be found in disciplines as wide ranging as business studies, social theory, education, neuroscience, political thought, linguistics, literature, history and historiography, religious studies, quantum physics, environmental studies, fine art and art history, media, and film. Similarly, analytical psychology as a therapeutic practice, is very much in demand within an eclectic range of fields of human care, including those that are relatively new, such as, terminal health care, HIV counselling, political consultation, reconciliation of interfaith groups, relief work to victims of natural disaster, consultation on matters of ecological sustainability, and so on. Analytical psychology's widespread appeal demonstrates its usefulness in establishing connections between otherwise disparate disciplines so as to make better sense of our human behaviors, motivations, and values.

The mutual interests of analytical psychology and the behavioral sciences in charting the territories of the human mind suggest that there are many fruitful and insightful conversations to be had between them. However, compared to other disciplinary pairings with analytical psychology, dialogues with the behavioral sciences have been a somewhat slow and cautious affair. Prejudices abound from either side about each other's epistemological and methodological concerns. Crudely put, behavioral science, on the one hand, attempts to arrive at verifiable, objective conclusions through rigorous experimental and statistical methods; analytical psychology, on the other, tries to make sense of the unconscious, which, by its very nature, evades rational comprehension and quantifiable measurement, expressing itself through the language of symbols, contradiction, and paradox. At a glance, the two are uncomfortable bedfellows, viewing each other with more than a degree of suspicion. From the perspective of behavioral science, analytical psychology may seem akin to a mystical quest, seeking ethereal, transcendent forms, and thus perhaps better off conversing with disciplines in the arts and humanities. Whilst, behavioral science, from the perspective of analytical psychology may appear too reductive, chasing after the chimera of "truth" and "proof", and missing the only authentic measurement of meaning: whatever the subject himself or herself 
understands to be true. One would be forgiven for holding such prejudices, but, as several of the chapters in this volume demonstrate, such polarization of the two fields is unwarranted, and, despite their epistemological differences, fruitful dialogue can be had between them.

The chapters within this volume make reference to a variety of different academic approaches and their attempts to elucidate the theory and practice of analytical psychology, including philosophy, cognitive psychology, neuroscience, quantum physics, social theory, historiography, and feminism. They also offer contrasting conclusions about the ease and manner in which analytical psychology can converse with the behavioral sciences; some accentuate fertile overlaps of the two, others emphasize barren margins that separate the two and which cannot be overcome. Some of the chapters seem almost unaware of the ideological differences between the two, as they focus instead on testing the central ideas of analytical psychology, and subject them to rigorous "scientific" experimentation in order to demonstrate their veracity and coherence with supporting empirical evidence. Others still, identify problems within specific ideas of analytical psychology with a view of resolving them problems that could potentially inhibit productive dialogues between analytical psychology and other disciplines, including the behavioral sciences.

The volume begins with a piece by Raya Jones (Chapter One), who puts forward a clear case for the mismatch between analytical psychology and the behavioral sciences, citing differences in their historical development and epistemological grounding as reasons for their estrangement. Jones describes some of the difficulties that behavioral scientists inevitably have in trying to engage and fathom Jung's methodology of inductive reasoning, and she outlines why Jung's methods and powerful writing style make him more receptive to artists and literary writers. One issue with Jung's ideas - which is both problematic and liberating - is that they can be interpreted in many different, often competing, ways, leading, at best, to a rich resource for hermeneutic exploration, and at worse, to riddles that frustrate and confuse with their lack of clarity.

From Jones' words of caution for those expecting a simple and straightforward dialogue between analytical psychology and the behavioral sciences, we move on to five studies that examine Jung's conception of the unconscious as transcendent and autonomous in its relationship to ego-consciousness, and thus as a non-rational force that underpins our behavior. These chapters explore the ramifications of the unconscious for making sense of human subjectivity. Three of these studies find Jung's model of the nature and role of the unconscious problematic in its failure to engage adequately with important aspects of our personal, cultural, and social experiences; namely, the material reality of our environment (Brooks); the collective norms of society and our social personas (Myers); and the feminine (Barone-Chapman). Each of these studies attempt to find resolutions to the problems they identify in order to present a more coherent or useful model that is faithful to the concerns of analytical psychology. The remaining two studies in this part of the volume expound on the uncanny effects of the autonomous unconscious. They describe how the unconscious can impact our conscious awareness, in such a way as to animate our sense of self; the unconscious often incites within us striking impressions of ourselves as having multiple faces (Caputo), and multiple personalities (Smythe). 
Robin McCoy Brooks' philosophical study (Chapter Two) outlines various cross-disciplinary studies that attempt to arrive at new conceptualizations of subjectivity through the lenses of neurobiology, psychoanalysis, and philosophy. Brooks argues that for analytical psychology to engage more widely in such debates, and thereby enable its important insights to be shared, analytical psychology needs to address more explicitly the role played by the material world in the formation of the subject. In other words, Brooks believes that Jung's understanding of subjectivity privileges independent, transcendent sources of meaning, at the expense of the material, organic conditions that also act on the subject in the course of its development. Brooks attempts to resolve this problem, as she perceives it, by revising Jung's model, but in such a manner that continues to acknowledge Jung's dependence on a post-Kantian epistemological foundation which regards the subject as essentially split between the social/biological and psychical realms. Brook draws on ideas of the post-Lacanian psychoanalysts/philosophers, Slavoj Žižek, Adrian Johnston, and Jean Laplanche in her arguments.

Steve Myers continues in Chapter Three to critique the notion of subjectivity that is extolled, not so much by Jung himself, but by post-Jungians and contemporary scholarship in analytical psychology. According to Myers, the tendency in recent years has been to focus too heavily on the process of individuation and, by extension, the relationship between the unconscious and ego-consciousness in the development of the subject. Myers claims that by doing so, such studies often overlook the value of Jung's ideas in relation to the external, social, and collective environments. Myers argues that conceptions of "normality" and the "normal" subject are rarely examined within the scholarship of analytical psychology, unlike that of psychoanalysis and mainstream psychology. This is due in large part to Foucault's grand attack of psychoanalysis, and his apparent lack of interest in analytical psychology. Importantly, Myers argues that the situation is unlikely to change if scholars of analytical psychology continue to devote their energies to processes of individuation at the expense of collective processes; for him, focusing too much on the relationship between the ego and the unconscious risks neglecting the equally important relationship between the ego and the social persona.

In Chapter Four, Maryann Barone-Chapman criticizes the classical models of analytical psychology and psychoanalysis for their unhelpful and unwarranted constructions of femininity, which seek to undermine the feminine in attempts to extol a patriarchal, essentialist concept of the subject. In this respect, echoing themes of Myers' study, we find in Barone-Chapman's essay the contrasting problem of finding within the values of depth psychology a notion of "normality" that has been over-determined; this is to say that the promotion of the masculine over the feminine prescribes a notion of normality that no longer fits (and perhaps never has fit) our needs. After outlining various problems with the reductive values instilled within these disciplines, Barone-Chapman cites some important works in contemporary Jungian scholarship that seek to redress the balance by revitalizing and freeing the feminine from its confines, and thereby presenting a more realistic, conception of subjectivity. 
Following Barone-Chapman's restoration of the feminine within analytical psychology, Jay Sherry (Chapter Five) presents an important historical paper that charts the career of Beatrice Hinkle-a feminist and the first Jungian psychoanalyst of America - and her invaluable efforts to help establish the institutional basis of analytical psychology in America. Hinkle is most often remembered for having translated Jung's great tome, Wandlungen und Symbole der Libido, as Psychology of the Unconscious (1916), a book now known as Symbols of Transformation. Regrettably for researchers, Hinkle's personal papers, which would have included her correspondence with Jung, have been destroyed. This makes Sherry's historical overview of Hinkle's life and works all the more important, as it enables us to recognize the significant career and influence of this important figure in both the development and reception of analytical psychology in the English speaking world.

From Sherry's historical overview, we return to the theoretical investigation of analytical psychology with William E. Smythe's study (Chapter Six). Smythe examines the plurality of subjectivity to explain how our experience of ourselves is irrevocably embedded within a composition of real and imagined dialogues with others. The notion of a 'dialogical' self, as opposed to a consciousness that is self-contained, has become increasingly popular within psychological theories since the 1990s. Smythe explains how its central idea, of the "otherness" within the self, can be traced within the theory and practice of analytical psychology, most notably within the method of active imagination, and the theory of archetypes. He goes on to explain how the common ground between analytical psychology and dialogical theory can lead to further insights for both fields of study.

Giovanni B. Caputo (Chapter Seven) continues to analyze the impact of the unconscious on our sense of self by explaining how the "otherness" of the unconscious can be detected through a mirror reflection of ourselves. Caputo first examines the object of the mirror and its symbolism within various related disciplines, as one that invites us to discover ourselves anew. Following this, he discusses recent empirical investigations that explain how a sustained gaze of one's face reflected in a mirror can lead to its distorted image, one that is uncanny and unfamiliar. Caputo makes sense of this curious phenomenon with the Jungian concepts of dissociation and projection, and understands it as an experience of the unconscious "other" that is projected on to the mirror image of the face. Interestingly, Caputo argues that patients with depression are able only to perceive slight changes or none at all in their mirror image - a consequence, Caputo claims, of their diminished capacity to dissociate from their experiences of self, which means the unconscious contents they have to project onto the mirror is less pronounced.

The final part of the volume concludes with four studies that each exemplify productive dialogues between analytical psychology and behavioral sciences. These studies consult a range of empirical "sciences" to both elucidate the central tenets of the theory and practice of analytical psychology and subject them to objective scrutiny. 
Diogo Valadas Ponte and Lothar Schäfer (Chapter Eight) consider the basic postulates that unite quantum physics and the archetypal theory of analytical psychology. This study offers an ironic twist to the claim that analytical psychology appears closer to mysticism than behavioral "science" per se, by asserting that the science of quantum physics is itself a form of mysticism, as it is grounded in the idea that all things are interconnected, which is to say that our individual minds are connected and part of a larger, non-material "cosmic mind". Valadas Ponte and Schäfer explain how the discoveries of quantum physics parallel those of analytical psychology. They outline in particular how the non-material basis of reality can appear as physical, material forms in the external world, and as archetypal contents within our minds. Arguably, it would require a thorough mathematical understanding of quantum physics and similar depth of knowledge of Jungian psychology to establish a comprehensive dialogue between the two. Nevertheless, Ponte and Schäfer, provide a lucid outline of the grounds upon which such a conversation can be had.

Caifang Zhu (Chapter Nine) investigates the nature and interpretation of dreams from the perspectives of archetypal psychology and neuroscience. He does so in order to explain how the findings of the latter both challenge, enrich, and to some extent, confirm Jung's own contributions to the theory of dreams. After outlining, through a textual exegesis of Jung's writings, Jung's changing views about the nature and dynamics of dreams, Zhu concludes that Jung's dream theory cannot be reduced to notions of compensation, as the majority of scholars of analytical psychology contend. Zhu ends his study with the assertion that our understanding of dreaming can be greatly enhanced with cross-disciplinary studies, not least those of neuroscience and analytical psychology.

From Zhu's study of dreams, which are for Jung, communications of the unconscious, archetypal meanings, we turn in Chapter Ten to an empirical study on the conscious recall of archetypal meanings. Milena Sotirova-Kohli, Klaus Opwis, Christian Roesler, Steven M. Smith, David H. Rosen, Jyotsna Vaid, and Valentin Djonov discuss the results of an experiment that tests the Jungian hypotheses of archetypes, archetypal memory, and the collective unconscious. The experiment involved 402 participants, who were tested in their capacity to learn and to recall meanings attributed to forty given archetypal images. Half of the images were presented to the participants with their accepted archetypal definitions or meanings, the remaining images were presented with definitions or meanings that did not correspond to them. The authors found that a statistically significant higher proportion of participants were able to learn and to recall the meaning pairings of those images that were matched with their associated archetypal definitions, compared to the mismatched pairings. Given that the findings of the experiment, which was conducted in the German-speaking region of Switzerland, corroborate those previously found in a similar experiment undertaken by English speakers in America, the authors conclude that the presentation of the image with its associated archetypal meaning facilitates a positive effect on learning and recall, one that cannot be accounted for by specific cultural or linguistic factors, but rather, goes some way to demonstrating the validity of the archetypes and the collective unconscious. 
Christian Roesler (Chapter Eleven) closes this volume with a review of empirical studies concerning the efficacy of analytical psychology as a therapeutic practice; these studies have been undertaken since the 1990s. The studies Roesler outlines demonstrate significant improvements to the patients and clients concerned; improvements that continue to be experienced for several years after the therapeutic treatment. Such improvements that were reported include decreases in the severity of symptoms and interpersonal problems, and in general, improved overall behavior. Roesler further outlines how significant improvements in the psychological health of those patients via Jungian therapy are achievable with an average of 90 fifty-minute sessions, thereby making Jungian therapy both a viable and cost-effective method of treatment.

\section{Acknowledgment}

I wish to thank the editors at MPDI for their help and friendliness with the production of this volume, especially Xiaoyan Liu, Xingxing Zhao, and Fuli Cao. I also thank the various reviewers for their insightful comments and expertise in helping to shape the studies in this book.

Lucy Huskinson

Guest Editor 


\title{
Chapter 1
}

\section{Jung's "Psychology with the Psyche" and the Behavioral Sciences}

\author{
Raya A. Jones
}

School of Social Sciences, Cardiff University, Glamorgan Building, King Edward VII Avenue, Cardiff CF10 3WT, UK; E-Mail: JonesRA9@cardiff.ac.uk; Tel.: +44-29-2087-5350;

Fax: +44-29-2087-4175

\begin{abstract}
The behavioral sciences and Jung's analytical psychology are set apart by virtue of their respective histories, epistemologies, and definitions of subject matter. This brief paper identifies Jung's scientific stance, notes perceptions of Jung and obstacles for bringing his system of thought into the fold of the behavioral sciences. The impact of the "science versus art" debate on Jung's stance is considered with attention to its unfolding in the fin de siècle era.
\end{abstract}

Reprinted from Behav. Sci. Cite as: Jones, R.A. Jung's "Psychology with the Psyche" and the Behavioral Sciences. Behav. Sci. 2013, 3, 408-417.

\section{Introduction}

To say that there is no place for analytical psychology in the behavioral sciences, does not mean that Jung's work has no intrinsic value or relevance elsewhere. Insofar as "behavioral sciences" denotes traditional modern psychology, analytical psychology may provide at best an Archimedean vantage point from which to critique it. Jung took that attitude. The "modern belief in the primacy of physical explanations has led ... to a 'psychology without the psyche,' that is, to the view that the psyche is nothing but a product of biochemical processes," he contended, and called for summoning up "courage to consider the possibility of a 'psychology with the psyche,' that is, a theory of the psyche ultimately based on the postulate of an autonomous, spiritual principle" ([1], par. 660-661). Conversely, analytical psychology could be critiqued from the standpoint of the behavioral sciences, especially in terms of its methodology.

Jung was making his point in 1931. Twenty-first century behavioral sciences have moved on from the psychologies he was criticizing. Yet, there remains the disparity he noted. On the one hand, sophisticated mathematical models applying dynamical systems theory, along with insights from brain imaging studies, have revitalized the interrelated notions of complexity and emergence. On the other, the trend has not resulted in a turn to holistic epistemology (on the contrary, much of it reinforces reductionism). While some contemporary Jungian analysts are attuned to conceptual trends in science (e.g., [2]), science is not attuned to the concerns of analytical psychology. The excitement about "embodied embedded cognition" is not without controversy in contemporary 
cognitive neuroscience (see, e.g., [3]); but those debates invariably concern the objective living body, not the subjectivity of the lived-in body.

Pursuits of knowledge in analytical psychology and in the behavioral sciences are set apart by virtue of their respective histories, epistemologies, and definitions of subject matter [4-6], as summarized in this communication.

\section{How did Modern Psychology Lose the Psyche}

Jung begins his essay "On the Nature of the Psyche" with a historical review [7]. Up to the seventeenth century, psychology consisted of numerous doctrines concerning the soul, but thinkers spoke from their subjective viewpoint, an attitude that is "totally alien" to the standpoint of modern science ([7], par. 343). Incidentally, the German word Seele (soul) is usually translated into English as "psyche" when Jung writes about his own theory, perhaps because to Anglophone ears of the mid-twentieth century "psyche" sounded more scientific than "soul". Jung's point was that in the past philosophers' theorizing was based on a naïve belief in the universal validity of their subjective opinions. Having reviewed the objectivity of modern science as an improvement upon pre-Enlightenment thinking, he comments that we can never remove ourselves from the subjective situation: "every science is a function of the psyche, and all knowledge is rooted in it" ([7], par. 357). Psychology as a science thus finds itself in an acute paradox, for "only the psyche can observe the psyche" ([8], par. 384).

Spelling out the absurdity of the mind trying to observe itself, Comte had relegated psychology to a prescientific stage, and contended that psychologists mistook their own fantasies for science [9]. In Comte's "metaphysical" stage, the supernatural beings of the primitive stage are replaced with "abstract forces, veritable entities (that is, personified abstractions) inherent in all beings, and capable of producing all phenomena" ([9], p. 26). This characterization readily applies to notions of libidinal forces and to innate archetypes. In the "scientific" stage, according to Comte, the mind applies itself to the study of the laws of phenomena, describing their invariable relations of succession and resemblances. The behavioral sciences have aspired towards the positivist ideal. The discipline's historiography dissociates psychology not only from philosophy but also from "metaphysical" depth psychology.

Comte was referring to the long history of psychology as a natural science. Philosophers following the Aristotelian tradition regarded the science of the mind as belonging to physics (i.e., the science of nature). However, in the twentieth century, psychology became equated with quantitative experimental methodology, and this "scientific" character was contrasted with the "metaphysical" character of its earlier namesake [10]. Textbooks written by psychologists typically describe psychology as coming into being by virtue of its split from philosophy when Wundt opened the first laboratory in Leipzig in 1879. Between 1880 and 1920, American psychologists waged a battle against spiritualism and psychic research in their attempt to define boundaries for their new discipline [11]. William James started his essay "A Plea for Psychology as a "Natural Science", with the contention that although psychology was "hardly more than what physics was before Galileo ... a mass of phenomenal description, gossip, and myth," it nonetheless included enough "real material" to justify optimism about becoming "worthy of the name of natural science at no very distant day" ([12], p. 146). Four decades later, Lewin admitted that the battle "is not by any means 
complete," but optimistically opined that the "most important general circumstances which paved the way for Galilean concepts in physics are clearly and distinctly to be seen in present-day psychology" ([13], p. 22). To date, a Galilean revolution has not happened. Yet, as Coon put it, psychology "has never recovered from its adolescent physics envy" ([11], p. 143). Although psychologists today seldom compare their science to physics, they tend to locate it within the natural sciences. For instance, Fuchs and Milar trace the origins of psychology to physiology (not philosophy) and its branching into psychophysics, and then through behaviorism to cognitive psychology [14].

Any telling of history is selective, biased in some way; and the bias serves an agenda. Costall exposes "a comprehensive and highly persuasive myth" about the origins of scientific psychology ([15], p. 635). He notes that according to most textbooks, psychology began as the study of mind based on the introspective method (associated with Wundt's laboratory). In reaction to the unreliability of that method, behaviorism redefined psychology as the study of behavior, based on experimentation. In reaction to the bankruptcy of behaviorism, the cognitive revolution restored the mind as the proper subject of psychology, but now with the benefit of the rigorous experimental and statistical methods developed by the behaviorists - a storyline that has the structure of Hegelian thesis-antithesis-synthesis. Revisiting the early literature, Costall demonstrates that all three stages of this history are largely fictional. Moreover, "the inaccuracies and outright inventions of "textbook histories' are not just a question of carelessness. These fictional histories help convey the values of the discipline, and a sense of destiny" ([15], p. 635).

The psychoanalytic movement has been written out of that history and destiny (Costall does not mention it). However, in Jung's time and place, "medical psychology" was more separate from the then-new science of psychology than present-day clinical psychology is from the behavioral sciences. In late-nineteenth century German universities, vested interests of influential professors played a key role in the designation of experimental psychology to the natural sciences [16]. Dilthey regarded psychology as belonging in the humanities on grounds that it concerns inner experience [17]. Drawing a contrast between the outer experience of nature (which is presented as phenomenal and in isolated data) and the inner experience of psychic life, which is holistically presented as a living active reality, Dilthey argued that for psychology to imitate a method that was successful in the natural sciences would involve treating an interconnected whole as if it were merely an assemblage of discrete entities. It would mean overriding descriptions of the subjectively lived experience in favor of the hypothetico-deductive method [18]. This argument has lost out in university departments; but it is implicitly sustained by analytical psychology to date.

\section{Jung's Scientific Stance}

Foucault attributed the creation of the modern "soul" to historical conditions set in motion in the eighteenth century. Concepts such as psyche, subjectivity, personality, consciousness, etc., were created so as to carve out domains of analyzing the post-Enlightenment soul, building upon it "scientific techniques and discourses, and the moral claims of humanism" ([19], p. 30). The moral claim is implicit in Jung's statement, "We doctors are forced, for the sake of our patients, ... to tackle the darkest and most desperate problems of the soul, conscious all the time of the possible 
consequences of a false step" ([20], par. 170). Yet, it is a paradox of modernity that when we seek to apply scientific techniques and discourses, the soul — the seat of subjectivity—vanishes.

Jung was a man of science by virtue of being a medical doctor, but he was not a scientist. He averred that unlike experimental psychology, analytical psychology does not isolate functions and then subject them to experimental conditions, but is "far more concerned with the total manifestation of the psyche as a natural phenomenon" ([20], par. 170). To him, the totality includes the unconscious as well as conscious mind. Being centered on the unconscious characterizes analytical psychology as a psychology with the psyche; and this characterization means that it would "certainly not be a modern psychology," since "all modern 'psychologies without the psyche' are psychologies of consciousness, for which an unconscious psychic life simply does not exist" ([1], par. 658).

However, his psychology does not merely state that an unconscious exists. It is premised on the notion that its existence can be demonstrated through observations of its effects. In this regard, his psychology is modern. It subscribes to the worldview — not the method — of modern science. As Weber put it in 1918, "The fate of our times is characterized by rationalization and intellectualization and, above all, by the 'disenchantment of the world"' ([21], p. 155); (see [22] for a historian's account of this worldview). The model of the psyche that Jung was formulating in the same era could be viewed as an attempt to rationalize and intellectualize the enchantment of the world in myths, beliefs in the supernatural, and so forth.

Jung unwaveringly professed a scientific stance, as did Freud. Making a case for psychoanalysis as a science, Freud defined Weltanschaunng (worldview) as "an intellectual construction which solves all the problems of our existence uniformly on the basis of one overriding hypothesis" ([23], p. 195). Unlike religion, the Weltanschauung of science does not provide final answers. It "too assumes the uniformity of the explanation of the universe; but it does so only as a program, the fulfillment of which is relegated to the future" ([23], p. 196). Jung took a more categorical view: "A science can never be a Weltanschauung but merely a tool with which to make one" ([8], par. 731). Therefore "Analytical psychology is not a Weltanschauung but a science, and as such it provides the building-material ... with which a Weltanschauung can be built up" ([8], par. 730).

From the standpoint of behavioral sciences, depth psychology is a Weltanschauung that purports to solve all the mysteries of mind and behavior on the basis of one overriding (and irrefutable) hypothesis; namely, there is an unconscious mind. Could the unconscious be an object for scientific study? Such an object must exist independently of any description or interpretation of it and potentially be knowable in its entirety. Jung recognized the problems inherent in applying those criteria to the study of the psyche. Modern psychology "does not exclude the existence of faith, conviction, and experienced certainties of whatever description, nor does it contest their possible validity," he pointed out, but "completely lacks the means to prove their validity in the scientific sense" ([24], par. 384). The dilemma stems from a mismatch between what we may want psychology to do for us (explain matters of faith, etc.) and what the scientific method permits us to do.

The history of psychology in general could be viewed as an ongoing struggle with that dilemma. Often the "solution" has been to construe what Jung regarded as expressions of the psyche as being epiphenomena of either brain processes or language. As William James vividly put it, scientific thinking regards our private selves like "bubbles on the foam which coats a stormy sea ... their destinies weigh nothing and determine nothing" ([25], p. 495). Yet nevertheless there is the reality of 
an "unshareable feeling which each one of us has of the pinch of his individual destiny," a feeling that "may be sneered as unscientific, but it is the one thing that fills up the measure of our concrete actuality" ([25], p. 499). Jung could be viewed as endeavoring to formulate a system of concepts towards the systematic description of how that unshareable feeling becomes shareable - not only with other people, but first and foremost with one's conscious self. It becomes accessible to conscious reflection through spontaneous symbolic representations of subjective states, Jung tells us throughout his works.

\section{Perceptions of Jung from the Standpoint of Scientific Psychology}

Jung engaged with matters that were central to the formation of psychology as a modern science in the early twentieth century [26]. His early theory of the complexes, supported by the word association tests [27], accorded well with the experimental psychology of the day. Piaget still engaged with Jung's theory in 1946 [28]; but by then Jung had fallen from grace in his home discipline, psychiatry.

A browse through archives of Nature is illuminating. In a 1942 book review, the reviewer derogatorily labeled the Jungian approach a mystical psychology [29]. While applauding Jung's early theory of the complexes as "scientific as any made before or since" in psychiatry, he reflected that Jung subsequently "abandoned his clinical work and most unfortunately started upon the study of religions and myths," having "forsaken science for religion" ([29], p. 622). The critic misconstrued what Jung was doing. Jung was trying to explain religion scientifically. Nevertheless, after the word association experiments, the way Jung develops his ideas is not recognizably science as scientists know it. Consequently, even sympathetic critics were ambivalent about how to assess Jung's contribution to science. In a 1954 review for Nature, Westmann commented that the book in focus (a collection of Jung's writings) "shows the fundamental weakness of Jung's psychology, which by having no fixed scheme appears to be full of contradictions and paradoxes; but this weakness is at the same time a sign of his greatness" ([30], p. 842). He elucidates by citing Heraclitus's adage that you cannot step twice into the same river, and averring that "the life in the psyche manifests itself thus" ([30], p. 842). Talking of "life in the psyche" as taken-for-granted locates the speaker in the historical moment when the peculiarly modern Western conception of the self as an atomic unit was at its zenith. That conception has led to postulations of a universal mental structure as a necessity of nature. Jung reasoned, "Just as the human body represents a whole museum of organs, with a long evolutionary history behind them, so we should expect the mind to be organized in a similar way" ([31], par. 522). And yet, this inner structure is in constant flux like the proverbial river.

Despite the proliferation of Jungian books in the second half of the twentieth century, there are no more reviews of such books in Nature after 1961 [32]. Readers of Nature are no longer expected to be interested in a mystical psychology. Contemporary scholars who study Jung are far more likely to be based in the humanities than in the behavioral or social sciences.

Analytical psychology has been thoroughly removed from the scientific gaze. While there are sound reasons for dismissing claims that analytical psychology is scientific [5,6], there are not-so-good reasons, based in ignorance and misconceptions, for dismissing Jung. "We American psychologists are brought up to think of Jung as a mystic" ([33], p. 34). This applies also to British 
psychologists; or, rather, we have been brought up to think of Jung as a non-entity. In a typical syllabus, Jung features as a historical footnote to Freud. The Freudian story, which depicts Jung as a dissenting disciple, persisted after the behaviorists had debunked Freudianism. It was retained after behaviorism had given way to cognitivism. By the time that social constructionist critics of cognitivism appeared on the scene, Jungianism was too remote even to criticize. Meanwhile Freud was rediscovered, partially reinvented, by luminaries of postmodernism, and consequently arrived also in some variants of postmodern psychology. Jung remains excluded. Psychologists' heightened moral and political sensitivities coincided with highly publicized allegations of Jung's Nazi sympathies and anti-Semitism. The allegations are mostly unfounded [34,35], but the scandal has placed Jung off-bounds: "For political reasons I cannot allow myself to read Jung with pleasure," stated Billig ([36], p. 6).

Reading Jung is difficult with the best of will. The vast sweep of his eclectic knowledge results in verbose density and opacity. Navigating his voluminous writings inevitably means selecting threads of personal interest. Hence, Jung speaks differently to different readers. While there are books that reliably disseminate Jungian theory at a basic level, any simplification forfeits what historian Pietikäinen has aptly described as the kaleidoscopic nature of Jung's psychology [37]. Many Jung-oriented publications have little in common with each other, and some have a dubious relation to Jung's own work. There is "a profusion of "book-length commercials of Jungian therapy" and "pseudo-religious apologetics" ([37], p. 27). There are also works of academic excellence in analytical psychology; but their content tends to be too esoteric for the uninitiated. All that does not help to make Jung's work a respectable pursuit for a behavioral scientist.

\section{Obstacles to Bringing Jung into the Fold}

In and out of academia, "Jung" has become a kind of brand name that can be stamped on a variety of products. Since Jung regarded himself as first and foremost a psychologist, it is ironic that his work is appreciated by psychologists least of all. For the "typical" psychologist, the above barriers to engaging with Jung's work are compounded by bafflement about what he was doing exactly. Readers of Jung schooled in the humanities may recognize a hermeneutic approach in his interpretation of myths, ancient scripts, and patients' fantasies and dreams. Traditionally trained academic psychologists are not attuned to such methods. It is not clear how Jung gets from observation to theory. His transition from observing recurrent motifs in clinical and mythological material to a full-blown theory of archetypes is too rapid. He seems to be reading into the material his own expectations about the structure and dynamics of the psyche. Jung's hypotheses must be taken on faith. Believers see the evidence everywhere, and seem to understand the task of empirical research as a matter of compiling catalogues of instances. It is not the logic of scientific discovery (cf. [38]; see [4-6] for an expanded discussion).

Jung talked the talk but didn't do the walk. For most psychologists, it is primarily the praxis of psychological inquiry that differentiates it from other disciplines that also investigate mind and behavior. To some psychologists, it is not just any methodology but specifically the hypothetico-deductive method that makes it a science. Not all psychologists adhere to it in practice; but historically that classic ideal has dominated the behavioral sciences. The hypothetico-deductive method had been proposed by William Whewell in the nineteenth century, though it was Popper who 
has given it its best-known articulation [38]. In the 1930s, Popper contested the then-prevalent viewpoint associated with logical positivism, which regarded inductive reasoning as the basis for scientific inquiries. Induction proceeds from an initial explanation of some observations to its confirmation by collecting further empirical examples. This epistemological sin can be found in Jung's progression from (a) observing recurrent motifs in dreams, visions, myths, etc., through (b) theorizing those as archetypal manifestations, to (c) seeking to conform the existence of archetypes by observing more instances of the same.

Despite Jung's scientific stance, it is difficult to assimilate his ideas into the behavioral sciences not only due to how he went about validating them but also due to a lack of obvious connections with the ongoing preoccupations of the behavioral sciences. Even within Jungian circles, it is far from clear what "archetype" really means - lively debates continue to present day - partly because Jung's own ideas changed over time [39]. Brooke attributed the difficulties that "psychologists of other persuasions" have with the concept to the fact that "archetypes seem mysterious, deep, remote, frightening, and enchanting, and thinking about them remains equally murky and ambivalent" ([40], p. 157). From my position as a non-Jungian psychologist, the problem is not necessarily the murkiness of the concept. There is little certainty at the cutting edge of science. If the concept were to excite scientists, its ramifications would have been explored. Rather, it is the point of postulating archetypes in the first place which eludes us "psychologists of other persuasions". The very postulation seems redundant, a solution to a non-existing problem, an answer to a question that nobody else is asking.

\section{Science versus Art}

The concept of archetypes failed to interest behavioral scientists, but has long fired the imagination of artists and literary writers. Jung's theory is a powerful narrative. It might be correct in the way that a poem or a literary novel is correct; that is, as a whole coherent unto itself, all its elements in perfect relation to each other. A poetic gestalt-image impacts upon us aesthetically and emotionally irrespective of the factual veracity of its content. Whereas science seeks to establish objective truths about the world (and human nature) by narrowing down rival interpretations, the poetic process creates subjective truths through the multiplicity of overlain images and subjective connotations.

Jung uses a similar strategy (cf. [41]). His hypotheses are speculative explanations-not testable predictions à la Popper — and he builds them by piling examples upon examples. Making a similar point, Hillman commented that Jung uses the word "empirical" to refer to a subjective process within him: "The empirical event - the solar-phallus image in a patient-releases a movement in the mind setting off a hypothesis ... as a poem may start in a concrete perception"; and like a poet, "Jung returns ever and again to the concrete world of perceptions (cases, dreams, religious fantasies, ancient texts)" ([42], p. 32-33).

Jung struggled with the incommensurability of science and art. In a talk on poetry, he asserted his standpoint as a scientist by endorsing the view of the two as mutually exclusive: "Art is by its very nature not science, and science by its very nature is not art" ([43], par. 99). The conflict came to his awareness in a typically Jungian manner, through a fantasy generated by his unconscious [44]. In 1913, whilst writing down disturbing fantasies he was having, he wondered, "What is this I am doing, it certainly is not science, what is it?"- and a voice from nowhere told him it was art, a 
suggestion he strongly resisted though conceding that "obviously it wasn't science" ([44], p. 42). The ambivalence carries across to his formal exposition of his theory. Analytical psychology is premised on the hypothesis that the psyche is an autonomous reality commanding specific energy. Yet such hypothesis "has its disadvantages for the scientific mind," Jung comments; and continues, "In accordance with my empirical attitude I ... prefer to describe and explain symbol-formation as a natural process" ([45], par. 338). His preference discloses a language game in Wittgenstein's sense (cf. [46]). Language games are not "games" but profoundly shape attitudes and perceptions. In Jung's milieu, the language game of science empowered those who came up with theories using words such as instincts, evolution, and energy; and eschewed words such as spirit. Jung labored to disengage his theorizing from religious mystification, seeking instead to explain all psychological phenomena as based in natural processes.

\section{Conclusions}

Jung's theory feels as true to some because it sounds scientific; to others it feels as false because it only sounds like that [5]. This seems like a deadlock of opinions. Instead of pinning the merit of Jung's legacy on a categorical judgment of scientific/non-scientific status, it may be best to evaluate it in terms of applicability. We should ask, for whom and in what context does it serve particular purposes, and whether those would be served by the scientific method.

The appeal of the Jungian approach in psychotherapy is evident in the worldwide success of the movement, but the clinical utility of particular concepts or techniques is not the same as their potential for generating hypotheses that scientists may explore in pure basic research. As seen, Jung himself made a categorical distinction between analytical psychology and experimental psychology [20]. Elsewhere, I revisit the implications of the differences between the practitioner's ethic and the scientist's ethic for analytical psychology and other contemporary approaches to the self [47].

Analytical psychology is not monolithic. It has its factions, and those too continuously evolve. Nevertheless, in all its versions, it concerns the holistic inner experience. It provides a way of thinking about and working with inner experiences. Hence, to echo Dilthey, it cannot be adequately served by methods of the natural sciences. Conversely, analytical psychology cannot readily serve a purpose in the behavioral sciences (in my view). It is clearly not a science of behavior in the way that the behaviorists have envisaged it. It is not a science of the mind in the way that cognitive science has been. By labeling it a psychology with the psyche, Jung implicitly positions its practitioner - not as someone who detachedly studies something called a psyche — but as someone trained to apply his or her own psyche as a tool towards trying to fathom how human beings attune themselves to own existence. 


\section{Acknowledgment}

The author wishes to thank the anonymous reviewers of an earlier draft for their helpful comments.

\section{Conflicts of Interest}

The author declares no conflict of interest.

\section{References}

1. Jung, C.G. Basic Postulates of Analytical Psychology. In The Collected Works of C. G. Jung; Routledge and Kegan Paul: London, UK, 1931; Volume 8.

2. Cambray, J. Towards the feeling of emergence. J. Anal. Psychol. 2006, 51, 1-20.

3. Van Dijk, J.; Kerkhofs, R.; van Rooij, I.; Haselager, P. Can there be such a thing as embodied embedded cognitive neuroscience? Theory Psychol. 2008, 18, 297-316.

4. Jones, R.A. Jung, Psychology, Postmodernity; Routledge: London, UK, 2007.

5. Jones, R.A., Ed. Vicissitudes of a Science-Complex. In Jung and the Question of Science; Routledge: London, UK, 2014; in press.

6. Jones, R.A. On innatism: A response to Hogenson. J. Anal. Psychol. 2003, 48, 705-718.

7. Jung, C.G. On the nature of the psyche. In The Collected Works of C. G. Jung; Routledge and Kegan Paul: London, UK, 1954; Volume 8.

8. Jung, C.G. Analytical Psychology and Weltanschauung. In The Collected Works of C. G. Jung; Routledge and Kegan Paul: London, UK, 1927; Volume 8.

9. Comte, A. The Positive Philosophy of Auguste Comte; Cosimo: New York, NY, USA, 2009; Volume I.

10. Hatfield, G. Remaking the Science of Mind: Psychology as Natural Science. In Inventing Human Science; Fox, C., Porter, R., Wokler, R., Eds.; University of California Press: Berkeley, CA, USA, 1995.

11. Coon, D.J. Testing the limits of sense and science: American experimental psychologists combat spiritualism, 1880-1920. Am. Psychol. 1992, 47, 143-151.

12. James, W. A plea for psychology as a "natural science". Philos. Rev. 1892, 1, 146-153.

13. Lewin, K. A Dynamic Theory of Personality; McGraw-Hill: New York, NY, USA, 1935.

14. Fuchs A.H.; Milar K.S. Psychology as a Science. In Handbook of Psychology: Volume 1, History of Psychology; Freedheim, D.K., Weiner, I.B., Eds.; Wiley: New York, NY, USA, 2003.

15. Costall, A. "Introspectionism" and the mythical origins of scientific psychology. Conscious. Cognit. 2006, 15, 634-654.

16. Kusch, M. Psychologis; Routledge: London, UK, 1995.

17. Dilthey, W. Introduction to the Human Sciences; Princeton University Press: Princeton, NJ, USA, 1989; Volume 1.

18. Scanlon, J. Dilthey on psychology and epistemology. Hist. Philos. Q. 1989, 6, 347-355.

19. Foucault, M. Discipline and Punish; Penguin: London, UK, 1991.

20. Jung, C.G. Analytical Psychology and Education. In The Collected Works of C. G. Jung; Routledge and Kegan Paul: London, UK, 1946; Volume 17. 
21. Weber, M. Science as a Vocation. In Max Weber: Essays in Sociology; Gerth, H.H., Wright Mills, C., Eds.; Oxford University Press: New York, NY, USA, 1946.

22. Harrington, A. Renenchanted Science; Princeton University Press: Princeton, NJ, USA, 1999.

23. Freud, S. New Introductory Lectures on Psycho-Analysis; W.W. Norton: London, UK, 1965.

24. Jung, C.G. The Phenomenology of the Spirit in Fairytales. In The Collected Works of C. G. Jung; Routledge and Kegan Paul: London, UK, 1948; Volume 9i.

25. James, W. The Varieties of Religious Experience; Longmans, Green and Co.: London, UK, 1902.

26. Shamdasani, S. Jung and the Making of Modern Psychology; Cambridge University Press: Cambridge, MA, USA, 2003.

27. Jung, C.G. The Association Method. Am. J. Psychol. 1910, 31, 219-269.

28. Piaget, J. Play, Dreams and Imitation in Childhood; Routledge \& Kegan Paul: London, UK, 1962.

29. Allen, C. A mystical psychology. Nature 1942, 149, 622-623.

30. Westmann, H. Selections from the works of C.G. Jung. Nature 1954, 173, 842.

31. Jung, C.G. Symbols and the Interpretation of Dreams. In The Collected Works of C. G. Jung; Routledge and Kegan Paul: London, UK, 1961; Volume 18.

32. Allen, C. Jungian psychology. Nature 1961, 4795, 1235.

33. Rychlak, J.F. Jung as Dialectician and Teleologist. In Jung in Modern Perspective; Papadopoulous, R.K., Saayman, G.S., Eds.; Wildwood House: Middlesex, UK, 1984.

34. Bair, D. Jung; Little, Brown \& Company: Boston, MA, USA, 2003.

35. Shamdasani, S. Cult Fictions; Routledge: London, UK, 1998.

36. Billig, M. Freudian Repression; Cambridge University Press: Cambridge, MA, USA, 1999.

37. Pietikäinen, P. C.G. Jung and the Psychology of Symbolic Forms; Academia Scientiarum Fennica: Helsinki, Finland, 1999.

38. Popper, K.R. The Logic of Scientific Discovery; Hutchinson: London, UK, 1958.

39. Jones, R.A. Mixed metaphors and narrative shifts: Archetypes. Theory Psychol. 2003, 13, 651-672.

40. Brooke, R. Jung and Phenomenology; Routledge: London, UK, 1991.

41. Rowland, S. Jung as Writer; Routledge: London, UK, 2005.

42. Hillman, J. Healing Fiction; Spring: Woodstock, CT, USA, 1983.

43. Jung, C.G. On the relation of analytical psychology to poetry. In The Collected Works of C. G. Jung; Routledge and Kegan Paul: London, UK, 1922; Volume 15.

44. Jung, C.G. Analytical Psychology: Notes of the Seminar Given in 1925; Princeton University Press: Princeton, NJ, USA, 1989.

45. Jung, C.G. Symbols of Transformation. In The Collected Works of C. G. Jung; Routledge and Kegan Paul: London, UK, 1952; Volume 5.

46. Wittgenstein, L. Philosophical Investigations; Blackwell: Oxford, UK, 1953.

47. Jones, R.A. The science and meaning of the self. J. Anal. Psychol. 2004, 49, 217-233. 


\title{
Chapter 2
}

\section{Accounting for Material Reality in the Analytic Subject}

\section{Robin McCoy Brooks}

New School for Analytical Psychology, 927 N. Northlake Way, Suite 220, Seattle, WA 98103, USA; E-Mail: robin.mccoy@comcast.net; Tel.:+206-947-7078

\begin{abstract}
Scientific advances made in the 21 st century contend that the forces of nature and nurture work together through an ongoing series of complex correspondences between brain and mental activity in our daily activities with others. Jung's cosmological model of the psyche minimizes the fundamental corporeal condition of human nature and as such is critiqued and amended, influenced by the transcendental materialist theories of subjectivity inspired by Žižek, Johnston and Laplanche.
\end{abstract}

Reprinted from Behav. Sci. Cite as: Brooks, R.M. Accounting for Material Reality in the Analytic Subject. Behav. Sci. 2013, 3, 619-633.

\section{Introduction}

"It is not easy formulating a metaphysical position that meets the demands of a material world; there is still a lot of philosophical work to do." ([1], p. 582).

Contemporary sciences deeply engage the role of the "sensuous brain" in emotional life, decentering long held psychoanalytic views of mind, brain, libidinal economy and subjectivity [2]. Various psychoanalytic traditions have opened up and are extending our understanding of the relational unconscious in psychoanalytic treatment (such as in transgenerational trauma). However, contemporary theory has not adequately articulated how material forces (bodily and environmental) influence, or impinge, upon the process of subjectification: the formation of the subject. A neuroscientific stance contends that the forces of nature and nurture work together through an ongoing series of complex correspondences between brain and mental activity in our daily activities with others [3]. New materialism theories do not confine nature to a singular biological body but extend materiality to the more-than-human. They view the interface of history, culture, technology, political and scientific environmental practices to be as equally valid as social constructions in the ways we can account for ourselves as subjects [4]. Thus, as human beings we are living and dying in the midst of an agentic natural world whose actions have consequences for both human and non-human alike. In this view, we are always already engaged in multiple agentic-often invisibleecological/and biological materialisms (such as air and water pollution, epigenetics) whether we know it or not [5]. 
How the body gives rise to the mind certainly perplexed Jung as he wondered "how life produces complex organic systems from the organic" in his final reformulation of the psychoid archetype in 1946 ([6], para. 375). He was of course limited in his view (as we are) due to limits of the knowledge systems (political, social, scientific, cultural, philosophical etc.) that he was historically entangled in. In this paper, I critique aspects of Jung's model of subject formation because, in my opinion he minimizes the fundamental material condition of human nature by privileging independent transcendent sources of subjectivity that originate outside of personal experience and personal unconscious fantasy. While retaining Jung's crucial post-Kantian insight of a split subject I attempt to articulate a model of subjectivity that recognizes the correspondences between the social/biological/ and psychical realms. To that end, I turn to a transcendental materialist theory of subjectivity inspired by post-Lacanian psychoanalysts/philosophers such as Slavoj Žižek, Adrian Johnston and Jean Laplanche. These theorists view the psychoanalytic subject through unique materialist/metaphysical lenses.

\section{Debates in Science and Psychoanalysis}

An explosion of knowledge about the neurodynamics of the brain is stimulating many kinds of cross disciplinary applications. This is notable in the work of John Bowlby (attachment theory), Antonio Damasio (neuro-biological model of consciousness [7]), Mark Solms and Oliver Turnbull (neural unconscious paradigm [8]), Christian Roesler (epigenetic conceptualization of archetypes [9]), Julia Kristeva (depression [10]) and Johnston and Malabou [2]. These authors creatively rethink subjectivity through the lenses of neuro-biology, philosophy and psychoanalysis, thereby opening up new conceptual possibilities.

How can psychoanalysis remain culturally relevant in an age when neuro-cognitive science seems to be emerging as the dominating master discourse? One stance is for psychoanalysis to do nothing holding the view that the analytic method already is a 'science' that is sufficient onto itself that will stand the test of time on its own merits. Proponents of this stance (although richly varied) generally assert that neuro-science is irrelevant to our understanding of the human subject $[11,12]$. In the much discussed series of papers, Blass and Carmeli make the case against both neuro-science and neuropsychoanalysis by calling into question the claim that neuroscientific findings are relevant for the justification of psychoanalytic theory and practice $[13,14]$. They argue for the efficacy of the analytic stance which in their minds focuses on "the understanding of meanings and the role of interpersonal discourse in discerning and justifying these meanings", versus what they call "biologism" which asserts "only what is biological is real" ([15], p. 1584). A case could here be made that adhering to psychoanalytic principles alone as the complete means for understanding the mind and its self-disruptions (to include brain disorders) can be a reverse variation of biologism, a kind of psychoanalytic-ogism or psychoanalytic reductionism.

Another response is for psychoanalysis to creatively assimilate neuro-science by entering meaningful correspondences between brain and mind. Assimilation of material from one discipline to another can take on various and discrete distinctions that Talvitie and Ihanus [15] organize into three neuropsychoanalytic conceptions that I will amend for our purposes here.

The reductionist conception reduces the basic assumptions of one theory of mind or brain to the other. However some authors, who identify themselves as "new wave reductionists" (versus 
classical) clarify their position as one that while interested in mechanistic explanations, does not view the autonomy of psychology and reduction as contradictory views. They favor "explanatory pluralism... a non-reductivist approach that is neither reductive nor anti-reductive" ([15], p. 1585). A less favorable variation of this stance might see it as psychoanalysis subordinating itself to the leading science, like Anna Freud's "identification with the aggressor" [16]. From this perspective, one would interpret psychoanalytic questions through the neuroscientific lens as if neuroscience is the basis of all human sciences, in a kind of pervasive neuro-ism [11].

A second or hybrid approach attempts to integrate (versus reduce) or unify the views of psychoanalysis and neuroscience without negating the basic assumptions of either [15]. While this may be a more diplomatic strategy it can minimize or whitewash the irreducible aspects of either discipline, ultimately diminishing the potency of both the organic and immaterial (das ding an sich) views.

Allan Schore's (the "American Bowlby") integration of human development and neuroscience culminating in his attachment theory model is an example of a stance which seems to lose the depth dimension of psychoanalytic reflection [17]. There are also many prejudiced notions on the psychoanalytic side. For instance, many contemporary Anglo-American psychoanalysts have theoretical biases in their collective conviction that infants are primarily object seeking $[18,19]$. This turn in conceptual framework was emboldened by the unification of neuro-scientific models of attachment theory; turning people from the centrality of Freudian psycho-sexuality drive theory [20]. In my opinion, this loses the richness of alterity, of the human psyche in its excesses of desire, its aberrant drives and intrapsychic conflicts.

Talvitie and Ihanus' third approach or an interfield conception does not attempt to unify any theories but respects the gap between the natural sciences and the humanities [21]. Roesler is an example of an interfield theorist who argues for an epigenetic model of the archetypes, viewing Jung's own biological arguments as outdated [8]. While agreeing with Knox [22] and Hogenson [23] - also inter-field theorists - that the emergence model is so self-evident as to be 'banal', he challenges their contentions that archetypes have a universal component (a priori). Malabou and Johnston, both philosophers - the latter a psychoanalyst - compellingly embrace neurobiology. They acknowledge both the irreducible aspects of each discipline to each other (of mind and brain). In a sustained dialogue with the disciplines of philosophy, psychoanalysis and neuroscience they radically rethink what it means to be a human subject.

The French psychoanalytic tradition (in general contrast to many American models), particularly the work of Jean Laplanche continues to emphasize the centrality of infantile sexuality. He advances and clarifies Freud's central ideas of drive and instinct and the interplay between what is physiological (biological) and what comes from outside of the infant via (enigmatic/ unconscious) messages from the $(\mathrm{m})$ other. In other words, sexuality is not endogenous to the infant but emerges from the fundamental asymmetrical relationship (attachment) with the other due to its dependence (hilflösigkeit) and difference [24]. Although Laplanche does not rely on neuro-scientific developments to broaden his theories, his theories "lean upon" ("anlehnung") the biological but cannot be reduced to it [25].

\section{Jung and Kant}


It is well known that Jung was closely aligned to and influenced by threads of thinking derived from Kant's transcendentalism, generally associated with the philosophical movement known as German Idealism. Kant's subject was split between two irreducible realms-the first positing a pure noumenal, transcendental a-temporal, logical, "I" and the second positing a phenomenal, egoistic, spatio-temporal "I". The pure "I" can never know itself as arche (ipseity), and is inaccessible as an object of experience. Therefore, Kant stated; "through inner experience I always know myself only as I appear to myself" ([26], pp. 26-27, my italics). In other words, the "phenomenal I" intuits and does not cognize a thing in itself and what is presented through a sense is always an appearance ([27], p. 190). Yet, it is consciousness that turns all "presentations" (Vorstellung) into thoughts, even though one is not able to adequately cognize the conditions that make the act of cognition possible [27]. Vorstellung can be translated as meaning whatever is given as present to awareness and within that Kant designated various kinds of general appearances ([27], p. 155). The term Vorstellung was mistranslated into the English editions of Jung's collected works calling immediate experience "image" or "idea" rather than "appearance" or "phenomena" therefore rendering Idee (idea) and Vorstellung (representation and presentation) as the same ([28], pp. 8-11).

Returning to the specific topic of subjectivity, Johnston succinctly summarizes the Kantian arrangement of the divided subject thus:

Self-consciousness is limited to apprehending the phenomenal subject. Midway between intuition and reason, the understanding necessitates an iterable "I" accompanying every determinate act of cognition...From this iterability, reason, in accordance with the transcendental idea of psychological unity of subjectivity, treat the iterable "I" of the understanding as indicative of the need for a regulative principle of a timeless self-sameness. This is nothing other than the purely noumenal subject, a subject that must be posited given the systematic aspirations of the interests of reason, although no experiential correlate can ever be adequate to this idea ([29], pp. 103-104).

Johnston's characterization of a zone "midway between intuition and reason" is an elaboration of Kant's boundary concept. Kant introduced what he called and empty space' or gap between the two concepts, which was neither purely noumenal (negative) nor phenomena (positive), or jointly both ([30], pp. 4, 354; [31], p. 497). In another context, Eyal's Weizman's depiction of a fixed border that separates deeply fragmented, constantly shifting and elastic [sovereign] territories' while somehow benefiting both realms comes to mind ([32], p. 7). In this context, Weizman is describing his view of the wall separating Palestinians from Palestine.

It cannot be understated how essential Jung's use of Kant's boundary concept was to his project; indeed he attributed his philosophical epistemological basis of esse in anima (soul) to Kant ([31]; [33], p. 123). For Jung, human nature was divided between the inconsistent surfaces of the phenomenal realm that was contained by a unifying transcendent ground beneath its surface. Jung then situated a "world soul", anima mundi, or "spirit of God" in the very heart of the noumenal territory - whose explicit goal was to advance the individual (and the whole of mankind) towards a union of spirit and soul ("unio mentalis") in the body ([34], para. 707; [35], paras. 388, 293). The archetypes, or emmisarial productions of the world soul, could breach the irreducible boundary between the realms and make themselves known through phenomena (affect, instincts) and representation (image, 
idea). The self therefore was a "borderline concept," a mediating and unifying force located in the gap between the phenomenal and noumenal realms, yet containing both ([36], p. 258).

Jung was not interested in personal unconscious processes, which he equated with Freud's unconscious considering its function as inferior to the objective psyche [37]. Understanding human experience therefore was largely dependent on the interpretation of archetypal "images", which of course could not be understood in terms of merely personal unconscious processes [38]. This view of subjectivity does not account for sources of signification deriving from personal unconscious processes (fantasies, dream material, transference phenomena, nachträglich shifts in temporality, etc.), or those that emerge in relationship, or from relation to organicity (affect, brain states, physical suffering, the role of drives and instincts and organic and psychic trauma).

\section{The Metaphysical Subject in a Material World: Žižek, Levinas, Laplanche}

Central to Žižek's project is the "redeployment of a German idealist theory of subjectivity" as it is revised through the lens of post-Lacanian psychoanalytic metapsychology ([39], p. 125). While Jung and Lacan's projects are epistemologically incompatible, Žižek and Jung both found abundant theoretical inspiration in German Idealist theory. Žižek's contemporary re-reading of German Idealist theory blows fresh air into the possibilities of reviving aspects of Jung's model of subjectivity through a Žižekian lens. In what follows, I roughly sketch relevant aspects of Žižek's arguments while reworking aspects of Jung's model of subjectivity that crisscross and overlap this discussion within other sections along the way.

Most compelling of Žižek's claims is his assertion that the Cartesian conception of a split subject as Kant, Schelling and Hegel rethink it is not only relevant today but also central to his project (one that has spanned for decades). Johnston succinctly summarizes Žižek's central claims (as derived by late modern transcendental philosophy) thus:

The subject is "emergent in relation to the body-that is to say, such 'immaterial' (or more accurately, more-than-material) subjectivity immanently arises out of a material ground...Cogito-like subjectivity ontogenetically emerges out of an originally corporeal condition as its anterior ground, although, once generated, this sort of subjectivity thereafter remains irreducible to its material sources... subject conditions immanently arise out of a series of conflicts and tensions internal to the foundational embodied condition of human nature, a nature inherently destined for denaturalization” ([40], p. 231).

Žižek's basic thesis opens up psychoanalytical consideration for the interpretation of both unconscious mental and organic influences to selfhood. Hence, he creates a space for investigation into the aspects of the corporeal constitution of human nature that in addition to the human sciences includes the cognitive, neural and molecular dynamics (to include epigenetics) at play in becoming a person. While retaining the assumption that "truth" emerges from encounters with the Lacanian Real (somewhat akin to Kant's pure negativity) and is therefore the major source of human knowledge, cogito-like subjectivity emerges out of its corporeal condition and is subject to tensions internal to its foundational embodied condition ([40], p. 230). These tensions may be in response to productions of the mind and/or the emotional brain as well as external sources. In contrast, cogito-like subjectivity for Jung emerges instead from the productions of a world soul located outside of the corporeal 
individual and is transported via the archetypes through the psychic matrix of the collective unconscious penetrating the body via the psychoid spectrum through affect, instinct or representation (image/idea).

Žižek makes a crucial distinction between subjectivity and subjectification. He defines the self or subject as pure negativity (the noumenal "I") such as the Kantian subject-as-Thing or Cartesian cogito. The subject is not the "I" of the "self" that is associated with mental processes or the egoistic phenomenal "I" ([39], pp.166-167). Subjectification as clarified by Johnston, is defined "as a series of interminable efforts, of vain attempts structurally doomed to partial success at best...to reinscribe the subject within gentrified domain of actualized re/presentations" ([39], p. 167). Subjectification therefore is an anxiety-ridden and frenzied attempt to re-absorb the void revealed by the negative rupture of what is alien to the phenomenal "I" back within the order of the ontological plane from which it broke [39]. Put another way, the phenomenal I takes an inner distance from its -self (the noumenal "I") to absorb the trauma of the void made known to itself through alterity's rupture. On this Žižek's comments:

"We could say, paradoxically, that the subject is substance [by substance is referring to the stuff of 'the thing'] precisely in external, positive Entity, existing in itself: "subject is nothing but the name for this inner distance of 'substance' towards itself, the name for this empty place from which the substance can perceive itself as something 'alien'. Without this self-fissure of the essence, there can be no place distinguished from essence in which essence can appear only in so far as it is already external to itself" ([41], p. 167).

From this perspective, subject will always be "external to itself" while existing "in itself"-an ongoing oscillation between alteration and iteration (25). Žižek's exquisite extension of Kant's boundary concept can apply to the basic elements of Jung's model of subjectivity with the crucial exception of the sources of tension that purportedly ignite the mind's emergence. Žižek accounts for subjectivization's genesis (or the body giving rise to the mind) in two ways- "something going terribly wrong", or an ontogenetic account - "a kind of snag in the biological weave" ([42], p. 59). Zizek is extending his reading of the Lacanian Real to include both material and psychic sources of traumatizing sources of tension that continually rupture and make our ontological incompleteness known. Jung, in contrast held the objective psyche as the foundational ground and central source of ultimate truth via the founding principles of being that he described later as the psychoid realm. Jung's subject was constructed through inter-actions with psychoid entities that were guided through the emanations of a divine world soul.

Something goes "terribly wrong” in Žižek's ontology when a person encounters what Lacan called the "Real". Over sixty years ago, Lacan claimed he was returning to what he perceived was an often abandoned insight in psychoanalysis about the intrinsic unintelligibility of the unconscious [43]. The goal of analytic treatment, he claimed was not to elevate ego functions vis-a-vis the unconscious but contrarily to confront the barriers to experiencing the "Real" or the site of the "traumatic truth" [43]. Žižek rearticulates (from Lacan through a Kantian lens) the Real as "voids entirely immanent to the representational fabric of reality rather than presupposed as a pre-representational transcendence" ([41], p. 173). 
The Real described in this way is somewhat akin to the gap between Jung's collective unconscious and person that he deemed the "psychoid". It is in this gap or boundary that the possibility for subjectification could occur via Jung's self (as an archetype), through its implosion into the body and the individual's response to it. The mechanism that regulates the possibility of Jungian individuation is personified or reified into a single agent from beyond (God, world soul), in contrast to the "Big Other", of our cultural thrownness in Lacanian parlance.

Žižek's subjectification is evoked through encounters with the Real (via the many appearances of the virtual character of the Big Other that appear in various materialisms such as politics, economics etc.). The Real in its various dimensions is a dynamic process embedded in our everyday codes of behavior (conscripted socially amongst relations with people, one's self, things) and revealed in the cracks (gaps or inconsistencies) of the virtual symbolic matrix that structures reality for us. Including the materialist sensibilities of Alaimo [4] noted in the introduction, I include the conscription of material agencies as well as the psychical in the various realms of the Real such as political, economic, technical, and scientific systems of coding as well. These gaps or inconsistencies can be partially detected in their traces via the effects of our fantasies, our dreams, or other evidences of the inscription of the subject in its field of objects (metaphor, metonym, après coup, etc.) or the counter inscription of the Other onto the subject. We are, in this model always already embedded in this social symbolic/material (I add) matrix, and "subjective symbolic identity" is historically determined [43]. Zizek makes a compelling partial parallel between the Lacanian virtual symbolic order that structures reality for us and the controlled virtual reality portrayed in the tri-part movie the "Matrix". He relays a poignant shard of dialogue between Morpheus (the leader of the resistance group) and Neo, a naive and future savior figure:

MORPHEUS: "It's that feeling that you have had all your life. That feeling that something was wrong with the world. You don't know what it is but it's there, like a splinter in your mind, driving you mad...The Matrix is everywhere, it's all around us, here even in this room...it is the world that has been pulled over your eyes to blind you from the truth. NEO: What truth? MORPHEUS: That you are a slave, Neo. That you, like everyone else, was born into bondage...kept inside a prison that you cannot smell. Taste, or touch. A prison of your mind" [44].

Thus, from the beginning, the subject is divided, decentered and incoherently unintelligible to itself and subsumed in the groundless ground of the multiple dimensions of the Real. Analysis for Lacan can only be an ethical undertaking as its central task is an awakening to the truth of our desire that is barred by the unconscious fantasy that controls us.

The Lacanian subject encounters the Real through the Aristotelian notion of tuché (a unexpected fist in the gut) that is literally reinterpreted as a missed encounter with the Real. Similarly, Levinas thought of the subject as trauma, or of ethics (the site of the ethical relation to alterity) as traumatology ([45], pp. 90-94). He poignantly elaborated on the affective response of the body (trauma) to the effect of being taken hostage by the other's demand [46] as being the heteronomous site of subject formation and ethics. The thought of an act can only be born through the violent and traumatic struggle of being overcome by the other's demand. Contra Jung, no teleological account is sufficient for this primal ethical awareness [38]. 
Lacan links the tuché with the Real by arguing that such encounters radically destabilize ipseity and are therefore foundational to subject formation. The fundamental opacity of the other's desire can utterly rupture the ego's ability to assimilate or restore a sense of equilibrium. Lacan held that subjects' manner of being could be transformed by investigating the questions posed at the traumatic sites 'of truth' imposed through the missed encounters with the Real [47].

The body gives rise to the mind by fielding its impingements in a kind of desperate attempt to restore libidinal equilibrium. These unpredictable and inassimilable disruptions to the helpless phenomenal "I" are constitutive to subjectivity and to one's relationship to others. Again, Johnston artfully summarizes this dynamic process:

This shift of substance becoming subject is followed by subjectification processes in which certain master elements engage in the labor of hegemonic articulation, retroactively reconfiguring the very ground of being-substance from which they arose. This shift occurs both at the ontogenetic and phylogenetic levels ([39], pp. 173-174).

This statement clearly links the biological evolutionary influences to subject formation holding the mind in relation to its biology (or "a snag in the biological weave") while not being reduced to it. Thus, subject (transcendent "I") transcends corporeality (corporeal embedded phenomenal "I") and in the Levinasian sense becomes "otherwise than" or "beyond being" [48]. Both Žižek, Johnston and Malabou (in separate works) attempt to address the mind and brain in relation to its psychic and neuro-unconscious aspects and their mutually constituting generativity $[2,49]$.

Johnston correlates the emotion from a neurobiological perspective on emotion with drive. Dialoguing with the thinking of neuroscientist Damasio, and Žižek's reading of Damasio, Johnston 're-elaborates' cerebral organization, psychical apparatus and unconscious processes. He situates the neurobiological emotional brain within a paradoxical emotional libidinal economy-one which recognizes that emotions organize and coordinate cerebral activity. He states..."In the brain, there are no regulatory mechanisms of adaption to the external world and the environment without emotional adaption to the inside of the brain by the brain itself' (i.e., the brain taking the drives and energetic tensions upon itself alone-my clarification) ([2], pp. 217, 219). He appropriates Damasio's conception of a "protoself" (the primitive form of identity or cerebral unconscious) as a kind of central command post of auto-regulation between internal processes and the external world. He states:

The proto-self is a coherent collection of neural patterns which map, moment by moment, the state of psychical structure of the organism in its many dimensions [in a constant synthesis of different states of relation between body and psyche, as an equilibrium, in a word of the organism] ([2], p. 220).

This kind of organic self-regulatory nexus is perversely reminiscent of Jung's diametrically oppositional concept of anima mundi, or world soul. Jung's regulatory nexus or world soul is psychical, and embedded in a cosmic nether-land.

Catherine Malabou in her work exploring how brain damage changes subjectivity contends that while the brain is sculpted by the contents of mental experience (of the self and its experiences), so do the brains affectations (such as in auto-affection for example) shape the subject's experience of itself ([2], p. 46). The cerebral self is anonymous and a kind of primal core of corporeality, yet one 
that is implicitly an internal reminder of our mortality as the organism is always on the edge of impending partial or total collapse ([2], p. 223). This notion can shed new light on Freud's ever haunting presence of a death drive ([2], p. 223). In contrast, the psychoanalytical unconscious, or Jung's objective psyche does not believe in its own death representing only atemporal dimensions of experience. Malabou and Johnston contend that the link between the subject (personal unconscious) and the brain (proto-self) can best be theorized through affect. Consequently, the brain gives rise to the mind through the interplay of affective signification, the body's autoregulation of it and the process of subjectivation as outlined above.

\section{Laplanche}

Laplanche's insight into the central role of the "sexual" unconscious is relevant to the theoretical discussion at hand and gives clinical flesh to Zizek's transcendental materialist theory of subjectivity. Indeed, he considered himself to be a materialist and stated: "I think that anything that exists in the realm of the mind also exists somewhere in space, in the brain" [50]. In the same vein, he later stated: "I have never left the body and I have never opposed the body to the mind. By placing the drive and instinct in opposition I am not opposing the psychical to the somatic" ([24], p. 11). He enlarges the Freudian notion of infant sexuality into a "polymorphous perverse" infantile sexuality that can be translated into English as "the sexual". Infant sexuality therefore is associated with the unconscious residue of the symbolization-repression and fantasy that is fundamental to the primal relationship with the "Big Other" from birth and is the object of psychoanalysis ([24], pp. 159-190). Laplanche takes the Lacanian Real and particularizes it to the asymmetric relationship between Big Other and infant. He argues that sexuality, broadly speaking, consists of universal unassimable communications from the mother to infant that are implanted in the infant's body as "primal repressions".

Self-preservation is also active in the infant from the start and mediates communications that are more reciprocal and less enigmatic. That is what is commonly understood as "attachment" (or adaptional) in today's psychology. Laplanche contends that Freud anticipated what we know as attachment theory with his notion of "affection". Thus, he states: "owing to the hegemony of attachment theory there is a risk that the debate over attachment and sexuality may never in fact take place, unless attachment can be accommodated within the framework of a rigorous metapsychology" ([24], p. 36). On the other hand, enigmatic (and untranslatable) messages that originate beyond language remain unmetabalized and untranslatable. These enigmatic elements eventually form a core "internal foreign body" - a sort of "alien inside of me, put inside me by an alien" ([51], p. 65). These he calls 'source objects' equivalent to drives that stimulate endless fantasy, both destructive and creative, throughout life. Laplanche asks us why the poet poetizes... except as a response to an enigmatic presence in an unknown future ([51], p. 223).

Laplanche views instincts as such to be self-preservative, adaptive and innately programmed to secure survival and homeostasis. The sexual instinct he claims is situated in the biological maturation of the organism and does not emerge until the pre-pubertal period. The sexual drive in contrast, is ubiquitously situated in infancy as Freud foresaw, is not innate, is connected to fantasy, and is necessarily repressed (and therefore unconscious). The abject helplessness (Hilflössigkeit) of the infant requires a helping other to compensate for the infant's deficiencies of self-preservation and 
ensures that "the sexual" takes over. Thus, the sexual order always already overlies the instinctual order [52]. Unconscious sexual messages are exchanged from the mother to infant within the attachment relationship that remain unintelligible and "implanted" later appearing as what Laplanche refers to as "enigmatic signifiers" that are provoked through the transference in life and/or analysis where they can be detranslated, and retranslated [53]. In other words, the emergence of repressed fantasies (via enigmatic signifiers) in the analysis can unveil originary drive (part instinct to survive and part drive to reduce the recurring anxiety-ridden need), but the enigmatic core, like the Lacanian Real, is never "resolved" or "integrated". Crucial to the Laplanchian analytical stance is the analyst's capacity to maintain 'the dimension of interior alterity which allows alterity to be set up in the transference, and for the reactivation and working through the originary enigmas ([50], pp. 228-229). That is, it is crucial that the analyst be in touch with his/her own enigma.

Jung, (using Soni Shamdasani's translation) conflated the terms drive and instinct in his final reconceptualization of what he would later refer to as the "psychoid archetype" ([35]; [54], pp. 258-260). Drives/instincts had two aspects in that they were dynamic instinctual patterns in human biology and secondly would enter into consciousness as images. Jung called them "apriori instinct-types", or "instinct image[s]" stating that the image represent[ed] the meaning of the instinct' ([35], paras. 398-399). Thus the drive/instinct was both psychical and biological and the instinct-Vorstellung could be translated into meaning through Jung's method of active imagination. While both Jung and Laplanche viewed the psychical to always already overlie the biological order with regard to subject genesis, Laplanche's elaboration is more profound on multiple levels. To begin with, Laplanche includes both psychical (sexual drive) and biological (self-preservation, attachment) relational elements from the beginning of life that shape whom and how we become and understand ourselves to the degree one ever can. He clearly distinguishes a nuanced model of drive and instinct and their correspondences in relation to infant/m-other from the beginning while accounting for a split subjectivity that is generated from these early relations between infant and world. The big Other for Jung is the world soul, and its correspondences via the archetypes with an isolated mind. Biological participation, for Jung in subject formation, is grossly understated and undeveloped in an already troubled concept.

Central to Laplanche's general theory of seduction is the concept of afterwardness (après-coup -Lacan, or nachträglichkeit- Freud). In a surprising homage to Jung, Laplanche cites both Freud's concept of Nachtraglichkeit and Jung's concept of retrospective fantasizing (Zurückphantasieren) into his own conception. He differs from both Jung and Freud as well as from Lacan's earlier nod to Freud [51]. Freud proffered a determinist conception (what happens before determines what happens after) of nachträglichkeit which followed a temporal trajectory of trauma from past to future by positing that trauma implanted in the past can be reactivated later, although reinterpreted from the standpoint of a more sexual mature individual. Indeed, he discussed how that could increase trauma because of the added dimensions of meaning. Jung's retrospective or hermeneutic conception involved a reinterpretation of experiences relating to past trauma through the lens of the archetype. That is, the actual experience of the past was devalued. Laplanche essentially adds two crucial elements in his extended version of après-coup; his translation model (identifying the trace of retroactive enigmatic translation, retranslation and reinterpretation) and the introduction of the relational unconscious through the $(\mathrm{m})$ other infant relationship. 
Jung's aversion to Freud's sexual libidinal theory is well known as well as his dislike of reduction to the past. He was opposed to child analysis and did not develop a theory of childhood development. Fordham recalls attempting to discuss child therapy at a dinner party with the Jung's. Of Jung he stated: "He was starting on a monologue when Mrs. Jung intervened: 'You know very well that you are not interested in people, but [only] your theory of the collective unconscious"” ([55], p. 109). Jung clinically interpreted childhood motifs (to include mother symbology) as representing archetypes without considering the importance of actual childhood experiences or the fantasies of these experiences as having analytic relevance to subject formation [56,57]. Elsewhere, I elaborated on the rigid stance of epistemological authority that Jung relied upon when it came to the archetypal explications of the patient's experience that can be noted in his method of amplification [38]. I state that the term "amplification" itself was a misnomer, in that it implied that Jung's intent was to expand the signification of unconscious content, yet this process was in fact only a precursor to a formulaic reduction of the expanded material to a presumed archetypal core ([38], p. 87). His phenomenological-descriptive approach however, was one he retained for working with the personal unconscious and was derived from his earlier research with the word association test ([56], para. 174). This approach employed a discursive process between patient and analyst that expanded or opened up possibilities by following the patient's own associations. Jung would probably be opposed to Laplanche's notion of enigmatic signification entirely and his general theory of seduction. However, because Jung minimized or did not understand the importance of personal unconscious processes in general most particularly in childhood development or subject formation, this gap in his theory and practice, to my mind requires serious supplementation. Laplanche's work revives Freud's abandoned theory of seduction and extends it to embrace a metapsychological position that meets the demands of a corporeal reality across the arch of an individual's life. Laplanche's model can be incorporated into the clinical realm that recognizes neural diversity and other materialisms as relevant to subject formation, and adds crucial psychoanalytic dimension to personal unconscious processes as well.

\section{Concluding Discussion: Returning Jung's Subject to the Material World}

Via Žižek, Johnston and Laplanche I have described a process of subjectification that leans on the biological yet is not reduced to it. The forces of nature (brain/body, the biologic) and nurture (mind, the psychoanalytic) work together through an ongoing series of complex correspondences between brain and mental activity. These forces interface with co-extensive material agencies (m (other), political, economic, technological, social environments, etc.) from the beginning of human life. It is beyond the scope of this paper to elaborate further on what and how these coextensive material agencies interact in subjectification other than the scope of the brain and the mind, an unfortunate omission and certain topic for another essay. From the beginning, the subject is divided, decentered and incoherently unintelligible to itself, subsumed in the groundless ground of the multiple dimensions of the Real. For Laplanche, a primal psychic split occurs simultaneously with the birth of the ego and the repressed unconscious because of infants failed attempts to translate the $m$ (other's) unconscious sexual messages despite the adequacy (or inadequacy) of the attachment relation ([52], p. 12). The instinctual realm (that regulates self-preservation), in other words cannot adequately regulate this surplus of demand unconsciously initiated from the $(\mathrm{m})$ other, or her environments. 
Johnston correlates emotion with a neurobiological drive in brain/mind collaboration between cerebral organization, psychical apparatus and unconscious processes. In Johnston's perspective, emotions organize and coordinate cerebral activity in an adaptive (self preservational) stance to the environment. The psychical stuff of the thing (or noumenal "I") appears to have a material counterpart in the brain's cerebral unconscious (adapted from Damasio's conception for the "protoself"), the central command post of auto-regulation between internal processes and the world. In both theories, the body and mind are co-extensive agents to the rise of the immaterial human subject from its corporeal origins.

Jung's notion of the subject does not allow for new or unthought configurations of alterity that can account for present experience within personal unconscious processes, or co-extensive material systems described above. The mechanism that regulates the possibility of Jungian individuation is personified or reified into a single agent from beyond (God, world soul), in contrast to the "Big virtual Other" of our cultural thrownness in Lacanian parlance. Following Žižek's reading of Kant, I retain crucial aspects of Jungian transcendental subjectivity while reconceptualizing its source of genertivity from the objective psyche to alterity. Encounters with alterity are instead initiated through the individual's uncanny encounter with the "other" located in the gaps of a groundless extraontological reality at the organic and psychical enigmatic core of the human condition. This enigmatic core of the subject was designated by Kant as the "noumenal I", by Jung as the self (implanted via the self-archetype via the world soul), and Žižek as "subject”. For Žižek and Laplanche, the subject is always "external to itself" while also existing "in itself" or emergent in relation to its material ground (the body).

Jung's self is an archetype generated from an external cosmological nexus whose only contact with corporeality is through the instincts or affect. Unlike alien enigmatic signification generated in the $\mathrm{m}$ (other) in relation with her infant in the Laplanchian landscape, Jungian archetypes arrive from inner or outer space (a cosmic other) like meteors crashing into the earth. Staying with Žižek's model, I demote the archetype from its cosmologic origins to referents, representations or enigmatic signifiers that emerge in personal unconscious processes (affect, language, sensation and fantasy). This includes the virtual symbolic matrix (codes provided by culture) that interfaces with the body/mind and is coextensive with the body in the material world and its many environments. While some Jungian theorists are attempting to scientize the archetype as a viable representative of the collective unconscious, Jung's lingering totalizing cosmology remains crucially problematic.

\section{Acknowledgments}

The author wishes to thank Ladson Hinton, Jon Mills, Sharon Green, Lucy Huskinson and the anonymous reviewers for their helpful comments along the way.

\section{Conflicts of Interest}

The author declares no conflict of interest. 


\section{References}

1. Hogan, T. From Supervenience to Superdupervenience: Meeting the Demands of a Material World. Mind 1993, 102, 555-583.

2. Johnston, A.; Malabou, C. Self and Emotional Life Philosophy, Psychoanalysis and Neuroscience; Columbia University Press: New York, NY, USA, 2013.

3. Aamodt, S.; Wang, S. Welcome to Your Child's Brain; Bloomsbury: New York, NY, USA, 2011.

4. Alaimo, S. Bodily Natures Science, Environment, and the Material Self; Indiana University Press: Bloomington, IN, USA, 2010. New materialism is an approach that upholds the importance of materiality that has and is emerging in the 21 st century. It cannot be contained to a single approach and includes a wide variety of realist perspectives to include the disciplines of feminist and queer theory, disability studies, cultural studies, science studies and neuropsychoanalysis.

5. Alaimo, S.; Hekman, S. Material Feminisms; Indiana University Press: Bloomington, IN, USA, 2008.

6. Jung, C.G. The Conjunction. In The Collected Works of C. G. Jung; Routledge \& Kegan Paul: London, UK, 1970; Volume 8.

7. Damasio, A. The Feeling of What Happens; Harcourt, Inc.: New York, NY, USA, 1999.

8. Solms, M.; Turnbull, O. The Brain and the Inner World: An Introduction to the Neuroscience of Subjective Experience; Other Press: New York, NY, USA, 2002.

9. Roesler, C. Are archetypes transmitted more by culture than biology? Questions arising from conceptualizations of the archetype. J. Anal. Psychol. 2012, 57, 223-246.

10. Kristeva, J. Black Sun Depression and Melancholia; Columbia University Press: New York, NY, USA, 1989.

11. Brothers, L. The trouble with neurobiological explanations of mind. Psychoanal. Inq. 2002, 22, 857-870.

12. Verhaeghe, P. Psychoanalysis in Times of Science. Journal of the Jan van Eyke Circle for Lacanian Ideology Critique 2012, 4, 11-23.

13. Blass, R; Carmeli, Z. The Case against Neuropsychoanalysis: On Fallacies Underlying Psychoanalysis' latest Scientific Trend and Its Negative Impact on Psychoanalytic Discourse. Int. J. Psychoanal. 2007, 88, 19-40.

14. Carmeli, Z.; Blass, R. The case against neuroplastic analysis: A further illustration of the irrelevance of neuroscience to psychoanalysis through a critique of Doidge's The Brain that Changes Itself. Int. J. Psychoanal. 2013, 94, 391-410.

15. Talvitie, T.; Ihanus, J. On neuropsychoanalytic metaphysics. Int. J. Psychoanal. 2011, 92, $1583-1601$.

16. Freud, A. The Ego and the Mechanisms of Defense; Karmac Books: Exeter, UK, 1993.

17. Allan Schore. Available online: http://www.alanschore.com/ (accessed on 5 May 2013).

18. Fairbairne, R. Psychological Studies of the Personality; Routledge \& Kegan Paul: London, UK, 1952.

19. Waintrater, R. Intersubjectivity and French Psychoanalysis: A Misunderstanding? Stud. Gender Sex. 2012, 13, 295-302. 
20. Fonagy, P. Attachment Theory and Psychoanalysis; Other Press: New York, NY, USA, 2001.

21. Darden, L; Maull, N. Interfield theories. Philos. Sci. 1977, 43, 44-64.

22. Knox, J. Archetype, Attachment, Analysis. Jungian Psychology and the Emergent Mind; Brunner-Routledge: New York, NY, USA, 2003.

23. Hogenson, G.B. Archetypes: Emergence and the Psyche's Deep Structure. In Analytical Psychology: Contemporary Perspectives in Jungian Psychology; Cambray, J., Carter, L., Eds.; Brunner-Routledge: New York, NY, USA, 2004.

24. Laplanche, J. Freud and the Sexual: Essays 2000-2006; IPBooks, International Psychoanalytic Media Group, 2011.

25. Hinton, L. New School for Analytical Psychology. Seattle, WA, USA. Personal communication, 2013.

26. Kant, I. Anthropology from a Pragmatic Point of View; Dowdell, V.L., tran.; Southern Illinois University Press: Carbondale, IL, USA, 1978.

27. Kant, I. Critique of Pure Reason; Cambridge University Press: New York, NY, USA, 1998.

28. Tougas, C. The Phenomena of Awareness Husserl, Cantor, Jung; Routledge: New York, NY, USA, 2013.

29. Johnston, A. Time Driven Metapsychology and the Splitting of the Drive; Northwestern University Press: Evanston, IL, USA, 2005.

30. Kant, I. Prolegomena to Any Future Metaphysic; Cambridge University Press: Cambridge, UK, 2005.

31. Brooks, R.M. Un-thought out metaphysics in analytical psychology. J. Anal. Psychol. 2011, 4, 492-513.

32. Weizman, E. Hollow Land: Israel's Architecture of Occupation; Verso: London, UK, 2007.

33. Jung, C.G. Letters of C.G. Jung. Volume I: 1906-1950; Routledge \& Kegan Paul: London, UK, 1973-1975.

34. Jung, C.G. The Conjunction. In The Collected Works of C. G. Jung; Princeton University Press: Princeton, NJ, USA, 1970; Volume 14.

35. Jung, C.G. On the Nature of the Psyche. In The Collected Works of C. G. Jung; Routledge \& Kegan Paul: London, UK, 1954; Volume 8.

36. Jung, C.G. Letters of C.G. Jung. Volume II: 1951-1961; Adler, G., Ed.; Hull, R.F.C., trans.; Routledge \& Kegan Paul: London, UK, 1975.

37. Jung, C.G. Psychology and Religion: West and East. In The Collected Works of C.G. Jung; Routledge and Kegan Paul: London, UK, 1938; Volume 11.

38. Brooks, R.M. The ethical dimensions of life and analytic work through a Levinasian lens. Int. J. Jungian Stud. 2013. 1, 88-99.

39. Johnston, A. Žižek's Ontology A Transcendental Materialist Theory of Subjectivity; Northwestern University Press: Evanston, IL, USA, 2008. Johnston consistently demonstrates a masterful capacity to succinctly summarize dense philosophical material. On this Žižek comments in a blurb on the back-cover of this text: 'While reading it, I often had the uncanny feeling of being confronted by a line of argument which fits better than my own texts what I am struggling to formulate-as if he is the original and I am a copy'. 
40. Johnston, A. Against embodiment: The material ground of the immaterial subject. Int. J. Lacanian Stud. 2004. 2, 230-254.

41. Žižek, S. The Sublime Object of Ideology; Vergo: London, UK, 1989.

42. Žižek, S.; Daly, G. Conversations with Žižek; Polity Press: Malden, MA, USA, 2004.

43. Žižek, S. How to Read Lacan; W.W. Norton \& Company: London, UK, 2006.

44. Zizek, S. The matrix, or two sides of perversion. Available online: http://www.egs.edu/faculty/slavoj-zizek/articles/the-matrix-or-two-sides-of-perversion/ (accessed on 5 May 2013).

45. Levinas, E. Basic Philosophical Writings; Indiana University Press: Bloomington, IN, USA, 1996.

46. Levinas, E. Totality and Infinity: An Essay on Exteriority; Duquesne University Press: Pittsburgh, PA, USA, 1969.

47. Barnard, S. Diachrony, tuchè, and the ethical subject in Levinas and Lacan; Gantt, E.E., Williams, R.N., Eds.; In Psychology for the Other: Levinas Ethics and the Practice of Psychology; Duquesne University Press: Pittsburgh, PA, USA, 2002.

48. Levinas, E. Otherwise than Being or beyond Essence; Duquesne University Press: Pittsburgh, PA, USA, 2008.

49. Žižek, S. The Parallax View; MIT Press: Cambridge, MA, USA, 2006.

50. Laplanche, J. The other within: Rethinking psychoanalysis (interview). Radic. Philos. 2000, 102, 31-41, interviewed by Fletcher, J. and Osborne, P.

51. Laplanche, J. Essays on Otherness; Routledge: London, UK, 1999.

52. Scarfone, D. A brief introduction to the work of Jean Laplanche. Int. J. Psychoanal. 2013, 3, 545-566.

53. Hinton, L. The enigmatic signifier and the decentered subject. J. Anal. Psychol. 2009, 54, $637-657$.

54. Shamdasani, S. Jung and the Making of Modern Psychology the Dream of a Science; Cambridge University Press: Cambridge, UK, 2003.

55. Fordham, M. Memories and thoughts about C.G. Jung. J. Anal. Psychol. 1975, 20, 102-113.

56. Jung, C.G. Psychology and Religion: West and East. In The Collected Works of C. G. Jung; Princeton University Press: Princeton, NJ, USA, 1975; Volume 11.

57. Jung, C.G. The Psychology of the Child Archetype. In The Collected Works of C.G. Jung; Princeton University Press: Princeton, NJ, USA, 1981; Volume 9. 


\title{
Chapter 3
}

\section{Normality in Analytical Psychology}

\section{Steve Myers}

Centre for Psychoanalytic Studies, University of Essex, Wivenhoe Park, Colchester CO4 3SQ, UK; E-Mail: spmyers@teamtechnology.co.uk

\begin{abstract}
Although C.G. Jung's interest in normality wavered throughout his career, it was one of the areas he identified in later life as worthy of further research. He began his career using a definition of normality which would have been the target of Foucault's criticism, had Foucault chosen to review Jung's work. However, Jung then evolved his thinking to a standpoint that was more aligned to Foucault's own. Thereafter, the post Jungian concept of normality has remained relatively undeveloped by comparison with psychoanalysis and mainstream psychology. Jung's disjecta membra on the subject suggest that, in contemporary analytical psychology, too much focus is placed on the process of individuation to the neglect of applications that consider collective processes. Also, there is potential for useful research and development into the nature of conflict between individuals and societies, and how normal people typically develop in relation to the spectrum between individuation and collectivity.
\end{abstract}

Reprinted from Behav. Sci. Cite as: Myers, S. Normality in Analytical Psychology. Behav. Sci. 2013, 3, 647-661.

\section{Introduction}

C.G. Jung's interest in the subject of normality waxed and waned during the second half of his life, but at no time did he assemble a coherent account of his multifaceted view. In 1926, he introduced the word normal into the title of the first of his Two Essays [1], and in the 1930s he cited the lack of inclusion of normal psychology in Freud's thinking as one of the main factors in their separation [2]. He also used the term complex psychology to make his theory more relevant to general psychology [3]. However, Jung had some esoteric values - seeing normal people as of lesser value ([1], p.149) and having a poor view of groups and society ([1], pp. 152-154) - and in 1943 he removed the word normal out of the Two Essays title ([1], pp. 7-8). However, when Jung sketched out his wish-list for the future of analytical psychology in 1948, normal psychology was one of the main topics he highlighted:

In normal psychology, the most important subjects for research would be the psychic structure of the family in relation to heredity, the compensatory character of marriage and of emotional relationships in general. A particularly pressing problem is the behaviour of the individual in the mass and the unconscious compensation to which this gives rise [4]. 
Although Jung continues by suggesting a broad range of further applications-including the humanities, religion, science, and other areas of psychology - this paper is going to focus on the "pressing problem" that he highlighted. Both aspects of the problem-the individual-mass relationship and unconscious compensation - feature heavily in many of Jung's writings about normality. Also, this problem is close to some of the main themes in analytical psychology, such as individuation, rapprochement between consciousness and the unconscious, the union of opposites, the transcendent function, etc.

For Jung, normality is finding one's needs being met in the situations of daily life ([1], p. 55) - a deceptively simple description that belies a sophisticated understanding. In order to explore what this entails, and its implications, we first have to differentiate Jung's understanding from the related disciplines from which it emerged, i.e., psychoanalysis and mainstream psychiatry/psychology. Also, we need to examine Foucault's criticisms of normality to establish whether they might undermine Jung's concepts and their application.

\section{Foucault}

\subsection{Foucault and Psychoanalysis}

Foucault did not make any comment about Jung's theories, but provided a critique of the use of normality in mainstream psychiatry, psychology and psychoanalysis. Mainstream definitions of normality, where they are accepted, are usually derived from the mass. For example, one psychology textbook describes "the idea of normality [as] socially constructed and a contested notion" [5]. Norms naturally develop in group situations, which individuals then use to govern their own personal behaviour [6]. These norms are more powerful in shaping individual behaviour than education [7]. Foucault's criticism was targeted primarily at this type of norm, i.e., "order defined by natural and observable processes" [8]. He argued that those in authority, such as psychiatrists, used norms alongside artificial regulation to impose treatment, exclusion or imprisonment on those who were decreed as being abnormal. For Foucault, treatments were not based on medical science because "Madness-Disorder relations centred on the theme of social and moral order" [9]. He saw the advent of psychoanalysis as bringing a change in the style rather than the substance of treatment:

What we call psychiatric practice is a certain moral tactic contemporary with the end of the eighteenth century...all nineteenth century psychiatry really converges on Freud [who] demystified the asylum...[but] to the doctor, Freud transferred all the structure Pinel and Tuke had set up in confinement ([9], pp. 164-165).

Foucault's criticism was that "the formulations [Freud] hears are always those of transgression" ([9], p. 152) (of the limits of standard knowledge and experience [10]). He saw the psychoanalytic doctor-patient interaction as a continuation of normalisation processes - using the tactics of observation, silence, unspoken judgement and the mirroring of madness. However, Foucault's argument has itself been criticised: he "could never give up the temptation to valorize transgression [so] was unable to pursue the dialogue with unreason in a systematic way" [11]. In his archaeology of the ideas of madness and their discursive formation, Foucault looked only at the context in which psychoanalysis had developed and he didn't engage with Freud's actual theory [12]. 
The relevance of Foucault's criticisms therefore start to unfold with the advent of psychoanalysis because it was Foucault, not Freud, who could only hear formulations based on transgression. This meant he only saw Freud's understanding of normality as a social construct and he failed to recognise that Freud's understanding of pathology was based on intra-psychic processes rather than the transgression of social norms. Freud viewed a normal person as someone for whom the preconscious and the unconscious were not in conflict [13] or who was "free from neurosis" [14]. These attributes were not (as Foucault's criticism implies) prevalent within the population and which some transgressed, but rather they were attributes that no one possessed. Also, even though Freud wrote about normality and claimed psychoanalysis "developed into a psychology of normal mental life" [15], his starting point was pathology (e.g., see [16]) which meant his understanding went in the opposite direction to Foucault's claims. Whereas Foucault saw Freud as using social norms to define what was pathological, Freud in fact used, what could be viewed as, abnormal phenomena in order to understand normal ones (e.g., see [17]).

However, there have been some post-Freudian developments that could bring some psychoanalytic conceptions of normality back into the scope of Foucault's criticisms. Abraham, Jones, Glover, Gitelson, Klein, Krapf, Anna Freud and others have all developed their own thinking on the subject, taking the concept of psychoanalytic normality in several directions. Kubie described the main strands as being phenomenological, sociological, and ontogenetic but, to provide a better differentiation of psychological health from illness, he added his own criteria of flexibility and (similar to Freud) intra-psychic harmony [18]. Offer and Sabshin suggested there were four main psychoanalytic understandings of normality [19]: an average, such as Glover's "social standards of adaptation" [20]; a disease, such as Gitelson's view that it is living behind a façade of adaptation [21]; a process, such as Anna Freud's stages of child development; and a healthy (but unobtainable) ideal, such as Jones' definition that it is the capacity to endure as a result of the "fullest possible development of the organism" [22]. Krapf offered a less idealistic definition-as the ability to maintain a (dynamic) psychic equilibrium with ego and reason predominating [23]. In 1982, Joseph attempted to integrate previous attempts at defining normality by describing it as what is average or expectable, as defined by research or clinical experience [24]. Some of these concepts are touched on in the definition of normal in the Critical Dictionary of Psychoanalysis, though Rycroft also adds the idea that a "norm is that member of a class by comparison with which other members are described" [25].

Some of these psychoanalytic concepts of normality are more socially oriented than Freud's definition. They have probably contributed, along with related work such as Bion's research with groups, to an acceptance of psychoanalysis by some psychologists as "a form of social psychology" ([5], p. 111). Although Foucault's original criticism of Freud may have been misplaced for the reasons stated earlier, the subsequent direction of psychoanalytic thought has established the potential for some renewed Foucault-style criticism. An early example of this can be seen in Thibaut's criticism of Glover's concept of social adaptation, saying that it leads to compartmentalisation, fails to recognise the possibility that abnormalities can occur on a mass basis, is difficult to validate, and fails to do justice to the societal 'rebel' who is, in fact, more normal than the abnormal mass [26].

\subsection{Foucault and Analytical Psychology}


The relation of analytical psychology to Foucault over time is almost a mirror image to psychoanalysis. Although Foucault's early criticism of Freud's concept of normality was misguided, later developments muddy the picture and raise issues about which Foucault might have had some valid points. Jung's early work, however, is based on the type of approach that Foucault criticised, and it is Jung's later theories that muddy the picture and move analytical psychology away from definitions of normality that are based on social norms.

Throughout most of his working life, Jung recognised the role played by collective norms [27]. He used them in his early work on word associations, first conducting experiments on normal subjects so he could subsequently distinguish pathological results [28]. This was an overt example of the process of normalisation that Foucault had suggested was covertly part of Freud's practice. In later years, however, Jung took a more individually-oriented view of normality, rejecting Adler's socially-oriented normalisation [29] because of the depreciating impact it has on the unconscious. He also objected to statistical averages because "individual exceptions... are murdered by statistics" [30], though he still saw a need for the notion of "average functioning" [31]. He held both views, not through inconsistency but because they were aspects of one of the "great number of antinomies...required to describe the nature of the psyche satisfactorily" [32], the universal and the individual. Although Jung began his career using the process of normalisation of which Foucault was so critical, as time went on Jung's position became more aligned with Foucault, e.g., observing the fact of normalisation whilst recognising the damaging impact it could have on the individual.

\section{The Concept of Normality in Analytical Psychology}

\subsection{Differences between Freud and Jung}

By comparison with mainstream psychology or psychoanalysis, the concept of normality within analytical psychology remains relatively undeveloped. Although there is a body of work that is relevant to normality - such as that which describes the "normal" archetypal stages of life (e.g., [33]), applies Jung's ideas to the social sciences (e.g., [34]), or discusses normality in opposition to pathology (e.g., [35]), there are three problems with it. Firstly, discussions that utilise analytical psychology tend not to focus on the mainstream of normal life but on the fringes. For example, the Jungian analyst Marian Woodman seems to position analytical psychology as not being relevant to "happy carrot" normal people [36], and research into Jung's theories in mainstream academic psychology is very limited. Secondly, the existing body of work is missing a cornerstone of definition, because the post-Jungian development of the concept of normality itself is relatively limited (e.g., [37]). For example, there is no entry for "normal" in A Critical Dictionary of Jungian Analysis [38], and Samuels' summary in Jung and the Post-Jungians cites mostly the work of psychoanalysts [39]. And, thirdly, the focus of the existing body of work is overwhelmingly on the relationship between the ego and the unconscious. In psychoanalysis, the emergence of ego psychology broadened its scope, leading to a greater awareness of the need to adapt to external reality, rather than focusing primarily on the ego's relation to unconscious processes. There has been no parallel in analytical psychology because the vast majority of development has been based on the relationship of the ego to the Self. As a result, the relationship between the ego and the persona has been neglected. Although this, in part, reflects Jung's emphasis on the unconscious, he nevertheless 
had some radical and important things to say about normality, the relationship between the ego and the persona, and the application of analytical psychology to the normal population. To begin any substantive discussion on the subject of normality, therefore, one has to start by going back and reviewing the oft-overlooked aspects of Jung's original work.

There are some overlaps between Jung's notions and those of psychoanalysis, such as the idea of there being an "average course of events" [31]. However, whilst Jung recognised the role of inner conflict in creating neurosis ([1], p. 211), he did not share Freud's view that normality was freedom from such conflict. Jones' ideal state of development, or Freud's "ideal fiction" [40], corresponds to Jung's state of wholeness that is the final goal of individuation. Therefore, although the word normal is used in both psychoanalysis and analytical psychology, there are two separate meanings being used. Freud's "normal" equates to Jung's "individuation", and Jung's concept of "normal" can include a group that is opposite to Freud's - those who lack any significant development of consciousness [41]. Also, whilst Freud's normality is a fiction because it is unattainable, Jung says "the normal man is a fiction" [42] because there is no individual who is identical to the collective norms, i.e., that "every individual is an exception to the rule" [41].

\subsection{Bi-Directional Adaptation}

In Jung's view, "normality is a most relative conception" ([31], p. 210), a dynamic balance between the inner and outer worlds. Achieving this balance is central to analytical psychology:

[The] main purpose [of analytical psychology] is the better adaptation of human behaviour, and adaptation in two directions (illness is faulty adaptation)...to external life-profession, family, society - and secondly to the vital demands of his own nature...to bring it to the right pitch of development [43].

Jung used the metaphor of specific gravity to suggest that each individual has their own natural level of adaptation between the two worlds [42] — an image that can be clarified by likening the ego to a hydrometer, which sits at a certain height between a fluid and a gas depending on the fluid's specific gravity. Individuals can become neurotic when they are unable to find the right position between the two, e.g. not having a desired level of adaptation to the context, or being unfulfilled by it because of an inner disposition ([29], p. 70). This means that, in broad terms, there are two types of neurosis either side of normality, "collective people with underdeveloped individuality [or] individualists with atrophied collective adaptation" ([32], p. 7):

The first type is...the kind of neurosis which...is a form of maladjustment based on personal weakness... The reason for [the second type's] neurosis seems to lie in their having... an overplus for which there is no adequate outlet [44].

This adaptation is not just a function of the individual psyche and immediate context, i.e., adjustment to the conditions of the moment, but it also needs to take account of both historical trends and emerging possibilities in the two domains of adaptation:

In the eyes of the Extravert...adjustment...must seem like complete adaptation [but] the objective situation... can quite well be temporarily or locally abnormal...Adjustment is not adaptation: adaptation requires far more than merely going along smoothly with the conditions of the moment... It requires observance of laws more universal than the immediate conditions of time and place [45]. 
Therefore, normality in analytical psychology is a psychic ecology in which there is a sustainable balance between the inner and outer worlds. This definition does not require being free from complexes, and there are many psychic processes that Jung viewed as normal that Freud and others viewed as pathological. For example, it is normal for the psyche to split and for individuals to fall painfully or permanently under the control of complexes:

Complexes are the normal foci of psychic happenings, and the fact that they are painful is no proof of pathological disturbance. Suffering is not an illness, it is the normal counter pole to happiness [46].

The presence of autonomous complexes is not itself pathological, since normal people, too, fall temporarily or permanently under their domination. This fact is simply one of the normal peculiarities of the psyche [47].

The sophistication of Jung's understanding of normality is illustrated by his oxymoronic phrase "normal peculiarities". Normality is not a particular psychic state but an overall pattern that embraces a wide range of emerging psychic states, including peculiar ones. This is similar to observations in statistics, where a normal distribution is not just a single, average result but a pattern that emerges from a wide range of values - including ones at the extreme of the curve. A practical example of this is Christopher Hauke's argument that fragmentation and narcissism can be seen in a positive light, as motors that drive the process of individuation [48]. For some people fragmentation can be viewed as normal, as it is expectable in the overall context of a psyche working towards its need of individuation through therapy. For others, fragmentation is not expectable in daily life and it might disturb their psychic balance by interfering with the basic level of collective adaptation that is required for individuation to progress ([41], p. 449).

\subsection{Conscious Conflicts and Projections}

Jung's definition of normality has a number of significant and oft-overlooked implications. In Jung's scheme, one of the key distinctions between neurotics and normal people is the nature of the conflicts they experience. When someone is neurotic, the ego has not found the individual's natural level between the two domains of adaptation so, in terms of the metaphor of specific gravity, the (unconscious) fluid tries to restore balance either by pushing the ego up to better adapt to the context, or by pulling it back down into the unconscious. This means that, for a neurotic, there is some form of conflict between the ego and the unconscious, which might only be detectable through unexplained symptoms such as chronic anxiety. For normal people, however, that positional conflict between consciousness and the unconscious is not there. They still experience conflicts, as these are a part of normal life, but to the individual they seem to have a different nature:

The mental and moral conflicts of normal people [are of] a somewhat different kind: the conflicting opposites are both conscious [49].

For normal people, there are still differences between consciousness and the unconscious, and there are still conflicting aspects within both the conscious and unconscious psyche. However, they experience them in different ways to neurotics, by being unaware of those conflicts in oneself, and/or experiencing them as a conscious conflict through projection. This may be a reason why theories such as Isabel Briggs Myers' version of psychological type are so popular - the normal person can experience and deal with otherness unconsciously by seeing themselves as one personality type and 
another person as a different type. The theory enables them to project their own unconscious intra-psychic conflict into what are viewed consciously as inter-psychic differences between people.

Another illustration of Jung's "normal" condition, and the unconscious compensation that goes with it, can be seen in Alexander Solzhenitsyn's satirical reflection, where good and evil are placed in relation to oneself and others:

If only there were evil people somewhere insidiously committing evil deeds, and it were necessary only to separate them from the rest of us and destroy them. But the line dividing good and evil cuts through the heart of every human being. And who is willing to destroy a piece of his own heart [50]?

This illustrates how normal people deal with the presence of both good and evil within one's own psyche. If it is untenable to recognise the presence of evil within oneself, or to deal with the internal conflict that this creates, it is dealt with unconsciously. The individual takes a one-sided approach, seeing the good in oneself whilst excluding from consciousness the unacceptable aspects. These evil parts of one's own personality then "sink into the unconscious, where they form a counter-weight to the conscious orientation" ([41], p. 419). This unconscious compensation is akin to the balancing effect of the keel of a boat that is leaning to one side in the wind. It can sometimes take a benign form, for example in dreams that can play a compensatory role for normal people even when the dreamer does not understand its meaning [51]. Also, normal people may be shielded from the potential negative effects of unconscious conflict by myths and symbols [52] which can be effective even when they are not understood [53].

However, compensation often takes the form of projection, which can sometimes have damaging side-effects. For example, if we take a one-sided, conscious view of ourselves as wholly good, then the psyche compensates by finding "willing carriers of our projections" [53], projecting the evil into them, and then sustaining a well-distributed web of reciprocal projections in which relationships are largely imaginary, i.e., more projection than objective reality. To maintain the split between good and evil, these negative projections have to "settle outside our circle of intimate relationships" [54], a principle that applies at all levels, even to international relations. An example of how this works in practice can be seen in the prediction made in 1989 by the Jungian analyst Jerome Bernstein, who used this principle of compensatory projection to predict the rise of terrorism from the Middle East. His argument was that the changing relationship between the US and USSR would mean that the latter could no longer carry the collective projections of the former. Another group of nations would therefore have to emerge as carriers of the collective projections of the US. This displacement of projections was epitomised 15 years later in George W. Bush's labelling of Iran, Iraq and North Korea as the "axis of evil".

Projections are not inherently a bad thing, because they can be vital to maintaining psychic equilibrium in the person or society who is projecting, and raising awareness of those projections can become "an impediment to our relations with others" [54]. Normal people come through times of difficulty unconsciously ([1], p. 129), but this can lead to problems when negative projections are placed on people over whom one has some power or influence, or with whom one needs to have a good working relationship. When these projections aggregate at a cultural level, and can be acted out using 20th century technology, they pose a significant risk to whole groups or societies: 
The only real danger that exists is man himself. $\mathrm{He}$ is the great danger, and we are pitifully unaware of it. We know nothing of man, far too little. His psyche should be studied, for we are the origin of all coming evil [55].

Man's worst sin is unconsciousness... and in all seriousness [we need to] seek ways and means to exorcize him, to rescue him from possession and unconsciousness, and make this the most vital task of civilisation [56].

For Jung, unconsciousness and the excessive one-sidedness that can accompany it were amongst the greatest threats to civilisation. The increase of consciousness by integrating unconscious contents (i.e., individuation) was therefore a moral imperative that affects not only individuals but also international and cultural relations.

\subsection{Individual-Collectivity Spectrum}

One of the common misperceptions about analytical psychology is that individuation is its central goal, e.g., the Wikipedia page on Jungian or analytical psychology explicitly states: "The overarching goal of Jungian psychology is the attainment of self through individuation" [57]. At the time of writing this paper, that page goes on to describe neurosis in terms of adaptation to the Self (i.e., the central archetype in the inner world) and the goal of psychotherapy as re-establishing a healthy relationship with the unconscious. However, although individuation is very significant aspect of Jung's theory, it is not the only goal for normal people - it is not even the only goal in therapy ([41], p. 449). Neurosis can also arise from the other direction of adaptation, i.e. the context or environment. Jung gave some specific examples of this, such as an American businessman who became neurotic because he could not adapt to retirement after running a business for his entire life ([1], pp. 50-52), or how a young person can sometimes be cured of a neurosis through a new start, if it is rich in possibilities. These examples are in line with contemporary research, such as that showing the importance of continuity of social roles in retirement [58].

Promoting individuation as the sole aim of analytical psychology creates some problems in applying Jung's theory to normal (non-neurotic) people. Jung's primary goal, as stated earlier, is two-way adaptation, to both the inner and outer worlds, and a main theme that runs through all aspects of his theory is dealing with the problem of opposites through the transcendent function [59]. An exclusive focus on individuation presents his theory, ironically, in a one-sided way. It misses the point that individuation and collectivity are themselves a pair of opposites, and it neglects applications of analytical psychology at one of the poles (collectivity) that are relevant to many in the normal population:

There are countless people who are not only collective [but whose] ambition [is] to be nothing but collective ([32], p. 7).

Individuation and collectivity are a pair of opposites, two divergent destinies...The individual is obliged by the collective demands to pursue his individuation...Anyone who cannot do this must submit directly to the collective demands, to the demands of society [60].

The choice between individuation and collectivity is not a binary one, because both are involved at both ends of the individuation-collectivity spectrum. Working towards individuation "presupposes and includes collective relationships" [39], p. 77), and pursuing the goal of collectivity also includes an element of individuation. In defining the main goal for analytical psychology, Jung did not 
suggest that everyone should work towards individuation, but rather that they should "get involved in the very fate for which they were suited" ([1], p. 149). Furthermore, he gave strong warnings against forcing someone into anything other than their own destiny. For example, it can be dangerous to artificially bring unconscious contents to the surface ([27], p. 153), akin to "digging an artesian well and running the risk of stumbling on a volcano" ([1], p. 114), and it could lead to such a "disastrously wrong turning" [61] that he would be the first to hold back. He also gave a warning in the other direction, against the collectivisation of those whose destiny is individuation, because "the suppression of individuality through the predominance of collective ideals and organisations is a moral defeat for society" [62].

Jung's theory already contains many inherent problems, paradoxes and contradictions - such as the dichotomy that it can be in the individual's best interests to remain unconscious but in society's interest to become more conscious. However, if the goal of Jung's theory is presented only as a psychology of individuation and of rapprochement with the unconscious, then this creates an additional problem. It positions analytical psychology as not particularly relevant to normal people, it overlooks societal/contextual causes of neurosis, and it means we may miss some of the potential insights and applications that it has to offer mainstream psychology and everyday living. It also means we are less likely to resolve the dichotomy discussed above-of the individual $v s$. societal benefits of consciousness remaining the same or increasing.

\subsection{Personal and Collective Awareness}

One of the perhaps surprising implications of Jung's definition of normality is the relationship between the individuation-collectivity spectrum and an increase in consciousness. Raising awareness of the personal unconscious makes one more collective, whilst raising awareness of the collective unconscious makes one more individual. Also, the first type of awareness tends to lead naturally to the latter, because the two types of content are "inextricably merged" ([39], p. 139):

$[\mathrm{R}]$ aising the personal unconscious to consciousness...[makes one] less individually unique, and more collective ([1], p. 148).

The ego-consciousness is at first identical with the persona...[T]hrough the analysis of the personal unconscious, the conscious mind becomes suffused with collective material which brings with it the elements of individuality ([1], p. 158).

Jung's first statement, about becoming more collective, may seem surprising to some, but Jacobi makes a similar point when she describes "analysis of the personal unconscious" as "adjustment to external reality" [63]. Although this may seem counter-intuitive, it can perhaps be explained by considering what happens in the process of 360-degree feedback, which is now a normal occurrence in many business and organisational contexts. In this process, colleagues at all levels - bosses, peers, and subordinates - give an individual feedback on their behaviour. The common themes from this feedback are very likely to be dominated by the collective cultural values of the organisation, and how well the individual's behaviour fits with those values. As a result, people receiving such feedback are likely to change their attitudes and behaviour to be more in line with the cultural norms, i.e., become more collective. However, some feedback may also contain comment on the person's unique potential and deeper aspects of his/her individual personality. If so, this may lead towards a 
process of individuation, which may result in the person making a more unique contribution to the development of the organisation.

The nature of this collectivisation process, based on awareness of the personal unconscious, has not been investigated in any depth within analytical psychology. The most relevant aspects of Jung's writings are those that discuss the persona, which is a portion of the collective psyche. Collectivisation doesn't necessarily involve analysis of the persona, for "when we analyse the persona we strip off the mask" ([1], p. 158). Rather it involves the formation of a "properly developed persona" ([61], p. 199) for, as Casement notes, "the development of a well-functioning persona is an essential task for any individual" [64] and it can provide protection for the ego and psyche. The development of a healthy persona will eventually lead back towards individuation because it involves a differentiation of ego and persona. That is, in the public life of the persona one becomes more collective, but in the private life of the ego, which may be apparent only in contained relationships such as marriage, one starts to individuate.

From the perspective of individuation, "fundamentally the persona is nothing real: it is a compromise between individual and society as to what a man should appear to be" ([1], p. 158) and it can present an obstacle to growth (e.g., see [65]). However, for the normal population, Jung's work on the persona sits at an important point of intersection between analytical psychology and social psychology, which views the persona as vital and providing a channel through which the normal person can find meaning [66], or through which meaning emerges [67].

\section{Conclusions}

It is likely that people who seek Jungian analysis, or otherwise have a personal interest in analytical psychology, tend to be interested in their own individuation. However, if analytical psychology is to be applied to the normal population then the goal is a little different - it is to help them find their own natural balance on the spectrum between individuation and collectivity, and then to increase consciousness at their own natural pace if it suits their individual destiny. For collective people there may only be one direction of development - they are defined by their social roles, and they continue to play that role (or similar ones) throughout the whole of life. For others, whose natural destiny is individuation, there may be two phases. The first is a move towards collectivity through increased awareness of the personal unconscious. This then leads naturally back towards the individuation end of the spectrum, through the emergence of contents from the collective unconscious. These two phases are related to the two movements of individuation described by Stein [68] and they highlight some of the key problems in applying analytical psychology to the normal population. For example, it is a truism to say that, for society to function, there has to be a degree of collectivity, but too much emphasis on collectivity can suppress the individual. Another problem is the dual impact of unconsciousness, which can protect the individual from intra-psychic conflicts, but can also damage other people and society through projection. Associated with unconsciousness is one-sidedness - a key feature of the first movement of individuation - but too much one-sidedness can become an obstacle to progress, preventing the reconciliation of opposites and the integration of the unconscious.

The key challenge in applying analytical psychology to normal people, therefore, is to find the right balance between individuation and collectivity in a way that both serves society and meets each individual's needs and destiny. This requires a culture that values all parts of the 
collectivity-individuation spectrum, encourages individuals to find their natural place on it, and enables an ongoing progression whilst avoiding the problems of excessive one-sidedness, unconsciousness, and the analytic risks to the individual. Whereas neurotics are forced by their neurosis to become more conscious ([1], p. 272), an increase in consciousness in normal people can only be pursued through a natural process of transformation within the individual [69]. Meeting this challenge requires more research and development, particularly in the area of the persona. Whereas analytical psychologists tend to emphasise the ego-self axis, for the normal population the ego-persona axis is also very significant because of their direct involvement in collectivity. Yet neither axis represents a complete picture, so further development of the concept of normality in analytical psychology needs to be based on a healthy triangular relationship that affords value to all three.

\section{Conflicts of Interest}

The author declares no conflict of interest.

\section{References}

1. Jung, C.G. On the Psychology of the Unconscious. In Two Essays on Analytical Psychology, Collected Works 7; Bollingen Paperbacks: Princeton, NJ, USA, 1966; originally published in 1917, revised in 1926 and 1943; p. 6 fn.

2. Jung, C.G. Foreword to Von Koenig-Fachsenfeld: "Wandlungen des traumproblems von der romantic bis zur gegenwart". In The Symbolic Life, Collected Works 18; Routledge \& Kegan Paul: London, UK, 1977; originally published in 1935; pp. 773-774.

3. Shamdasani, S. Jung and the Making of Modern Psychology; Cambridge University Press: Cambridge, UK, 2003; pp. 13-14.

4. Jung, C.G. Address on the Occasion of the Founding of the C.G. Jung Institute, Zurich, 24 April, 1948. In The Symbolic Life, Collected Works 18; Routledge \& Kegan Paul: London, UK, 1977; originally published in 1948; pp. 475-476.

5. Wetherall, M. Identities, Groups and Social Issues; Sage Publications: London, UK, 1996; p. 359; published in association with The Open University.

6. Sherif, M. The Psychology of Social Norms, quoted in [5], p. 14; originally published in 1936.

7. Lewin, K. Group Decision and Social Change, quoted in [5], p. 46; originally published in 1947.

8. Foucault, M. Discipline and Punish: The Birth of the Prison; Penguin Books: London, UK, 1991; p. 179.

9. Foucault, M. Madness and Civilization. In The Foucault Reader; Rabinow, P., Ed.; Penguin Books: London, UK, 1984; p. 162.

10. Craig, E., Ed. The Shorter Routledge Encyclopaedia of Philosophy; Routledge: Abingdon, UK, 2005 ; p. 282.

11. Whitebook, J. Freud, Foucault and 'the Dialogue with Unreason'. J. Philos. Soc. Critic. 1999, 6, 29-66.

12. Gutting, G. The Cambridge Companion to Foucault; Cambridge University Press: Cambridge, UK, 2005; p. 331. 
13. Freud, S. The Interpretation of Dreams, 1st ed.; Crick, J., trans.; Oxford University Press: Oxford, UK, 1999; originally published in 1900; p. 380.

14. Freud, S. The Psychopathology of Everyday Life: Forgetting, Slips of the Tongue, Bungled Actions, Superstitions and Errors. In The Standard Edition of the Complete Psychological Works of Sigmund Freud; Psychoanalytic Electronic Publishing: Wilmington, DE, USA, 1901; Volume 6, p. 152.

15. Freud, S. Psychoanalysis: Freudian School. In Encyclopaedia Britannica, 13th ed.; Haverford College: Haverford, PA, USA; 1926. Available online: http://www.haverford.edu/psych/ ddavis/p109g/freud.psa.html (accessed on 22 July 2008)

16. Freud, S. Letter from Freud to Fliess, May 25, 1895. In The Complete Letters of Sigmund Freud to Wilhelm Fliess; Psychoanalytic Electronic Publishing: Wilmington, DE, USA, 1895.

17. Freud, S. Psychical (or Mental) Treatment. In The Standard Edition of the Complete Psychological Works of Sigmund Freud, Volume VII; Psychoanalytic Electronic Publishing: Wilmington, DE, USA, 1890; p. 286.

18. Kubie, L.S. The Fundamental Nature of the Distinction between Normality and Neurosis. In The Psychoanalytic Quarterly, Volume 23:167-204; Psychoanalytic Electronic Publishing: Wilmington, DE, USA, 1954.

19. Offer, D.; Sabshin, M. Normality; Basic Books: New York, NY, USA, 1973.

20. Glover, E. Medico-Psychological Aspects of Normality. Br. J. Psychol. 1932, 23, 152-166.

21. Gitelson, M. Therapeutic Problems the Analysis of the 'Normal' Candidate. Int. J. Psychoanal. 1954, 35, 174-183.

22. Jones, E. The Concept of a Normal Mind. Int. J. Psychoanal. 1942, 23, 1-8.

23. Krapf, E.E. The Concepts of Normality and Mental Health in Psycho-Analysis. Int. J. Psychoanal. 1961, 42, 439-446.

24. Joseph, E.D. Presidential Address-Normal in Psychoanalysis. Int. J. Psychoanal. 1982, 63, $3-13$.

25. Rycroft, C. Critical Dictionary of Psychoanalysis; Penguin Books: London, UK, 1995; pp. 111-112.

26. Thibaut, J.W. The Concept of Normality in Clinical Psychology. In Psychological Review; American Psychological Association: Washington, DC, USA, 1943; pp. 338-345.

27. Jung, C.G. The Significance of the Unconscious in Education. In The Development of Personality, Collected Works 17; Bollingen Paperbacks: Princeton, NJ, USA, 1981; originally published in 1928; p. 151.

28. Jung, C.G. The Associations of Normal Subjects. In Experimental Researches, Collected Works 2; Routledge \& Kegan Paul: London, UK, 1973; originally published in 1906; pp. 3-196.

29. Jung, C.G. Problems of Modern Psychotherapy. In The Practice of Psychotherapy, Collected Works 16; Routledge \& Kegan Paul: London, UK, 1966; originally published in 1929; pp. 67-68.

30. Jung, C.G. Flying Saucers: A Modern Myth. In Civilization in Transition, Collected Works 10; Routledge \& Kegan Paul: London, UK, 1970; originally published in 1958; pp. 393-394.

31. Jung, C.G. Letter to Smith Ely Jellife. In C.G. Jung Letters Volume I 1906-1950; Adler, G., Ed.; Routledge \& Kegan Paul: London, UK, 1973; originally published in 1936; p. 211. 
32. Jung, C.G. Principles of Practical Psychotherapy. In The Practice of Psychotherapy, Collected Works 16; Routledge \& Kegan Paul: London, UK, 1966; originally published in 1935; p. 4.

33. Neumann, E. The Origins and History of Consciousness; Bollingen Paperbacks: Princeton, NJ, USA, 1954; p. xvi.

34. Progoff, I. Depth Psychology and Modern Man; The Julian Press: New York, NY, USA, 1959.

35. Noll, R. Multiple Personality, Dissociation and C.G. Jung's Complex Theory. J. Anal. Psychol. 1989, 34, 353-370.

36. Woodman, M.; Mellick, J. Coming Home to Myself: Reflections for Nurturing a Woman's Body and Soul; Conari: Berkeley, CA, USA, 2001; p. 278.

37. Mizen, R. The Primitive and the Pathological (Review). J. Anal. Psychol. 1995, 40, 485-486.

38. Samuels, A.; Shorter, B.; Plaut, F. A Critical Dictionary of Jungian Analysis; Routledge: Hove, UK, 1986.

39. Samuels, A. Jung and the Post Jungians; Routledge: London, UK, 1986; p. 134.

40. Freud, S. Analysis Terminable and Interminable. In The Standard Edition of the Complete Psychological Works of Sigmund Freud, Volume XXIII; Psychoanalytic Electronic Publishing: Wilmington, DE, USA, 1937; p. 235.

41. Jung, C.G. Psychological Types, Collected Works 6; Routledge: London, UK, 1991; originally published in 1921; pp. 515-516.

42. Jung, C.G. Marriage as a Psychological Relationship. In The Development of Personality, Collected Works 17; Bollingen Paperbacks: Princeton, NJ, USA, 1981; originally published in 1925; p. 200.

43. Jung, C.G. Analytical Psychology and Education. In The Development of Personality, Collected Works 17; Bollingen Paperbacks: Princeton, NJ, USA, 1981; originally published in 1926, revised in 1946; p. 92.

44. Jung, C.G. Fundamental Questions of Psychotherapy. In The Practice of Psychotherapy, Collected Works 16; Routledge \& Kegan Paul: London, UK, 1966; originally published in 1951; p. 121.

45. Jung, C.G. Psychological Types, Collected Works 6; Routledge: London, UK, 1991; originally published in 1921; pp. 334-335.

46. Jung, C.G. Psychotherapy and a Philosophy of Life. In The Practice of Psychotherapy, Collected Works 16; Routledge \& Kegan Paul: London, UK, 1966; originally published in 1943; pp. 78-79.

47. Jung, C.G. On the Relation of Analytical Psychology to Poetry. In The Spirit in Man, Art and Literature, Collected Works 15; Routledge: London, UK, 2003; originally published in 1922; p. 91.

48. Hauke, C. Fragmentation and Narcissism. J. Anal. Psychol. 1995, 40, 497-522.

49. Jung, C.G. Techniques of Attitude Change Conducive to World Peace. In The Symbolic Life, Collected Works 18; Routledge \& Kegan Paul: London, UK, 1977; originally published in 1948; pp. 606-607.

50. Solzhenitsyn, A.I. The Gulag Archipelago, 1918-1956: An Experiment in Literary Investigation; Harper \& Row: New York, NY, USA, 1985; p. 75.

51. Jung, C.G. On the Nature of Dreams. In The Structure and Dynamics of the Psyche, Collected Works 8; Routledge \& Kegan Paul: London, UK, 1969; originally published in 1945, revised in 1948; pp. 294-297. 
52. Jung, C.G. Symbols of Transformation, Collected Works 5; Bollingen Paperbacks: Princeton, NJ, USA, 1967; originally published in 1911-1912; p. 231.

53. Jung, C.G. On the Psychology of the Trickster Figure. In The Archetypes and the Collective Unconscious, Collected Works 9i; Routledge \& Kegan Paul: London, UK, 1968; originally published in 1954; pp. 267-268.

54. Jung, C.G. General Aspects of Dream Psychology. In The Structure and Dynamics of the Psyche, Collected Works 8; Routledge \& Kegan Paul: London, UK, 1969; originally published in 1916, revised in 1948; pp. 271-272.

55. Jung, C.G. The "Face to Face" Interview. In C.G. Jung Speaking; Bollingen Paperbacks: Princeton, NJ, USA, 1977; originally published in 1959; p. 436.

56. Jung, C.G. The Phenomenology of the Spirit in Fairytales. In The Archetypes and the Collective Unconscious, Collected Works 9i; Routledge \& Kegan Paul: London, UK, 1968; originally published in 1945, revised in 1948; pp. 253-254.

57. Analytical Psychology. Available online: http://en.wikipedia.org/wiki/Analytical_psychology (accessed on 23 August 2013).

58. Stokes, G. On Being Old; Falmer Press: London, UK, 1992; pp. 33, 119.

59. Miller, J.C. The Transcendent Function; State University of New York Press: Albany, NY, USA, 2004.

60. Jung, C.G. Adaptation, Individuation, Collectivity. In The Symbolic Life, Collected Works 18; Routledge \& Kegan Paul: London, UK, 1977; originally published in 1916; p. 452.

61. Jung, C.G. The Relations between the Ego and the Unconscious. In Two Essays on Analytical Psychology, Collected Works 7; Bollingen Paperbacks: Princeton, NJ, USA, 1966; originally published in 1928; p. 224.

62. Jung, C.G. The Structure of the Unconscious. In Two Essays on Analytical Psychology, Collected Works 7; Bollingen Paperbacks: Princeton, NJ, USA, 1966; originally published in 1916; p. 303.

63. Jacobi, J. The Process of Individuation. J. Anal. Psychol. 1958, 3, 95-114.

64. Casement, A. Persona. In Encyclopaedia of Psychology and Religion; Blanton-Peale: New York, NY, USA, 2010; pp. 670ff.

65. Hudson, W.C. Persona and Defence Mechanisms. J. Anal. Psychol. 1978, 23, 54-62.

66. Perlman, H.H. Persona: Social Role and Personality; University of Chicago Press: Chicago, IL, USA, 1986.

67. Miell, M., Dallos, R., Eds. Social Interaction and Personal Relationships; Sage Publications: London, UK, 1996; p. 310; published in association with The Open University.

68. Stein, M. Principle of Individuation: Toward the Development of Human Consciousness (Polarities of the Psyche); Chiron Publications: Wilmette, IL, USA, 2006.

69. Jung, C.G. A Study in the Process of Individuation. In The Archetypes and the Collective Unconscious, Collected Works 9i; Routledge \& Kegan Paul: London, UK, 1968; originally published in 1934, revised in 1950; p. 349. 


\title{
Chapter 4
}

\section{Gender Legacies of Jung and Freud as Epistemology in Emergent Feminist Research on Late Motherhood}

\section{Maryann Barone-Chapman}

School of Social Sciences, Cardiff University, Glamorgan Building, King Edward VII Avenue, Cardiff CF10 3WT, UK; E-Mail: Barone-ChapmanM@cf.ac.uk; Tel.: +44-20-8785-0043

\begin{abstract}
While conducting doctoral research in social science on late motherhood, two analytical engagements with the feminine came to my attention as evidence of a patriarchal bias toward the realm of womanhood. Jung's mythopoetic tension between symbolism and enactments with the feminine and Freud's supposition that a denial of the feminine was necessary for psychological and emotional development appeared to be perpetuating a social problem continuing in current times. Across affective behavior and narrative within stories of late procreative desire, dream journals and Word Association Tests of eight participants was the memory of a male sibling who had enjoyed primacy of place in the parental home over the daughter. The female body with a voice was missing in the one-sided perspectives of Analytical Psychology and Psychoanalysis on the subject of the feminine, until a whole view of psyche's discontents in Feminist inspired Psychoanalytic theories from both schools on the female body were included. Freud and Jung's views became evidence of patriarchy as background while extension of Feminist inspired psychoanalytical thinking, Queer theories and Creation Myth allowed new meanings of the embodied feminine to emerge through a recapitulation of a union of opposites as a union of epistemology and ethos. The essence of Jung's mid-life theories, altered by modernity and eclipsed by female advancement, remains replicatable and paradigmatic outside of essentialist gender performance.
\end{abstract}

Reprinted from Behav. Sci. Cite as: Barone-Chapman, M. Gender Legacies of Jung and Freud as Epistemology in Emergent Feminist Research on Late Motherhood. Behav. Sci. 2014, 4, 14-30.

\section{Introduction}

In the course of engaging with women's stories and affects while exploring memories, dreams, and associations on the subject of delayed motherhood, two analytical ideas-Jung's mythopoetic tension between symbolism and enactments with the feminine and Freud's [1] "Repudiation of the Feminine" attracted my attention to the realm of womanhood as a social problem, in particular the way in which themes of psychic bisexuality produced a feminine that is "thereby displaced from its forced equivalence to the object and from its inevitable localization in the woman" ([2], p. 87). What kept coming up as both privation and deprivation across affective behavior and narrative among 
eight participants was the existence of a male sibling who had more privilege, encouragement and engagement with mother (and father if he was around) than the daughter. I realized these participants were demonstrating the very bones of this research, distinguishing the making of a complex between personal experience, cultural and collective contexts. The affects before me at micro level were emerging into a macro view of how feminism emerged when the feminine could no longer quietly accept being thwarted to favor the masculine. Like the Sumerian goddess Inanna, participants had taken their procreative desire underground until the clamor of mid-life beckoned them to reclaim the right to enjoy an ordinary life.

My aim in this paper is to examine the plural definition and uses of the feminine in Analytical Psychology and Psychoanalysis in particular against Western culture at large in order to define a Feminist ethos for this research. Though Jungian by qualification and perspective I must include my own reflexivity on theoretical problems such as the anima and animus in Analytical Psychology so that I do not unconsciously analyze the subjectivity of participants to Jungian or Freudian grand narratives on what it means for a woman to desire and experience motherhood in the fourth decade. But more so, not only does it appear that the first analytical fathers offered us a useful theory of patriarchy [3] along with other documented effects of 'the mind doctors' on women [4,5], their androcentric frames of feminine reference becomes an important epistemology for delayed motherhood. Female diseases, such as depression, promiscuity, paranoia, eating disorders, self-mutilation, panic attacks, and suicide attempts, whether reported/treated or not, are all female role rituals ([5], p. 110) to which I'd like to add one more: the expectation of fertility after forty years of age.

\section{Discovery Process}

What is determined to be masculine and feminine behavior, expression, and choices continues in post Jungian psychotherapies as a question regarding development, even when these are attached to archetypes [6,7]. The biological difference in women with an implied imperative to reproduce opens the depth question of a woman's unconscious use of her body as a means of separation, individuation and psychic growth ([8], p. 83). Delayed motherhood in a bio-technological age may be yet another form of power and control [9-11]. To consider late motherhood in a technological age begins with a review of Jung's [12] early working through his ideas on the contra-sexual other of anima and animus, drawing from his real world experience of what a lack of procreativity means for a woman.

“...then you get into a special kind of hell...for a woman there is no longer any way out; if she cannot $<$ does not $>$ have children, escape into pregnancy, she falls into hellfire... she discovers that she is not only a woman, she is a man too" ([12], p. 794).

Before the myths and terms of feminine and femininity are unpacked there is something very important to register about the finding of a favored male sibling in this research. Across all participants' stories deep wounds to do with early gender learning of the superior value placed on the masculine in a brother, whether or not he was younger or older, while the good things of the feminine in the daughter were difficult to see by parental caretakers, were present. In effect these women had been groomed to feel inferior to the masculine, by being less considered, desired and entitled, resulting in a view they might be less capable in life than a male. That most of the eight participants 
enjoyed engagement in the world long past many of their peers due to onset of pregnancy around the fourth decade, goes some way to suggesting how their choice of delaying motherhood resonates, at minimum, with having to prove something to themselves and others regarding the very definition of what embodying the feminine is about; normative, predictive generative identity via motherhood was not going to be enough.

"The difference in a mother's reaction to the birth of a son or daughter shows that the old factor of lack of a penis has even now not lost its strength. A mother is only brought unlimited satisfaction by her relation to a son; this is altogether the most perfect, the most free from ambivalence of all human relationships. A mother can transfer to her son the ambition which she has been obliged to suppress in her-self, and she can expect from him the satisfaction of all that has been left over in her of her masculinity complex." ([1], pp. 112-113).

The feminine principle equating to female inferiority by the founders of both Analytical Psychology and Psychoanalysis, appears along a continuum ranging from Freud's perspective of causation, for example, his penis envy/castration theory was grounds for hysteria based on a phallo-centricity [2] to Jung's invisible realm of the collective unconscious through the use of mythopoetics as if to rationalize logos as the sole propriety of men and Eros to women as a universal structuring element of psyche conceptualized as animus and anima, respectively. Jungian Analyst Polly Young-Eisendrath [13] frames these ideas as androcentric in their ignorance of the woman's experience, her social context, and the nature of her female gender identity in context to traditional sex roles. Without conscious feminine experience "an anxious middle-aged woman, identified with the idea that she is inferior intellectually, may be called 'animus-ridden' by a Jungian psychotherapist because she speaks in an opinionated and insistent manner about a general or vague idea" ([13], p. 23).

\subsection{Feminine Riddles into Myths}

Image, emotion, enactments, projection, rituals and fantasies emerging as beliefs in early Psychoanalytical theories reify mental phenomena, blurring the lines between illusion and reality. Jung and Freud appear as early social scientists looking to explain the split between matter and mind. Once Freud's descendents opened the gate to allow for the impact of culture on phenomena observed by the analytical founding fathers, the groundwork was laid for Feminist inspired Psychoanalysis to evolve into psychosocial research, including embodied subjectivity. "For example, for Lacan, the Oedipus complex becomes not simply the exclusion of the child from the mother-infant dyad and parental couple which is thought by Freudians to be crucial for developing personality, but more a depiction of the beginning of the acculturated individual - that is, the entry into, and the reproduction of, culture itself repeated in the development of each human being" ([14], p. 294). Culture reproducing itself also extends to mothering [15]. What follows is the effect these analytical ideas can have on society.

"...some psychoanalytic concepts have taken on the quality of myths. I define myths as symbolic representations of cultural ideologies, reflecting unconscious dynamics. As with individuals, sometimes stale and outgrown myths persist, sustained by inherent societal forces 
even beyond their point of usefulness, resistant to change and often obstructing growth and creativity. Most psychoanalytic concepts originate as explanatory hypotheses. However, once formulated and disseminated, they become rooted both in theory and in society, acquiring an explanatory force, generating self-fulfilling prophesies and remaining unchanged as long as the myth serves a purpose... even when there have been changes in phenomena upon which the initial observations were made, the original hypothesis, reified and elevated to the proportion of a myth, remains immutable, sustained for the social, economic, political or psychological purpose it now serves." ([16], p. 8).

Though Freud is credited with asking the question, "What do women want?" he never found an answer to the "riddle of femininity" [16] and neither did Jung except through personal foibles [17]. The favoring of Jungian Psychology I had intended for this research was discovered to be insufficient to reflect on an emerging cultural problem with the feminine. There was danger of falling into Jung's earliest reifications of gender on archetypal and functional levels underpinned by his interest in alchemical processes of the solar king meeting the lunar queen ([18], pp. 282-284). Jung's ([19], para. 4-46) identification of two kinds of thinking along gender lines of masculine and feminine, classified as "direct" and "indirect" (feeling) thinking, is a case in point where early psychological typology function is confused with gender function. Indirect thinking was deemed to be intuitive, irrational, pictorial, diffuse and symbolic. Jung assumed it was the foundation of feminine psychology ([20], p. 54) under the principle heading of Eros, to include psychic relatedness, love and soul which also put women under pressure to perform as such in the activities of wife, consort and mother. Direct thinking, logical, goal oriented, rational, differentiated, and spoken skills, gathered together under the principle of Logos became the expectation of the masculine principle and ergo for men. Jung assigned words like judgment, discrimination and insight as well as spirit to 'maleness' ([19], para. 87).

My sense of Jung is that he read into the reproduction of gender performance and culture as if his identification of its' contents was fact, confusing fears and fantasies with real women [13]. Not all post-Jungians read gender the way he did, but of those women clinicians presenting themselves as Jungian Feminists, such as Cowan [17], Douglas [6], Kulkarni [21], and Anthony El Saffar [22] few other than Young-Eisendrath [23] are known and published within the larger context of Psychoanalytically inspired feminism, I believe, because she draws from social constructivism to assert the 'feminine archetype' which is a product of patriarchy [24]. Yet Kulkarni [21] was among the first to lay down a paradigm for a research that "marries Jung's respect for psyche with feminism's insistence on context" ([21], p. 218), an ethos this research on late motherhood endeavors to achieve. In addition, two academics, Demaris Wehr [25] and Susan Rowland [7,26,27], have made breakthrough and remarkable contributions. In particular is Rowland's ([7], p. 135) view of Jung's connection to feminism through his concept of the subtle body, a union of mind and body in his alchemical writings, which includes "the abject and excluded body to reveal it as the constituting boundary of heterosexuality that must be renegotiated" ([7], p. 144). In a parallel but different language, de Beauvoir's "One is not born, but becomes, a woman" ([28], p. 301) was a favoring of lived experience which inspired emerging feminism to make the distinction between sex and gender, an idea meant to "secure internalization of contrasting patterns of behavior... thus to displace the role of biology in determining 'masculinity' and 'femininity” ([29], p. 39). 
Psychoanalytical theorists have gone further than Freud's ideas of the feminine, contributing to and developing Feminist theory aligned with clinical and social psychology theorists. Raphael-Leff's [30] inquiry into femininity, the unconscious, gender and generative identity in a bio-techno age argues that a basis of psychoanalytic theory in place throughout Freud's life was the limitation of femininity and masculinity on original bisexuality. The perception of Freud's bisexual fluidity concept was ultimately eroded by occluding "reification of body-based dichotomies" ([30], p. 500) leading to multilayered views of fantasies/relational configurations/identifications proffered by Harris [31], Dimen [32], Benjamin [33], and Sweetnam [34] allowing Raphael-Leff [30] to frame Freud's notion of bisexuality as the dichotomy of conscious unity twinned with unconscious diversity attributable to Person [35], based on Goldner's [36] notion of culture as authorizing agent. Thus Raphael-Leff's ([30], p. 501) synthesis of 'sex' as an accommodation between chromosomes present at birth and gender as a self categorizing psychosocial construct produces new categories for 'gender role' and 'sexual orientation': “'Embodiment' (femaleness/maleness), 'Gender Representation' (femininity/masculinity) and 'Desire' (sexuality)." Can Jungian Feminist literature ever be on par with the impact Psychoanalysis has had on mainstream feminism? Jung's dichotomous idealization of the feminine as a man's anima while denigrating the masculine in a woman (animus) as a character flaw, at first blush creates a problematic for the researcher who wishes to use Analytical Psychology as the theoretical basis for emergent feminine Feminist psychosocial dilemmas, until we shortly come to discussing his alchemical works. Jung's mythopoetical views, theories, imaginations, foibles and proclivities regarding the feminine, along with Freud's fluid notions of bi-sexuality, are both offered as evidence; acceptance of the feminine as different but equal remains a long standing difficulty for both genders, inspiring perhaps the intra-psychic and inter-subjective cultural phenomena of a pregnant pause [37] on the way to late motherhood, to revision the feminine out of patriarchal paradigms.

\subsection{The Feminine and Feminism}

By emphasizing the feminine within feminism, I am including ways of incorporating agency and nurturing through the holistic union of Jung's two kinds of thinking [19] in addition to Feminist concerns of equality with men such that procreative identity does not become equated to essentialist gender norms nor to performance in male terms. Holding on to the feminine within feminism allows for sexual difference and keeps in mind the ways the feminine has long been suppressed in culture [22], her wound the subject of myths and fairy tales ([38], pp. 193-194). Without this view it would be all too easy to see women who fell into delayed motherhood as 'father's daughters' who abandoned the archetypal feminine to pursue career rather than respect the body Marion Woodman [39] likens to the Mother in us. What happens to women who like Inanna must go underground with their procreativity is far more complicated than being 'father's daughter'. Late motherhood does not appear as a sin against the feminine by the woman who has delayed, but as a 'repudiation of the feminine' preceding adult choices necessitating a late search for the mother within. Hence feminism and the feminine as Great Mother is a vital link to re-balancing humankind.

While aspects of Analytical Psychology are relevant to this study Feminist inspired Psychoanalytic perspectives help to make two halves of analytic history a whole view of psyche's discontent with patriarchal views of the feminine. Analytical psychology has a proud history of finding 
truth in the cosmos through archetype and image "rooted in the unconscious as transcendent of knowledge" ([7], p. 143) while Swartz reminds us that "Feminism has a proud history of interrogating the truth claims of psychiatric science, and of foregrounding the ways in which the machinery of psychiatric diagnosis and treatment has been used to obscure or amplify the psychological effects of patriarchies" ([9], p. 41) for which she credits Chesler [5], Smith [40] and Ussher [41]. In particular, in reviewing psychiatric diagnosis from a Feminist perspective, Swartz ([9], p. 41) gives credit to Jessica Benjamin's [33] work concerning the long history of patriarchal domination where Feminists have challenged Freudian psychoanalytic diagnostic premises and opened up new ideas on the formation of female identity such that experience as mother, sister, wife, or daughter can no longer be automatically synonymous with a lack of agency. My purpose is not a rapprochement between Jungian and Freudian theorists and clinicians, but observation early views of Jung and Freud on the feminine provide grounded evidence their theories continue to reflect a problem for and with women.

Given the nature of this study, to explore delayed motherhood and its connection to individual and collective complexes, and the long history of women being diagnosed as "prone to depression" ([9], p. 23) it is important to clearly differentiate the identification of a complex from a diagnosis. In a diagnosis the root of the disorder is placed within an individual while social, cultural, political and collective contexts remain as background or in ignorance [9]. Delayed motherhood in the 21st century begins to appear more as an emerging 'epidemic' with plural longitudinal gender roots between the sexes [37] rather than a disorder (though it may have been viewed so by Freud and Jung at one time). Identifying a complex through the study of affective behaviors provides a way to see into emotional rupture as phenomena, which does not originate in the individual alone, but through a network of associations involved in memories with others. These 'others' do not only contribute to personal complexes, as they may be unknown to the individual, because they occupy a place in the social through the cultural unconscious $[42,43]$. When these impersonal contexts are included in what happens when a woman is unconscious toward her body, we must consider the feminine in context to patriarchy, and by extension Feminist ideas. It must also be noted that patriarchy does not always have a penis, nor do Feminists always come with a vagina, and shortly I will elaborate on this further.

\section{Defining Problems}

Both Analytical Psychology and Psychoanalysis have framed woman as subject, object, abject, Mother, other, caregiver, mirror, animus ridden, anima woman, receptive, castrated, empathic, relationally oriented, envious of a penis, a uroboros for renewal and imaged as the contra-sexual unconscious. When the female is not referred to as part object and part symbol, we find a purpose for her existence as "another subject whose independent center must be outside her child if she is to grant him the recognition he (she) exists" ([44], p. 24). The use and relationship to the 'feminine' in all its variations, including 'femininity' emerged as the 'last straw' turning Freud and Jung from sparring partners on 'universal principles' to 'warring opposites'. Both men were caught in the prejudices of patriarchal culture to do with rights, roles and conduct of women in relation to men, pleasure and becoming a mother, until the mother-son incest taboo provided grounds for their ultimate parting of ways ([22], pp. 46-47). 
The difference between sparring over the existence of an underlying universal principle and the mother-son incest taboo may seem to be intellectually far apart until we discover how each of these men interpreted their necessity. For Jung mother-son incest functioned as a mythopoetic in intra-psychic life. It was seen as an enactment within his counter-transference dynamics with patients, such as Spielrein, while his wife Emma and consort Toni Wolff, and collection of female colleagues known as the Jungfrauen, all allowed him to be convinced "that the father's law against incest is regularly broken on the symbolic level, and that regression to the womb is also part of the hero's journey to rebirth" [22]. Whereas in Freud's [1] thinking a girl's cure for narcissism is not only founded on the discovery she does not have a penis, but on the move from mother to father to husband where her triumph and cure is the production of a son with whom she can "transfer to her son all the ambitions she has been obliged to suppress in herself...” ([1], p. 133). Freud's thinking is a natural wellspring for feminism. While Jung's psychology continues to entice women into believing they could be a man's muse and inspiratrice, just as Echo helped Narcissus to continue looking at his image, believing it to speak to him in his favor [45].

One of the first Jungian Analysts to question the masculine psychologies of Jung and Freud, James Hillman ([46], pp. 291-292), finds in Freud ([47], p. 219) a definition of the conditions under which an analysis may end, based upon the achievement of "feminine inferiority', finding it to be 'the root of repression and neurosis... bringing about both our psychic disorders and method of analysis aimed at these disorders" [46].

“...one reaches the 'bedrock', the place where analysis could be said to end, when the 'repudiation of femininity' both in a man and a woman has been successfully met. In a woman the repudiation of femininity is manifested in her intractable penis envy; in a man his repudiation does not allow him to submit and be passive to other men" ([47], p. 219).

Thus for Hillman [46], Freud's [47] "repudiation of femininity" is biologically founded and part of the natural psychical world in contrast with his own view "the end of analysis coincides with the acceptance of femininity" ([46], p. 292). Here Hillman takes on misogyny by undermining Freud's basis as "biologically given and thus 'bedrock' to the psychical field" ([46], p. 292), finding instead a psychological basis of 'Apollonism' as the 'bedrock' of the "first-Adam-then-Eve" perspective. This Apollonic archetype seeks physical form through "an objective and detached selfhood, a heroic course of... quest and search... above all the ego-Self as its carrier, and analysis as its instrument" ([46], p. 293). With Freud we must put aside the feeling and relational aspect of the feminine; biology rules. Re-creation of the myth 'first-Adam-then-Eve' appeared in the earliest memories of research participants in the triangulation with parents and male siblings. As young women, they purposely chose to use their minds and make non-uterine choices tending to put them more in the world of men, such that the structure of their lives begins to suggest an extended Apollonic phase. From just this small glimpse into Freud's thinking of the feminine through one of his last writings in Vienna, it may be possible to see the necessity of Feminist thought to salvage Psychoanalysis from Freud's complaint "psychology cannot solve the riddle of femininity" ([1], p. 149).

For Jung the analytic process reaches its ultimate goal in conscious bisexuality through the alchemical image of the coniunctio/the conjunction [46,48,49]. Rowland [7] redeems Jung for Feminists in analyzing his work as a whole, and in particular on alchemy where there is "recognition 
of the limitations of heterosexual opposition... what is cast out, what is structured as an abject body, must be reconfigured within" ([7], p. 145). This is the maddening aspect of Jung, saddling Analytical Psychology with his biases of appropriating the feminine as a hidden virtue of men with the anima concept only to find him projecting onto women the worst attributes of the masculine with the concept of animus, opposite and not equal yet destined for bilateral unity. What is required here is a slow careful reading of Jung as a trickster [27] writer to be read for multiplicity as an evolving narrative rather than authority [26]. "Jung's writings are characterized by an entwined dual purpose in which an acknowledgement of the roots of his ideas in his individual experience (personal myths) work with, and against, a drive to universalize and construct a comprehensive psychological scheme" ([26], p. 25). Nowhere is this more evident than in his move from the oppositional neurotic on gender to alchemy's subtle body and external reality to social discourses ([7], p. 145). Samuels [50] questioned whether Jung's concept of anima and animus/femininity and masculinity, entwined in the syzygy to endure the alchemical processes of differentiation in an effort to re-unite as an androgynous pair of opposites, was a bonafide work on gender. "Jung often spoke as if he were unaware of the distinction between gender and sex, which is, by contrast, biologically determined" ([20], p. 60). The feminine as an aspect of men and the masculine as an aspect of women became tangled up in Jung's reflections between biological bodies, the embodiment of archetype and effects of culture and the collective unconscious. This is no different to what happens to anyone when the principle of 'masculine' and 'feminine' is concretized as first Adam then Eve. A false adaptation to compensate for psychic wounds to sexual identity, aroused by conformity to cultural stereotypes can sublimate the feminine such that men find they want babies and women are afraid to have them [49]. When the feminine in either gender is denigrated things go wrong, a link to the alchemical subtle body becoming physically and psychically blackened, precipitating a sulfuric decay to rise so that the problem as it is felt can dissolve [49].

In Feminist inspired Psychoanalytical literature longitudinal consideration has been given to self-images of feminine and masculine internalized through separation-individuation rituals within family as part of an evolving acquisition of gender-role identity commencing with "differential permutations of mother/father-boy/girl interactions, with the 'feminine' situated in the historical fact primary caregivers were invariably women" ([30], p. 503). Raphael-Leff [30] offers the observation of mother frustrating dependency, thus becoming the confusing feared and desired catalyst for counter denigration of all that is designated female [51]. In Rapahel-Leff's view it is the mother that carries reproduction of the patriarchal social order of inferior social position, through unconscious same-sex identification with their daughters [30]. This identification can be seen later in threats to reproductive body integrity [52], preferred female relatedness [53] and an ego with porous boundaries like a mother [54] compelling a daughter to give into/ resign herself to the patriarchal social order $[3,55]$.

\subsection{Confounding Gender}

It is essential to return now to amplification of Jung's alchemical opus, as a psychic process which involved extracting the gold and liquefying the dung within primal matter, including elevating the 'opposites' to the regal status of Sol King (conscious) and Luna Queen (unconscious). Appearing in every culture, these motifs were intuitively drawn over millennia to signify psychic renewal, 
forecasting how dominant factors in the psyche undergo processes of decomposition and clarification by fire, out of which emerges the 'new king' or new consciousness [49]. This alchemical process may also serve as a paradigm for developmental processes within the pregnant pause of midlife [37]. The emergent new conscious of desire for a baby becomes the new king after years of licking the wounds inflicted upon the feminine within procreative possibility due to modern cultural conditioning to favor the masculine over the feminine for economic performance. Thus women's lives take on the appearance of a two-part structure: first Adam then Eve. This is perhaps the basis of Jung's division between the Logos of a monotheistic God whose "essential separation from nature sponsors rationality as dependent upon a division from matter and body" ([56], para. 29, 41) and the need of Eros to be connected and related as the Mother Earth [28]. "Jung's early disposition for gendering opposites, with varying degrees of denigration and idealization, though evidence of extraordinary early work on identifying contradictions in nature seeking reconciliation" [49] similarly to Freud, appears to be reinforced by the mythopoetics of misogyny and female inferiority in the collective unconscious ([46], pp. 215-298).

"Jung's entire project, I am suggesting, is, in mythical terms an attempt to re-balance modernity that has been brought to crisis by an over-valuing of Logos at the expense of Eros-relating...by essentializing the creation myths, he is able to stabilize the masculine signifying he wants to retain it, while insisting upon its re-formation to include the feminine, which remains marginal” ([27], pp. 290-291).

\subsection{Queer and the Feminine Hero}

Queer theory emerges in personal identification and political organization as non-normative performance in a range of experiences of being and doing, inspiration for intra-psychic unions where achieving and nurturing, penetrating and receiving, are un-assigned to gendered bodies but co-exist in any body [49]. Citing Queer theorists Elizabeth Freeman and Judith Halberstam, Emanuela Bianchi [57] presents a movement "From Feminine Time to Queer/Feminist Time" ([57], p. 41) to notice how temporality in Queer strays from the normative, "unaccountable and dilated time" ([57], p. 41) arguing that pregnancy and mothering both participate in temporal counter-normativity. When viewed as a formulation of 'women's time' with “women's characteristic capacity to be interrupted, by the demands of family, by pregnancy... we take into account the necessity for protecting against hostile and unwanted interruptions as well as promoting a liberatory trans-valuation of interrupted time... to strange new, queer formations of kinship, gender, and social life" ([57], p. 43). When gender performance enacts a great leap of faith outside of predictive maternal identity as biological destiny, late motherhood, as I have found in participants' case studies, is the struggle to achieve and nurture, penetrate and receive; a modern developmental task for the feminine hero. Theoretically, "the androgyne, a union of masculine and feminine which cannot be defined as either, resisting normative gender identity, is the essence of Queer. Understood this way, Queer is in effect the conclusion of Jung's alchemical opus, the Philosopher's Stone" [49].

The assumption of heterosexuality and gender certainty is a problematic of classical Jungian canon. Despite my and other Jungian Analysts' criticisms of 'gender certain' contra-sexual opposites, the archetypes of anima and animus, continue to appear in dreams to reveal shadow 
aspects, those parts of the self that are unknown, unwanted and un-integrated, as principles of both agentic and allowing energies seeking conscious integration in men and women. To dismantle gender performance from procreative identity and sexual desire was a pre-requisite for analyzing the embodied feminine as she coursed her way through intra-psychic association networks and inter-subjective affects aroused by the methodologies used in this study.

Recognizing "the effect of the patriarchal animus on generations of women" ([6], p. xviii) Jungian Analyst Claire Douglas examined the outmoded aspects of Jung's theories including the ephemeral, contaminated, and biased, to find what would free women, and the feminine from patriarchal precepts. She proposes a re-examination of the words and ideas within 'Jung's map' rather than conforming to concretized descriptions as normative. "The feminine ego needs to learn how to connect without being engulfed, and how to differentiate without severing or splitting off' ([6], p. 299). Where Douglas' thinking can be most readily applied is to the idea that the masculine as animus must reside solely in the internal world of the woman, and for men the feminine anima must stay safely locked inside. While I do not question the psychic reality of these figures, identification of what is anima and animus has an unfortunate link to opposite sex gender in a straightjacket of inferiority. Anima and animus need each other in dialogue, taking turns as sources of authority.

Gray [58] set out to examine, in philosophical terms Jung's individuation idea next to the subject of the feminine by drawing from Irigaray's work.

"Individuation, I claim, is the telos of Luce Irigaray's ideal of a feminine-feminine symbolic/imaginary or system of meanings and significances that arises out of sex/gendered embodiment and collective responses to it...lest this reading of Jung be interpreted as reinscribing masculine notions of the feminine, I take a new look at the idea of essentialism, which has plagued Jung's own theoretical construction of the feminine and 'woman'... and also Irigaray's approach to the woman question” ([58], p. ix).

Jung perhaps explains his gender biases best in describing his view of opposites in male and female terms followed by problems when the opposites are not in their 'right order'.

"...woman's conscious is characterized more by the connective quality of Eros than by the discrimination and cognition associated by Logos. In men, Eros... is usually less developed than Logos. In women on the other hand, Eros is an expression of their true nature, while their Logos is often a regrettable accident" ([56], para. 29).

"...instances to the contrary leap to the eye: men who care nothing for discrimination, judgment and insight, and women who display an almost excessively masculine proficiency in this respect... Wherever this exists we find a forcible intrusion of the unconscious, a corresponding exclusion of the consciousness specific to either sex, a predominance of the shadow and of contra-sexuality" ([59], para. 225).

In her chapter on the 'Feminine Hero' in The Presence of the Feminine in Film, Jane Alexander Stewart [60] analyzes the role of Clarice Starling (played by Jodie Foster) in The Silence of the Lambs [61] as a "new heroic journey of the feminine" ([60], p. 95). Clarice's story in the film begins with her lifting herself out of a chasm to stand at the top of the hill prepared to go forward. Stewart makes meaning of the scene in that "Clarice begins her story where classic stories of the heroine's 
journey end; at the return to ordinary life after the descent... from a metaphorical feminine center...a heroine making a return from the deep process of self examination and affirmation" ([60], p. 96). Though the context of her meaning making resides in the modern American landscape where unseen killers await, her real message is not so much based on geography but an endemic fear of psychological and physical denigration of the feminine.

"Not only do they fear men's attacks on their bodies but also they face denigrating social systems that reinforce a second-class status and devalue what it means to live through a feminine point of view" ([60], p. 96).

These dangers, horrors and defilements have been described and examined by both Kristeva [62] and Douglas [63] within a frame of prohibitions leading to abjection on a platform of incomprehensible fear for the dangers facing the feminine if it is not pure. With Clarice Starling we get a character who succeeds because she manages to claim and hold fast to her feelings, what Alexander Stewart refers to as "a set of feminine ethics... [to]... create hope for the safety of a feminine presence in our society" ([60], p. 96). Clarice defies conventional wisdom on what is safe for a woman in a man's world, by not behaving like a man who fears for his survival. Instead Clarice chooses to trust what the feminine has to offer, "her inner forces (for example trusting in intuition, in revealing herself and interacting on the level of intimacy)" ([60], p. 99) traits that invoke fear for her and of her, a greater threat to her survival than Hannibal Lecter himself, including "searches for meaning from the way his actions make her feel" ([60], p. 104).

Citing Barbara Walker's [64] The Woman's Encyclopedia of Myth and Secrets, Alexander Stewart ([62], p. 103) offers an image, not only of the filmic style of Demme's Lambs to evince the underground, underwater, under-position of Starling's journey, but an insight into the journey toward motherhood in the fourth decade of life.

"Students in mythology find that when the feminine principle is subjected to sustained attack, it often quietly submerges. Under the water (where organic life began) it swims through the subconscious of the dominant male society, occasionally bobbing to the surface to offer a glimpse of the rejected harmony" ([64], p. 1066).

\section{Discussion}

The feminine hero may be different from the heroine in my observations. The heroine comes up in life believing it is safe to be female because her nurturing early environment made it so. Throughout her development she does not cower at real life challenges, even those threatening her with domination and sublimation rituals [44]. Whereas the feminine hero has had to learn how to have a relationship to her body, the root of having what Jung called a Self ([18], p. 282). But as the feminine body can be interrupted through "punctuations" of menstruation, penetrative intercourse, becoming pregnant and breast feeding, rhythms resonating with vulnerability ([57], pp. 39-40) it can take time to make or find a Self if it has not been installed in early childhood through conducive social interactions [65] altering the lived experience of temporality. An unconscious relationship to her body difference from the masculine counterpart, including her vagina, womb, breasts and ovaries, may indicate her feelings are as an unknown aspect of self, therefore making her unavailable for 
relationship or procreative identity until how she appears to others, how she fears she will be used/not used, no longer betrays her loss of integrity through some kind of violation [66], even one of abjection, but emerges in synthesis toward the primary task of finding integrity within herself. The dichotomous struggle to achieve equality in political, social and economic fields between the sexes only to abandon the struggle in the sexual realm confuses the need to uphold sexual difference ([67], p. 139). In this dichotomous state lay the ingredients for an individuation process: psychic-physical tension with the potential for a union of opposites. "Creativity springs from the resolution and the reconciliation of opposing psychic forces within an individual" ([68], p. 83). This creativity is at the heart of the conclusion of the fairy tale Young-Eisendrath ([13], p. 18) draws from in considering the story of Sir Gawain and the Lady Ragnell ([13], p. 171 n.7), regarding what women really want: sovereignty over their own life. Here then lies the ethical methodological junction, where Feminist inspired Psychoanalytic and Feminist leaning Analytical Psychology join up to write an ethos for the use of intra-psychic and inter-subjectivity in research with female participants. The tension we are considering is when the body matters and when it does not.

"A complex... results from the blend of an archetypal core... and human experience particularly in the early years of life" ([69], p. 6). It is both these complex processes of psychic development this research seeks to bring together-is delayed motherhood a revolt against domination of the biological imperative to reproduce in uncertain relationship to patriarchy? This is an ethical question to do with non-normative sexual behavior, the place where Queer theory began its linguistic life before moving into gay and lesbian caucuses, Feminist politics upward to academic institutions, in parallel to rising awareness of AIDS [70] before turning on gender itself as an encasement of an "oppressive system of classification — both heterosexuality and homosexuality ... as artificial categories" ([71], p. 29).

Queer is evasive. "Just what 'queer' signifies or includes or refers to is by no means easy to say" ([72], p. 20). "Queer is a relation of resistance to whatever constitutes the normal" ([70], p. 99), the "open mesh of... excesses of meaning where the constituent elements of anyone's gender, anyone's sexuality aren't made (or can't be made) to signify monolithically" ([73], p. 8). Queer as a theoretical and non-predictive-performative condition may be emerging as a new signifier of normative behavior. In this way Queer undermines notions of feminine, masculine and eclipses both the conflict and union of opposites [49], something Jagose [70] describes as "holding open a space whose potential can never be known in the present" ([70], p. 107). Yet, "the conceptual slippage" in Butler's theorizing of subject formation has resulted in "a lack of clarity... [regarding] the capacity for action held by subjects relative to the power that enables their existence in the first place" ([74], p. 28). The use of Queer Theory and consideration of Judith Butler's later elucidation of a "'third way' between voluntarism and determinism" ([75], p. 291) is as much about reconceiving agency [76,77] as it is about holding an ethical position against pathologizing women who discover the need for motherhood and partnership later in life. Thus late motherhood is turning upside down Jung's views of individuation in mid-life for women as a time of integrating the repressed masculine, a shift from an identity centered upon dependence and nurturer of others to one of agentic "embrace of one's own development" ([13], p. 87). The task of procreative identity at mid-life appears as a new definition of a union of opposites, following the paradigm of first Adam then Eve. Unwittingly bio-technology has 
challenged, even re-arranged Jung's life stages for women, though not the essence of his observation of the mid-life 'calling' to integrate what has been overlooked in the first half of life.

\section{Concluding Thoughts}

I did not enter into the research topic of a midlife pregnant pause [37] leading to late motherhood with Feminist intentions. Rather I had a Jungian perspective that cultural and collective complexes with hooks into personal complexes were getting in the way of the developmental aspect of achieving motherhood due to difficulties between the sexes. Delayed motherhood did not emerge as a Feminist issue until particular themes in regard to men in the form of absent or wayward fathers, overtly privileged brothers and betraying mothers began to surface. I came to see women as having to struggle with 'indigenous' cultural assumptions about their bodies being ordained for motherhood, extending a long period of adolescence while striving for accomplishment in the masculine world. Coming to motherhood was a reparative process the closer in age they came to embodying the stage of life known as 'an older woman' (Crone/Witch Archetype). In looking more closely at Psychoanalytically informed Feminist literature mainly written by women, I also discovered in Freud and Jung similar problems with the feminine, at different points in their professional development. These 'problems' mirrored the problems participants were implying with real male others regarding their own relationship with the feminine and integration of the masculine. In Feminist inspired analytic literature I found the body of the woman who had lost time during her most fertile years as context for the messages from the unconscious. In short, I came to see Jung and Freud as reproducing what has been long standing in civilization, a feminine split between denigration and idealization, and have used their words as evidence of patriarchal privilege, the screen through which each man analyzed female patients. It is my belief their work was the beginning of a longer work on the reproduction of misogynistic culture, with late motherhood appearing as a protection against androcentric interruption. Therefore, an ethical position to mutable and evolving expression and repression of the feminine necessitates in-depth understanding of these ingredients as alchemical products of intra-psychic and inter-subjective primal material, rather than constructing pathologies for non-participation in essentialist notions of feminine performance. Unconscious processes of the embodied feminine achieving late motherhood in mid-life emerged as a Feminist issue of power, control, defense, separation and repair. From this, a new union of epistemology and ethos has become impossible to ignore, in part because what is emerging in late motherhood is a different kind of mothering, on which rests the future of a different relationship to patriarchy.

\section{Acknowledgments}

The author wishes to thank the anonymous reviewers of an earlier draft of this paper for their sympathetic views and encouragement on this subject matter and the collaborative patience of the editorial staff.

\section{Conflicts of Interest}

The author declares no conflict of interest. 


\section{References}

1. Freud, S. New Introductory Lectures on Psycho-Analysis. In The Complete Works of Sigmund Freud; Strachey, J., Gay, P., Eds.; The Hogarth Press and the Institute of Psychoanalysis: London, UK, 1933; Volume 24, pp. 3-182.

2. Glocer Fiorini, L. The Analyst's Meta-Theories Concerning Sexual Difference and the Feminine. In On Freud's “Femininity”; Glocer Fiorini, L., Abelin-Sas Rose, G., Eds.; Karnac Books Contemporary Freud Turning Points and Critical Issues: London, UK, 2010; pp. 79-96.

3. Mitchell, J. Psychoanalysis and Feminism; Pantheon: New York, NY, USA, 1974.

4. Appignanesi, L. Mad, Bad and Sad: A History of Women and the Mind Doctors from 1800 to the Present; Virago Press: London, UK, 2008.

5. Chesler, P. Women and Madness, 2nd ed.; Palgrave MacMillan: New York, NY, USA, 2005.

6. Douglas, C. Woman in the Mirror, 2nd ed.; iUniverse.com Inc.: Lincoln, NE, USA, 2000.

7. Rowland, S. Jung: A Feminist Revision; Polity Press: London, UK, 2002.

8. Pines, D. A Woman's Unconscious Use of Her Body; Yale University Press: New Haven, CT, USA and London, UK, 1993.

9. Swartz, S. Feminism and psychiatric diagnosis: Reflections of a feminist practitioner. Fem. Psychol. 2013, 23, 41-48.

10. Showalter, E. Sexual Anarchy: Gender and Culture at the Fin de Siècle; Virago Press: London, UK, 1992.

11. Oppenheim, J. "Shattered Nerve" Doctors, Patients, and Depression in Victorian England; Oxford University Press: Oxford, UK, 1991.

12. Jung, C.G. Visions. In Notes of the Seminars Given in 1930-1934, 2nd ed.; Douglas, C., Ed.; Routledge: London, UK, 1932.

13. Young-Eisendrath, P. Hags and Heroes: A Feminist Approach to Jungian Psychotherapy with Couples; Inner City Books: Toronto, Canada, 1984.

14. Hauke, C. Jung, modernity and postmodern psychology. In Contemporary Jungian Analysis; Alister, I., Hauke, C., Eds.; Routledge: London, UK, 1998.

15. Chodorow, J. The Reproduction of Mothering, 2nd ed.; University of California Press: Berkeley and Los Angeles, CA, USA, 1999.

16. Raphael-Leff, J. Myths and modes of motherhood. Br. J. Psychother. 1984, 1, 6-30.

17. Cowan, L. Dismantling the Animus. The Jung Page. Available online: http://www. cgjungpage.org (accessed on 7 December 2013).

18. Plaut, F. What do I Mean by Identity? In Jungian Analysis; Alister, I., Hauke, C., Eds.; Routledge: London, UK, 1998.

19. Jung, C.G. Two Kinds of Thinking. In The Collected Works of C.G. Jung, 5th ed.; Read, H., Fordham, M., Adler, G., Eds.; Routledge: London, UK; Bollingen Foundation Inc. and Princeton University Press: Princeton, NJ, USA, 1995; Volume 5.

20. Samuels, A.; Shorter, B.; Plaut, F. A Critical Dictionary of Jungian Analysis; Routledge: London, UK, 1986.

21. Kulkarni, C. Lesbians and Lesbianism; Routledge: London, UK, 1997. 
22. El Saffar, R.A. Rapture Encaged The Suppression of the Feminine in Western Culture; Routledge: London, UK, 1994.

23. Young-Eisendrath, P. The Female Person and How We Talk about Her. In Psychoanalytic Reflections on a Gender-free Case: Into the Void, 2nd ed.; Toronto, E.L.K., Ainslie, G., Donovan, M., Kelly, M., Keiffer, C., McWilliams, N., Eds.; Brunner-Routledge: Hove, East Sussex, UK, 2013; pp. 177-193.

24. Young-Eisendrath, P. Gender and Desire: Uncursing Pandora; Texas A\&M University Press: College Station, TX, USA, 1997.

25. Demaris, D. Jung \& Feminism Liberating Archetypes; Routledge: London, UK, 1988.

26. Rowland, S. Jung as a Writer; Routledge: London, UK, 2005.

27. Rowland, S. Jung, the trickster writer, or what literary research can do for the clinician. J. Anal. Psychol. 2006, 51, 285-299.

28. De Beauvoir, S. The Second Sex; Vantage/Random House: London, UK, 1949.

29. Segal, L. Why Feminism? Polity Press: Cambridge, UK, 1999.

30. Raphael-Leff, J. Femininity and its unconscious 'shadows': Gender and generative identity in the age of biotechnology. Br. J. Psychother. 2007, 23, 497-515.

31. Harris, A. Gender as contradiction. Psychoanal. Dialogues 1991, 1, 197-224.

32. Dimen, M. Deconstructing difference: gender, splitting, transitional space. Psychoanal. Dialogues 1991, 1, 335-352.

33. Benjamin, J. In defence of gender ambiguity. Gend. Psychoanal. 1996, 1, 27-43.

34. Sweetnam, A. The changing contexts of gender between fixed and fluid experience. Psychoanal. Dialog. 1996, 6, 437-459.

35. Person, E. The Sexual Century; Yale University Press: New Haven, CT, USA, 1999.

36. Goldner, V. Ironic Gender, Authentic Sex. In Psychoanalytic Reflections on a Gender-free Case: Into the Void, 2nd ed.; Toronto, E.L.K., Ainslie, G., Donovan, M., Kelly, M., Kieffer, C.C., McWilliams, N., Eds.; Routledge: Hove, UK, 2013; 243-255.

37. Barone-Chapman, M. Pregnant pause: Procreative desire, reproductive technology and narrative shifts at midlife. In Body, Mind and Healing after Jung a Space of Questions; Jones, R., Ed.; Routledge: Hove, UK, 2010; pp. 174-191.

38. Braverton, W.J. The Collective Unconscious and Primordial Influences in Gender Identity. In Contemporary Jungian Analysis; Alister, I., Hauke, C., Eds.; Routledge: London, UK, 1998; pp. 183-197.

39. Woodman, M. The Stillness Shall Be the Dancing: Feminine and Masculine in Emerging Balance; Texas A\&M University Press: College Station, TX, USA, 1994.

40. Smith, D. Conceptual Practices of Power: A Feminist Sociology of Knowledge; Northeastern University Press: Boston, MA, USA, 1990.

41. Ussher, J. Women's Madness: Misogyny or Mental Illness? Harvester Wheatsheaf: New York, NY, USA, 1991.

42. Henderson, J. Cultural Attitudes; Inner City Books: Toronto, Canada, 1984.

43. Singer, T.; Kimbles, S.L. The Cultural Complex Contemporary Jungian Perspectives on Psyche and Society; Routledge: Hove, UK, 2004. 
44. Benjamin, J. The Bonds of Love: Psychoanalysis, Feminism, and the Problem of Domination; Pantheon Books: New York, NY, USA, 1988.

45. Graham Fuller, V.; Robinson, H. Understanding Narcissism in Clinical Practice; Karnac: London, UK, 2003.

46. Hillman, J. On Psychological Femininity. In The Myth of Analysis Three Essays in Archetypal Psychology; Hillman, J., Ed.; Northwestern University Press: Evanston, IL, USA, 1972; pp. 215-298.

47. Freud, S. Analysis Terminable and Interminable. In The Standard Edition of the Complete Psychological Works of Sigmund Freud; Strachey, J., Ed.; The Hogarth Press and the Institute of Psychoanalysis: London, UK, 1937; Volume 23, pp. 211-253.

48. Samuels, A. The Plural Psyche; Routledge: London, UK, 1989.

49. Barone-Chapman, M. Sulphur Rises Through The Blackened Body. In Alchemy and Psychotherapy; Mathers, D., Ed.; Routledge: London, UK, 2014; in press.

50. Samuels, A. Jung and the Post-Jungians; Routledge: London, UK, 1985.

51. Dinnerstein, D. The Rocking of the Cradle and the Ruling of the World; Women's Press: London, UK, 1976.

52. Klein, M. The Oedipus complex in light of early anxieties. Int. J. Psycho-Anal. 1945, 26, 11-33.

53. Irigaray, L. Female Hom(m)osexuality: Speculum of the Other Woman, Gill, G.G., Trans.; Cornell University Press: Ithaca, NY, USA, 1985; pp. 98-104.

54. Chodorow, N. Feminism and Psychoanalytic Theory; Yale University Press: New Haven, CT, USA, 1989.

55. Orbach, S.; Eichenbaum, L. Outside in inside out: A Feminist Psychoanalytic Approach to Women's Psychology; Penguin: Harmondsworth, UK, 1982.

56. Jung, C.G. The Syzygy: Anima and Animus. In The Collected Works of C.G. Jung; Read, H., Fordham, M., Adler, G., Eds.; Routledge \& Kegan Paul Ltd.: London, UK, 1959; Volume 9ii, pp. 11-22.

57. Bianchi, E. The Interruptive Feminine: Aleatory Time Feminist Politics. In Undutiful Daughters New Directions in Feminist Thought and Practice; Gunkel, H., Nigianni, C., Soderback, F., Eds.; Palgrave Macmillan: New York, NY, USA, 2012; pp. 35-47.

58. Gray, F. Jung, Irigaray, Individuation Philosophy, Analytical Psychology, and the Question of the Feminine; Routledge: Hove, UK, 2008.

59. Jung, C.G. The Personification of the Opposites. In The Collected Works of C.G. Jung, 2nd ed.; Read, H., Fordham, M., Adler, G., Mc Guire, W., Eds.; Princeton University Press: Princeton, NJ, USA, 1970; Volume 14, pp. 89-257.

60. Alexander Stewart, J. Feminine Hero. In The Presence of the Feminine in Film; Apperson, V., Beebe, J., Eds.; Cambridge Scholars: Newcastle upon Tyne, UK, 2008; pp. 94-113.

61. Demme, J., Dir. The Silence of the Lambs [Film]; Orion Pictures: Los Angeles, CA, USA, 1991.

62. Kristeva, J. Powers of Horror An. Essay on Abjection; Colombia University Press: New York, NY, USA, 1982.

63. Douglas, M. Purity and Danger; Routledge Classics: Abingdon, Oxon, UK, 1966.

64. Walker, B. The Woman's Encyclopedia of Myth and Secrets; Harper and Row: San Francisco, CA, USA, 1983. 
65. Zinkin, L. Your Self: Did you find it or did you make it? J. Anal. Psychol. 2008, 55, 389-406.

66. Beebe, J. Integrity in Depth; Texas A\&M University Press: College Station, TX, USA, 1992.

67. Schaeffer, J. The Riddle of the Repudiation of Femininity. In On Freud's "Femininity"; Fiorini, L.G., Abelin-Sas Rose, G., Eds.; Karnac Books Contemporary Freud Turning Points and Critical Issues: London, UK, 2010; pp. 129-143.

68. Seligman, E. The Half-Alive Ones. In The Father: Contemporary Jungian Perspectives; Samuels, A., Ed.; Free Association Books: London, UK, 1985; pp. 69-93.

69. Samuels, A. Introduction. In The Father: Contemporary Jungian Perspectives; Samuels, A., Ed.; Free Association Books: London, UK, 1985; pp. 1-44.

70. Jagose, A. Queer Theory: An Introduction; New York University Press: New York, NY, USA, 1996.

71. Young, A. Out of the Closets, into the Streets. In Out of the Closets: Voices of Gay Liberation; Gay and young, Eds.; Gay Men's Press: London, UK, 1992.

72. Abelove, H. From Thoreau to queer politics. Yale J. Crit. 1993, 6, 17-27.

73. Sedgwick, E.K. Tendencies; Duke University: Durham, NC, USA, 1993.

74. Brickell, C. Masculinities, performativity, and subversion: A sociological reappraisal. Men Masculinities 2005, 8, 24-43.

75. Cadwallader, J. How Judith Butler Matters? Aust. Fem. Stud. 2009, 24, 289-294.

76. Morrison, T.; Macleod, C. A performative-performance analytical approach: Infusing Butlerian theory into the narrative-discursive method. Qual. Inq. 2013, 19, 566-577.

77. Dow Magnus, K. The unaccountable subject: Judith Butler and the social conditions of inter-subjective agency. Hypatia 2006, 21, 81-103. 


\title{
Chapter 5
}

\section{Beatrice Hinkle and the Early History of Jungian Psychology in New York}

\author{
Jay Sherry
}

34 Plaza Street E., \#1109, Brooklyn, NY 11238, USA; E-Mail: jay.sherry@verizon.net

\begin{abstract}
As the leading proponent of psychoanalysis, Jung made trips to New York in 1912 and 1913. The first was to give his Fordham lectures, the second has escaped notice but was crucial in the early dissemination of Jungian psychology in the U.S. This paper will elaborate on this development by highlighting the career and influence of Beatrice Hinkle, the country's first Jungian psychoanalyst. She was an M.D. and ardent feminist who introduced Jung to her Greenwich Village circle, translated his magnum opus Transformations and Symbols of the Libido, and helped establish the institutional basis of Jungian psychology in America.
\end{abstract}

Reprinted from Behav. Sci. Cite as: Sherry, J. Beatrice Hinkle and the Early History of Jungian Psychology in New York. Behav. Sci. 2013, 3, 492-500.

As the gaps in the history of Jungian psychology in the United States continue to be filled in, its place in modern American cultural life will need reassessing. The work of Burnham, Hale, and Taylor make clear Jung's contributions to American psychiatry and psychotherapy but, after his break with Freud, he was to be increasingly marginalized in the professional literature [1-3]. Charles Oberndorf, an early New York analyst, explained it this way in his history of psychoanalysis in America. "Jung's later works contain so much of spiritual, mystical, and quasi-theological admixtures, which he engrafted on Freud's basic theories in the attempt to defend 'religious instincts,' that it is questionable whether his concepts would still come within any broad definition of psychoanalysis. His theory and procedures have appealed strongly to the inexactitude and fantasy of many laymen" ([4], pp. 132-133). This paper will discuss the early history of Jungian psychology in New York, its first outpost in the United States, using the life and career of Beatrice Hinkle, the country's first Jungian psychoanalyst, as its lens.

She is now best-remembered as the translator of Jung's Wandlungen und Symbole der Libido as Psychology of the Unconscious, a book now known as Symbols of Transformation [5]. Her translation was one of the publishing sensations of 1916 and she single-handedly kept it in print for the next thirty years. She was one of the many Progressive-era women with college degrees who moved to New York to stake out their professional careers. Research by Judith Schwarz and Kate Wittenstein in the 1980s documented Hinkle's membership in the Heterodoxy Club, America's first feminist organization [6,7]. This fact means that her career must now be contextualized as that of a 
pioneering feminist who championed Jung's new approach to the creative potential of the psyche as a powerful tool for personal and social transformation.

One unfortunate fact for researchers is that her personal papers were destroyed after her death as stipulated in her will [8]. This is a great loss to Jungian historiography as they would have included letters from Jung, spanning the entire development of his thought. The Kristine Mann Library in New York does have a Hinkle file, but a note therein indicates that, at some point, many of its contents were disposed of. Her family has a collection of more personal documents from various stages of her life.

Although 1874 is routinely given as the year of Hinkle's birth, horoscopes in their possession make certain that the date was actually 1870 since in one "1870" is crossed out and over-written with "1874" and on the other the year was ripped off [9]. She was born on October 10th to B. Frederick and Elizabeth Moses and raised in San Francisco. The daughter of one lawyer she married another, Walter Scott Hinkle, an assistant district attorney. After having a son, Walter, and a daughter, Consuelo, she decided to become a doctor and in 1899 graduated from Cooper Medical College, which later became part of Stanford University [10]. She was appointed San Francisco's city physician and so became the first woman in the U.S. to hold that position. She developed an interest in the emotional dimension of public health issues after noticing that during a bubonic plague her rate of success was higher than that of other doctors. She later said that the reason for this was that she "poured her own vitality, her own belief into the patient" and that a doctor's work was to "reinforce the spirit that makes for recovery" ([11], pp. 46-47). After the death of her husband she moved to New York City in 1905 where she took up residence at \#10 Gramercy Park where the influential realist painter and teacher Robert Henri had his studio; she later owned a brownstone down the block at \#31. One colleague remembered that "she looked into all the various kinds of cures, or isms, like New Thought, Christian Science and hypnotism, (etc.) ... [and that] Her energy was always superlative and her undivided interest in anything she was doing was outstanding" [12]. After spending time upstate on the staff of a New Thought sanatorium in Kingston, NY, she joined the staff headed by Charles L. Dana, America's leading neurologist, at Cornell Medical College where they opened one of the first psychotherapy clinics in the U.S. [13]. In 1909 she wrote that "several German physicians have devised methods for bringing up from the depths of the patients' mind circumstances and incidents forgotten by them at the present time..." ([14], pp. 16-17).

Around this time she married Philip Garrett Eastwick, a businessman, and went to Europe to study psychoanalysis. She attended the 1911 Psychoanalytic Congress, traveling to Weimar by train in the company of Freud and Jung [15]. After her return from Europe Hinkle rejoined the Cornell staff and began a private analytical practice. She expressed her new method in the following quote "It is this definite recognition and use of the emotions and feelings in the service of the patient himself which constitutes one of the many differences between the so called persuasion and advice giving reeducational methods, and psychoanalysis. In the latter method no advice or persuasion, nor suggestion of any sort is given. Everything must come from the patient and be felt and understood by him for himself" ([16], p. 1085). She would likely have attended some or all of Jung's 1912 Fordham lectures that were soon published as "The theory of psychoanalysis" in the inaugural issue of Psychoanalytic Review, the first American journal devoted to the new field. She arranged for Charlotte Teller, one of her protégés, to interview Jung for the New York Times when he was in town for the conference. Teller (1876-1953) was an aspiring writer who had lived at the A Club, a 
collective apartment house run by a group of Greenwich Village radicals. She wrote to a friend "I met Jung on Wednesday the day he arrived at Dr. Hinkle's. He has a quick sense of humor and good English at his command. We walked up Fifth Avenue afterwards and he spoke of a prophetic dream about me..." [17].

Hinkle was a member of the Liberal Club, one of New York's leading reform clubs, which was located at 132 19th Street, only a block from her Gramercy Park home. It was an intellectual forum for discussing such issues as birth control, divorce, and the labor struggle and counted among its other members the muckraking journalist Lincoln Steffens. It turns out that the two were also fellow members of the California Club on whose reception committee Hinkle served in 1911. Another member was Percy Stickney Grant, the rector of the Episcopal Church of the Ascension on Fifth Avenue, who had begun the Public Forum at his church where current social issues were debated on Sunday evenings. In March, 1913, Jung spoke to the Club about "Dreams" and although no record of the talk seems to exist, we can get some idea of what he said from a paper he wrote shortly afterward. In it he wrote that "anyone keenly interested in the dream problem cannot have failed to observe that a dream has also a progressive continuity ... since dreams occasionally exert a remarkable influence upon the conscious mental life... These occasional after-effects are usually seen in a more or less distinct change in the dreamer's frame of mind" ([18], p. 299).

Later that year a radical high school teacher, Henrietta Rodman, engineered a split with the more mainstream members of the Club and moved it down to MacDougal Street where it became the unofficial headquarters for the rebellious young people gravitating to Greenwich Village. Many of them worked in settlement houses where they helped newly-arrived immigrants adjust to their new urban environment. Most of them found socialism to be the most promising solution to the inequities and injustices created by industrial capitalism and voted for Eugene Debs in the election of 1912 that was won by the Democrat Woodrow Wilson.

Jung's celebrity status in New York coincided with that enjoyed by the French philosopher Henri Bergson who also visited the city in 1913. Hinkle noted this connection when she wrote that "It is most interesting, therefore, to find that a modern philosopher, Henri Bergson, has evolved a philosophy by an entirely different route, corroborative and analogous, in many of its conceptions, with that which analytical psychology has produced . . [ [psychic energy] is called by Dr. Jung, the libido, and will be recognized as similar to Bergson's élan vital or 'creative energy"' ([16], p. 1081).

Hinkle introduced Jung to her down-town avant-garde circle. She took him to a dinner party at Patchin Place hosted by some members of the Heterodoxy Club. It had been founded in 1912 by a group of feminists who met every other Saturday until the 1940s. One of their husbands, Carl Zigrosser, later related an anecdote from that evening. "Guests ranged from university professors and writers to distinguished labor administrators... Patchin still talked about a visit by the famous analyst, Carl G. Jung. The atmosphere had been rather stiff and formal until Jung broke the ice by addressing a pet dog who was misbehaving with his leg: 'Come, come, be reasonable, I'm not a female"” ([19], pp. 100-101). One of the Heterodites, Mary Alden Hopkins, soon left for Zurich where she did analysis with Maria Moltzer, Jung's research assistant. Hinkle introduced Jung to Kahlil Gibran who drew his pencil portrait, most likely at his studio apartment nearby. It is also probable that she accompanied Jung to the famous Armory Show of modern art, which was being 
held at the National Guard armory just a few blocks north of her Gramercy Park apartment. Her neighbor, Robert Henri, was involved in the show and one wonders if Hinkle introduced the two men.

Blackballed by the New York Psychoanalytic Society in 1915 for her allegiance to Jung, Hinkle still remained one of New York's leading psychoanalysts along with A. A. Brill and Smith Ely Jelliffe; she was to remain in contact with several members of the more eclectic American Psychoanalytic Association such as Trigant Burrow and L. Pierce Clark. She encouraged a wealthy patient, Annette Rankine, to subsidize the Seven Arts, a literary journal being started by James Oppenheim another of her patients. The story goes that she encouraged Rankine to do something constructive with her wealth who then sold her collection of Whistlers to raise the necessary capital. After publishing such up-and-coming literary figures as Robert Frost, Eugene O'Neill, and D.H. Lawrence it was forced to close because of Rankine's disapproval of its outspoken opposition to America's entry into World War I.

Hinkle's translation of Jung was widely reviewed and became one of the publishing sensations of 1916. Eugene O'Neill said that "The book that interested me the most of the Freudian school is Jung's Psychology of the Unconscious... If I have been influenced unconsciously, it must have been by this book more than any other...” ([20], p. 245). Jack London said that after reading it he was "standing on the edge of a world so new, so terrible, so wonderful that I am almost afraid to look over into it" ([21], p. 323). Encouraged by reading Jung to drink from the well of world mythology London wrote a series of tales narrated by a Polynesian story-teller that was published after his death as Tales from a Makaloa Mat (1919). He animated them with a philosophy decidedly more humane and optimistic than the Social Darwinism found in such earlier works as The Call of the Wild and The Sea Wolf.

When did Hinkle learn German well enough to take on the daunting task of translating Jung's magnum opus? Since it was the leading language of science in the years before World War I it is likely that she began to learn it during her medical school years and improved her command of it during her stay in Europe. Besides the translation she wrote a lengthy introduction that was released by Moffat, Yard as a separate publication [22,23]. One Greenwich Villager, Clement Wood, celebrated Hinkle in the following doggerel verse "We marched in a body to Hinkle - sort of jung sybil she were; She taught us so much about symbols and such, That we learned about women from her" ([24], p. 22). Another member of her circle was Jean Starr Untermeyer whose husband Louis did the German literary translations for Psychology of the Unconscious. Her memory of Hinkle had a critical edge. "But the less said about my months with Dr. Hinkle the better. I found her shallow in insight, expedient rather than constructive in her advice, and in a time of crisis - the death of my father, who incidentally, was paying for the analysis - inadequate and inhuman as well ... if, in my sessions with Dr. Hinkle, I did not progress as far in self-knowledge as I had hoped, I did 'learn about women' from her" ([25], p. 48).

Hinkle's major book The Re-Creating of the Individual was published by Harcourt Brace in 1923. Through her membership in the Heterodoxy Club she got to know Susan Glaspell, a founding member of the Provincetown Players, and along with Eugene O'Neill, its most prolific dramatist; I would contend that The Verge, Glaspell's 1921 play about a woman conducting highly unorthodox botanical experiments was partly influenced by her discussions with Hinkle about gender and creativity. Considering the theme of the play I would point out that one of Hinkle's favorite analogies 
for Jung's process of individuation was the life-work of Luther Burbank, the California "plant wizard." She applied Burbank's insights into plant growth in her rock garden at Roughlands, her country home in Connecticut, where she cultivated her collections of heather and barberry.

Another of her sisters in the Heterodoxy Club was the anthropologist Elsie Clews Parsons. They would have compared the fieldwork Clews conducted among the Pueblo Indians of the Southwest with the observations Hinkle had made among the Malays in the Philippines. Parsons was a founding member of the New School for Social Research where she taught Ruth Benedict her first course in anthropology; Benedict's interest in cultural typology later appeared in her classic study Patterns of Culture [26]. Hinkle divorced her husband in 1926 and later developed a close personal relationship with Katherine Thaxter.

Hinkle attracted other women some of whom later formed what I would call the "outer circle" of the Analytical Psychology Club of New York. These included Fola LaFollette whose father, Robert, was the Progressive senator from Wisconsin; among her many activities was teaching at the City and Country School, a progressive school in Greenwich Village. Another was Margaret Doolittle Nordfeldt who had been active in the Provincetown Players and met Jung in New Mexico in 1925 and eventually became an analyst. Finally, Amy Spingarn participated in one of Hinkle's women's groups and went to Zurich for analysis; her husband Joel was a founding editor at Harcourt Brace, which became Jung's American publisher.

Another analysand was Margaret Naumburg who opened the Children's School with a philosophy based on the work of the Zurich School of psychoanalysis and who later taught art therapy at New York University into her 80 s. She had been married to Waldo Frank, a critic, who was on the editorial board of The Seven Arts along with James Oppenheim [27]. Aline Bernstein, a costume designer with The Neighborhood Playhouse, analyzed with Hinkle and would recount her sessions to her lover, the novelist Thomas Wolfe. Finally, Alice Lewisohn, one of the founders of the Playhouse, was attracted to Jungian psychology and spent her last years in Zurich.

During the 1920s Hinkle's articles about women, marriage, and education appeared frequently in such magazines as The Nation and Harpers. There are several sidebars to Hinkle's career during that period, which are worth mentioning. She was a member of the American Society for Psychical Research and investigated Eileen Garrett, one of the most prominent mediums of the time. The other involves her friendship with an African-American celebrity figure named Lobagola. In his autobiography Man Without a Country (1930) he billed himself as an African who had stowed-away on a steamer to Glasgow and was finally able to make his way to America. His mix of intelligence and "primitivity" captured the imagination of the American public but it turned out that he was, in fact, not a native African but an African-American hoaxer who later dropped out of sight. We will probably never know the exact nature of their relationship, but it evokes the zaniness of the movie Zelig where the woman analyst Eudora Fletcher played by Mia Farrow treats the shape-shifting Trickster figure played by Woody Allen. There is a family story that Franklin Roosevelt met with Hinkle at Roughlands for help in regaining his self-confidence after contracting polio in 1921. We do know that Hinkle was acquainted with his wife Eleanor through their membership in Chi Omega, the society of professional women and that she attended at least two awards dinners at the White House.

In 1928 Hinkle opened Smoky Hollow Lodge, a residential treatment facility in a renovated farmhouse just down the road from Roughlands. Bing Crosby spent time there for treatment of 
alcoholism and the New Yorker writer Nancy Hale, who credited Hinkle with helping her to overcome a serious case of writer's block, wrote a fictionalized account of her stay in the novel Heaven and Hardpan Farm (1957). After Hinkle's death the property was sold, one of its later owners was the artist Jim Dine who sold it to its present owner.

At this point it is important to tell something about her friendship with someone who almost became one of the founding mothers of the American Jungian movement. Her name was Constance Long and in many ways she was Hinkle's British twin-sister. She was an M.D. and active in a number of different professional organizations and public health projects. She edited a volume of Jung's works entitled Collected Papers on Analytical Psychology in 1916, the same year that Psychology of the Unconscious came out. In them the two women brought Jung's new approach to psychology to the attention of the English-speaking world. In 1919 Long attended the YWCA-sponsored International Congress of Women Physicians in New York where she got acquainted with the local group. After the conference was over Kristine Mann decided to start analysis with Hinkle while Eleanor Bertine went to London to work with Long. Hinkle recalled those early years at the memorial service for Dr. Mann in 1946. "[In] about 1922, Dr. Constance Long again came to this country and in the latter part of that year Dr. Harding arrived on a brief visit to Dr. Bertine. We were now a little group of five and to celebrate that expansion we introduced our English friends over the New Year to a New England winter at my country home. We were all very congenial and our welcome to the New Year was centered around a huge open fireplace where we talked and discussed many things of mutual interest, with no intimation that one of our number would be gone in less than two months" [28]. Long suddenly took ill and died, Hinkle buried her ashes on the grounds of Roughlands, the memorial plaque is inscribed with the phrase "She followed the gleam." She also dedicated her book Re-Creating the Individual (1930) to the memory of her departed friend.

What exactly was Hinkle's relationship to Mann and Bertine? As they received their medical degrees from Cornell at a time when Hinkle was on still on staff it is possible that they knew about her before their meeting at the YWCA conference. In 1920, they all attended Jung's Sennen Cove seminar in the U.K. and entertained him when he visited New York after his trip to the American Southwest in 1925. By this time they had been joined by Frances Wickes, a school psychologist, who found Jung's psychological approach helpful in her practice and wrote several books from that perspective. Together they founded the Analytical Psychology Club of New York in 1936, attended the Bailey Island seminar that year, and hosted him the next after his Terry lectures at Yale. In her reminiscences Millicent Kelley remembers Emma Jung visiting Hinkle at Roughlands, which would most likely have occurred at this time.

What explains Hinkle's being less well-known to Jungians than the others? The first thing to consider is that besides the fact she was their senior in both the professional and psychoanalytic fields she also pursued a more independent path. As an extraverted social activist she was never quite the orthodox Jungian that they were. Their more introverted orientation to the "inner journey," evident in such works as Esther Harding's Women's Mysteries, was in contrast to her own psychologically-oriented reformism. It comes as no surprise that they opposed the use of group psycho-therapy which Hinkle pioneered, she functioned as something of a "den mother" to the young women of the Heterodoxy Club and helped organize the first of what would later be called "consciousness-raising" sessions. 
Now to her relationship with Jung. It is important to recognize that when Hinkle went to Europe she met Jung and Freud as a professional equal and not as a mere disciple. "I was compelled to follow the creative and prospective tendencies in the human being as well as the regressive and destructive ones. Although my work is closely related to Jung's, I do not present 'it' [this book] as an exposition of Jung's ideas" ([29], p. 6). She was independent enough of him to develop a psychological typology distinct from his; based on her analytic experience Hinkle divided extraverts and introverts into "Objective, Simple, and Subjective" types. She used Presidents Teddy Roosevelt and Woodrow Wilson as examples of the extraverted and introverted types and was ahead of the times in discussing bisexuality in positive terms.

She continued to be one of Jung's primary American contacts in the 1930s when the question of his alleged anti-Semitism became an issue. This got its most public hearing at the 1936 Harvard Tercentenary where Henry Murray came to his defense in the pages of the Harvard Crimson. When Jung left Boston he went directly to Bailey Island for his seminar. I think that the most likely reason for Hinkle's going up there early was to talk to Jung about what she knew of the allegations against him and the impact they were having on his reputation in the States [30].

Hinkle remained active into her $80 \mathrm{~s}$ when she developed bone cancer and died at Columbia-Presbyterian Hospital on February 28, 1953. Her body was cremated and the ashes scattered around the grounds of her country home; a memorial plaque was affixed to the boulder beside that of her friend Constance Long. Obituaries in the New York Times, the Herald Tribune, and a number of professional journals all recognized her pioneering role in establishing the professional status of analytic therapy in this country. The Analytical Psychology Club established the Beatrice M. Hinkle Scholarship to assist analysts wishing to study at the Jung Institute in Zurich and it operated into the 1960s. She was remembered in Spring (1954) this way. "Those who knew her will cherish the memory of her warm cordiality, of her love for people, of animals, of flowers, which was part of her zest for living. Here she showed the same welcoming acceptance of life in all its aspects that led her to recognize the scope and human usefulness of Dr. Jung's theories. Dr. Hinkle has left us a lasting example of a full, productive, and courageous life."

What is Beatrice Hinkle's legacy? She agreed with Jung's critique of Freud's theoretical premises and concurred with his new focus on the importance of the mother and the role of creative fantasy in overcoming current life problems. "[Jung's] real interest lies in the forward striving principle or progressive element of life" ([29], p. 26). She taught Jung's approach to the psyche to a network of young Greenwich Villagers who expressed their creativity in such fields as art, costume and set design, and progressive education. Finally, her feminist critique of the patriarchal bias of psychoanalysis came years before that of better-known writers from the Women's Movement of the 1960s. Hinkle was a pioneering American woman analyst whose contributions to the development of Jungian psychology in the United States deserve greater recognition today.

\section{Acknowledgment}

This is a revised version of a paper presented at the Founding Mothers Conference, C.G. Jung Foundation of New York, 31 March 2012. The author wishes to thank the anonymous reviewers of an earlier draft for their helpful suggestions. 


\section{Conflicts of Interest}

The author declares no conflict of interest.

\section{References}

1. Burnham, J.C. Psychoanalysis and American Medicine: 1894-1918; Psychological Issues, Vol. V, No. 4; International Universities Press: Madison, CT, USA, 1967.

2. Hale, N.G. Freud and the Americans, the Beginnings of Psychoanalysis in the United States, 1876-1917; Oxford University Press: New York, NY, USA, 1971.

3. Taylor, E.C.G. Jung and the Boston Psychopathologists 1902-1912. Voices 1985, 21, 131-144.

4. Oberndorf, C. A History of Psychoanalysis in America; Harper Torchbooks: New York, NY, USA, 1964.

5. Read, H., Fordham, M., Adler, G., Eds. The Collected Works of C. G. Jung; Hull, R.F.C. Translator; Princeton University Press: Princeton, NJ, USA, 1970; Volume 5.

6. Schwarz, J. Radical Feminists of HETERODOXY: Greenwich Village 1912-1949; New Victoria Publishing: Lebanon, NH, USA, 1982.

7. Wittenstein, K. The Feminist Uses of Psychoanalysis: Beatrice M. Hinkle and the Foreshadowing of Modern Feminism in the United States. J. Wom. Hist. 1998, 10, 38-62.

8. The executor strictly followed the terms of the document.

9. She maintained a friendship with a Professor Whipple, an astrologer who had settled in Los Angeles.

10. $25 \%$ of Hinkle's class of 1899 were women; she wrote her medical thesis on enuresis in children.

11. O’Hagan, A. Beatrice Hinkle, mind explorer. Woman J. 1927, 12, 46-47.

12. MacKay, H. Reminiscences. Analytical Psychology Club of New York archives, Midtown East, New York, NY, USA, n.d.

13. See "Psychic Clinic Opened", a short, anonymous item that appeared in the "Medical News" section of Journal of the American Medical Association, 31 October 1908; LI, No. 18, 1519.

14. Hinkle, B. Methods of psychotherapy. Psychotherapy 1909, II, 16-17.

15. The conference photo is arguably the best class picture ever taken of the early psychoanalytic movement. See Jaffe, A. Word \& Image; Princeton University Press: Princeton, NJ, USA, 1979; pp. 54-55.

16. Hinkle, B. Jung's Libido Theory and the Bergsonian Philosophy. New York Medical Journal 30 May 1914.

17. Teller letter to Mary Haskell, 24 September 1912. Minis Family Papers (Collection \#2725), Southern Historical Collection, Wilson Library, The University of North Carolina at Chapel Hill, Box 24, File 159.

18. Long, C., Ed. Collected Papers on Analytical Psychology, 2nd ed.; Baillière, Tindall and Cox: London, UK, 1922. This article now comprises the opening section of "General Aspects of Dream Psychology" (Collected Works, Volume 8), paragraphs 443-476.

19. Zigrosser, C. My Own Shall Come to Me; Joh. Enschede en zonen: Haarlem, The Netherlands, 1971.

20. Sheaffer, L. O'Neill: Son and Artist; Little, Brown: Boston, MA, USA, 1973.

21. London, C. The Book of Jack London, Volume 2; The Century Co.: New York, NY, USA, 1921. 
22. Alfred Stieglitz heavily underlined her introduction in his copy of the book, see Pyne, K. Modernism and the Feminine Voice: O'Keeffe and the Women of the Stieglitz Circle; The University of California Press: Berkeley, CA, USA, 2007; p. 175.

23. An anonymous review that dismissed Jung's book for its "muddy morass of medieval mysticism" considered her introduction the most valuable part of the book. The American Journal of Urology 1916; Volume 12, p. 288.

24. Wood, C. A Song of the Village. In The Greenwich Village Blues; H. Harrison: New York, NY, USA, 1926.

25. Untermeyer, J.S. Private Collection; Knopf: New York, NY, USA, 1965.

26. There is a family story that Hinkle was a friend of Margaret Mead's until the two had a falling out.

27. For other connections that Hinkle had, see: Sherry, J. Faint voices from Greenwich Village: Jung's impact on the first American avant-garde. J. Anal. Psychol. 2011, 56, 692-707.

28. Hinkle at the Kristine Mann memorial service, 6 January 1946, Analytical Psychology Club of New York archives.

29. Hinkle, B. Re-Creating the Individual; Harcourt, Brace: New York, NY, USA, 1923.

30. See Jung's letter to Henry Murray, 19 December 1938. C.G. Jung Letters Vol. 2; Princeton University Press: Princeton, NJ, USA, 1975; p. xxxv. 


\title{
Chapter 6
}

\section{The Dialogical Jung: Otherness within the Self}

\author{
William E. Smythe
}

Psychology Department, University of Regina, 3737 Wascana Parkway, Regina S4S 0A2, SK, Canada; E-Mail: william.smythe@uregina.ca; Tel.: +306-585-4219; Fax: +306-585-4772

\begin{abstract}
This paper explores dialogical currents in Jung's analytical psychology, with reference to contemporary theories of the dialogical self. The dialogical self is a notion that has gained increasing currency in psychology since the 1990s, in response to the limitations of traditional notions of the self, based on monological, encapsulated consciousness. Modern dialogical self theory construes the self as irrevocably embedded in a matrix of real and imagined dialogues with others. The theme of dialogical otherness within the self is also taken up in Jung's analytical psychology, both in the practice of active imagination and psychotherapy and in the theory of archetypes, and a dialogical approach to inquiry is evident in Jung's work from the outset. The implications of a dialogical re-conceptualization of analytical psychology and of analytical psychology for dialogical theory are considered in detail.
\end{abstract}

Reprinted from Behav. Sci. Cite as: Smythe, W.E. The Dialogical Jung: Otherness within the Self. Behav. Sci. 2013, 3, 634-646.

\section{Introduction}

In a recent essay Charles Taylor identified the problem of understanding the other as "the great challenge of this century both for politics and social science" ([1], p.24). What analytical psychology can uniquely contribute with respect to this challenge is to give an account of the other within the self. This paper takes up the theme of otherness in Jung's analytical psychology from the perspective of contemporary theories of the dialogical self. I begin by reviewing current notions of the dialogical self, focusing on the seminal theory of Hubert Hermans and colleagues. Next, I examine some dialogical currents in Jungian thought from early childhood experiences to the pattern of dialogical engagement portrayed in Jung's The Red Book [2], to his account of dialogical psychotherapy, to the apotheosis of Jung's understanding of dialogical otherness in the archetype of Self. Critical to the discussion is the notion of background understanding and the different ways it is understood in contemporary dialogical theory versus Jung's archetypal theory, and the distinction between dialogue and dialectics. I conclude that Jung's approach to dialogical thinking can both inform and be informed by current developments in dialogical self theory.

\section{The Dialogical Self}


The dialogical self has attracted a good deal of attention and discussion since the notion was first seriously taken up in psychology in the early 1990s. The proliferation of recent academic volumes, articles, special issues and conferences devoted to the topic is noteworthy, especially in light of the fact that, as Stam [3] has pointed out, the basic idea of a dialogical self is still far from clear. In some respects the dialogical self is a thoroughly familiar aspect of everyday experience. We all find ourselves inescapably embedded in a world of others, whose actual and virtual presence continually shapes our self-understanding in ways we cannot fail to notice. Even our most personal and private reflections are invariably saturated with the voices and perspectives of others urging us on, cajoling, criticizing, praising and pleading with us, seemingly at every turn. Yet, as is often the case, it takes theory some time to catch up with common experience. Much of our theoretical and conceptual discourse about the self still remains in the grip of a centuries-old epistemological tradition that goes all the way back to Descartes and Locke and was fueled by 19th Century notions of privacy and self-scrutiny [4-6]. This is the traditional, monological picture of disengaged, first-person, "radically reflective" subjectivity that still underlies much of what we say about the self as an abstract concept. However, our day-to-day experience in actually negotiating our sense of self in the world obviously suggests a different picture.

\subsection{The Hermans Formulation}

The formulation of the dialogical self that has had the most influence in psychology is that of Hubert Hermans and colleagues [7-11], who define the dialogical self as a dynamic multiplicity of voiced positions in an extended dialogical landscape of mind that includes actual others in the social world and imagined others that are intimately intertwined with them. Self, on this conception, is both multivoiced and dialogical. In expressing and reflecting on one's self, one can be said to occupy any number of distinct positions in dialogical space and to give voice to them in unique ways. In this formulation it is critical to distinguish between voices and positions, where voice refers to "the motivated, emotional, and agentic starting point of a message that is addressed to any other person or to another part of the self" and position refers to "the place where a voice is located in an imaginal [dialogical] space" ([12], p. 380). This merging of voices with positions in dialogical space is said to be a function of the agency of the "I", which "has the capacity imaginatively to endow each position with a voice" ([7], p. 148). The composite I-positions that result from this imaginative endowment are said to reflect both continuity and discontinuity in the dialogical self [9]. Discontinuity derives from the diverse and often contradictory character of the positions that the self takes up, whereas continuity is said to be provided by the "I" itself, insofar as "it is one and the same I who is doing this" ([8], p. 139). The essence of the dialogical self in any case is to be found in the continual movement among positions in dialogical space - a process called positioning, which is undertaken not only in relation to others but also in relation to oneself [8].

Although Hermans and colleagues, in a recent publication, have dismissed the notion of a singular self as a mere "trick of grammar" ([12], p. 380), they nonetheless invest the "I" with substantial agentic powers to endow dialogical positions with voice. The dialogical self, on this view, is identified with its possibilities for agentic movement in dialogical space, in terms of which it voices its various possibilities. One might well question whether the kind of radical dialogical freedom 
implied by this view is always a good thing; could it not also tend to foster confusion, disorientation and indecisiveness in one's sense of self?

\subsection{The Dialogical Background}

In any case, to focus in this way on the agentic possibilities of the dialogical self is to overlook its grounding in pre-intentional and inarticulate dialogical processes. This is a common theme both in early formulations of the dialogical self, prior to the Hermans work [6], and also in recent critiques [13-16]. Burkitt, for example, questions the status of Hermans's agentic, dialogical "I" as "something that originally exists apart from voice with the ability to move at will between positions and voices, seemingly animated by its own agency"; this, he points out, overlooks "the sense of 'otherness' within the self: that from the earliest years our sense of self is intertwined with the voices of others, often in unwanted, unplanned, unwelcome, and surprising ways" ([14], p. 306). That is, long before we can exercise the capacity for intentional positioning in dialogical space, in the way that Hermans and colleagues envision, our dialogical selves are already formed by the pre-intentional and inarticulate matrix of our relations with others. The dialogical self does not just range freely over positions and voices in dialogical space, then, it is also fundamentally constituted by them. What the Hermans et al. conception of the agentic dialogical self tends to overlook is the ways in which dialogue is inherently constitutive of self.

Charles Taylor [6] understands the dialogical constitution of self as a form of background understanding. Background understanding, or pre-understanding, is a notion that has played a fundamental role in modern hermeneutic philosophy and in philosophical discussions of language and meaning generally [17-20]. It refers to the tacit, inarticulate, taken-for-granted contexts of human meaning that are grounded in our embodied capacities, dispositions, shared practices and forms of life, which constitute a fundamental condition of intelligibility of meaningful human activities and expressions.

Our articulate and intentional construals of self, then, inevitably presuppose and are grounded in a tacit background of situated and embodied practices that cannot in the nature of things be made fully explicit. These practices are, from our earliest moments of experience, grounded in our shared life with others and in forms of dialogical activity that possess what Taylor [6] called a "common rhythm" long before they have any articulate content. The dialogical structures that are deeply buried in these common rhythms of communal life remain generally inaccessible to conscious awareness; as Martsin has more recently observed, "we cannot and usually do not need to talk about this invisible and taken-for-granted background, yet it constantly regulates our way of being as our new encounters with the world are made sense of in relation to it" ([16], p. 439). It is only when there is a significant disruption in the flow of our coordinated activities with others that the full range of dialogical possibilities of self begins to come to consciousness. As Martsin went on to point out, it is in these "moments of rupture" that "our united and backgrounded sense of being becomes foregrounded and multiple... When we look at these moments of rupture we see no unified sense of identity, bur multiple situation-bound ways of defining our fuzzy sense of being" ([16], p. 441). Moreover, inasmuch as we cannot fully extricate ourselves from the concrete contexts of our background dialogical understanding, the sense of otherness that in this way comes into the self is inevitably partial, fragmentary and unknowable. 
Barresi [21] further analyzed the epistemological limits of the dialogical self in terms of an important distinction between first-person (actor's) and third-person (observer's) perspectives on dialogical self-understanding. Whereas our own current first-person activities and third-person information about the activities of others with whom we are currently involved are both directly witnessed, the first-person perspective of another and a third-person perspective toward oneself can only be imagined. We resort to imagination in these instances in an attempt to fill gaps that cannot be filled by direct experience and, as Barresi noted, "imagination can never fully achieve that job" ([21], p. 246). The reason is that we can never, even in our most vivid acts of imagination, actually inhabit the embodied, first-person experience of another nor entertain a fully objective, third-person view of ourselves.

The other within the dialogical self cannot be an object of explicit, discursive knowledge, then. In its more tacit form it lies buried in our background understanding of the social world; in its more active or intentional form, it is occluded in the fundamental asymmetry between first- and third-person knowledge. It is not something that can be objectively known but only imaginally projected; it is fundamentally an "as if" [22].

\subsection{Dialogue and Dialectics}

Critical to an understanding of dialogical "otherness" within the self is the distinction between dialogue, or "dialogic", and the closely related notion of dialectic. The origins of dialectic go back in the Western tradition to the ancient Greek philosophers, where it finds its most complete expression in the Socratic dialogues of Plato. In this context, dialectic was understood as a method of rational argument based on dialogue between two or more individuals who hold contrary positions and proceeds by identifying contradictions and inconsistencies in one's assumptions along the way toward discovering truth. Beginning with Hegel, dialectic subsequently came to be understood as a fundamental aspect of thought and reality itself, not just of discourse. In particular, dialectic is evident in the dynamic interplay between contradictory or oppositional parts of any living process and their subsequent resolution or integration into a new synthesis. Dialectical materialism derives from a Marxist recasting of the Hegelian dialectic in terms of concrete historical and economic processes $[23,24]$. Common to the myriad forms of dialectic is the notion of dynamic interaction among pairs of opposites and the emergence some form of resolving synthesis.

Dialogical thought, in contrast to dialectics, involves constituents that coexist but are not generally resolved or synthesized into a new whole. Writing of the polyphonic novel, for example, Bakhtin asserted that each such work "presents an opposition, which is never cancelled out dialectically, of many consciousnesses, and they do not merge in the unity of an evolving spirit” ([25], p. 26). In Bakhtin's dialogism, all language and thought is seen to be in response to past utterances and in anticipation of future ones, such that any given expression is always thoroughly saturated and enmeshed with the voices of others, which is the essence of what he termed polyphony. These mutually entangled voices and perspectives do not finally converge into a coherent overall picture but, rather, coexist in an unresolved plurality of "unmerged voices and consciousnesses" ([25], p. 6). Whereas dialectical thinking is based on tension and resolution among pairs of opposites, dialogical thinking is based, not merely on opposition, but on otherness; and, while dialectical opposites are to be resolved, integrated or transcended, dialogical others can coexist 
in polyphonic plurality of voices and perspectives. As Hermans [26] has shown, characters in the dialogical self frequently arrange themselves in pairs of opposites but dialogical self theory also makes room for an otherness within the self that cannot be resolved or synthesized dialectically.

\section{Dialogical Elements in Analytical Psychology}

The theme of dialogical otherness within the self is also taken up in Jung's analytical psychology, which predates the modern dialogical self tradition by several decades but can nonetheless inform and be informed by it. Papadopoulos $[27,28]$ has extensively documented the theme of "otherness" in Jung's life and work, making a compelling case that this was an essential preoccupation of Jung's throughout his long and productive career. The contributors to a recent volume edited by Jones and Morioka [29] focus more specifically on dialogical aspects of Jung's approach to otherness within the self, which is the focus of the present paper as well. The aim is not to attempt to assimilate or "domesticate" analytical psychology to the categories of dialogical self theory but, rather, to extend the reach of both traditions through mutual engagement. Although the notion of dialogue does not receive systematic treatment in the corpus of Jung's theorizing, it is evident that he was in many respects a dialogical thinker from the outset.

\subsection{Childhood Experiences}

During his early childhood years, for example, Jung often played an imaginary game with a favorite stone in the garden of his family home, which, as he later described it,

went something like this: "I am sitting on top of this stone and it is underneath." But the stone also could say "I" and think: "I am lying here on this slope and he is sitting on top of me." The question then arose: "Am I the one who is sitting on the stone, or am I the stone on which he is sitting?" This question always perplexed me, and I would stand up, wondering who was what now ([30], p. 20).

Jung's feeling of perplexity and uncertainty in playing this simple game was also accompanied by a distinct sense of curiosity and fascination. This was among a series of childhood games Jung invented, in which he imagined himself in a "secret relationship" with an object; in the case of the stone, the relationship was a fluid and reversible one. Plainly, the notion of dialogical positioning of self was not unknown to Jung even as a young child.

Jung's experience of a dialogical other within himself developed further when, by the age of 12 , wrote Jung, "it occurred to me that I was actually two different persons. One of them was the schoolboy who... was far from sure of himself; the other was important, a high authority, a man not to be trifled with... an old man who lived in the eighteenth century" ([30], pp. 33-34). This marked the first appearance of what Jung came to call his "No. 1 and No. 2 personalities", a motif that would run through the rest of his life. Personality No. 1 represented his ordinary sense of self, the son of his parents who attended school along with other children, whereas No. 2 was a mysterious "other" whose character was archaic and close to nature but remote from the world of everyday experience. Nonetheless, he came to recognize No. 2 as a bona fide aspect of himself and the dynamic interplay between No. 1 and No. 2 as something that takes place in others as well. Jung wrote: 
The play and counterplay between personalities No. 1 and No. 2, which has run through my whole life, has nothing to do with a "split" or dissociation in the ordinary medical sense. On the contrary, it is played out in every individual. In my life No. 2 has been of prime importance, and I have always tried to make room for anything that wanted to come to me from within ([30], p. 45).

\subsection{Dialogue in the Red Book}

In 1913, Jung's willingness to open up to the world of No. 2 was put to a decisive test. Following his break with Freud, Jung went through a period of profound psychological disorientation marked by a series of disturbing dreams and visions. In an effort to come to grips with this visionary material, Jung set out over a series of evenings to "drop" down into it and subsequently record what he experienced. The initial record of these extraordinary experiences was in a series of notebooks, as yet unpublished, called the Black Books. A reworked and highly stylized version of some of this material, including a calligraphic transcription of the text and abundant pictorial illustrations, constitutes what became known as The Red Book. Jung felt that this elaborate format was the best way to do justice to the richness of his original experiences. This work was finally published in 2009 in a full sized facsimile edition that includes a lengthy historical introduction and an extensive scholarly apparatus by Editor, Sonu Shamdasani [2].

At the core of the textual content of The Red Book is a narrative sequence of encounters with a host of imaginary figures, some loosely based and Biblical and mythological sources, others being more or less free creations. An example of the latter is a figure called "The Red One", who appears at the outset of Liber Secundus, the second part of The Red Book. Jung's confrontation with The Red One, like his encounters with other figures in the work, is thoroughly dialogical. Jung's "I", as protagonist and narrator, does not merely listen to and record what the Red One tells him but actively questions, disputes with, challenges and even at times contradicts him. The first question he asks is "who are you?" ([2], p. 259), which The Red One refuses to answer in a straightforward way, although he is aware that he has been taken to be the devil. In the conversation that ensues, The Red One states that he finds Jung's protagonist to be "an unbelievably ponderous and serious person" ([2], p. 259), whom he encourages to abandon seriousness and instead to "dance through life" ([2], p. 260). Jung's "I" meanwhile defends his seriousness but acknowledges that, although he knows how to dance, he has not yet found the way to joyful expression before God that dancing could evoke; to this, The Red One replies: "brother, I am joy" ([2], p. 260). Following the conversation, while Jung's "I" does not abandon his initial assessment of The Red One as the devil, he is now prepared to assimilate him as "my devil... the joy of the serious person" ([2], p. 260).

In a subsequent episode, Jung's "I" meets Ammonius, the Anchorite, who is in many respects an opposite character to The Red One. Upon their initial meeting he finds Ammonius sitting in a desert hut reading the same scriptural text over and over again. Jung's protagonist is puzzled by this seemingly unfulfilling, repetitive activity until Ammonius explains to him the art of deep reading. In a still later chapter, The Red One and Ammonius appear together. They have been traveling in each other's company in the interim, out of view of Jung's narrator, and each looks a little worse for wear, having partially assimilated each other's qualities and both blaming Jung's protagonist for their predicament. Nonetheless, both have been transformed in the process, as has Jung's own sense of self. 
There are some noteworthy features of this form of dialogical engagement from the perspective of dialogical theory. First, Jung's "I", who serves as protagonist and provides narrative continuity to the text, is an actual participant in the dialogues; as Shamdasani [31] has pointed out, the "I" in the Red Book dialogues is not to be identified with Jung himself but is, itself, a full-fledged dialogical character in its own right. In contrast with Hermans's dialogical self theory, where the "I" serves to give voice to various dialogical positions, in The Red Book dialogues the "I" is, itself, a dialogical position. Moreover, the characters in Jung's narrative function autonomously with, as it were, their own voice, rather than needing to be voiced through the external agency of the "I." Finally, as exemplified by the interaction between The Red One and Ammonius, these internal dialogues can take place entirely unconsciously, out of view of the "I"'s intentional control.

In the final part of The Red Book, the figure of Philemon finally emerges as the most authoritative voice amongst Jung's interlocutors - the ultimate personification of Personality No. 2 - and plays a critical role in fostering a sense of "otherness" within the self. Jung later wrote:

Philemon and other figures of my fantasies brought home to me the crucial insight that there are things in the psyche which I do not produce, but which produce themselves and have their own life. Philemon represented a force which was not myself. In my fantasies I held conversations with him, and he said things which I had not consciously thought. For I observed clearly that it was he who spoke not I ([30], p. 183).

\subsection{Dialogical Psychotherapy}

In the subsequent development of his theory and practice, inner dialogue with an imaginary other went from being a merely personal preoccupation to an actual method of self-exploration and therapy. The dialogical approach that Jung developed in The Red Book was subsequently elaborated into the method of active imagination, which became the cornerstone of Jungian psychotherapy. In one of the few places in Jung's Collected Works where he took up the theme of inner dialogue explicitly, he acknowledged that: "To anyone accustomed to proceed purely intellectually and rationally, this may seem altogether too ridiculous" ([32], para. 322); but he then went on to say that:

I mean this as an actual technique. We know that practically everyone has not only the peculiarity, but also the faculty, of holding a conversation with himself. Whenever we are in a predicament we ask ourselves (or whom else?), "What shall I do?" either aloud or beneath our breath, and we (or who else?) supply the answer. Since it is our intention to learn what we can about the foundations of our being, this little matter of living in a metaphor should not bother us. ([32], para. 323).

Jung also came to recognize dialogical engagement as essential to the interpersonal process of psychotherapy. In a late essay entitled "Principles of Practical Psychotherapy", Jung described the therapeutic process as "a dialogue or discussion between two persons", where: "A person is a psychic system which, when it affects another person, enters into reciprocal reaction with another psychic system" ([33], para. 1). This confrontation with an unknown other fosters unpredictable and uncontrollable outcomes that ultimately require the therapist to give up any pretentions to expert knowledge or authority. A genuinely dialogical relationship with another must afford full voice and authority to each participant, notwithstanding the constraints inherent in the asymmetrical roles of 
"therapist" and "client". Dialogical psychotherapy, as Jung understood it, stood in stark contrast to proceduralized forms of therapy (what today is called "manualized" therapy), where psychotherapy is understood as "a method which anybody could apply in stereotyped fashion in order to reach the desired result" ([33], para. 1). Jung's dialogical approach, in contrast, entails that the therapist let go of claims to expert authority and open up to the individuality of another in a way that changes the therapist along with the client.

As Jung readily acknowledged, the dialogical approach is not meant for everyone. It is pointless, he suggested, "to subject a simple soul who lacks nothing but a dose of common sense to a complicated analysis of his impulses, much less expose him to the bewildering subtleties of psychological dialectic" ([33], para. 11); on the other hand, "with complex and highly intelligent people we shall get nowhere by employing well-intentioned advice, suggestions, and other efforts to convert them to some kind of system" ([33], para. 11). The second type of person, Jung argued, can best be helped by providing them an opportunity in a genuinely dialogical situation to develop and express their own uniquely individual understandings of their difficulties. It is the individuality of the person that is of paramount importance in dialogical psychotherapy, for "inasmuch as he is an individual he can only become what he always was" ([33], para. 11). This encapsulates the therapeutic objective of individuation, which became the hallmark of Jungian psychotherapy.

\subsection{The Archetypal Background}

Jung's theoretical understanding of dialogical otherness within the self culminated in the notion of archetype and with the archetype of Self in particular. In his most definitive characterization of the notion, Jung identified the Self as the archetype that "expresses the unity of the personality as a whole" ([34], para. 789), which most often manifests as "a complexio oppositorum, a union of opposites" or a "united duality" ([34], para. 790). On this construal, the primary function of the Self is to unify contradictory tendencies of a person into an integrated whole. Here, as in his formulation of therapeutic method, dialogue merges with dialectic, consistent with Jung's well-known penchant for dialectical thinking. Although Jung generally eschewed the "dry-as-dust philosophical dialectic" ([35], para. 286) and was no fan of the Hegelian formulation [36], his reference to the union of opposites and integrated wholes is plainly more dialectical than dialogical. Beebe [37] further developed a dialectical formulation of the archetypal Self by putting together Jung's notion of archetypes with his theory of psychological types to produce an elaborate framework of opposites that is said to pattern dialogical activity within the Self. To the extent that these pairs of opposites are seen as something to be resolved, synthesized or integrated, however, the centering or centripetal tendencies of the Self are privileged at the expense of its non-integrative, decentering or centrifugal tendencies; in contrast, the dialogical self of Hermans and colleagues attempts to make room for both tendencies [8].

A more dialogical view of Jung's archetypal Self opens up when it is seen as the archetype, not only of wholeness or unity, but of otherness itself. Papadopoulos referred to it as the "ultimate other" inasmuch as its alleged wholeness is always purely potential and thus lies forever beyond the bounds of what can be experienced. The archetypal Self is in this way ultimately and inescapably other; moreover, it is also, according to Papadopoulos, the "master archetype" or "archetype par excellence" ([27], p. 87). Archetype is a notion that Jung characterized in various ways in the 
Collected Works, both biologically and metaphysically. In his final substantive formulation of the theory of archetypes, Jung distinguished the archetype as such from its concrete expression in archetypal symbols. The archetype as such, wrote Jung, is fundamentally "irrepresentable", inarticulate and unknowable; it constitutes "a background not previously suspected, a true matrix of all conscious phenomena" ([38], para. 356), a characterization to which he frequently returned in his subsequent work. Thus, archetypes in general, and the archetype of Self in particular, can be considered an aspect of background understanding, in the sense considered earlier in our discussion of the dialogical self.

However, while the Jungian archetypal psychology of Self and contemporary theories of the dialogical self thus share a notion of tacit, background understanding, they construe it differently. The dialogical background, as discussed earlier, is embedded in the local background of the immediate, communal contexts in which one is situated; whereas, the archetypal background is submerged in the deep background of the human way of being in the world that includes fundamental, existential concerns of human life [39-41]. This deep existential background constitutes a radical otherness that makes way for an unending depth of experience that is beyond "dialogue" in the ordinary sense; it is not so much a matter of relating to an other but, rather, to an indeterminate and undifferentiated otherness that constitutes the depths of unconscious life itself.

This difference, between the local and deep background, cuts to the heart of the tension between Jungian and postmodern construals of self. Zinkin has formulated the issue in terms of essentialism versus constructionism; the issue, as raised in the title of his seminal essay, is: "Your Self: did you find it or did you make it?" [42]. Whereas Jung is traditionally understood as advocating the essentialist position of a pre-existing Self that subsequently structures experience, the constructionist position is that the self is something made rather than found; Zinkin, in particular, advocated the social constructionist view that "the self comes into experience only through interaction with others and the form it takes, the sense the individual has of being or having a self, will depend greatly on the culture in which he or she has been brought up" ([42], p. 394).

The issues at stake in Jungian versus postmodern approaches to the self are not so straightforward as the essentialist/constructionist dichotomy might suggest, however, given that, as Roesler [43] has pointed out, Jung continually fluctuated between both epistemological positions in his writings. Jones [44] advocated a dialogical "middle ground" position that recognizes the importance of both the embodied and social contexts of self, while acknowledging an ongoing tension between them. In dialogical terms, the local background of the socially constructed self constitutes what Papadopoulos [28] has called the "familiar other", while the deep background of the archetypal self constitutes a "distant or exotic other"; and, as Papadopoulos went on to show, Jung tended to neglect the former and to unduly romanticize the latter. But the social constructionists have also tended to neglect the deep, archaic background of the embodied self, especially as manifest in non-conceptual and non-discursive modes of expression.

If the archetypal Self, as an aspect of deep background understanding, can never be fully articulated, then it cannot in the nature of things be reduced to a concept or hypothetical postulate in Jung's system, much less to a dialectical synthesis of its existing postulates. As Huskinson has pointed out, "we do not have a substantial and precise theory of the Self because Jung did not develop one" ([45], p. 443). But what eludes conceptual understanding can nonetheless be enacted and 
expressed in non-literal, non-conceptual ways via visual art, myth, metaphor, religious ritual, and narrative fiction - in a word, symbolically. As Smythe and Baydala pointed out: "What cannot be captured adequately in concepts can nonetheless be hinted at, alluded to, or suggested through exemplifying, symbolizing, myth making, and storytelling" ([40], p. 66). For example, Jung found the dynamics of Self to be expressed in a diverse array of mythological motifs, including "the interplay of yang and yin, or of the hostile brothers, or of the hero and his adversary (arch-enemy, dragon), Faust and Mephistopheles, etc." ([34], para. 790). Key to an understanding of such symbolic expressions of the archetypal Self is to distinguish the expressive function of symbols from the descriptive and explanatory functions of conceptual language. Smythe and Baydala [40], following Goodman [46], characterized symbolic expression as a form of metaphorical exemplification, that is, as a matter of metaphorically showing or presenting something, rather than literally defining or describing it. Symbolic expression thus opens up possibilities for the dialogical self beyond the domain of discursive and conceptual practices, to realms of the non-discursive and non-conceptual. There are substantial traditions of scholarship in philosophy, aesthetics and comparative religion on symbolic expression and the symbolic, non-conceptual uses of language that are potentially relevant here but which are beyond the scope the present paper to discuss at length.

\section{Conclusions}

The dialogical currents in Jung's analytical psychology can both inform and be informed by contemporary developments in dialogical self theory. On the one hand, analytical psychology offers in some respects a more thoroughly dialogical perspective than dialogical self theory, inasmuch as the "I" or ego functions, itself, as a dialogical position amongst others within the self; these others are seen to function autonomously and with their own voice, beyond the intentional control and oversight of an "I". Moreover, "dialogues" within the self can take place wholly unconsciously and non-discursively through non-conceptual modes of expression that reflect the deep archetypal background of embodied life, which opens the way to an undifferentiated otherness that goes beyond relationship to a specific other. On the other hand, dialogical self theory opens up dimensions of dialogical otherness hitherto occluded by analytical psychology. These include the decentering or centrifugal aspects of self that become evident when dialogue is detached from dialectic - the recalcitrant and "unmerged" voices that remain resistant to any form of dialectical synthesis or integration. Moreover, dialogical self theory highlights the local background of socioculturally embedded life and how it is taken up into the self, in a way that analytical psychology has traditionally been reluctant to do.

In neither the dialogical self nor the analytical psychology tradition, however, can the other within the self be considered an object of knowledge in the usual sense, viz., something that can be explicitly represented and subjected to truth claims. The background understanding of the other that is implicated in both traditions can only function as such so long as it remains tacit and hidden from view. When the "inner other" becomes foregrounded in experience as a participant in dialogue, it is invariably projected in an act of imagination that can never fully capture the unknown otherness that it expresses. While these imaginative constructions do not constitute discursive knowledge in any obvious sense, they do function to express, perform and exhibit our ongoing self-understanding in 
endlessly creative ways. How to properly evaluate such imaginative products for psychological meaning remains an open question.

\section{Acknowledgments}

Portions of this paper were presented at the Canadian Psychological Association's Annual Convention in Toronto, Ontario in June 2011. I thank my colleagues in the History and Theory of Psychology Section of CPA for their helpful feedback on that presentation.

\section{Conflicts of Interest}

The author declares no conflicts of interest.

\section{References}

1. Taylor, C. Dilemmas and Connections: Selected Essays; Harvard University Press: Cambridge, MA, USA, 2011.

2. Jung, C.G. The Red Book: Liber Novus; Shamdasani, S., Ed.; Kyburz, M., Peck, J., Shamdasani, S., trans.; W.W. Norton: New York, NY, USA, 2009.

3. Stam, H.J. Self and dialogue: Introduction. Theor. Psychol. 2010, 20, 299-304.

4. Danziger, K. Naming the Mind: How Psychology Found Its Language; Sage: London, UK, 1997.

5. Stam, H.J. The dialogical self and the renewal of psychology. IJDS 2006, 1, 99-117.

6. Taylor, C. The Dialogical Self. In The Interpretive Turn: Philosophy, Science, Culture; Hiley, D.R., Bohman, J.F., Shusterman, R., Eds.; Cornell University Press: Ithaca, NY, USA, 1991; pp. 304-314.

7. Hermans, H.J.M. The dialogical self as a society of mind: Introduction. Theor. Psychol. 2002, $12,147-160$.

8. Hermans, H.J.M.; Hermans-Konopka, A. Dialogical Self Theory: Positioning and Counter-Positioning Is a Globalizing Society; Cambridge University Press: Cambridge, UK, 2010.

9. Hermans, H.J.M.; Kempen, H.J.G. The Dialogical Self: Meaning as Movement; Academic Press: San Diego, CA, USA, 1993.

10. Hermans, H.J.M.; Kempen, H.J.G.; Van Loon, R.J.P. The dialogical self: Beyond individualism and rationalism. Am. Psychol. 1992, 47, 23-33.

11. Hermans, H.J.M.; Salgado, J. The dialogical self as a minisociety. In The Sociocultural Turn in Psychology: The Contextual Emergence of Mind and Self; Kirschner, S.R., Martin, J., Eds.; Cambridge University Press: New York, NY, USA, 2010; pp. 13-204.

12. Dimaggio, G.; Hermans, H.J.M.; Lysaker, P.H. Health and adaptation in a multiple self: The role of absence of dialogue and poor metacognition in clinical populations. Theor. Psychol. 2010, 20, 379-399.

13. Adams, M.A. Losing one's voice: Dialogical psychology and the unspeakable. Theor. Psychol. 2010, 20, 342-361.

14. Burkitt, I. Dialogues with self and others: Communication, miscommunication, and the dialogical unconscious. Theor. Psychol. 2010, 20, 305-321. 
15. Burkitt, I. Fragments of unconscious experience: Towards a dialogical, relational, and sociological analysis. Theor. Psychol. 2010, 20, 322-341.

16. Martsin, M. Identity in dialogue: Identity as hyper-generalized personal sense. Theor. Psychol. 2010, 20, 436-450.

17. Dreyfus, H.L. Being-in-the-World: A Commentary on Heidegger's Being and Time, Division I; MIT Press: Cambridge, MA, USA, 1991.

18. Searle, J.R. Consciousness and Language; Cambridge University Press: Cambridge, UK, 2002.

19. Taylor, C. Philosophical Arguments; Harvard University Press: Cambridge, MA, USA, 1995.

20. Taylor, C. Modern Social Imaginaries; Duke University Press: Durham, NC, USA, 2004.

21. Barresi, J. From 'the thought is the thinker' to 'the voice is the speaker': William James and the dialogical self. Theor. Psychol. 2002, 12, 237-250.

22. Smythe, W.E. On the psychology of 'as if'. Theor. Psychol. 2005, 15, 283-303.

23. Angeles, P.A. Dictionary of Philosophy; Harper \& Row: New York, NY, USA, 1981.

24. Pascual-Leone, J. Dialectics. In Encyclopedia of Critical Psychology; Teo, T., Ed.; Springer-Verlag: Berlin, Germany, 2012. Available online: http://www.springerreference.com/ index/chapterdbid/306855 (accessed on 13 September 2013).

25. Bakhtin, M.M. Problems of Dostoevsky's Poetics; Emerson, C., trans.; University of Minnesota Press: Minneapolis, MN, USA, 1984.

26. Hermans, H.J.M. Opposites in a dialogical self: Constructs as characters. J. Constr. Psychol. 1996, 9, 1-26.

27. Papadopoulos, R.K. Jung and the concept of the other. In Jung in Modern Perspective; Papadopoulos, R.K., Saayman, G.S., Eds.; Wildwood House: Hounslow, UK, 1984; pp. 54-88.

28. Papadopoulos, R.K. The other other: When the exotic other subjugates the familiar other. J. Anal. Psychol. 2002, 47, 163-188.

29. Jones, R.A., Morioka, M, Eds. Jungian and Dialogical Self Perspectives; Palgrave Macmillan: New York, NY, USA, 2011.

30. Jung, C.G. Memories, Dreams, Reflections, rev. ed.; Jaffe, A., Ed.; Winston, R.C., trans.; Vintage Books: New York, NY, USA, 1989.

31. Shamdasani, S. Liber Novus: The "Red Book" of C. G. Jung. In The Red Book: Liber Novus; Shamdasani, S., Ed.; Kyburz, M., Peck, J., Shamdasani, S., trans.; W.W. Norton: New York, NY, USA, 2009; pp. 193-221.

32. Jung, C.G. Two Essays on Analytical Psychology. In The Collected Works of C. G. Jung, 2nd ed.; Read, H., Fordham, M., Adler, G, McGuire, W., Eds.; Hull, R.F.C., trans.; Princeton University Press: Princeton, NJ, USA, 1966; Volume 7.

33. Jung, C.G. The Practice of Psychotherapy. In The Collected Works of C. G. Jung, 2nd ed.; Read, H., Fordham, M., Adler, G, McGuire, W., Eds.; Hull, R.F.C., trans.; Princeton University Press: Princeton, NJ, USA, 1966; Volume 16.

34. Jung, C.G. Psychological Types. In The Collected Works of C. G. Jung, 2nd ed.; Read, H., Fordham, M., Adler, G, McGuire, W., Eds.; Hull, R.F.C., trans.; Princeton University Press: Princeton, NJ, USA, 1971; Volume 6. 
35. Jung, C.G. Alchemical Studies. In The Collected Works of C. G. Jung, 2nd ed.; Read, H., Fordham, M., Adler, G, McGuire, W., Eds.; Hull, R.F.C., trans.; Princeton University Press: Princeton, NJ, USA, 1967; Volume 13.

36. Rychlak, J.F. Jung as Dilectician and Teleologist. In Jung in Modern Perspective; Papadopoulos, R.K., Saayman, G.S., Eds.; Wildwood House: Hounslow, UK; 1984; pp.34-53.

37. Beebe, J. An archetypal model of the self in dialogue. Theor. Psychol. 2002, 12, 267-280.

38. Jung, C.G. On the Nature of the Psyche. In The Collected Works of C. G. Jung, 2nd ed.; Read, H., Fordham, M., Adler, G, McGuire, W., Eds.; Hull, R.F.C., trans.; Princeton University Press: Princeton, NJ, USA, 1969; Volume 8, pp. 159-234.

39. Baydala, A.; Smythe, W.E. Hermeneutics of continuity: Theorizing psychological understandings of ancient literature. Theor. Psychol. 2012, 22, 842-859.

40. Smythe, W.E.; Baydala, A. The hermeneutic background of C. G. Jung. J. Anal. Psychol. 2012, $57,57-75$.

41. Smythe, W.E.; Chan, G.C. Jungian Archetypes and Evolutionary Psychology. In Varieties of Theoretical Psychology: International Philosophical and Practical Concerns; Teo, T., Stenner, P., Rutherford, A., Park, E., Baerveldt, C., Eds.; Captus Press: Concord, ON, Canada, 2009; pp. 289-298.

42. Zinkin, L. Your Self: did you find it or make it? J. Anal. Psychol. 2008, 53, 389-406.

43. Roesler, C. The self in cyberspace: Identity formation in postmodern societies and Jung's Self as an objective psyche. J. Anal. Psychol. 2008, 53, 421-436.

44. Jones, R.A. Between the analytical and the critical: Implications for theorizing the self. J. Anal. Psychol. 2003, 48, 355-370.

45. Huskinson, L. The Self as violent Other: The problem of defining the self. J. Anal. Psychol. 2002, 47, 437-458.

46. Goodman, N. Languages of Art, 2nd ed.; Hackett: Indianapolis, IN, USA, 1976. 


\title{
Chapter 7
}

\section{Archetypal-Imaging and Mirror-Gazing}

\section{Giovanni B. Caputo}

DIPSUM, University of Urbino, via Saffi 15, 61029 Urbino, Italy; E-Mail: giovanni.caputo@uniurb.it

\begin{abstract}
Mirrors have been studied by cognitive psychologists in order to understand self-recognition, self-identity, and self-consciousness. Moreover, the relevance of mirrors in spirituality, magic and arts may also suggest that mirrors can be symbols of unconscious contents. Carl G. Jung investigated mirrors in relation to the unconscious, particularly in Psychology and Alchemy. However, the relationship between the conscious behavior in front of a mirror and the unconscious meaning of mirrors has not been clarified. Recently, empirical research found that gazing at one's own face in the mirror for a few minutes, at a low illumination level, produces the perception of bodily dysmorphic illusions of strange-faces. Healthy observers usually describe huge distortions of their own faces, monstrous beings, prototypical faces, faces of relatives and deceased, and faces of animals. In the psychiatric population, some schizophrenics show a dramatic increase of strange-face illusions. They can also describe the perception of multiple-others that fill the mirror surface surrounding their strange-face. Schizophrenics are usually convinced that strange-face illusions are truly real and identify themselves with strange-face illusions, diversely from healthy individuals who never identify with them. On the contrary, most patients with major depression do not perceive strange-face illusions, or they perceive very faint changes of their immobile faces in the mirror, like death statues. Strange-face illusions may be the psychodynamic projection of the subject's unconscious archetypal contents into the mirror image. Therefore, strange-face illusions might provide both an ecological setting and an experimental technique for "imaging the unconscious". Future researches have been proposed.
\end{abstract}

Reprinted from Behav. Sci. Cite as: Caputo, G.B. Archetypal-Imaging and Mirror-Gazing. Behav. Sci. 2014, 4, 1-13.

\section{Mirrors in Psychology}

Mirrors have been studied in cognitive psychology in relationship to self-recognition, self-identity and self-consciousness. The attainment of a developmental stage of basic self-recognition is commonly gauged through reactions to a mirror [1-3]. Mirrored-self recognition involves the connection between the representation of a visual image that is external to the subject and the representation of the subject's self. This process most probably requires the binding of visual information (i.e., the subject's mirrored image), somaesthetic, kinaesthetic, affective and motor representations into a global representation of the subject's self. 
Mirrors are, by definition, virtually perfect "imitators" of the observer's own bodily face, since mirror feedback is instantaneous in time. Moreover, if the mirror is flat and without visible imperfections, the reflected image is completely coherent in space with respect to the original visual stimulus. In addition to these perceptual and spatial characteristics, mirrors are perfect "imitators" of facial emotions and expressions, since they presumably produce unconscious mimicry and emotional contagion [4] within the subject itself by gazing at its own reflected image. In turn, unconscious mimicry can presumably produce empathic resonance [5] and emotional contagion within the subject. In other words, the mirror can create a sort of "closed loop" between perception, action and emotion within the observed/observing subject.

Contrary to a simplistic view that describes mirror gazing as equivalent to looking at static photos, some phenomenological investigations describe a more unsettling encounter with one's mirrored double [6-8]. Merleau-Ponty [6,7] described the mirror as an object that allows the subject to perceive its own facial features and to apprehend its own body's unity in a way which is different from that which is available from interoceptive, proprioceptive and exteroceptive sources. The subject becomes a spectator when it recognizes its mirror image: seeing itself in the mirror is seeing itself as others see it. Therefore, mirror self-recognition exemplifies a troubled form of self-knowledge, since the mirror facilitates the subject's alienation into its double. The decisive and unsettling impact of mirror self-recognition is the realization that the subject exists in an intersubjective

space. This finding strongly distinguishes mirror self-recognition from self-identification in photos. The uncanny character of the mirrored image is due to intermingling of self and other representations within the subject - a process that is completely absent when identifying photos. "Thereupon I leave the reality of my lived me in order to refer myself constantly to the ideal, fictitious, or imaginary me, of which the specular image is the first outline. In this sense I am torn from myself, and the image in the mirror prepares me for another still more serious alienation, which will be the alienation by others." ([7], p. 136).

Developmental, neurophysiological and neuropsychological studies show that mirrored reflections are not equivalent to pictures and live videos [9]. Children show signs of self-recognition in photos much sooner than they are able to pass the mark test with mirrors [10]. On the other hand, children pass mirror versions of the mark task before the versions involving live videos [11]. The neural signatures for self-recognition differ depending upon whether a mirror or photo is used [12]. Some neuropsychological patients may not recognize themselves in mirrors (mirrored-self misidentification; [13]), while retaining their capacity to recognize themselves in photos [14]. Feinberg [15] proposed to group various syndromes that present alterations in the patient's self-identity within the category of neuropathologies of the self. These produce an alteration in the regulation of the self-boundaries, either in the direction of the under-relatedness to personally significant aspects of the self (as mirrored-self misidentification) or in the direction of the over-relatedness to selected aspects of the world that the patient inappropriately over-incorporates into the self.

In connection to phenomenological experiences of alienation or dissociation of the subject in front of its reflected image [6-8], a relationship to out-of-body experiences [16] can be discussed. Experiments with virtual reality showed that a multi-sensory bodily self-representation is bound 
through the integration of visual virtual reality and touch information in experiments of spatial self-location [17-19]. During mirror self-recognition, a similar binding process is probably present for multi-sensory integration of visual (i.e., the mirrored image of the subject's body), somatic, kinaesthetic, affective and motor representations into a global representation of the subject's self.

Strange-face illusions in the mirror have been recently described by subjects who gaze at their own face reflected in the mirror for a few minutes at a low illumination level (Figure 1). Healthy observers sometimes see huge distortions of their own faces, and they often see monstrous beings, prototypical faces, faces of relatives and deceased, and faces of animals [20,21].

Figure 1. The mirror stand used in the experiment of mirror-gazing. The room should be without external light. A uniform illumination of the face (about 0.8 lux) can be obtained by placing a small lamp, or a candle, on the floor at some distance from the subject's back $[20,21]$. The subject's task is to stare at its eyes in the mirror.

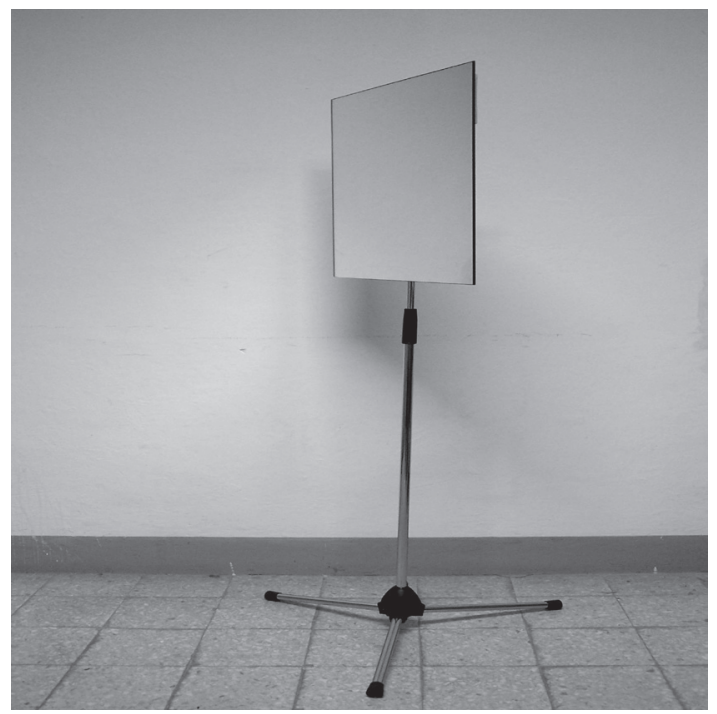

Strange-face illusions often involve the perception of strange-others who appears beyond the mirror, thus indicating the subject's dissociation [21-24]. In general, naïve observers describe their feeling of losing control when strange-faces suddenly pop out from the mirror [21]. Dissociative experiences of strange-face illusions in healthy individuals typically dissipated after $15 \mathrm{~min}$ [23].

Consistent with these ideas of a dissociative process, observers wearing a full-face theatrical mask during mirror-gazing (e.g., a Japanese ko-omote mask of Noh theatre, [25]) have described how the facial features of the mask become animated (e.g., opening the physically closed mouth, as for lip movement or speaking, or shifting the animated eyes) and strange-faces in place of the physical mask are perceived.

In healthy individuals, strange-face illusions during mirror gazing usually involve the perception of one strange-face at a time. The duration of the illusion has been reported to be roughly seven seconds [21]. However, there are some healthy observers who describe intense flux or streaming experiences of continuously changing faces of unknown persons; the stream of new faces can last for a relatively long time. Only a few healthy individuals describe the perception of a second face, like another man/woman, just behind their face that instead becomes dark and unmoved like an inanimate mask. Alternatively, some schizophrenic patients describe the perception of multiple-others that fill 
the mirror surface surrounding the strange face [26]. Many patients were convinced that strange-face illusions were truly real and identify themselves with strange-face illusions, differently from healthy individuals who never identify with them [26]. This deficit in schizophrenia can be caused by pathological ego dysfunction [27].

Similar or even stronger strange-face illusions can be produced through an interpersonal setting (Figure 2) in which a pair of individuals are facing and gazing at each other in the eyes [28]. In such an inter-subjective setting, unconscious synchronization of responses is apparent in some dyads. On the basis of this finding, it is possible to hypothesize that strange-face illusions during mirror-gazing enact an interpersonal subject-other interaction in which the subject is facing its dissociative other located beyond or behind the mirror. A possible explanation of stronger strange-face illusions in some dyads with respect to mirror-gazing can be due to an increase of unconscious mimicry and emotional contagion within the dyad. Therefore, the symmetry of the interpersonal setting can lead to mirroring the bodily, affective, and psychological contents of strange-face illusions within these dyads.

Emotional responses to strange-face illusions are usually relatively intense in healthy individuals, and can be dramatic in some schizophrenic patients. Most frequent emotions are: surprise, interest and astonishment; other emotions include negative emotions such as moderate fear, anguish and fright, while positive emotions, such as hilarity and joyfulness, are rare.

Figure 2. The interpersonal symmetric setting used for inter-subjective strange-face illusions [28]. The subject's task is to stare into the eyes of the other participant.

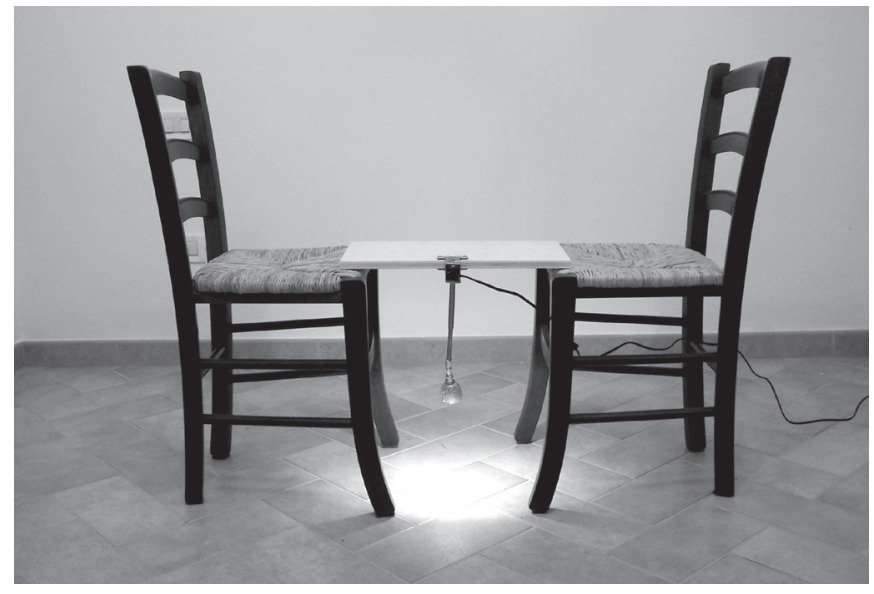

As discussed above, self-recognition in mirrors is based on multiple cognitive processes. Therefore, strange-faces in the mirror are probably complex illusions involving different processes, from visual perception to motor facial mimicry, from self-other boundary to affective empathy, from unconscious contagion to conscious misidentification. Consequently, different mechanisms hypothesized as generative to strange-face illusions may be proposed. An initial hypothesis is that strange-face illusions are perceptual and involve the Troxler effect [29]. This effect can explain merging of facial features into a uniform silouette of the facial contour; however, perception of entirely new faces remains unexplained. A second hypothesis is that prolonged adaptation to mirrored face disrupts multi-sensory binding between visual and bodily representations. This explanation can account for the frequent experiences of dissociation $[23,24]$ and experiences that are similar to out-of-body perceptions of another person who is located beyond the mirror [21]. 
A third hypothesis is that low illumination can induce self-hypnosis and altered states of consciousness as a consequence of sensory deprivation [30], thus leading to perceptual and somatic pseudo-hallucinations of the subject's face. A fourth hypothesis is that gazing at a low illumination can alter the self-other boundary [15] and by consequence can bring to mirrored-self misidentification and dissociation. A fifth hypothesis, which we prefer, can be based on emotions and empathy through facial mimicry and contagion [4,5], which can operate within the subject, resonating with its own face reflected in the mirror. Prototypical strange-faces could be a consequence of prototypical somatic/motor facial patterns of basic emotions. Self/other dissociation can facilitate "projection" of unconscious meaningful contents into the external mirrored image. In the inter-subjective setting, some dyads can show unconscious synchronization of illusions as a consequence of synchronized facial mimicry between two individuals who are staring at each other's eyes.

\section{Strange-Face Illusions and Analytical Psychology}

In relation to the concept of "projection", the early idea of empathy, which was proposed by Lipps and Jung, is relevant. Lipps ([31], chapter 13) hypothesized that empathy is a form of objectification of the subject's vital impulse, or activity into an external object that is different from the subject. Hence, the peculiar ability of empathy is that inanimate targets can become animated and appear alive. The targets that are animated by empathy appear as immediate Dasein and real, since the ego has become external and self-objective [31]. Jung ([32], chapter 7) hypothesized that Lipps's idea of empathy is at the core of the psychodynamic concept of "projections" of the subject's unconscious dissociative contents into others. Jung proposed an empathic personality trait which may be complemented by an opposite personality trait of abstraction in order to explain differences among individuals.

These ideas of empathy [31] and "projection" [32] can be relevant with respect to strange-face illusions. Strange-faces may be produced by unconscious contents that can only emerge within the subject's consciousness when dissociated from the subject's self and "projected" into the external mirrored-self image. In mirror-gazing, an overlapping between the conscious-self and the unconscious-self may provoke negative emotions and conflicts within the subject's consciousness. Moreover, in inter-subjective gazing, a "projection" of the unconscious-self into another person can be much more easily produced and accepted by the subject's consciousness.

Jung ([32], see Appendix 1) posited that the empathic personality trait is correlated to extroversion, while abstraction is correlated to introversion. If we assume that strange-face illusions are projections of unconscious contents, then Jung's idea can make the prediction that extroverted subjects would show more proneness to strange-face illusions than introverted subjects. In agreement with this statement, we found that patients with major-depression [33] do not typically perceive strange-face illusions, or they perceive very faint changes of their immobile faces, like "death statues", in the mirror [34]. In fact, according to Jung, depression is characterized by profound introjections of libido from the external world [35]. This may possibly reflect affective inhibition and blunting on the dissociative process which may require at least the potential for strong affective activation; a potential clearly dampened by depression [36]. Further support to Jung's ideas comes from finding a positive correlation between individual differences in the proneness to strange-face 
illusions and empathic personality traits ("empathic-concern" and "fantasy" subscales of Interpersonal Reactivity Index [37]), as I have highlighted in recent research [38].

Jung ([32], see Definitions: Self) conceived the self as a totality of conscious and unconscious contents, together with a transcendent function that has the purpose to gain progressive awareness of unconscious contents. Another aspect of strange-face illusions concerns the integration of dissociated contents into the individual's self. Integration starts through awareness of strange-faces, a process that is favoured by the fact that the mirror is also a physical object. Also, schizophrenic patients can take advantage of this awareness, since they can ground their (often dramatic) hallucinations elicited by mirror-gazing upon objectivity of the physical mirror. In this way, unconscious projections of dissociated contents can be integrated into the consciousness of the self. At present, only in a few cases have I had the opportunity to examine healthy observers who underwent a number of mirror-gazing sessions over a number of days (about 5 to 20 sessions of 30-60 minutes). The strange-face that they perceived the first time in the mirror was regarded by them as a person who was unknown or opposite to their conscious character and bodily appearance or sexual genre (e.g., a dark man, an old ancestor, a bad witch). The observers described their progressive comprehension of the identity of the strange-face during the sessions. This process of integration by awareness of the unknown aspect of the self can be similar to imaginatio, according to Jungian terminology [39].

Strange-face illusions could be classified according to archetypes described in analytical psychology [40]. In particular, the archetypes of shadow, anima/animus, mother, old-sage, hero, puer, and androgyne may be observed among strange-face illusions that are perceived by naïve observers [21] (see below). According to Jung, an archetype is structured into opposites. The process of individuation of the self presupposes the integration of opposites.

A phenomenological experience that is often described both by healthy and psychotic individuals is the "numinosity" of some strange-faces that they perceived. According to Jung, any time an unconscious archetypal content is constellated and emerges, it is characterized by numinosity, that is its fascinating power of attraction of the ego toward the unconscious, in a form of deep interest or even possession [41].

The synchronization of inter-subjective strange-face illusions [28] can be discussed in relation to Jung's idea of synchronicity $[42,43]$, which indicates the co-occurrence of events with roughly the same meaning at about the same time. According to Jung, synchronistic events arise whenever archetypes are constellated and, on the other side, synchronistic phenomena can be elicited by putting an individual into an unconscious state, as hypnosis or trance [41]. Archetypes of collective unconscious make synchronicity of individuals around numinous symbols. According to Jung, these events characterize telepathy between individuals and synchronistic events between the psychic and the physic. For example, numbers are archetypes of the order both of the physical world and of the self. Archetypal numbers not only express order of the world, but in addition the unconscious uses numbers as a factor that creates order [42].

Projection can probably be considered a form of synchronicity between the subject's unconscious and the other's body and mind. In the case of a pair of individuals, the synchronization of inter-subjective strange-face illusions [28] could be a form of Jung's synchronicity [42] between the somatic, emotional, and psychic domains of the two individuals. This can produce a crossed projection of 
unconscious contents that are merged between the two individuals, with unconscious contents of one individual becoming also in part the unconscious contents of the other, on the basis of collective archetypes. According to Jung, this syzygy can create a crossed conjunction within the dyad ([39], chapter 5.6).

In addition to previous cognitive and analytical accounts of strange-faces, other aspects of these illusions need to be discussed in a wider cultural and anthropological context. In fact, unsettling experiences with mirrors is largely documented in arts and religion [44,45], magic, alchemy and spirituality [46]. In the following sections a review is made about these aspects of mirror usage, in order to gain a better understanding of strange-face illusions from these viewpoints. Then, we compare mirror illusions with Jung's psychology of alchemy.

\section{Mirrors in Magic and Alchemy}

The magic power of mirrors dates back probably from the beginning of their invention. The art of using mirrors in divination and prediction of individual destiny (named catoptromantia) is found in the Dionysian testimonies [47]. The legend, chanted in the poem Dionysiaca by Nonnus of Panopolis, describes the killing of Dionysus (as a child) by his brothers the Titans, just when Dionysus gazes into the fascinating mirror (Figure 66b in [47] from Birth of Dionysus, Archaeological Museum of Bologna, Italy). A very large number of Greek and Roman vases show Bacchantes or Satyrs dancing in trance while gazing into a portable mirror. The great Alexander mosaic (named also Battle of Isso) at the Archaeological Museum of Napoli, Italy, shows an important detail in the lower centre part of the mosaic: a dying warrior gazes into the back side of his reflecting shield to see his ghost.

The most revealing information about the secret Dionysian mysteries is shown hermetically in the cycles of frescoes from the Villa of Mysteries in Pompei, Italy. An old Silenus offers some wine in a large reflecting silver bowl to a young man. The Silenus averts his gaze from the bowl, whereas the young man gazes into the mirror-reflecting bowl and has an astonished expression. Behind the young man there is another young man with identical facial features and clothes, but another expression of awareness - probably the same man that is doubled and yet has been initiated to the Mysteries. His double holds up a frightening mask which the drinking young man probably sees reflected in the bowl. Next to these characters sits a goddess, Ariadne or Aphrodite or mother Semele, with Dionysus who is euphoric or drunk, lying across her lap.

In the Renaissance, the use of magic mirrors is well documented. For example, John Dee, the Elizabethan magician, used a mirror made of oxydian stone (British Museum of London, England) to evoke angels and ghosts. The magical procedure is well illustrated by Rembrandt (Faust and the magic mirror; Figure 55 in [48]). The magic mirror is not used for reflecting faces or objects. It is placed at a distance of a few meters from the observer. Faust perceives the magical apparition out of the mirror in its left side (right outside the mirror with respect to Faust).

Paracelsus ([49], chapter 5) describes the construction of magic mirrors through the fusion of seven metals in order to establish a connection between macrocosm and microcosm. Jung ([39], chapter 3.4.D) quotes and discusses an intriguing text created by Paracelsus [50], in which the moon and the mirror are considered equals in their magic powers. According to Paracelsus, the mirror produces inter-relations between different human beings who have gazed or are gazing into it. 
Moreover, the moon is a mirror (see [39] chapter 3.4 for the complex implications of the moon in alchemy). Hence, the moon-mirror creates an explosive effect in the increase of the number of influences and contagions between human beings and astrological effects of the planets.

The Italian philosopher Julius Evola and co-workers (Ur group; [46]) describe the use of mirrors in order to perceive ethereal or spiritual presences. The same technique has been investigated in recent years with the so-called psychomanteum [51-54]. The setting requires a dark room, with the walls covered in black opaque curtain cloth, and the mirror is placed near the ceiling at a distance of a few meters from the observer. The mirror reflects the empty space above seated individuals who did not see their reflected body. This setting requires isolating the participant within the psychomanteum during a long session (60-90 minutes). Participants experience hallucinations of visual imagery, voices, sounds, light, body sensations and smell. Visual hallucinations of the mirrors are usually described as a halo around the mirror, or emitting light from the mirror, or colour changes in the light shining from the mirror [46].

In summary, the mirror in itself may create altered states of consciousness and trance when the mirror is displayed at a low illumination or when the subject has assumed drugs or alcohol. However, traditional and modern studies on magic reported above have never described strange-face illusions $[20,21]$ when a subject gazes at its own image reflected in the mirror.

\section{Mirrors in Carl G. Jung's Psychology and Alchemy}

In Psychology and Alchemy [48], Jung studied extensively the symbols connected to mirrors in relationship to the analysis of Wolfgang Pauli's dreams. Jung's investigation of mirrors is initially based on Schopenhauer's idea [55] that Intellect is like a mirror, which reflects the Will ([48] part 2, chapter 3, dream 11 and dream 12). At the first apparition in the Pauli's dreams, the mirror is being broken. In some ways, this fracture can also symbolize that Schopenhauer's division between Will and Representation has been surpassed by the discovery of the unconscious.

In the course of Pauli's dreams, the simple idea of the intellect as a mirror needs to be amplified in its symbolic meanings. In fact, Pauli's dreams concerning mirrors are related to the problem of symmetry ([48], part 2, chapter 3, dream 25). Through the latter, the mirror is directly connected to the relationship between the conscious and the unconscious ([48], part 2, chapter 3, dream 25) and acknowledging parapsychology ([48], dream 25, note 112). The problem of symmetry in relation to mirrors occupies a number of dreams up to the "Great Vision" ([48], dream 59). Finally, the problem of symmetry leads toward the idea of synchronicity ([48], part 3, chapter 3.3). It can be noted that, in quantum physics, the symmetry is a form of synchronicity or, as Pauli preferred, of "complementarity".

The symbols of mirror and symmetry can also be found in alchemy (Figure 209 in [48]). Although Jung [48] did not dedicate a specific essay to symbolic meanings of mirrors, it seems that mirrors and symmetries were most relevant for the development of the theory of synchronicity $[42,43,56]$. The Opus (e.g. the Lapis) is the term, used in alchemy, to describe the transformation of mind and matter. Alchemists after Paracelsus used the term Unus Mundus in order to indicate the same transformation, which leads different levels of reality toward unity or microcosm. According to Jung, the terms Opus, Unus Mundus, and synchronicity indicate the same psychoid reality in which physic and psychic, somatic and mental, mind and matter, are non-dualistic [39]. In the non-dualism of the psychoid, events which apparently occur at different dualistic levels actually co-occur. 
"Unus est lapis, una medicina, unum vas, unum regimen, unaque dispositio"-is said in the Rosarium Philosophorum ([39], chapter 3.4.B, note 316).

\section{Strange-Face Illusions and Archetypal Imagery}

Mirror-gazing at a low illumination produces visual illusions that are specific to one's own face $[20,21]$. It is possible to hypothesize that strange-face illusions found in a controlled setting may be similar to pseudo-hallucinations obtained by catoptromantia, as described in Roman mosaics and frescoes. However, strange-face illusions seem different from hallucinations obtained with magic mirrors, as described in books by John Dee, Paracelsus, and other authors of the Renaissance. Strange-face illusions are clearly different from multi-sensory hallucinations produced within the psychomanteum [46,51-54]. Strange-face illusions seem more specific to reflect the projection of archetypes.

Strange-face illusions may provide both an ecological setting and an experimental technique for "imaging of the unconscious". In fact, archetypal contents often characterize strange-face illusions. Jung's ideas about alchemy [48] and particularly Jung's psychological explanations of the different stages of the opus [39], can easily be applied to the phenomenological descriptions that naïve observers spontaneously produce about their experiences of strange-face illusions. From the findings in previous works [20,21], naïve observers very often described the archetype of shadow ([48], part 1). In some cases, as reported above, there is evidence for dissociation between the archetype of shadow and the social mask of the person. The feeling of the observers in response to strange-shadows is not pleasant. The archetype of the shadow is perceived very frequently in strange-face illusions of monsters, witches, skulls or cadavers. This finding is akin to the proposal to interpret the archetype of shadow in terms of alchemical nigredo (Figures 34 and 115 in [48]). Also, at this stage the relatively frequent perception of strange-animals in the mirror can be connected (Figures 90 and 175 in [48]). A very frequent archetypal content of strange-face illusions is an old man/woman, usually in the form of grand-father/mother, sometimes with black skin. Usually, observers in response to the old man/woman feel his/her intense numinosity: observers often state that the old man/woman seems to want to communicate something important. The strange old man/woman can be considered an archetype of the old-sage (or alchemical magister; Figures 168 and 179 in [48]). Another archetype that is also described by naïve observers is the archetype of anima/animus (Figure 9 and illustrations of the albedo in [48]), in the form of a strange-face of the opposite sex to the observer, usually having a cheerful presence. The numinous child (Figure 121 in [48]), usually seen with shining eyes, is also found in strange-face illusions by relatively few naïve observers. In strange-face illusions, a relatively rare archetype is the androgyne (Figures 164 and 208 in [48]). Therefore, these preliminary findings may indicate that the frequency of different archetypes can be correlated to the difficulty in the achievement of the process of individuation, according to Jung's ideas of the archetype of the Self $[39,48]$. A direction of future research is to compile a questionnaire made of a list of possible archetypes that persons perceive in their strange-face illusions.

In psychiatric patients, strange-face illusions are usually characterized by nigredo. Most schizophrenics [26] perceive skulls, suicidal doubles, and dangerous felines. Some schizophrenics describe angels and gods in their hallucinations, but, when they are placed in front of the mirror, they discover that angelical presences are, in fact, satanic strange-face illusions. Some schizophrenics, but 
none of the healthy individuals, experienced multiple concomitant apparitions of different people in the mirror surrounding their strange-faces. In contrast, most patients with major-depression (MD; [33]) do not perceive strange-face illusions, since they perceive their immobile faces without emotions, as death statues in the mirror [34]. Further research may be done in patients with body-dysmorphic-disorder (BDD; [57]) and anorexia nervosa (AN; [58]), who suffer from their bodily imaginary appearance that, in terms of their actual physical body, is strongly dissociated. Notwithstanding the important psychopathology of BDD and AN patients, relevant differences in perceptual processes with respect to healthy individuals have not been found in previous studies. A hypothesis is that BDD patients can be very vulnerable to strange-face illusions and project their unconscious self into archetypal images in the mirror: for example, AN patients might perceive strange-faces of fat archetypal shadows. In general, strange-face illusions might constitute a technique of psychotherapy, since patients directly perceive unconscious dissociated parts of their selves, which may henceforth be recast into the ego's awareness and possibly reintegrated. Re-absorbing projections involves affective empathy towards dissociated images. In alchemical psychology [39,59], this transformation is characterized as the dealbatio of sol niger into the specular bath of silver [60,61].

From previous research in healthy individuals [20,21], another finding is that a participant can often perceive different strange-face illusions, which can be classified into opposite archetypal contents or pairs of archetypes. Examples of strange-face archetypal pairs may be: the young man/woman and the old man/woman, the shining child and the very old man/woman, the unknown man and the unknown woman, the animal and the witch, and so on. This finding may agree with Jung's idea that the individuation process is produced through coniunctio oppositorum [39] or crossing conjunctions of archetypal opposites [60].

In conclusion, in my opinion mirror gazing at a low illumination level could be a tool for integration of unconscious contents, which are usually projected, toward individuation of the self.

\section{Conflicts of Interest}

The author declares no conflict of interest.

\section{References}

1. Gallup, G.G. Chimpanzees: Self-recognition. Science 1970, 167, 86-87.

2. Amsterdam, B. Mirror self-image reactions before age two. Dev. Psychobiol. 1972, 5, 297-305.

3. Rochat, P. Five levels of self-awareness as they unfold early in life. Conscio. Cognit. 2003, 12, 717-731.

4. Dimberg, U.; Thunberg, M.; Elmehed, K. Unconscious facial reactions to emotional facial expressions. Psychol. Sci. 2000, 11, 86-89.

5. Sonnby-Borgstrom, M. Automatic Mimicry reactions as related to differences in emotional empathy. Scand. J. Psychol. 2002, 43, 433-443.

6. Merleau-Ponty, M. L'oeil et l'esprit (in French); Gallimard: Paris, France, 1964.

7. Merleau-Ponty, M. The Child's Relations with Others. In the Primacy of Perception; Merleau-Ponty, M., Ed.; Northwestern University Press: Evanston, IL, USA, 1964; pp. 96-155. 
8. Rochat, P.; Zahavi, D. The Uncanny mirror: A re-framing of mirror self-experience. Conscio. Cognit. 2011, 20, 204-213.

9. Suddendorf, T.; Butler, D.L. The nature of visual self-recognition. Trends Cognit. Sci. 2013, 17, 121-127.

10. Bahrick, L.E.; Moss, L.; Fadil, C. Development of visual self-recognition in infancy. Ecol. Psychol. 1996, 8, 189-208.

11. Suddendorf, T.; Simcock, G.; Nielsen, M. Visual self-recognition in mirrors and live videos: Evidence for a developmental asynchrony. Cognit. Dev. 2007, 22, 185-196.

12. Butler, D.L.; Mattingley, J.B.; Cunnington, R.; Suddendorf, T. Mirror, mirror on the wall, how does my brain recognize my image at all? PLoS One 2012, 7, e31452.

13. Breen, N.; Caine, D.; Coltheart, M. Mirrored-self misidentification: Two cases of focal onset dementia. Neurocase 2001, 7, 239-254.

14. Villarejo, A.; Martin, V.P.; Moreno-Ramos, T.; Camacho-Salas, A.; Porta-Etessam, J.; Bermejo-Pareja, F. Mirrored-self misidentification in a patient without dementia: Evidence for right hemispheric and bifrontal damage. Neurocase 2011, 17, 276-284.

15. Feinberg, T.E. Neuropathologies of the self: A general theory. Neuropsychoanalysis 2010, 12, $133-158$.

16. Brugger, P. Reflective Mirrors: Perspective-taking in autoscopic phenomena. Cognit. Neuropsychiatry 2002, 7, 179-194.

17. Blanke, O. Multisensory brain mechanisms of bodily self-consciousness. Nat. Rev. Neurosci. 2012, 13, 556-571.

18. Ehrsson, H.H. The Concept of Body Ownership and Its Relation to Multisensory Integration. In The Handbook of Multisensory Processes; Stein, B., Ed.; MIT Press: Boston, MA, USA, 2012; pp. 775-792.

19. Tsakiris, M. My body in the brain: A neurocognitive model of body-ownership. Neuropsychologia 2010, 48, 703-712.

20. Caputo, G.B. Strange-face-in-the-mirror illusion. Perception 2010, 39, 1007-1008.

21. Caputo, G.B. Apparitional experiences of new faces and dissociation of self-identity during mirror-gazing. Percep. Mot. Skills 2010, 110, 1125-1138.

22. Rugens, A.; Terhune, D.B. Guilt by dissociation: guilt primes augment the relationship between dissociative tendencies and state dissociation. Psychiatr. Res. 2013, 206, 114-116.

23. Brewin, C.R.; Ma, B.Y.T.; Colson, J. Effects of experimentally induced dissociation on attention and memory. Conscio. Cognit. 2013, 22, 315-323.

24. Brewin, C.R.; Mersaditabari, N. Experimentally-induced dissociation impairs visual memory. Conscio. Cognit. 2013, 22, 1189-1194.

25. Caputo, G.B. Mask in the mirror: The living mask illusion. Perception 2011, 40, 1261-1264.

26. Caputo, G.B.; Ferrucci, R.; Bortolomasi, M.; Giacopuzzi, M.; Priori, A.; Zago, S. Visual perception during mirror gazing at one's own face in schizophrenia. Schizophr. Res. 2012, 140, 46-50.

27. Sass, L.A. Self-disturbance and schizophrenia: Structure, specificity, pathogenesis. Schizophr. Res. 2013, in press.

28. Caputo, G.B. Strange-face illusions during inter-subjective gazing. Conscio. Cognit. 2013, 22, 324-329. 
29. Wade, N.J. A Natural History of Vision; MIT Press: Cambridge, MA, USA, 2000.

30. Kihlstrom, J.F. The Domain of Hypnosis, Revisited. In The Oxford Handbook of Hypnosis; Nash, M.R., Barnier, A.J., Eds.; Oxford University Press: Oxford, UK, 2008; pp. 21-52.

31. Lipps, T. Leitfaden der Psychologie, dritte, teilweise umgearbeitete Auflage (in German); Engelmann: Leipzig, Germany, 1909.

32. Jung, C.G. Psychological Types. In Collected Works of C.G. Jung; Princeton University Press: Princeton, NJ, USA, 1971; Volume 6.

33. Disner, S.G.; Beevers, C.G.; Haigh, E.A.P.; Beck, A.T. Neural mechanisms of the cognitive model of depression. Nat. Rev. Neurosci. 2011, doi:10.1038/nrn3027.

34. Caputo, G.B.; Bortolomasi, M.; Ferrucci, R.; Giacopuzzi, M.; Priori, A.; Zago, S. Visual perception during mirror gazing at one's own face in depression patients. 2014, unpublished work.

35. Jung, C.G. The Relations between the Ego and the Unconscious. In Collected Works of C.G. Jung; Princeton University Press: Princeton, NJ, USA, 1972; Volume 7.

36. Watt, D.F.; Panksepp, J. Depression: An evolutionarily conserved mechanism to terminate separation distress? A review of aminergic, peptidergic, and neural network perspectives. Neuropsychoanalysis 2009, 11, 7-51.

37. Davis, M.H. Measuring individual differences in empathy: evidence for a multidimensional approach. J. Pers. Soc. Psychol. 1983, 44, 113-26.

38. Caputo, G.B. Empathy and Mirror-Gazing. In Neurobiology and Psychology of Empathy; Pankseep, J., Watt, D.F., Eds.; Nova Science: Hauppauge, NY, USA, 2014, in press.

39. Jung, C.G. Mysterium Coniunctionis. In Collected Works of C.G. Jung; Princeton University Press: Princeton, NJ, USA, 1977; Volume 14.

40. Jung, C.G. The Archetypes and the Collective Unconscious. In Collected Works of C.G. Jung; Princeton University Press: Princeton, NJ, USA, 1981; Volume 9, part 1.

41. Jung, C.G. On the Nature of the Psyche. In Collected works of C.G. Jung; Princeton University Press: Princeton, NJ, USA, 1970; Volume 8.

42. Jung, C.G. Synchronicity: An Acausal Connecting Principle. In Collected Works of C.G. Jung; Princeton University Press: Princeton, NJ, USA, 1970; Volume 8.

43. Atmanspacher, H.; Fach, W. A Structural-phenomenological typology of mind-matter correlations. J. Anal. Psychol. 2013, 58, 219-244.

44. Baltrusaitis, J. Le Miroir, essai sur une Légende Scientifique: Révélations, Science-Fiction et Fallacies (in French); Elmayan: Paris, France, 1978.

45. Gregory, R.L. Mirrors in Mind; Oxford University Press: Oxford, UK, 1996.

46. Ur group. Introduction to Magic; Inner Traditions: New York, NY, USA, 2001; originally published in 1927-1929.

47. Kerenyi, K. Dionysos; Langen-Muller: Munchen-Wien, Austria, 1976.

48. Jung, C.G. Psychology and Alchemy. In Collected Works of C.G. Jung; Princeton University Press: Princeton, NJ, USA, 1968; Volume 12.

49. Paracelsus, T.B. Archidoxis Magicae Libri VII (in Latin); Robert Turner: Genève, Swiss, 1656.

50. Paracelsus, T.B. De pestilitate (in Latin); Iohannes Huser: Basel, Swiss, 1599.

51. Moody, R.A. Family reunions: visionary encounters with the departed in a modern-day psychomanteum. J. Near-Death Stud. 1992, 11, 83-121. 
52. Hastings, A.; Hutton, M.; Braud, W.; Bennett, C.; Berk, I.; Boynton, T.; Dawn, C.; Ferguson, E.; Goldman, A.; Greene, E.; et al. Psychomanteum research: Experiences and effects on bereavement. Omega 2002, 45, 211-228.

53. Roll, W.G. Psychomanteum research: A pilot study. J. Near-Death Stud. 2004, 22, 251-260.

54. Terhune, D.B.; Smith, M.D. The induction of anomalous experiences in a mirror-gazing facility. J. Ner. Mentl Dis. 2006, 194, 415-421.

55. In his book The World as Will and Representation, Schopenhauer used the term 'mirror' always as a metaphor. According to Schopenhauer, the intellect, through knowledge, becomes free from will and exists in itself as a polished mirror of the world (chapter 27). In this way the individual becomes a pure subject like a pristine mirror in which an object of the world is reflected and, complementarily, the subject loses itself into that object (chapter 34). The scope of arts is to free the individual from will, in order to attain pure contemplation, like a mirror of the genius's spirit or of Platonic Ideas (chapter 51).

56. Miller, A.I. Deciphering the Cosmic Number: The Strange Friendship of Wolfgang Pauli and Carl Jung; Norton \& Company: New York, NY, USA, 2009.

57. Windheim, K.; Veale, D.; Anson, M. Mirror gazing in body dysmorphic disorder and healthy controls: effects of duration of gazing. Behav. Res. Ther. 2011, 49, 555-564.

58. Urgesi, C.; Fornasari, L.; Perini, L.; Canalaz, F.; Cremaschi, S.; Faleschini, L.; Balestrieri, M.; Fabbro, F.; Aglioti, S.M.; Brambilla, P. Visual body perception in anorexia nervosa. Int. J. Eat. Disord. 2012, 45, 501-511.

59. Hillman, J. Alchemical Psychology; Spring Publications: Dallas, TX, USA, 2011.

60. Jung, C.G. The Psychology of the Transference. In Collected Works of C.G. Jung; Princeton University Press: Princeton, NJ, USA, 1969; Volume 16.

61. Jung, C.G. Aion: Researches into the Phenomenology of the Self. In Collected Works of C.G. Jung; Princeton University Press: Princeton, NJ, USA, 1979; Volume 9, part 2. 


\title{
Chapter 8
}

\section{Carl Gustav Jung, Quantum Physics and the Spiritual Mind: A Mystical Vision of the Twenty-First Century}

\author{
Diogo Valadas Ponte ${ }^{1, *}$ and Lothar Schäfer ${ }^{2, *}$
}

1 Associação AVC (Cerebral Vascular Diseases), 4750-175 Barcelos, Portugal

2 Physical Chemistry, University of Arkansas, Fayetteville, AR 72701, USA

* Authors to whom correspondence should be addressed; E-Mails: diretor@associacaoavc.pt (D.V.P.); schafer@uark.edu (L.S.); Tel.: +351-253-812-547 (D.V.P.); Tel.: +1-479-575-5079 (L.S.).

\begin{abstract}
We describe similarities in the ontology of quantum physics and of Carl Gustav Jung's psychology. In spite of the fact that physics and psychology are usually considered as unrelated, in the last century, both of these disciplines have led at the same time to revolutionary changes in the Western understanding of the cosmic order, discovering a non-empirical realm of the universe that doesn't consist of material things but of forms. These forms are real, even though they are invisible, because they have the potential to appear in the empirical world and act in it. We present arguments that force us to believe, that the empirical world is an emanation out of a cosmic realm of potentiality, whose forms can appear as physical structures in the external world and as archetypal concepts in our mind. Accordingly, the evolution of life now appears no longer as a process of the adaptation of species to their environment, but as the adaptation of minds to increasingly complex forms that exist in the cosmic potentiality. The cosmic connection means that the human mind is a mystical mind.
\end{abstract}

Reprinted from Behav. Sci. Cite as: Ponte, D.V.; Schäfer, L. Carl Gustav Jung, Quantum Physics and the Spiritual Mind: A Mystical Vision of the Twenty-First Century. Behav. Sci. 2013, 3, 601-618.

\section{Introduction}

When René Descartes declared that the world consisted of two kinds of material, i.e., thinking substance and extended substance, and when Isaac Newton ([1], p. 400) declared that "God in the beginning formed Matter in solid, massy, hard, impenetrable, moveable Particles...so very hard, as never to wear or break in pieces", Western Science then became a form of materialism, and anything that wasn't matter didn't matter. When Darwin introduced Newton's materialism into biology, having-or-not-having stuff became the essence of life, and greed and aggression became the natural virtues of our society, segregating one individual from the next, one country from another, and one species from the next. In this way, the classical world was a segregative world, and all aspects of life were affected: The physical sciences had nothing to do with ethics, philosophy had nothing to do with the arts, and the order of the universe had nothing to do with the way in which we 
should live. As Jacques Monod described it: "Man must at last wake out of his millenary dream and discover his total solitude, his fundamental isolation. He must realize that, like a gypsy, he lives on the boundary of an alien world; a world that is deaf to his music, and as indifferent to his hopes as it is to his suffering or his crimes" ([2], p. 160).

In this totalitarian materialistic environment, Carl Gustav Jung had the courage to propose that our mind is guided by a system of forms, the archetypes, which are powerful, even though they don't carry any mass or energy, and which are real, even though they are invisible. The archetypes exist, as Jung ([3], pp. 43-44) described, in a "psychic system of a collective, universal, and impersonal nature". Out of this system, the invisible forms can appear in our mind and guide "our imagination, perception, and thinking".

As it turns out, Carl Gustav Jung's revolutionary views of the human mind are in perfect agreement with the discoveries of Quantum Physics, which, during the last century, also came as a shock, because they revealed the fundamental errors of Classical Physics and led to a radical change in the Western view of the world. The quantum phenomena now force us to think that the basis of the material world is non-material, and that there is a realm of the world that we can't see, because it doesn't consist of material things, but of non-material forms. These forms are real, even though they are invisible, because they have the potential to appear in the empirical world and to act on us. They form a realm of potentiality in the physical reality, and all empirical things are emanations out of this realm. There are indications that the forms in the cosmic potentiality are patterns of information, thought-like, and that they are hanging together like the thoughts in our mind. Accordingly, the world now appears to us as an undivided wholeness, in which all things and people are interconnected and consciousness is a cosmic property.

In this essay, we will describe the similarities between Carl Gustav Jung's psychology and Quantum ontology. Our description will show that Jung's teaching is more than psychology: it is a form of spirituality. By "spirituality", we mean a view of the world that accepts the numinous at the foundation of the cosmic order. In the same way, Quantum Physics is more than physics: it is a new form of mysticism, which suggests the interconnectedness of all things and beings and the connection of our minds with a cosmic mind.

\section{Quantum Physics and the Spiritual Foundation of the Empirical World}

If we want to characterize Carl-Gustav Jung's psychology in one sentence, we can say that Analytical Psychology, embodied in the archetype structure, leads us to the view that there is a part of the world that we can't see, a realm of reality that doesn't consist of material things but of non-material forms. These forms are real even though they are invisible, because they have the potential to appear in our mind and act in it. In the following sections, we will show that this view of the world is identical with the ontology of Quantum Physics. Our description is necessarily short, but the interested reader will find many details and references in our previous works [4-22]; particularly, in a recent book, "Infinite Potential. What Quantum Physics Reveals About How We Should Live" [23].

\section{The Basis of the Material World is Non-Material}


The first aspect of the quantum world that we have to consider concerns the fact that the basis of material things is not material. This view is in complete contrast to our experience of the world, but it follows from Schrödinger's quantum mechanics, which is currently the only theory that allows us to understand the properties of atoms and molecules. In this theory, the electrons in atoms and molecules aren't tiny material particles, little balls of matter, but standing waves or forms.

All atoms consist of a positively charged nucleus, which contains most of the mass of an atom, and of electrons, which are somehow arranged in the space surrounding the nucleus. Electrons are tiny elementary particles: they have a definite mass and, whenever we see one, it appears as a tiny dot: for example, as a flash on a TV screen or a little mark on a photographic film.

In contrast to their appearances, the electrons in atoms and molecules aren't tiny material particles or little balls, which run around atomic the atomic nuclei like planets around the sun, but they are standing waves: when an electron enters an atom, it ceases to be a material particle and becomes a wave. We owe Max Born for the discovery that the nature of these waves is that of probability waves. That is, the electrons in atoms are probability fields.

When this aspect of electrons first became known was unclear. What are probabilities? Probabilities are dimensionless numbers, ratios of numbers. Probability waves are empty and carry no mass or energy, just information on numerical relations. Nevertheless, the visible order of the world is determined by the interference of these waves. The interferences of atomic wave patterns, for example, determine what kind of molecules can form. In addition, the interferences of molecular wave forms determine how molecules interact. The molecules in your body, for example, interact in such a way that they keep you alive.

In view of these properties of the elementary units of matter, we have to conclude that the order of the visible world is based on phenomena, which transcend the materialism of classical physics. If one pursues the nature of matter to its roots, at the level of atoms and molecules all of a sudden one finds oneself in a realm of mathematical forms and numbers, where all matter is lost: Thus, one is led to the view that the basis of reality is nonmaterial.

In modern science, this finding was unexpected, and many scientists still don't accept it, but the idea isn't new. For example, in the sixth century B.C.E. Pythagoras ([24], p. 54) was already teaching that "all things are numbers" and that "the entire cosmos is harmony and number." In Plato's philosophy, atoms are mathematical forms. St. Augustine wrote in his Confessions: "The older I got, the more despicable became the emptiness of my thought, because I could think of no entity in any other way than as bodily visible". Moreover, Nicolas da Cusa, a fifteenth century German theologian, is credited with the statement: "Number was the first model of things in the mind of the Creator."

At this point, the reader may already note the importance of the quantum world for Carl Gustav Jung's psychology: The discovery of a realm of non-material forms, which exist in the physical reality as the basis of the visible world, makes it possible to accept the view that the archetypes are truly existing, real forms, which can appear in our mind out of a cosmic realm, in which they are stored. Thus, we can confirm here on the basis of the quantum phenomena Jung's view that "it is not only possible but fairly probable, even, that psyche and matter are two different aspects of one and the same thing" ([25], para. 418).

\section{Consciousness Is a Cosmic Property}


An important concept that arises in the Quantum phenomena concerns the wholeness of the physical reality. By the concept of wholeness, we mean that seemingly separated things can be connected and can act instantaneously on each other over arbitrarily long distances. In a holistic universe, decisions made by an observer in one part of the world can have an instantaneous effect on the outcome of processes somewhere else, an arbitrarily long distance away. For example, a thought that appears in my mind at this moment may instantly appear in your thinking somewhere else, in another part of the world. In physics, we speak of "nonlocality", when two particles, which at one time interact and then move away from one another, can stay connected and act as though they were one thing, no matter how far apart they are.

In the world of ordinary things, no influence or signal can travel at a speed faster than the speed of light. Thus, any action taken at one part of the world can have an effect somewhere else only after the time that it takes for a signal to get from one point to the other. In the quantum world, the situation is different: Influences can act instantaneously over arbitrarily long distances; in principle, from one end of the universe to another.

The aspect of the wholeness of reality can be described in a simple way in connection with the wave properties of elementary particles. In the previous section, we have seen how the electrons in atoms are waves. Whenever we see an electron, it appears as a material particle. However, inside an atom, it is a wave.

This metamorphosis of particles to waves and waves to particles is a general phenomenon that doesn't only describe the modes of existence of electrons, but is a characteristic of all elementary particles, atoms and molecules. It means that, whenever we see what we call an elementary particle, it appears as a tiny material thing at a specific position in space. In contrast, when such a thing is on its own, like when it is in a vacuum, it ceases to be a material particle and becomes a wave. You can think of this process as a spontaneous transition of what we see as a particle from its particle state to a wave state.

In "Infinite Potential" [23] this phenomenon has been described in the following way: At the foundation of the visible world we find Entities, which always appear to us as Elementary Things, when we interact with them. However, when they are on their own, they become waves. As waves, they have lost all mass, and they have become pure forms, patterns of information, something mindlike or thoughtlike. Accordingly, we can call the units of existence at the foundation of the world "ETs", meaning Elementary Things, of Elementary Thoughts; or, simply, EntiTies.

Being a localized material particle is one state of existence of an ET; being a non-material wave is another. As it turns out, the wave state is the preferred state of an ET: It is the home, where it will go, when it is left alone. As a wave, an ET has lost all of its mass. It has become a nonmaterial and invisible form and, since waves are extended in space, it has no specific position in space, but many potential positions. We say that an ET in its wave state is in a state of potentiality. Since material particles, whenever we see one, always appear with a specific mass at a specific point in space, we must conclude that ETs in a state of potentiality aren't a part of the empirical world. By making a transition into a wave state, an ET leaves the empirical world.

This phenomenon is general and cosmic: There is a realm of the universe that we can't see. It is a background of nonmaterial forms, not things. The forms are real, even though they are invisible, because they have the potential to appear in the empirical world and act in it. In fact, we must now 
think that the entire visible world is an emanation out of a non-empirical cosmic background, which is the primary reality, while the emanated world is secondary.

We can't really know what the nature of the ETs is in the non-empirical background of the world. Indications are that they have wavelike properties. If so, we must think that the background of the visible world is like an ocean. The ETs in this ocean are hanging together, like the water waves in an ocean do, so that the nature of reality is that of an indivisible wholeness.

The wholeness of the cosmic background is also suggested by the following consideration: If the ETs in the realm of potentiality wouldn't form a coherent whole, the empirical world that is emanating out of the cosmic potentiality would be chaotic. However, the visible isn't chaotic. Rather, it always appears to us as a coherent system.

As patterns of information, the ETs in the realm of potentiality are more thoughtlike than thinglike. Thoughts usually appear in a conscious mind. Thus, the appearance of thoughtlike forms in the cosmic potentiality suggests that consciousness is a cosmic property. The universe is conscious and our thinking is the thinking of the cosmic mind, which finds consciousness in us!

The same conclusions follow from the holistic nature of reality. For example, in their book, "The Conscious Universe", Menas Kafatos and Robert Nadeau [26] have argued that, if the universe is an indivisible wholeness, everything comes out of this wholeness and everything belongs to it, including our own consciousness. Thus, consciousness is a cosmic property.

This quantum view of a holistic reality is in perfect agreement with one of Jung's most important seminal ideas; that is, the archetypal idea of Unus Mundus, which Jung [27] and Marie-Louise von Franz [28] derived from characteristic medieval views of the world. In Jung's words:

"Undoubtedly the idea of the Unus Mundus is founded on the assumption that the multiplicity of the empirical world rests on an underlying unity, and that not two or more fundamentally different worlds exist side by side or are mingled with one another. Rather, everything divided and different belongs to one and the same world, which is not the world of sense.” ([27], para. 767).

Ontologically, this archetype means that there is a reality that must be united, "apparently" divided, opposed, but beyond the illusion of matter, it is One. The reader will note the agreement of Jung's views with the quantum view of the world that we have described above.

The process of individuation is an innate capacity of the individual to become aware of the Self. According to Robert K. C. Forman [29], we have an innate capacity, which is an imperative, long life process of transformation. This is an impulse to unite what is divided. In "The Archetypes and the Collective Unconscious" Jung affirms that "I use the term 'individuation' to denote the process by which a person becomes a psychological 'in-dividual', that is, a separate, indivisible unity or "whole"” ([3], p. 275). Searching for wholeness would be meaningless in a Newtonian world of separate material things. In the quantum world, it has found a physical basis.

Jung also understood the process of individuation as a religious impulse, which is a wholesome spiritual archetype that directs and coordinates the flow of human life. The word religious is used in this context in the sense of its etymological roots, in which Re-Ligare means "to reconnect," or "to be in bond," or "to re-unite". As Anniela Jaffé wrote: 
"Individuation must be understood in religious language as the realization of the 'godly' in the human, as the fulfilling of a 'godly mission'. The conscious experience of life becomes a religious experience, one could just as well say, a mystical experience.” ([30], pp. 14-15).

Another characteristic aspect of Jung's work is his fascination with Alchemy [31] and, specifically, with the Philosophers' stone as a metaphor of the process of individuation. Jung considered this process as a transformational journey into the wholeness, in which we bring the invisible to the visible, spiritualize matter and materialize the spiritual. In "Septem Sermones ad Mortuos" (The Seven Sermons to the Dead, re-published in the recent Red Book, Jung, [32]), he uses the Gnostic term "Pleroma" to refer to the wholeness.

In agreement with the aspects of wholeness that appear in the quantum view of the universe, Jung believed that the psyche has a natural and innate urge toward wholeness. Henderson has pointed out that

"a sense of completeness is achieved through a union of the consciousness with the unconscious contents of the mind. Out of this union arises what Jung called 'the transcendent function of the psyche', by which a man can achieve his highest goal: the full realization of the potential of his individual Self." ([33], p. 149).

The craving for the wholeness is the real "opus" that underlies all of Jung's work. In accordance with quantum physics, the meaning and purpose of our nature is anchored in the numinous realm of reality. As Jung describes the spiritual quest:

"The main interest of my work is not concerned with the treatment of neurosis, but rather with the approach to the numinous. But the fact is that the approach to the numinous is the real therapy, and inasmuch as you attain to the numinous experience, you are released from the curse of pathology. Even the very disease takes on a numinous character.” (Jung cit. in [30], p. 16).

As we have pointed out before [21,22] the path of Ethos needs a non-empirical domain of reality. This invisible realm, which Jung assumed as "psychoid", provides an infinite field for the progress of the Ego-Self axis relation, nurturing consciousness as an element in which every phenomenon collapses. Quantum physics brings us a new kind of reality, in which it is our task to unlock our potential and to free us from our ignorance, the biggest shadow of all. In agreement with Jung's analytical psychology, Quantum physics provides us with direct suggestions of how we can live in accordance with the numinous realm of the universe.

Joseph Campbell [34] has used the metaphor of the hero to describe the process in which the Ego unites with the self. In the first half of our life, our Ego is separated from our unconscious. However, after this period, it has a longing to reach a primordial state of wholeness, facing all kinds of dangers and trials. The Portuguese language has a specific word for this longing: that is, saudade. We find this myth in countless ancient spiritual teachings (cf. [34]), in the writings of the classical poets, and now it reappears in the worldview of quantum physics. Anniela Jaffé writes:

"in religious language an image of a God who seeks man just as much He is sought by man. God seeks the individual in order to realize himself in his soul and his life. Expressed psychologically: the Self requires the ego-personality in order to manifest itself; the 
ego-personality requires the Self as the origin of its life and its fate. In religious language this means 'God needs man, just as man needs God'.” ([30], pp. 17-18).

As Jung wrote to Erich Neumann: "God is a contradiction in terms, therefore he needs man in order to be made One... God is an ailment man has to cure.” ([30], p. 99).

\section{Eddington's Views of a Conscious Universe}

In the 1930s, Sir Arthur Stanley Eddington a prominent British astrophysicist, was one of the first physicists who systematically searched for aspects of consciousness in the universe, concluding that "The universe is of the nature of 'a thought or sensation in a universal Mind"” ([35], p. 151).

One of Eddington's arguments was based on the fact that, when physicists make measurements, their observations make sense, because the measuring instruments are connected with a meaningful background of the objects that are measured. For example, when we observe the movement of a light dot through the sky at night, our observations make sense because we know the planetary background, where the planets revolve about the sun. In this situation, Eddington pointed out, observations of atoms are a problem, because their background isn't known. Whenever we see an atom, we can see phenomena that occur at its surface, but we don't know, what happens inside. Why is the background of atoms not known and even unknowable? Because, for example, as we have described above, the electrons in atoms are nonmaterial, nonempirical forms, and we don't know what that means. "Now we realize", Eddington ([36], p. 259) wondered, "that science has nothing to say as to the intrinsic nature of the atom".

If science has nothing to say about the building blocks of the visible world, it is a problem that must be addressed. As it turns out, it isn't the only puzzle of its kind. A similar situation arises, for example, in neurology, where no measurements of the surface of a brain can tell us what is going on in the mind behind it.

In spite of this similarity, watching a brain is fundamentally different to watching an atom. This is so, because behind the surface of a brain there is a mind and a person, who can tell, what is going on in this mind. In contrast, atoms aren't connected with elementary persons who live inside and can tell us what is going on behind the surface. Nevertheless, Eddington suggested thinking of the two situations together, that of the brain and that of the atom, and he concluded that the background of atoms is mindlike. Since we need something to which we can attach the measurements of an atom,

"why not then attach it to something of spiritual nature of which a prominent characteristic is thought. It seems rather silly to prefer to attach it to something of a so-called 'concrete' nature inconsistent with thought, and then to wonder where the thought comes from" ([36], p. 259).

The last part of this statement is a surprise: we usually take our thinking for granted, and the thoughts in our mind tell us a lot of things, but they say nothing about where they are coming from! Is our mind an invention of our brain? Or, do we have a mind because the background of the universe is mindlike and expresses itself in our mind? To Eddington the "unity" of the universe made it necessary to conclude that, behind all empirical appearances of the world, "there is a background continuous with the background of the brain" ([36], p. 312). Unity in this context means coherence. That the universe is a coherent system can be suggested on the basis of the unity of our mind: "If the 


\section{4}

unity of a man's consciousness is not an illusion, there must be some corresponding unity in the relations of the mind-stuff, which is behind [the visible surface of things]" ([36], p. 315). Thus, from our inner sense of unity we infer the unity of the world. If the universe wasn't a coherent system, but a random collection of disconnected piles of material debris, the unity of our thinking would be an illusion. On the other hand, if the universe is a coherent whole, the existence of our personal mind suggests that the background of the universe is mindlike.

In this way, Eddington was lead to the conclusion that,

"The universe is of the nature of 'a thought or sensation in a universal Mind'...To put the conclusions crudely - the stuff of the world is mind-stuff. As is often the way with crude statements, I shall have to explain that by 'mind' I do not here exactly mean mind and by 'stuff' I do not at all mean stuff. Still this is as near as we can get to the idea in a simple phrase" ([36], pp. 259-260).

Eddington ([36], p. 281) realized that his views were alien to physics. "It is difficult for the matter-of-fact physicist to accept the view that the substratum of everything is of mental character."

However, this is a problem of physics, not of Eddington's theses, and it shows the inability of the physical sciences to describe all the essential aspects of the universe.

Even though they are controversial, Eddington's theses are in perfect agreement with Carl Gustav Jung's basic assumptions, and with the quantum phenomena, which show us that there is a part of the world that we can't see, a background of potentiality, that doesn't consist of things, but of forms. These forms are thought-like, not thing-like, and they are real because they can actualize in the empirical world and act in it. As a matter of fact, the entire empirical world now appears to as an emanation out of a realm of invisible forms.

The agreement, if not identity, with Jung's basic theses is striking: our conscious thinking is based on an emanation of forms out of a non-personal, that is, cosmic realm.

"Consciousness is not sharply defined", Eddington [36] explained, "but fades into subconsciousness; and beyond that we must postulate something indefinite but yet continuous with our mental nature. This I take to be the world-stuff". We compare the mind-stuff "to our conscious feelings," Eddington concluded, "because, now that we are convinced of the formal and symbolic character of the entities of physics, there is nothing else to liken it to" ([36], p. 280).

\section{Quantum Physics Is the Psychology of the Universe}

An important concept in quantum chemistry is the concept of virtual states: virtual states are the empty states of atoms and molecules. (For a more detailed description of the concept of virtuality in chemistry, with additional examples, see "Infinite Potential" [23].

All atoms and molecules exist in quantum states. You can think of a molecule like of a mountain range with countless hills and valleys. Each valley is an energy hole, which contains an energy ladder. The steps of these ladders represent fixed, or quantized, amounts of energy: they are the quantum states of a molecule. Each molecule must occupy one of its states - it must stand on one of the steps of its ladders - so that a large number of states are empty. Quantum chemists call the empty states of things their virtual states. Virtual states are mathematical forms or patterns of information. 
They have the forms of waves, but these waves are invisible, because they are empty: there is nothing there to see. But they are real and they truly exist, even though we can't see them, because a molecule can jump into such a state and make it a visible state. You can think of virtual states as the logical structure of a system, which contains its future empirical possibilities: All that a molecule can do is to jump from an occupied state into a virtual state.

In an empirical science the appearance of entities, which have no matter, no energy and are invisible, is an embarrassment. You can very well compare the situation to Jung's thesis that behind our conscious thinking there is a realm of unconscious forms. If you have to describe the world by referring to an invisible, numinous realm of reality, you are leaving the realm of empirical science. Thus, many of the pioneers of quantum physics tried to explain the virtual states away as mere constructs that don't really exist. However, we have no choice: we have to think that the empty states of atoms and molecules are real, because they can control empirical phenomena.

For example, all chemical reactions are steered by the virtual states of the reacting molecules, which determine what kinds of molecules can form in a reaction. In a specific type of reactions, called Redox reactions, the products appear with characteristic magnetic properties, which are determined by their virtual states. In addition, oxygen can serve our metabolism, because it contains what chemists call degenerate states. Degenerate states are invisible and yet they are the basis for the particular reactivity of oxygen.

There is no doubt: invisible virtual states are real. Since their inner forms can affect visible phenomena, they must be truly existing, real entities. Molecules are guided in their actions by the wave forms of their virtual states, like by inner images.

The concept of the inner images derives from psychology. Brain scientist Gerald Hüther ([37], p. 17) calls inner images all that "which is hidden" behind the visible surface of living beings and steers their actions. Similarly, Jung [3] believed that archetypal images exist in our consciousness, which are manifestations of the pure forms of archetypes, which are unknowable.

In chemistry, a molecule doesn't do anything that isn't allowed by a wave form - an inner image - of one of its virtual states. In life, a human being does nothing that isn't allowed by an inner image of the mind. There is an equivalence of the mental and the physical. Psychology is the physics of the mind: Quantum physics is the psychology of the universe.

\section{Quantum Wave Functions Are Archetypes}

It is no accident that the development of psychology as a science took a quantum leap after 1900 C.E, when the era of the Classical Sciences came to an end and the Quantum era began. Jung's view of the human psyche presupposes a structure of the universe that is in perfect agreement with the Quantum universe, but impossible in Newton's world. For example, Jung's assumption that an invisible part of the world exists, which doesn't consist of material things, but of forms - the archetypes - is unacceptable in a Newtonian universe, in which all phenomena depend on the properties of matter.

Jung's collective unconscious is a non-personal part of the human psyche. It is a realm of forms - the archetypes - which can appear spontaneously in our consciousness and act in it, influencing "our imagination, perception, and thinking" ([3], p. 44). The archetypes are "typical 


\section{6}

modes of apprehension" ([25], p. 137), which shape, regulate and motivate the conscious forms in our mind in the same way, in which the virtual states of atoms and molecules shape and control empirical phenomena. We must constantly reach into the realm of the archetypes and actualize their virtual forms, in order to be able to live and to give meaning to life.

We have described above, how molecules are guided in their actions by the wave forms of their quantum states, like by inner images. Since the inner images control all the processes of the world, they must have guided, too, the evolution of life. In this way, biological evolution appears primarily not as an adaptation of life forms to their environment, but as the adaptation of minds to increasingly complex forms - archetypes - in the cosmic potentiality. In our minds, the cosmic forms appear as thoughts; in the physical reality they appear as material structures. We can understand the world, because the forms within our mind and the structures of the world outside, both derive from the same cosmic source.

It makes sense to think that all of reality is like the reality of the atoms. That is, behind the visible surface of things there is a realm of invisible forms, which have the potential to appear in the empirical world and act in it. As pointed out above, we can think of this realm like of an ocean, whose waves are hanging together and are mind-like, so that the universe now appears as an indivisible wholeness, and consciousness is a cosmic property.

The appearance of the archetypes in our mind shows our connection with a transpersonal order. Beyond the narrow confines of our personal psyche, Jung pointed out, the collective unconscious is

"a boundless expanse full of unprecedented uncertainty, with apparently no inside and no outside, no above and no below, no here and no there, no mine and no thine, no good and no bad...where I am indivisibly this and that; where I experience the other in myself and the other-than-myself experiences me... There I am utterly one with the world, so much a part of it that I forget all too easily who I really am.” ([3], p. 21).

Idealist philosophers and mystics have pursued such ideas through the ages. In the nineteenth century, for example, Georg Wilhelm Friedrich Hegel taught that "Absolute Spirit" is the primary structure of the universe. Everything that exists is the actualization of spirit, and everything is connected with it. Spirit is everything, creates everything, and thinking and being, subject and object, the real and the ideal, the human and the divine - all are One. Thus, Hegel concluded, our thinking is the thinking of the Cosmic Spirit, who is thinking in us.

Thousands of years prior to Hegel, the Indian Sages invented the allegory of the water pots, which are filled with water and placed into the sun: You can see the sun in each one of them, but there is only one sun. Similarly, you can find consciousness in countless human minds, but there is only one consciousness: the Cosmic Consciousness.

The word, "consciousness" derives from the Latin, "con" and "sciencia", and it means a state of "knowing together". Interestingly, when we speak of our consciousness and that of other people, we always speak of "our consciousness", and never use the plural form, speaking of our consciousnesses. There is no plural form, because there is only one consciousness: the cosmic consciousness. If our personal consciousness is merely a part of a cosmic system, it isn't amazing that archetypes can appear in our mind and act in it. 
By the way, in which it describes the world, quantum physics has taken science into the center of ancient spiritual teachings. For example, molecular wave functions have no units of matter or energy. They are pure, non-material forms. The same is true for Jung's archetypes: like the wave functions of quantum systems, they are pure, non-material forms. In Aristotle's metaphysics, all things are mixtures of matter and form. There was only one pure form: God.

The name that quantum chemists have given the empty states of atoms and molecules - that is, calling them "virtual states" - is a peculiar expression and one wonders, where it is coming from? As it turns out, the concept wasn't invented by quantum chemists, but by Meister Eckhart, a medieval Dominican Monk and Mystic. "The visible things are out of the oneness of the divine light", Meister Eckhart (cit. in [38], pp. 63-64) wrote, and their existence in the empirical world is due the "actualization of their "virtual being",

What a stunning phenomenon! The same unusual term appears in the mind of a medieval mystic and then, hundreds of years later, in the mind of a quantum chemist. The example shows, that absolute truths can appear, again and again, with the same messages, through thousands of years, in different minds, different ages and different parts of the world. It is difficult to avoid the impression that our minds are connected to a cosmic realm of thoughts: the realm of Jung's archetypes.

Jung's archetypes and the wave functions of quantum states are so similar that we could think of the archetypes as the virtual state functions of our mind; and we could speak of the virtual quantum wave functions as the archetypes of the physical reality. Because they "have never been in consciousness" before ([3], p. 42), the archetypes appear out of a nonempirical realm of the world. For each one of us the birth of a conscious self is out of a realm of nonempirical forms, in the same way in which the birth of an empirical world is out of a realm of virtual states. It is difficult to avoid the conclusion that the two families of forms have their home in the same cosmic realm; that is, in the realm of the cosmic consciousness. "That the world inside and outside ourselves rests on a transcendent background is as certain as our own existence." (Jung cit. in [30], p. 4).

\section{Synchronicity and the Mindlike Background of the Universe}

Carl-Gustav Jung is primarily recognized as a revolutionary psychiatrist and psychotherapist. However, the aspects of the psyche that he discovered are so profound, that they go beyond the limited concerns of the human psyche, making it possible to think, for example, that the universe itself is conscious and our own consciousness is connected with the cosmic consciousness.

In Jung's theories, the concept of synchronicity plays an important role. Jung's German term, sinngemäße Koinzidenz, means a "coincidence according to meaning". It is usually translated as "meaningful coincidence", referring to the coincidence of two or more events, and it describes phenomena in which an event in the external world coincides meaningfully with a psychological state of the mind; that is, two or more events are connected in meaning but not in their visible causes. As Jung ([25], para. 858) describes it, in the simultaneous appearance of synchronistic events "something other than the probability of chance is involved". Specifically, synchronicity "consists of two factors: (a) A unconscious image comes into consciousness either directly (i.e., literally) or indirectly (symbolized or suggested) in the form of a dream, idea, or premonition. (b) An objective situation coincides with this content. The one is as puzzling as the other." 
When someone dreams of an unusual event, and the next day that same event actually happens in another part of the world, then we are dealing with a case of synchronicity. As Jung ([25], pp. 520-531) pointed out, such experiences are particularly stunning, when an inner mental state coincides with an external event that "takes place outside the observer's field of perception, i.e., at a distance, and only verifiable afterward".

In the framework of classical physics, coincidences according to meaning are impossible as non-random events. That is, classical physics doesn't allow causally connected, physical phenomena, which don't involve the exchange of physical energy or forces. Jung ([25], pp. 520-531) was aware of this problem. "No one has yet succeeded", he wrote, "in constructing a causal bridge between the elements making up a synchronistic coincidence". Nevertheless, he had no doubt that synchronicity was a real phenomenon that is "based on some kind of principle, or on some property of the empirical world". The quantum phenomena make it now possible to identify this property. However, as it turns out, it isn't a property of the empirical world, but it involves the non-empirical realm of reality.

We have seen above that the phenomena of quantum physics force us to conclude that reality appears to us in two domains. There is the domain of the empirical, energetic and material things: the realm of the actuality of the visible phenomena. However, in addition, behind the visible surface of things is a hidden, invisible and non-empirical domain that doesn't consist of things, but of nonmaterial and nonempirical forms: the realm of the potentiality of the universe. You could think that the visible world is something like the consciousness of the universe; while the hidden part is its unconscious.

We have said that the nonempirical forms in the cosmic realm of potentiality are real, because they have the potential to appear in the empirical world and act in it. They can do this in two ways. They can appear as thoughts and images in our conscious mind; and as material structures and events in the external world. When one and the same form appears, at the same time, both as a thought and as an external event, a mental process and an empirical occurrence express the same meaning, and we experience a synchronistic event. In a Newtonian world, such events are impossible; in a quantum world, they must occur. We can't know what causes such events, because their causes, if any, are nonempirical. However, we can understand that synchronistic events are possible, because the universe is an indivisible wholeness that is aware of its processes, like a Cosmic Spirit. Thus, we are led again to Hegel's thesis that a Cosmic Spirit is thinking in us.

The lack of visible causal connections is an interesting aspect of synchronistic events. However, in the same way in which quantum events seem random, but are really caused by some nonempirical processes, so the randomness of synchronistic events is only an apparent randomness. The cosmic spirit is unfathomable, but not arbitrary or mindless.

Synchronicity can involve more than a single mind and more than a few events. In the early 1900 s, for example, Europe went through an era of revolutionary changes, which affected all aspects of life and show all the characteristics of synchronistic events. In 1900, for example, Sigmund Freud invented psychoanalysis, and Max Planck founded quantum physics. In 1903, Henry Ford founded the Ford Motor Company, and the Wright Brothers succeeded in the first human motor flight. In 1905, Albert Einstein developed Relativity Theory, and in Paris the first modern art show presented paintings by André Derain and Henri Matisse. In 1907, Cubism was developed by Georges Braque and Pablo Picasso. In 1910, Arnold Schönberg wrote the first composition of atonal music. In 1912, 
Wassily Kandinsky invented abstract painting. In 1913, Franz Kafka published his short stories. In 1914, James Joyce wrote The Dubliners and the First World War began, and 1917 was the year of the Russian Revolution.

All of these developments were revolutions in their corresponding fields. We perceive a synchronistic connection between these revolutions, because they had a common meaning: that is, each one of them took a given field away from the visible surface of things into a hidden, abstract and more fundamental realm of the world. For example, when quantum physicists discovered the nonempirical realm of the world, the painters of Modern Art began to search for the essence of things behind their visible surface; and psychologists discovered the hidden power of the unconscious. As Werner Haftmann [39] explains in his fascinating book Painting in the 20th Century, paintings became "evocative" and stopped being "reproductive". When physicists abandoned the notion of the eternal point like particle in quantum physics, the visual artists abandoned, in abstract paintings, the infinite point of perspective, which was the cornerstone of all classical paintings. In "Infinite Potential" [23], the reader can find additional facts, which show in a stunning way that the cultural and political revolutions that rocked Europe in the early twentieth century consist of a sequence of synchronistic events.

There was little physical contact or direct communication between the various pioneers of that time. The physicists, for example, didn't invent the phenomena of quantum physics by pondering the paintings of modern artists. Modern art wasn't invented by artists, while they listened to atonal music. Rather, the different minds were connected in the wholeness of the mindlike background of the cosmic potentiality: The cosmic spirit was at work in a synchronistic process.

By guiding the processes of our mind, the cosmic potentiality has shown its mindlike properties. The mental isn't fractured in the universe in isolated islands, but its thoughts form an ocean of thoughts that fills the entire world.

\section{Conclusions}

By studying the human psyche, Jung discovered mental properties of the universe, which Classical physics had suppressed: Quantum physics has now brought them back.

"If Materialism is false", writes Imants Baruss ([40], p. 41), "then what is true?" In "Infinite Potential" we have answered this question in many ways [23]. The facts show us that there is a non-empirical realm of reality, that doesn't consist of things, but of forms. These forms are real, even though they are invisible, because they have the potential to appear in the empirical world and act in it. They can do this in two ways: they can find consciousness as thoughts in our mind; and actualize as material structures in the external world. Thus, the conscious and empirical world is an emanation out of a realm of mind-like forms, and quantum physics is a form of psychology, the psychology of the cosmic mind. In the same way Jung's psychology is also a branch of physics; that is, the physics of the mental order of the universe.

A holistic universe is necessarily a mystical system. Scientific theories, which claim that all things and people are interconnected in a non-empirical realm of the world, are necessarily mystical theories. Jaffé has described the same conclusion in the following way:

"Both Jungian psychology and mysticism deal with the experience of the numinous. The difference is that mysticism speaks of an encounter with God and lets the matter test at that. 
Jungian psychology also speaks of an encounter with God, in the sense that 'God' represents the word or the designation for something incognizable and incomprehensible. For both God is a primordial human experience..." ([30], p. 12).

Thus, Quantum physics is a form of mysticism; and so is Jung's psychology. One hesitates to express such conclusions, but the form of mysticism that we find in contemporary science is different from its historic forms. This is so, because our concepts evolve in the same way in which our bodies evolve.

The evolution of our thinking is characterized by the fact that there are truths regarding the order of the world, which are so fundamental that they have appeared again and again, in the minds of different people, in different ages and in different parts of the world. The Indian sages called this phenomenon Sanatana Dharma. In the sixteenth century, Agostino Steuco, an Italian humanist, introduced the concept into Western philosophy as "perennial philosophy". We consider this phenomenon as a special form of synchronicity. It shows that our mind is a mystical mind, because it is connected with a cosmic background that has mindlike properties: That is, a cosmic mind.

For some reason, in our history, worldviews have always been accompanied by threats. That is, if you didn't believe a certain story of how the world was created by God, you were threatened to go to hell, and it isn't too long ago, that dissidents were really put on fire. Similarly, a scientist may find herself fired out of her job in no time, when she dares to question the narrow mind frame of the contemporary sciences!

Ancient concepts of the world are constantly reemerging in our thinking, but they are doing this in an evolving way. For example, Plato's claim, that true reality resides in a realm of ideas outside of the visible world, is very similar to the claim that the empirical world actualizes out of a realm of virtual quantum forms. Nevertheless, the quantum view isn't identical with the Platonic view. Rather, it is mathematical, quantitative and it has led to countless practical applications that have changed our way of life. In the same way, Jung's descriptions of the human psyche may be similar to ancient views, but they are evolved versions of ancient views. We believe that the evolution of concepts and their understanding is the true function of biological evolution. It is impossible to know, whether we are evolving with the cosmic mind, or whether it is merely our mind that has to evolve to a better understanding of a non-evolving cosmic order.

The practice of mysticism is an example of an evolving process. When we say that Quantum physics and Jung's psychology are modern forms of mysticism, we don't mean that they are identical with ancient religious practices. Rather, they share essential aspects with ancient practices in an evolved way. In her appealing book, “Was C. G. Jung a Mystic?”, Aniela Jaffé [30] has described fascinating aspects of Jung's mysticism, which confirm our view:

"If the concept 'mystic' suggests the immediate experience of the numinous or the perceiving of an originally hidden transcendent reality, the 'other side', then it involves an experience which also plays a central role in Jung's approach to analytical psychology; that is, the consideration of images and contents which enter into consciousness from the hidden background of the psyche, the collective unconscious. (...) [which] must be conceived of as a realm with neither space nor time that eludes any objective knowledge. What we perceive are its effects." ([30], pp. 1-2). 
At this point of our analysis, we might ask: Does it all matter? Why should we care? Our answer is the belief that happiness in this life can be found only by understanding the spiritual background of the universe, and by living in accordance with it. Carl Gustav Jung has shown that, living in accordance with the order of the universe is a prerequisite for a wholesome life. This means that we have to recognize the invisible background of reality and accept the importance of spirit in our life.

As shown in "Infinite Potential" [23], the quantum phenomena corroborate Analytical Psychology in the sense that the invisible layer of reality is not only the source but also the goal of our human significance. Influenced by Hindu Advaita philosopher Sankara, Forman has expressed similar ideas:

“One's atman [wholeness] cannot be 'produced' or 'attained', for it is already present (...) is the natural condition of the human spirit (...) The activity that seems to bring about the experience of it does so only by destroying the bondage that had hidden it. We are only revealing what had been present all along but hidden: atman. The mystic's techniques are not 'producing' something new but 'revealing' something preexistent: 'Thought Atman is an ever present reality, yet because of ignorance It is unrealized. On the destruction of ignorance, Atman is realized. It is like the case of the ornament on one's neck.' Discovering Atman [wholeness] is like finding a necklace hanging on one's neck: it has always been present and is indeed available, just overlooked. This image emphasizes that atman, and with it the possibility of its realization, is already present to one. It is, in a word, innate." ([41], p. 8).

The state of being innate upholds a Cosmic Order that lets us think that we are part of it, that we are born in it and that we are it, but we don't know it. In agreement with Jung's Weltanschauung, Quantum physics confirms William James' thesis, that twenty-first century science can no longer deny the non-empirical:

"[The] unseen region in question is not merely ideal, for it produces effects in this world. When we commune with it, work is actually done upon our finite personality, for we are turned into new men, and consequences in the way of conduct follow in the natural world upon our regenerative charge. But that which produces effects within another reality must be termed a reality itself, so I feel as if we had no philosophical excuse for calling the unseen or mystical world unreal." ([42], p. 516).

The view that reality has a non-empirical background can be found at various times in the history of philosophy. We find it, for example, in the theses of the Greek Pythagorean philosopher Timaeus of Locri (420-380 BCE). "God is a circle", he wrote, "whose center is everywhere and circumference nowhere".

The main goal of every spiritual tradition is to unite with the transcendent reality. Different traditions may give different names to the divine, but in all of them we find the same desire to become one with the Divine. Psychically, that state can adopt the symbolic and transformational meaning of rebirthing, synonymous with becoming one with the Self:

"To the Indian it is clear that the self as the originating ground of the psyche is not different from God, and that, so far as a man is in the self, he is not only contained in God but actually is God. Shri Ramana is quite explicit on this point. (...) The goal of Eastern religious practice is the 
same as that of Western mysticism: the shifting of the center of gravity from the ego to the self, from man to God. This means that the ego disappears in the self, and man in God" ([43], p. 581).

Jung's teaching is an incredible achievement and a blessing for humanity. He has shown that we are connected with a non-empirical realm of the universe, in which we can find our cosmic task. Denying the transcendent aspects of our nature can lead to serious problems for our physical health and spiritual well being. Our cosmic task isn't the task of slaves, who have to serve their creator. We are not the slaves of the cosmic spirit, but, rather, we are it, if only we try!

\section{Acknowledgments}

The authors thank António Cunha and Rita Almeida for their generous support of this project; and their wives, Joana Gomes and Gabriele Schäfer, for their untiring encouragement.

\section{Conflicts of Interest}

The authors declare no conflict of interest.

\section{References}

1. Newton, I. Opticks, 2nd ed.; Dover Publications: New York, NY, USA, 1979; first published in 1704.

2. Monod, J. Chance and Necessity; Collins: London, UK, 1972.

3. Jung, C.G. The Archetypes and the Collective Unconscious; Princeton University Press: Princeton, NJ, USA, 1969; Collected Works, Volume 9.

4. Schäfer, L. Die Quantenwirklichkeit als Manifestation eines kosmischen Bewußtseins und Grundlage für ein neues Bild vom Ursprung des Lebens. In Theologie und Naturwissenschaft (in German); Vogelsang, F., Ed.; Evangelische Akademie im Rheinland: Bonn, Germany, 2006; pp. 245-252.

5. Schäfer, L. In Search of Divine Reality; University of Arkansas Press: Fayetteville, AR, USA, 1997.

6. Schäfer, L. Em Busca de la Realidad Divina (in German); Lumen Publishing: Buenos Aires, Argentina, 2007.

7. Schäfer, L. Nicht-Empirische Wirklichkeit: Die Quantenwirklichkeit als Grundlage der Prä-Darwinistischen Konzeption der Evolution aus der Gesetzlichkeit der Natur. In Herausforderungen und Grenzen wissenschafticher Modelle in Naturwissenschaften und Theologie (in German); Vogelsang, F., Ed.; Evangelische Akademie im Rheinland: Bonn, Germany, 2007; pp. 169-176.

8. Schäfer, L. Versteckte Wirklichkeit: Quantentheorie und Transzendenz als Grundlage für ein neues Bild vom Ursprung des Lebens. In Glaube und Denken. Jahrbuch der Karl- HeimGesellschaft 20. Jg. 2007 (in German); Rothgangel, M., Beuttler, U., Eds.; Peter Lang GmbH: Frankfurt am Main, Germany, 2007; pp. 197-222.

9. Schäfer, L. Versteckte Wirklichkeit-Wie uns die Quantenphysik zur Transzendenz führt (Hidden Reality: How Quantum Physics Will Lead Us to Transcendence); Hirzel: Stuttgart, Germany, 2004. 
10. Schäfer, L. Die Bedeutung der Quantenwirklichkeit für das Verständnis lebender Systeme. Available online: http://www.auditorium-netzwerk.de/Neuerscheinungen-2010/Neuerscheinungen -Juni:::6424_7246.html (accessed on 24 September 2013).

11. Schäfer, L. Die Quantenphysik und die Philosophia Perennis. Grenzgebiete der Wissenschaften 2011, 60, 99-123, (in German).

12. Schäfer, L. Electron Diffraction as a Tool of Structural Chemistry. J. Appl. Spectros. 1976, 30, 123-149.

13. Schäfer, L. The gradient revolution in structural chemistry: The significance of local molecular geometries and the efficacy of joint quantum mechanical and experimental techniques. J. Mol. Struct. 1983, 100, 51-73.

14. Schäfer, L. Nonempirical reality: Transcending the physical and spiritual in the order of the One. Zygon 2008, 43, 329-352.

15. Schäfer, L. Paraklase der Weltsicht—Paraklase der Gottessicht. Wie Umwälzungen in den Naturwissenschaften globale, politische, soziale und religiöse Umwälzungen anzeigen und nach sich ziehen. Grenzgebiete der Wissenschaf 2009, 58, 3-48, (in German).

16. Schäfer, L. Quantum reality, the emergence of complex order from virtual states, and the importance of consciousness in the universe. Zygon 2006, 41, 505-532.

17. Schäfer, L. Quantum Reality and Evolution Theory. J. Cosmol. 2009, 3, 547-557.

18. Schäfer, L. A Response to Carl Helrich: The Limitations and Promise of Quantum Theory. Zygon 2006, 41, 583-592.

19. Schäfer, L. A Response to Erwin Laszlo: Quantum and Consciousness. Zygon 2006, 41, 573-582.

20. Schäfer, L. A Response to Stanley Klein: A Dialogue on the Relevance of Quantum Theory to Religion. Zygon 2006, 41, 593-598.

21. Schäfer, L; Diogo, D.P.; Roy, S. Quantenwirklichkeit und Weltethos: Zur Begründung der Ethik in der Ordnung des Kosmos. Ethica 2009, 17, 11-54, (in German).

22. Schäfer, L.; Diogo, D.P.; Roy, S. Quantum Reality and Ethos: A Thought Experiment Regarding the Foundation of Ethics in Cosmic Order. Zygon 2009, 44, 265-287.

23. Schäfer, L. Infinite Potential: What Quantum Physics Reveals about How We Should Live; Random House Inc.: New York, NY, USA, 2013.

24. Russell, B. History of Western Philosophy; London University: London, UK, 1979; first published in 1946.

25. Jung, C.G. The Structure and Dynamics of the Psyche; Princeton University Press: Princeton, NJ, USA, 1960; Collected Works, Volume 8.

26. Kafatos, M.; Nadeau, R. The Conscious Universe; Springer: New York, NY, USA, 1990.

27. Jung, C.G. Mysterium Coniunctionis; Princeton University Press: Princeton, NJ, USA, 1970; Collected Works, Volume 14.

28. Von Franz, M.-L. Psyche and Matter; Shamballa Pub.: Boston, MA, USA, 1992.

29. Forman, R.K.C., Ed. The Innate Capacity: Mysticism, Psychology, and Philosophy; Oxford University Press: Oxford, UK, 1998.

30. Jaffé, A. Was C. G. Jung a Mystic? And Other Essays; Daimon Verlag: Einsiedeln, Switzerland, 1989. 
31. Jung, C.G. Psychology and Alchemy; Princeton University Press: Princeton, NJ, USA, 1968; Collected Works, Volume 12.

32. Jung, C.G. The Red Book: Liber Novus; Shamdasani, S., Ed.; Norton \& Co.: New York, NY, USA, 2009.

33. Henderson, J.L. Ancient Myths and Modern Man. In Man and His Symbols, Jung, C.G., Ed.; Dell Publishing Co., Inc.: New York, NY, USA, 1964.

34. Campbell, J. The Hero with a Thousand Faces; New World Library: Novato, California, USA, 2008; first published in 1949.

35. Eddington, A.S. The Philosophy of Physical Science; Macmillan: New York, NY, USA, 1939.

36. Eddington, A.S. The Nature of the Physical World; Macmillan: New York, NY, USA, 1929.

37. Hüther, G. Die Macht der inneren Bilder (in German); Vandenhoeck und Ruprecht: Göttingen, Germany, 2010.

38. Kopper, J. Die Metaphysik Meister Eckharts (in German); West-Ost-Verlag: Saarbrücken, Germany, 1955.

39. Haftmann, W. Painting in the Twentieth Century; Praeger: New York, NY, USA, 1965.

40. Baruss, I. Science as a Spiritual Practice; Imprint Academic: Exeter, UK, 2007.

41. Forman, R.K.C. Mystical Consciousness, the Innate Capacity, and the Perennial Psychology. In The Innate Capacity: Mysticism, Psychology, and Philosophy, Forman, R.K.C., Ed.; Oxford University Press: Oxford, UK, 1998.

42. James, W. The Varieties of Religious Experiences: A Study in Human Nature; Longmans Green \& Co.: London, UK, 1904.

43. Jung, C.G. Psychology and Religion: West and East; Princeton University Press: Princeton, NJ, USA, 1958; Collected Works, Volume 11. 


\title{
Chapter 9
}

\section{Jung on the Nature and Interpretation of Dreams: A Developmental Delineation with Cognitive Neuroscientific Responses}

\section{Caifang Zhu}

Institute of Analytical Psychology, Department of Applied Psychology, City University of Macau, Avenida Xian Xing Hai, Ed. Golden Dragon Centre, $19^{\circ}$ andar, Macau;

E-Mail: caifangzhu@hotmail.com; Tel.: +853-2878-1698; Fax:+853-2878-1691

\begin{abstract}
Post-Jungians tend to identify Jung's dream theory with the concept of compensation; they tend to believe that Jung's radically open stand constitutes his dream theory in its entirety. However, Jung's theory regarding dreams was a product of an evolving process throughout his whole intellectual and professional life. Unfortunately, the theory has not been understood in such a developmental light. Based on a historical and textual study of all dream articles found throughout The Collected Works of C.G. Jung, this paper maps a concise three-phase trajectory of Jung's changing views on dreams and interpretation. The paper posits that Jung's last essay, "Symbols and the Interpretation of Dreams" (1961), epitomizes his final stand, although such a stand is also reflected in a less explicit and less emphatic way during the latter period of the second phase. The paper also briefly addresses where Jung and Jungians have been enigmatic or negligent. For example, it has not been explicated fully why compensation as slight modifications and compensation as parallels to waking life situations are rare in Jung's cases. In addition, contemporary cognitive and neuroscientific approaches to the study of dreams, as represented by Harry Hunt, William Domhoff, and Allan Hobson, among others, are presented in connection with Jung. The juxtaposition of Jungian, cognitive, and neuroscientific approaches showcases how cognitive and scientific findings challenge, enrich, and in some ways confirm Jung's dream theory and praxis.
\end{abstract}

Reprinted from Behav. Sci. Cite as: Zhu, C. Jung on the Nature and Interpretation of Dreams: A Developmental Delineation with Cognitive Neuroscientific Responses. Behav. Sci. 2013, 3, 662-675.

\section{Introduction}

My study of Jung on dreams extracted all the articles that are in The Collected Works of C.G. Jung ( $C W$ hereafter). I performed a comprehensive search of all essays explicitly citing the word "dream" in the title (although there is no doubt that Jung's references and discussions on dreams are spread much farther and wider throughout numerous other writings in $C W$ ). The General Index to $C W$ 
provides a long classified index (See [1], pp. 220-232) to virtually every noticeable piece of information pertinent to Jung's writings on dreams. Eleven articles, including one foreword, are scattered in 6 of the 20 volumes of $C W$, listed in ascending order by volume number as follows:

Vol. 2: Association, Dream and Hysterical Symptom (1904/1910)

Vol. 4: The Analysis of Dreams (1909)

On the Significance of Number Dreams (1910)

Morton Prince, "Mechanism and Interpretation of Dreams": A Critical Review (1911)

Vol. 8: General Aspects of Dream Psychology (1916/1948)

On the Nature of Dreams (1945/1948)

Vol. 12: Individual Dream Symbolism in Relation to Alchemy (1936)

Vol. 16: The Practical Use of Dream-Analysis (1934)

Vol. 18: Symbols and the Interpretation of Dreams (1961)

Sigmund Freud: On Dreams (1901)

Foreword to Fierz-David: The Dream of Poliphilo (1946)

Among these articles, the following three are presumably the most representative: "Association, Dream and Hysterical Symptom," "On the Nature of Dreams," and "Symbols and the Interpretation of Dreams." Each of these works epitomizes one of the three major developmental phases of Jung's theory and practice of dream interpretation. "Association, Dream and Hysterical Symptom" [2] highlights the first phase of Jungian theory. In this phase, Jung was a staunch supporter and advocate of Freud's repression and sex-drive-based theory of dream interpretation. "On the Nature of Dreams" [3], which is supplemented by "General Aspects of Dream Psychology" [4], as well as by "The Practical Use of Dream-Analysis" [5], marks the second phase. Here, we see the maturation of Jung's own theory of dreams as compensatory catharsis for one's waking life. This transformation in Jung's theoretical position spans a long period between 1916, the year the first version of "General Aspects of Dream Psychology" was published, and the late 1950s. Jung's work spanning the third or last phase, as represented by "Symbols and the Interpretation of Dreams" [6], illustrates an open, fluid, and pragmatic attitude towards the compensation theory developed during the second phase. In the third phase, Jung concludes that compensation theory is just a proposed hypothesis, however promising it might appear, which can be built upon and further scientifically explored.

\section{Solidarity with Freud}

The tone of Jung's partisanship with, and commitment to, Freud is somewhat mitigated in Jung's autobiography, entitled Memories, Dreams and Reflections (MDR) [7]. Jung's interest in Freud's theory is more strongly expressed in his early essays on dreams. Jung's earliest published dream article entitled, "Sigmund Freud: On Dreams" [8], is basically a summary of Freud's seminal work, The Interpretation of Dreams [9]. Jung recapitulates the central concept of the piece by delineating between the manifest content versus the latent content of dreams. Freud's dream work elaborates the disconnection between manifest and latent ideas "into a relatively unified dream-image" ([8], para. 844). After distancing himself from Freud, both on personal and academic fronts, Jung unequivocally challenges the façade under which the latent content is supposed to hide. 
Initially, Jung [8] aligns with Freud regarding the division of dreams into three classes representing: (1) an unrepressed wish in undisguised form (infantile type); (2) the fulfillment of a repressed wish in disguised form (most dreams belong to this type); and (3) a repressed wish in undisguised form (often accompanied by fear). As for the purpose or function of dreams in general, Jung, in agreement with Freud, articulates succinctly that: dreams are a façade for the preservation of sleep and represent the "guardian of sleep" ([8], para. 866-868).

Jung pays homage to Freud's methodology in "The Analysis of Dreams" [10], where he argues that Freud's method is based on empiricism alone - namely, the common experience that no psychic (or physical) fact is accidental. It must have, then, its train of causes, being always the product of a complicated combination of phenomena; for every existing mental element is resultant of anterior psychic states and ought in theory to be capable of analysis ([10], para. 66). However, after distancing himself from Freud, Jung theorizes a differing view: that "dreams are often anticipatory and would lose their specific meaning completely on a purely causalistic view" ([11], para. 312).

In a response article entitled 'Morton Prince, 'The Mechanism and Interpretation of Dreams': A Critical Review" [12], Jung refutes Prince's criticism of Freud's psychoanalytic theory of dream formation and interpretation. From the outset, Jung retains a diplomatic stance supporting Freudian theory. However, Jung gradually becomes ferociously critical, and even condescending, in his subsequent and thorough counter-criticism of Prince's work. For instance, the "anxiety dreams" reportedly experienced by Prince's patients, Jung asserts, "must be regarded from the standpoint of the sexual theory, unless Prince succeeds in proving to us that the sexual theory of anxiety is wrong" ([12], para. 184). Jung meticulously dissects Prince's criticism by pointing out the errors and deficiencies in Prince's interpretations of six dreams of a middle-aged female client who developed a dependency on Prince. At this stage, Jung contends that Freud's approach scientifically and authentically describes what one is. In contrast, Prince's moralizing of his clinical cases represents a rather pretentious assigning what one should be. For Jung, this was a serious flaw in Prince's approach.

Whereas the aforementioned three articles trumpet and defend Freud, "Association, Dream and Hysterical Symptom" provides an example of Jung applying Freudian theory, especially sexual theory, to rigorous clinical practice. Here, Jung shows in great detail his analytical process, which was in alignment with the Freudian sex-based dream theory of interpretation. In that work, Jung examines nine serial dreams of a 24-year-old inpatient. The work is an intricate and thorough case study, which, due to space limitations, cannot be elaborated any further here. It suffices to say that no direct confirmation came from the patient, and the "dream-analysis and the analysis of the illness as a whole remain[ed] incomplete" ([2], para. 843). Nonetheless, Jung concluded that there was "something about the brother that goes beyond a sibling relation" - and that the patient had a "Freudian trauma." Jung holds that all these dreams indicate "an intensive sexual complex, wherein the dreams are about nothing but the theme of mating" [2]. Here, Jung could not be a more faithful proponent of Freudian dream analysis, in addition to psychoanalysis in general.

\section{Jung's Original Contribution-Dream as Compensation}

Jung's original contributions to the interpretation of dreams are multiple, encompassing compensation theory, symbolism, direct image association, the archetypal unconscious, individuation, two-mind confrontation, and the analysis of dreams on both subject and object levels. 
It is probably safe to say that among Jung's foremost contributions on dream interpretation, "compensatory theory" is the more important. In some way, the theory becomes the cornerstone of the edifice of Jungian dream interpretation.

In 1934 Jung wrote: "Every process that goes too far immediately and inevitably calls forth compensation", and that, "[ $\mathrm{t}]$ he theory of compensation is a basic law of psychic behavior [...] When we set out to interpret a dream, it is always helpful to ask: What conscious attitude does it compensate ([5], para. 330)?” Thus, my article will focus on this compensatory concept and practice, and proposes that his other contributions formed a constellation around this central compensation theory.

Jung's remarks on the compensatory nature of dreams are scattered in many articles. Three articles, however, deserve major attention, namely: "General Aspects of Dream Psychology" (Aspects hereafter) [4], "The Practical Use of Dream Analysis" (Practical Use hereafter) [5], and "On the Nature of Dreams" (Nature hereafter) [3]. As the title itself suggests, Aspects deals with several important aspects of dreams, and devotes much attention to discussing compensation theory and its clinical applications. Practical Use not only designates compensation as "the basic law of psychic behavior" and "one of the best-proven rules of dream interpretation" ([5], para. 330), but also lays out the details of methodological skills, such as the directed association of images. Nature, the shortest of the trio, discusses exclusively the compensatory function of dreams as its true nature.

Interestingly enough, according to the editors' footnotes, both Aspects and Nature had their last editions published in the same year (1948). From the $C W$ footnotes, there is barely a way to tell which one of the two was written and published first. The order of their appearance in $C W$ might be the only clue for an educated guess. Aspects therefore is assumed to precede Nature. I rely more on Nature than Aspects, not only because of the exclusiveness of the topic of the former, but also because of its presumably later date of penmanship and publication.

Despite discussions in Aspects, Practical Use, and elsewhere, it is Nature that marked the maturity of Jung's compensation theory. In terms of the general mechanism of dream formation, compensation "means balancing and comparing different data or points of view so as to produce an adjustment or a rectification" ([3], para. 545). In Nature, the compensation theory is summarized in three possibilities or manifestations: (1) opposites, (2) satisfaction with slight modifications, and (3) parallels or coincidences. Formal definitions of these terms are as follows:

(1) Compensation as opposition to the tendency of the conscious mind if the conscious life situation is "in large degree one-sided."

(2) Compensation as satisfaction, with slight modification or deviation from the conscious life situation; this type of compensation does not go to extremes and is "fairly near the middle."

(3) Compensation as emphasizing or coinciding with the conscious attitude if the attitude is the best possible, or "correct" one. This kind of compensation (i.e., what is dreamt of coincides with what happens in conscious life) is also known as a parallel compensation [3].

Most of the cases that Jung cites for the compensatory theory allude to dream manifestations as opposites. The following cases are typical for this category.

(A) Jung was seeing a patient, who was a highly intelligent woman. Jung's analysis with her dream went well at first, but after a while he got stuck with the interpretation and noticed a 
shallowness in the dialogue with the analysand. Jung decided to communicate this to the patient. He then had a dream the night before he was to meet with her again. The dream is as follows:

I was walking down a highway through a valley in late-afternoon sunlight. To my right was a steep hill. At its top stood a castle, and on the highest tower there was a woman sitting on a kind of balustrade. In order to see her properly, I had to bend my head far back. I awoke with a crick in the back of my neck. Even in the dream I had recognized the woman as my patient ([7], p. 133; [13], para. 281).

The interpretation of the dream was immediate and crystal clear to Jung: if in the dream he had to look up at the woman, his analysand, then in waking life Jung had probably been looking down on her both intellectually and morally, as according to Jung, "dreams are, after all, compensations for the conscious attitude" ([7], p. 133). Jung shared his dream and interpretation of it with the patient and it produced an immediate positive change in the effect of her treatment thereafter.

(B) A patient who consciously thinks of himself as an individual with no moral problems dreams of "a drunken tramp willowing in a ditch beside the road" ([6], para. 507).

In Nature, Jung warns that sometimes and in certain cases, such as in the latent psychoses of hereditarily "tainted" individuals, "compensation may lead to a fatal outcome owing to the preponderance of destructive tendencies" ([3], para. 547). A brief comparative study is sketched by Caifang J. Zhu [14] outlining the possibility of becoming psychotic due to the integration of the unconscious into consciousness during the process of analytical psychotherapy and the practice of Daoist or Buddhist meditations.

Turning to compensation types 1 and 2, we may begin with the Daoist sage, ZHUANG Zi (庄子) (alternatively spelled as CHUANG Tzu), who says that one dreams at night what he or she thinks during the day. An antecedent of what Freud called "the day residue" effect, Zhuang Zi seems to favor the ubiquity of parallel dreams, as well as similar (satisfaction-with-slight-modification) type dreams. H. Dieckman [15] wonders if Jung or his analytical psychology overestimates the differences between dreams and waking experiences. G. William Domhoff proposes that "there is a continuity between dream content and waking thought" ([16], p. 21). Domhoff goes as far as saying that dreaming consciousness is "a remarkably faithful replica of waking life" ([17], p. 9). Later, he softens his tone after summarizing multiple researchers' findings and views, by concluding that "dreams are most often reasonable simulations of waking life that contain occasional unusual features in terms of settings, characters, or activities" ([17], p. 15).

Manifestation 2 of the compensation theory is disproportionately less articulated and much more enigmatic and obscure than manifestation 1. Jung's available elaborations on manifestation 2 span only a couple of sentences in para. 546 and 568 of Nature. This relative diminishment is elucidated further by von Franz in her book, Dreams. Here, she surmises that manifestation 2 "completes what is lacking in those contents of consciousness which are too narrow or are not considered sufficiently valuable (complementary)" ([18], p. 4). She presents as an example someone who has a "superficially felt sympathy" for his heterosexual partner in waking consciousness, whilst at night dreaming of a passionate love scenario with the sex partner. In this example, von Franz reasons that the dream "complements the stronger emotional importance of what has been recognized consciously, an importance which has been overlooked" ([18], p. 4). Complementation here occurs 
here as a means of compensation. That is to say, the dreamer brings the suppressed emotion ("superficially felt sympathy") in waking life to a full play in the dream.

Jung states that manifestation 3, i.e., compensation as confirmation or parallel to a life situation, is actually "rather rare." Jung does not elaborate why this is so, but simply asserts this as a conviction essentially based on his own experiences ([19], para. 48). Post-Jungians, such as Thayer Greene [20], James A. Hall [21], and Marie-Louise von Franz [17] continue to hold to this "rarity" position (this generally applies to manifestation 2, as well). Hall tries to explain it away in three ways:

(1) The report of parallel dreams - what Hall calls "dreams of reality-as-it-is" -is often erroneous because symbolic elements, when carefully inquired into, often turn out to be "significantly different from the reality of the dreamer's waking life" ([21], p. 90).

(2) Such dreams may not be "truly" dreams. That is, such dreams may occur at certain levels of consciousness during sleep, and such dreams resemble waking consciousness (such as in meditative states) ([21], p. 90). (We should be aware that the result of experimental study on lucid dreaming was presumably not published at the time James Hall wrote this.)

(3) If it does happen, then "the unconscious intends the waking situation to be viewed as if it were a dream" ([21], p. 91).

Few further references are available pertaining to Jung's explanation as to why parallel dreams are purportedly so rare. My hypothesis is that it might have to do with the development of personality (self-centered in Jungian sense vs. ego-centered), the era (ancient/pre-modern times vs. modern), and cultural milieu (dialectical/dynamic/integrative culture $v$ s. dichotomist/rational/linear thinking) [22]. It would be plausible to assume that people of the latter category of each dyad are more egocentric or less balanced than people of the former category, so that the latter (i.e., modern Westerners in general) manifest greater unconscious compensation for their conscious behavior. For Jungian and non-Jungian dream workers alike, perhaps it is time to explore this hypothesis with experimental studies in existent sleep and dream labs.

\section{Jung's Final Stand on Dreams: Relative and Fluid}

After approximately 60 years of work on dream interpretations, Jung concluded in his "Symbols and the Interpretation of Dreams" that:

There is no rule, let alone a law, of dream interpretation, although it does look as if the general purpose of dream is compensation. At least, compensation can be said to be the most promising and most fertile hypothesis ([6], para. 507).

Jung was considerably influenced by the Eastern wisdom traditions. One wonders how much of Jung's final position on dreams is a reflection of the dialectical, dynamic, and fluid philosophies of the East. In the same vein, we can ask how the Daoist philosophy of Yin-Yang regulation and reversion as the motion of Dao/Tao, and the concept of "enantiodromia" [13] Jung attributed to Heraclitus possibly influenced the shaping of Jung's compensatory theory. Exploration along this line deserves a separate paper to investigate such a hypothesis.

The essay Symbols is quite likely the very last paper, or at least one of the last papers, Jung wrote himself because it was written in 1961, the year he died. According to the editorial footnotes of 
Symbols, Jung composed the essay in English without a title. It was originally written as a contribution, together with four of his colleagues, towards a symposium called Man and His Symbols, which contributed to popularizing Jung's ideas. It is not known via the notes, however, whether Jung actually made it to the symposium or not. What is clear is that Jung's essay was, under the supervision of John Freeman and Marie-Louise von Franz, extensively re-worked and re-written with Jung's agreement, presumably to meet the purpose of a popular presentation. The version collected in $C W 18$ that I am referring to, to our delight, is Jung's original text. It is revised, however, by R. F. C. Hull, the principal translator of the bulky $C W$. The original organizational arrangement, except for some minor transpositions, has been kept intact. The title and sub-titles of four sections were all added post-production.

The assumption in the authenticity of Jung's definitive stand on dreams in Symbols finds support from a larger contextual study. There are a number of places in section four of Symbols ("The Problems of Types in Dream Interpretation") that re-state in different expressions this definitive stand on the nature of dreams and interpretation. For example, paragraph 495 [6] reads, "The process of interpretation consists in the confrontation of two minds, the analyst's and the analysand's, and not in the application of a preconceived theory." As a dream interpretation process, or the systematic analysis of dreams, requires a confrontation of two minds, Jung believed it would make a great difference if their types of attitude were the same. To Jung, himself an introvert, the extroverted Freud belittled introverted patients as morbidly engrossed in themselves ([6], paras. 498-499). The dynamics of the analyst and the analysand, rather than any preconceived theory, thus determine much of the process of dream interpretation. Alongside this, Jung reaffirms:

If you want to understand another person's dream, you have to sacrifice your own predilections and suppress your prejudices [...] if you don't make the effort to criticize your own standpoint and to admit its relativity, you will get neither the right information about, nor sufficient insight into, your analysand's mind [...] one has to remind oneself again and again that in therapy it is more important for the patient to understand than for the analyst's theoretical expectations to be satisfied ([6], para. 505).

Unmistakably, here Jung was pointing to the relativity of truth pertaining to any theory, including his own on dreams. By this, he was also pioneering humanistic psychology and a client-centered approach to psychotherapy [23].

Echoing no general rule (nor the law of dream interpretations), Jung reflected that 60 years of clinical practice had taught him that there was "no therapeutic technique or doctrine that is generally applicable" ([6], para. 515). Rather, he had to "regard each case as a new experience, for which, first of all, I have to seek the individual approach' ([6], para. 518). According to Jung, two individuals can have almost identical dreams, but if one is young and the other old, their perception and experience of the dream-scope may be markedly different. If anything, Jung proposed that maintaining the rapport with the patient and following his or her_inclination, supported by his or her own dream, is optimal.

Jung's final comments on the relativity of compensation as dream interpretation theory was heralded in articles published prior to Symbols. In Aspects alone, the formulation of such insights were emerging and expressed as follows: 
It is therefore not easy to lay down any special rules for the type of dream-compensation. Its character is always closely bound with the whole nature of the individual. The possibilities of compensation are without number and inexhaustible, though with increasing experience certain basic features gradually crystallize out ([4], para. 490).

A dream, like every element in the psychic structure, is a resultant of the total psyche ... so the dream cannot be explained by this or that element in it, however beguilingly simple such an explanation may appear to be [...] In order to do anything like justice to dreams, we need an interpretive equipment that must be laboriously fitted together from all branches of the humane sciences ([4], para. 527).

This definitive stand also finds antecedent voices in the essay Nature, where Jung states that the only justifiable interpretations of dreams are reached through a painstaking examination of the context. In doing so, the interpreter, however experienced he or she may be, is always obliged "to admit one's ignorance and, renouncing all preconceived ideas, to prepare for something entirely unexpected" ([3], para. 543). Renouncing all preconceived ideas necessarily includes that of compensation theory. Epistemologically or cognitively, this is reminiscent of Freud's analytic technique of "equally suspended attention". Likewise, phenomenologists contemporaneous with Jung, such as Edmund Husserl [24] and Maurice Merleau-Ponty, employed differing nomenclature to express a similar message: bracket, eliminate or suspend one's presuppositions to let things manifest themselves as they really are [25]. In Chan/Zen and Vipassana meditations, practitioners look inward at the thoughts, emotions, and memories whose constant flux constitute mental phenomena - the "original face" or the original nature of the mind. Heidegger [26] and Gadamer [27] assert that only after one has arrived at the pre-conceptual, pre-suppositional, and pre-judgmental state of mind can one's hermeneutics be justified as a "fusion of horizons."

In the last paragraph of Nature, Jung wrote that, in the study of dream psychology, we cannot boast that we have possessed:

a generally satisfying theory or explanation of this complicated phenomenon. We still know far too little about the nature of unconscious psyche for that [...] For the purpose of research is not to imagine that one possesses the theory which alone is right, but, doubting all theories, to approach gradually nearer to the truth ([3], para. 569).

If the doubting of theory allows us to come closer to the truth, then it is easy for us to understand why Jung hardly expresses any sense of positive construction in $M D R$. In retrospect, in the last chapter of $M D R$, Jung writes, "There is nothing I am quite sure about. I have no definite convictions - not about anything, really" ([7], p. 358). A man of advanced age, he ended up quoting the Chinese Daoist sage Laozi (Lao Tzu 老子), “All is clear, I alone am clouded” ([7], p. 359). Here, Jung appears deconstructive and post-modern, which is ironically pre-modern in the East-Asian wisdom tradition.

In fact such thoughts of deconstruction and openness can be traced further back in Jung's works. For example, in "The Aim of Psychotherapy," Jung could not have made it clearer when he wrote, "I have no theory about dreams; I do not know how dreams arise. I am altogether in doubt as to whether my way of handling dreams even deserves the name of 'method' ([11], para. 86). No law, no rule, not even a method is assured. On the other hand, Jung continued: "if we meditate on a dream 
sufficiently long and thoroughly, if we carry it around with us and turn it over and over, something almost always comes of it" ([11], para. 86). That is, there are techniques of interpretation (e.g., the directed association of dream images and symbols), although there is no general law or principle. In his chapter, "C.G. Jung's theory of dreams," Greene cited the above referenced para. 86. However, he did not see it as a final stand from a developmental viewpoint.

Readers may ask: since Jung's open stand is traced back to the early 1930s, how does my proposition make sense that it is within the last several years of his life that Jung's definitive theoretical stand was clearly formed? In answer to this, Jung [5], as in Practical Uses for instance, was much more enigmatic or ambivalent on the relation between compensatory theory as a law or rule, as opposed to it being a thoroughly open stand. Through a maturation process, however, culminating in Symbols, he unequivocally declares his definitive open stand: compensatory theory is just a hypothesis.

A physician and contemporary of William James and Edmund Husserl, Jung was apparently more pragmatic [28] and phenomenological than scientific, as he sometimes controversially claimed himself to be [29]. As long as his interpretation means "something to the patient and sets his life in motion again," Jung said he was wholly content with himself, leaving explanations as to "why it works" for his "spare time" in the form of "scientific hobby" ([11], para. 86).

\section{Challenges and Confirmations from Cognitive and Neuroscientific Dream Theories}

In The Multiplicity of Dreams, Harry T. Hunt [30] constructed a cognitive psychological interpretation of dreaming that distinguished dream psychology mediated by left hemispheric brain structures, which emphasize functions of language and memory, from dream psychologies mediated more by right hemispheric brain structures, which are associated with the processing of imagistic and organismic-holistic cognition. The former camp is represented by Sigmund Freud, David Foulke, and Allan Hobson, and the latter, by Jung and James Hillman [31], among others. For Hunt, the "polysemy and multiplicity" of dreams "deny any single fixed interpretative meaning or underlying structure" ([30], p. 208). This echoes Jung's final stand on dream interpretations. Though Hunt classified Hobson in the camp that analyzed left-brained dream psychology, Hobson noted the complexity of the issue by quoting his colleague Bob Stickgold: "Freud was 50 percent right and 100 percent wrong” ([32], p.148). Moreover, Hobson appears to be much more affirming and appreciative of Jungian contributions, as opposed to wholly critical. In relation to Jung's dream theory, Hobson and Hunt are close on one thing at least: both barely mention compensation as the core substance of Jung's dream theory.

Hunt goes to great lengths to justify and prioritize the reflexive presentational process of imagistic symbolic cognition over the verbal-representational cognition of labeling and thinking in language. To Jungians, this confirms the centrality of dream images, especially in archetypal or titanic dreams. Jean Knox [29,33], however, argues that Jungians have reified the unconscious structures, such as archetypes and the Self. The image schemas or archetypes that she challenges are "an early developmental conceptual achievement rather than being an inherited innate psychic component" ([32], p. 316). Moreover, although the concept of an archetype is "the earliest true concept," it is developed "after motor abstraction in the abstraction/de-coupling process" has been completed ([33], p. 316). Knox [33] certainly has to explain more concerning how the activation of 
mirror neurons' intentionality (however she defines intentionality) leads to the emergence of concept formation, not to mention the emergence of social or interpersonal interaction.

Hunt has outlined his contemplations on the proposition that so-called "reality" is an illusion or dream, stemming from cross-cultural perspectives. He appreciates the Eastern Wisdom Traditions where "[t] he adept is freed when long-term meditative practice renders the experience of waking reality as ephemeral as a dream" ([30], p. 217). However, he complains that since the positivism and rationalism of Descartes in the West, viewing life as a dream has been considered a "metaphysical horror to be refuted at all costs" ([30], p. 217). Like many others, here Hunt risks making a contrast using an unbalanced method/approach. At best, he is contrasting the selected few hundred years of the Western intellectual tradition with thousands of years of the Eastern Wisdom Traditions, within which various competing schools existed.

Hobson [28,31] takes an empirical position regarding dream science that boils down to the activation-synthesis theory. We dream, according to Hobson, because our brains, while we are in sleep, randomly and reflexively activate themselves in the brain stem, whereby these random activations are synthesized in the frontal lobes. In relation to Jung's approach to dreams, Hobson's major challenge is to downplay the meaning of dreams to the point where dream contents are no longer worthy of analyzing; such downplaying is premised on the proposition that dreams are basically biochemical activities of the brain that can be just as apparently "meaningless" as delirium or psychosis. Thus, under this framework, instead of asking what the dream possibly means, Hobson claims to have shifted the paradigm by asking what the mental (perceptual, cognitive and emotional) characteristics of dreaming are.

Still, in our case, Hobson deserves our attention for at least two major reasons. First, Hobson does not pinpoint Jung's dream theory to compensation. Instead, Hobson points out that 'Jung's dream theory emphasizes transparency and creativity, in contrast to Freud's emphasis on obscurity and psychopathology" ([28], p. 65). What does Hobson possibly mean by saying Jung's dream theory emphasizes "creativity"? Is he confirming the openness, fluidity, and relativity that characterizes the third phase of Jung's dream theory developmental trajectory? Probably yes. Cognitively speaking, creativity does presuppose openness or freedom of the habitual mindset. By "transparency," Hobson was likely referring to the directedness of Jungian dream symbolism, which directly expresses universal human concerns from the unconscious, and especially those concerns that emerge from the collective unconscious. Hobson, Greene, Hall, Samuel, and Whitmont [34], among others, all appreciate Jung's directness over Freud's disguise-censorship theory. Echoing Jung, Hobson does not believe in the disguise function of the latent layer of dream contents. Hobson tends to hold that "dreams reveal rather than conceal emotion and instinct," and therefore he concludes that "disguise-censorship is not only unnecessary but misleading. In fact, it is downright erroneous" ([31], p. 151).

The second point of Hobson's views that merits our attention pertains to Jung's ambiguous but pragmatic stand in relation to science. Hobson, aligning Jung with William James for their shared interests in psycho-spirituality, writes:

Pragmatic and experimental, they refused to accept any hypothesis that was not scientifically justified. Meanwhile, phenomena that could not be so explained were not denied existential 
status, ex cathedra. Thus, the apparent religiosity of James and Jung can obscure their fundamental scientific rigor ([28], pp. 67-68).

Hobson's comment has a two-fold meaning. First, it continues to support our reasoning above, that Jung saw his practice and theory of dreams (if there is any so-called theory he subscribed to) as having an open, fluid, and relative status. Such a status accounts for creativity in a two-mind therapeutic dynamic that is constantly changing intra-psychically and interpersonally, and involves subject-and-object levels of interpretation. Second, it is more congenial to see Jung as a pragmatist (i.e., a pragmatic analyst) rather than as a scientist; Jung kept claiming to be scientific at times and "ruefully" acknowledged deviating far from scientific norms [29]. Jung's work is an exemplar of the human science with which phenomenologists, existentialists, hermeneutics, and humanistic and transpersonal psychologists have been defending themselves with since the onset of the post-modern era; such individuals struggle against the excess and dominance of the Western natural sciences [26,27,35]).

Hobson claims that the most significant conclusion of his new dream theory is that it can predict that brain activation of a given chemical and regional type will always produce hallusinosis, hyperassociativity, hyperemotionality, false beliefs, and other cognitive errors. This is as far as scientific prediction can now go with dreams, but it is far enough to put the formal psychological analysis of dreams out of the reach of content analysis ([32], p. 158).

In his theory of dream formation, Hobson goes to great lengths to prove with experimental data (predominantly via empirical data with animals) that dreams are chemically mediated and enhanced within the brain. For example, he states, "We can safely conclude that REM sleep dreaming is mediated by acetylcholine when noradrenaline and serotonin are at very low levels" ([32], p. 69). The excitability level of cholinergic neurons, however, is subject to "a wide variety of genetic and experimental factors that contribute to long-and short-term differences in sleep, which are correlated with normal development, learning, and memory, and even mood and temperament" ([32], p. 70). Having reduced the concept of the "mind" to a self-activating brain, and the process of dreaming to cholinergic neuron stimulation, Hobson nonetheless takes a step back by using the term "brain-mind" and admitting that the self-activating brain's "capacity for subjectivity remains to be explained" ([31], p. 64).

Hobson attempts a defense against reductionism, or at least against a rigid reductionism, by reasoning that why dreams are so hyperassociative, instinctive, emotional, and perceptually intense, is because "the brain regions supporting these functions are more active" ([32], p. 113). In the same light, the reason we cannot keep track of time, place, and person, nor think and judge rationally and critically regarding our dreaming is simply because these brain regions were functionally less actively at the time. Hobson asserts; "This is the true meaning of reductionism" ([32], p. 113), implying his version of reductionism allows for leeway, ranging from the single neuronal level (acetylcholine) to regional levels of the brain. Alternatively, he avoids rigid reductionism via the synergic component of his activation-synthesis theory. Hobson proposes that when the brain stem randomly self-activates in sleep, the forebrain synthesizes the random activation into something like waking experience. While Hobson mitigates his reductionism in this way, Knox arguably sidesteps a reductionist snare with recourse to attachment theory. Knox concludes that the clinical phenomena indicating that many patients are stuck at the teleological or any other of the six levels of self-agency 
"may be seen as a failure to develop the abstract generalized image schema of self-agency that can integrate all the specific levels or frames of reference of self-agency" ([33], p. 320). Image is one of the key words used in Jung's interpretation of dreams.

Hobson's activation-synthesis theory of dream formation has been challenged by Mark Solms [17] since 1997. Based on his neurophysiological research on patients' reports, Solms finds that (1) dreaming originates in the ventral tegmental area of the midbrain, a few centimeters from Hobson's pons area of the brain stem that generates REM sleep; (2) many dreams can happen in non-REM sleep (a phenomenon that Hobson had attempted to explain away); and (3) it is a high level of dopamine, rather than acetylcholine, which is significant in modulating and enhancing dreaming process $[17,36]$.

Domhoff believes that the empirical and highly technical differences between Hobson and Solms are resolvable through research findings. Domhoff thus challenges both men for being "hard-nosed" scientists and refutes much of their neuropsychological speculation and theory "because the main findings on dream content are at odds with them" ([17], p. 17). Instead of relying on neurophysiology merely for formal analysis, Domhoff calls for "a new neurocognitive theory of dreams" ([17], p. 18) that blends studies pertaining to features of dreaming and waking cognitions with dream content using the extant neuroscientific technologies and findings. This seems to be a sensible new approach to the study of both dream formation and interpretation because it integrates the value of the dream content that Jung emphasized with cognitive and neuroscientific findings.

\section{Conclusions}

The full landscape of Jung's dream theory trajectory should contain three periods, despite the fact that there is some overlap of time between the phases. To single out one phase at the cost of the others is to provide only a partial picture. The developmental delineation of this paper features a solid contextual and textual exegesis that uses primary sources (although most of them are English translations). Hypotheses have been presented as to why unconscious compensation, as a parallel and/or satisfaction with slight modification, is so rare. References to the possible influences from Eastern thought, as well as from phenomenology and pragmatism, are also briefly mentioned. Cognitive and neuroscientific theories of dream formation both challenge and confirm the aspects of Jungian theory that concern dreams and interpretation. Our understanding on dreaming requires greater integrative applications. Cognitive and neuroscientific approaches can and should be combined fruitfully with the Jungian approach.

\section{Conflicts of Interest}

The author declares no conflict of interest. 


\section{References}

1. Jung, C.G. General Index to the Collected Works of C.G. Jung. Forryan, B., Glover, G.M., compliers; Princeton University Press: Princeton, NJ, USA, 1979; Volume 20.

2. Jung, C.G. Association, Dream and Hysterical Symptom, 1907/1910. In The Collected Works of C.G. Jung; Read, H., Fordham, M., Adler, G., McGuire, W., Eds.; Hull, R.F.C., Trans.; Princeton University Press: Princeton, NJ, USA, 1973; Volume 2.

3. Jung, C.G. On the Nature of Dreams, 1945/1948. In The Collected Works of C.G. Jung; Read, H., Fordham, M., Adler, G., McGuire, W., Eds.; Hull, R.F.C., Trans.; Princeton University Press: Princeton, NJ, USA, 1960; Volume 8.

4. Jung, C.G. General Aspects of Dream Psychology, 1916/1948. In The Collected Works of C.G. Jung; Read, H., Fordham, M., Adler, G., McGuire, W., Eds.; Hull, R.F.C., Trans.; Princeton University Press: Princeton, NJ, USA, 1960; Volume 8.

5. Jung, C.G. The Practical Use of Dream-Analysis, 1934. In The Collected Works of C.G. Jung; Read, H., Fordham, M., Adler, G., McGuire, W., Eds.; Hull, R.F.C., Trans.; Princeton University Press: Princeton, NJ, USA, 1954; Volume 16.

6. Jung, C.G. Symbols and the Interpretation of Dreams, 1961. In The Collected Works of C.G. Jung; Read, H., Fordham, M., Adler, G., McGuire, W., Eds.; Hull, R.F.C., Trans.; Princeton University Press: Princeton, NJ, USA, 1976; Volume 18.

7. Jung, C.G. Memories, Dreams, Reflections; Jaffé, A., Ed.; Winston, R., Winston, C., Trans.; Vintage Books: New York, NY, USA, 1989.

8. Jung, C.G. Sigmund Freud: On Dreams, 1901. In The Collected Works of C.G. Jung; Read, H., Fordham, M., Adler, G., McGuire, W., Eds.; Hull, R.F.C., Trans.; Princeton University Press: Princeton, NJ, USA, 1973; Volume 2.

9. Freud, S. The Interpretation of Dreams; Stratchey, J., Trans.; Basic Books: New York, NY, USA, 2010.

10. Jung, C.G. The Analysis of Dreams, 1909. In The Collected Works of C.G. Jung; Read, H., Fordham, M., Adler, G., McGuire, W., Eds.; Hull, R.F.C., Trans.; Princeton University Press: Princeton, NJ, USA, 1961; Volume 4.

11. Jung, C.G. The Aims of Psychotherapy, 1933. In The Collected Works of C.G. Jung; Read, H., Fordham, M., Adler, G., McGuire, W., Eds.; Hull, R.F.C., Trans.; Princeton University Press: Princeton, NJ, USA, 1954; Volume 16.

12. Jung, C.G. Morton Prince, "Mechanism and Interpretation of Dreams": A Critical Review. In The Collected Works of C.G. Jung; Read, H., Fordham, M., Adler, G., McGuire, W., Eds.; Hull, R.F.C., Trans.; Princeton University Press: Princeton, NJ, USA, 1961; Volume 4.

13. Jung, C.G. Two Essays on Analytical Psychology, 1953/1966. In The Collected Works of C.G. Jung, 2nd ed.; Read, H., Fordham, M., Adler, G., McGuire, W., Eds.; Hull, R.F.C., Trans.; Princeton University Press: Princeton, NJ, USA, 1966; Volume 7.

14. Zhu, C.J. Analytical psychology and Daoist inner alchemy: A response to C.G. Jung's Commentary on the Secret of the Golden Flower. J. Anal. Psychol. 2009, 54, 493-511.

15. Samuel, A. Jung and the post-Jungians; Routledge \& Kegan Paul: London, UK, 1985.

16. Domhoff, G.W. A new neurocognitive theory of dreams. Dreaming 2001, 11, 13-33. 
17. Domhoff, G.W. Refocusing the neurocognitive approach to dreams: A critique of the Hobson versus Solms debate. Dreaming 2005, 15, 3-20.

18. Von Franz, M.-L. Dreams; Shambhala: Boston, UK, 1998.

19. Jung, C.G. Individual dream symbolism in relation to alchemy, 1936. In The Collected Works of C.G. Jung; Read, H., Fordham, M., Adler, G., McGuire, W., Eds.; Hull, R.F.C., Trans.; Princeton University Press: Princeton, NJ, USA, 1953; Volume 12.

20. Greene, T.A.C.G. Jung's theory of dreams. In Handbook of Dreams: Research,Theories and Applications, Wolman, B.B., Ed.; Van Nostrand Reinhold Company: New York, NY, USA, 1979.

21. Hall, J.A. Jungian Dream Interpretation: A Handbook of Theory and Practice; Inner City Books: Toronto, Canada, 1983.

22. Peng, K.; Nisbett, R. Culture, Dialectics, and Reasoning about Contradiction. Am. Psychol. 1999, 54, 741-754.

23. Douglas, C. Analytical psychotherapy. In Current psychotherapies, 7th ed.; Corsini, R.J., Wedding, D., Eds.; Brooks/Cole-Thomson Learning: Belmont, CA, USA, 2005; pp. 96-129.

24. Husserl, E. The Idea of Phenomenology; Martinus Nijhoff: The Hague, the Netherlands, 1970.

25. Kockelmans, J.J. Phenomenology: The Philosophy of Edmund Husserl and Itsinterpretation; Doubleday: Garden City, NY, USA, 1967.

26. Heidegger, M. Being and Time; Harper Perennial: New York, NY, USA, 1962.

27. Gadamer, H.-G. Truth and Method, 2nd revised ed.; Continuum: London, UK, 2004.

28. Hobson, J.A. The Dreaming Brain; Basic Books: New York, NY, USA, 1988.

29. Knox, J. Developmental Aspects of Analytical Psychology: New Perspectives from Cognitive Neuroscience and Attachment Theory. In Analytical Psychology: Contemporary Perspectives in Jungian Analysis; Cambray, J., Cater, L., Eds.; Brunner-Routledge: New York, NY, USA, 2004.

30. Hunt, H.T. The Multiplicity of Dreams: Memory, Imagination, and Consciousness; Yale University Press: New Haven, USA, 1989.

31. Hillman, J. The Dream and the Underworld; Harper Perennial: New York, USA, 1979.

32. Hobson, J.A. Dreaming: An Introduction to the Science of Sleep; Oxford University Press: New York, NY, USA, 2002.

33. Knox, J. Mirror neurons and Embodied Simulation in the Development of Archetypes and Self-agency. J. Anal. Psychol. 2009, 54, 307-323.

34. Whitmont, E. Jungian Approach. In Dream Interpretation: A Comparative Study; Fosshage, J.L., Loew, C.A., Eds.; PMA Publishing Corp: New York, NY, USA, 1987.

35. Ricoeur, P. Hermeneutics and the Human Sciences; Thompson, J.B., Ed. and Trans.; Cambridge University Press: Cambridge, UK, 1981.

36. Rosch, E. A Lecture on REM and Dreaming, University of California at Berkeley, California, CA, USA, 20 September 2009. 


\title{
Chapter 10
}

\section{Symbol/Meaning Paired-Associate Recall: An "Archetypal Memory" Advantage?}

\author{
Milena Sotirova-Kohli ${ }^{1}{ }^{*}$, Klaus Opwis ${ }^{1}$, Christian Roesler ${ }^{1}$, Steven M. Smith ${ }^{2}$, \\ David H. Rosen ${ }^{3}$, Jyotsna Vaid ${ }^{2}$ and Valentin Djonov ${ }^{4}$
}

1 Department of Psychology, University of Basel, Missionstrasse60/62, Basel 4055, Switzerland;

E-Mails: klaus.opwis@unibas.ch (K.O.); christian.roesler@kh-freiburg.de (C.R.)

2 Department of Psychology, Texas A\&M University, College Station, TX 77843, USA;

E-Mails: stevesmith@tamu.edu (S.M.S.); jvaid@tamu.edu (J.V.)

3 School of Medicine, Oregon Health and Science University, Portland, OR 97239, USA;

E-Mail: drdavidhrosen@gmail.com

4 Institute of Anatomy, University of Bern, Balzerstrasse 2, Bern 3000, Switzerland;

E-Mail: valentin.djonov@ana.unibe.ch

* Author to whom correspondence should be addressed; E-Mail: milena.s.kohli@gmail.com.

Abstract: The theory of the archetypes and the hypothesis of the collective unconscious are two of the central characteristics of analytical psychology. These provoke, however, varying reactions among academic psychologists. Empirical studies which test these hypotheses are rare. Rosen, Smith, Huston and Gonzales proposed a cognitive psychological experimental paradigm to investigate the nature of archetypes and the collective unconscious as archetypal (evolutionary) memory. In this article we report the results of a cross-cultural replication of Rosen et al. conducted in the German-speaking part of Switzerland. In short, this experiment corroborated previous findings by Rosen et al., based on English speakers, and demonstrated a recall advantage for archetypal symbol meaning pairs $v s$. other symbol/meaning pairings. The fact that the same pattern of results was observed across two different cultures and languages makes it less likely that they are attributable to a specific cultural or linguistic context.

Reprinted from Behav. Sci. Cite as: Sotirova-Kohli, M.; Opwis, K.; Roesler, C.; Smith, S.M.; Rosen, D.H.; Vaid, J.; Djonov, V. Symbol/Meaning Paired-Associate Recall: An "Archetypal Memory" Advantage? Behav. Sci. 2013, 3, 541-561.

\section{Introduction}

The notions of archetypes and the collective unconscious, which are central to analytical psychology, have generally remained outside the domain of inquiry of mainstream academic psychology. Nevertheless, there are emerging efforts to integrate ideas from analytical psychology and those drawn from cognitive psychology, neuroscience and even physics, e.g., [1-9], etc. To date, 
these efforts have largely aimed at a theoretical or conceptual integration. Attempts to operationalize or empirically test ideas from analytical psychology are still fairly uncommon.

Two studies that did seek to provide an empirical test of the notion of archetypes are therefore noteworthy, see [2,10]. Rosen et al. [2] found that participants could not reliably identify the proposed associated meaning of symbols deemed to be archetypal when they relied only on resources available to consciousness. However, when participants were presented with pairs of symbols and meanings to learn in a paired-associate recall procedure, they showed significantly better recall of those pairs in which the archetypal symbols were matched with their associated archetypal meanings than those in which the associated meaning did not correspond to the archetypal meaning. In interpreting their results, the authors theorized that the presentation of the symbol and the associated meaning mobilized prior, implicit associations encoded in memory which under normal conditions are not available to conscious recall. The results of this initial study were subsequently replicated by Huston [11] and Bradshaw and Storm [12].

Although these results may be viewed as lending empirical support to the notion of the existence of collective unconscious (archetypal) memory, they may also reflect linguistic or cultural characteristics of the population tested (native speakers of English in the United States and Australia). To determine whether the obtained effect is not unique to this population it is important to conduct studies with native speakers of other languages, and in other cultural contexts. This was the aim of the present study. In this study we developed a German language adaptation of the materials used by Rosen et al. and tested participants residing in the German-speaking part of Switzerland. It was hypothesized that if certain symbols truly have underlying, perhaps universal, "archetypal" meanings, then they should be significantly better recalled if they are paired in a memory task with those meanings than if they are paired with other meanings unrelated to the archetypal ones.

Before proceeding with a description of our study a brief background discussion of archetypes as developed by Jung is in order.

\subsection{Archetypes}

Unlike Freud, Jung believed that the dynamic unconscious was not just the seat of sexual and aggressive instincts and repressed wishes. Through his work with the word association test, the study of myths and fairy tales, and of fantasy products of psychotic patients, Jung reached the conclusion that there was a layer of the unconscious which contains images, patterns of behavior and modes of perception accessible to the whole of the human race (and to the animal world, as well). He named these specific patterns of perception and behavior which crystallize in consciousness in the form of symbols archetypes (the word archetypos was used by Plato for his ideas and Jung knew this as was pointed out by Barnes [13]). Jung and suggested that archetypes were "empty and purely formal" ([14], p. 79, par. 155), "a possibility of representation given a priori” ([14], p. 79, par. 155). Further on, Jung stressed that "the representations themselves are not inherited" ([14], p. 79, par. 155). In this sense, Jung believed that the archetype-as-such is unknowable and "irrepresentable" ([15], p. 213, par. 417); rather, it affects consciousness mainly from its "ability to organize images and ideas" ([15], p. 231, par. 440). In Jung's view, the archetype "can be named and has an invariable nucleus of meaning - but always only in principle" ([14], p. 80, par. 155). Anything we say about the archetype remains a visualization which is made possible by the current state of consciousness at a 
given moment. Archetypes for Jung are numinous (that is, highly emotionally charged) and are associated with strong affective responses. Furthermore, the archetype was thought by Jung to have a "psychoid nature" ([15], p. 215, par. 419), which he described as follows: "the archetype describes a field which exhibits none of the peculiarities of the physiological and yet, in the last analysis, can no longer be regarded as psychic, although it manifests itself psychically" ([15], p. 215, par. 420). In other words, as conceptualized by Jung, archetypes-as-such while being universal are unknowable or unconscious, but can have a profound impact on consciousness and the life of the individual. They do not belong just to the psychic sphere and seem to be given a priori as a possibility or as a form without content.

It has been noted that Jung's account of archetypes is multifaceted. For example, Roesler [9] pointed out that we can speak of at least four different definitions of the archetype in Jung's writing. The first is a biological definition, according to which the archetype was considered as an inborn pattern of perception and behavior. The second definition is an empirical-statistical one based on Jung's work with the word association test, according to which the archetype is the nucleus of the categories of complexes noted by him in different individuals. A third definition views archetypes as transcending any particular time, place or individual and whose real nature can never become conscious. Finally, there is a cultural-psychological understanding of the archetype which differentiates between the archetype-as-such and its concrete manifestations which are culturally determined [9]. Although depending on the theoretical orientation there can be significant overlap between these definitions, the research reported here investigates primarily the first, biological, definition of the archetype but it is also compatible with the third definition.

Contemporary researchers have tried to reformulate the theory of the archetype to make it more compatible with notions in modern science. Among one of the most well formulated approaches is a model which theorizes that what Jung might have meant with the archetype is similar to the contemporary cognitive semanticists' notion of image schemas [3-5,16-18], that is, a structure of sensorimotor experience that captures a "dynamic, recurring pattern of organism-environment interactions" ([19], p. 136), that can be- "recruited for abstract conceptualization and reasoning" ([19], p. 141). Image schemas are thought to be "preverbal and mostly nonconscious" ([19], p. 144). Jean Knox [3] first proposed a connection between the notion of an image schema and the archetype-as-such. In this sense the archetype is looked at as an early achievement of development resulting from the qualities of the brain as a dynamic system and the interactions between the individual (biological and psychological) and the environment (social, cultural and physical). This understanding of the archetype uses a dynamic systems approach to the development of cognition and action. This approach to cognition and action relates to the process of formation of preverbal image schematic representations in the infant's brain which are largely determined by the history of the brain as a system, i.e., are based on the experience the system has in the physical world and the ability of the brain as a dynamic system to self-organize [20]. Later on, this pre-verbal neuronal activation pattern serves as a foundation for the development of conceptual thought - categories and concepts. In themselves these neuronal activation patterns constitute attractor states for the dynamic system of the brain.

The idea of the image schema also finds support in contemporary research on embodiment where embodiment is defined as the meaning of symbols to an agent and the reasoning about meaning and 
sentence understanding which "depends on activity in systems also used for perception, action and emotion" ([21], p. 4). Neuroimaging studies support the idea that sensory and motor systems are involved in concept understanding and retrieval [22]. Thus, image schemas can be understood as neuronal activation patterns which encode embodied experience in the world. They function automatically, i.e. unconsciously, and underlie concepts, narrative and ritual [23], all qualities which can be attributed also to archetypes.

Varela, Thomson and Rosch [24] propose a slightly different approach to cognition and action, namely, an enacted cognition approach to the study of mental processes and representations. According to this approach, cognition is "enaction: a history of structural coupling that brings forth a world" ([24], p. 172); this view seems consistent with most of the above mentioned ideas. Varela et al. go a step further to suggest that "the cognitive system projects its own world, and the apparent reality of this world is merely a reflection of internal laws of the system" ([24], p. 172).

Among Jungian scholars, George Hogenson [25] looked into the connection between archetypes and mirror neurons and proposed understanding the archetype as an "elementary action pattern" ([25], p. 325), which sounds similar to some of the ideas of the enacted cognition approach of Varela, Thomson and Rosch. Other Jungian scholars stress in their re-interpretation of the nature of the archetype non-linear dynamics which underlie both the functioning of the brain as a system and some aspects of the archetype related to, for example, synchronicity, enantiodromia, or the therapeutic relationship looked at as a dynamic open system. Hogenson proposed that the archetype could be understood as an "iterative moment in the self-organization of the symbolic world" ([26], p. 279). Saunders and Skar have suggested that the archetype is an emergent structure which derives from the self-organizing properties of the brain (a notion very similar to the theory of the image schema) [27]. McDowell stressed that the archetype was a pre-existing principle of the organization of personality [28], while van Eewynk [29,30] looked at archetypes as strange attractors of the dynamic system of the psyche whose non-linear dynamics underlie individuation and the therapeutic relationship.

Perhaps one of the most controversial aspects of the notion of archetypes is that of innateness. How do we understand innateness and what was actually meant by Jung when he stated that archetypes are a priori given to us? Furthermore, how do we understand the innateness of archetypes in an age in which the meanings of symbols are not likely to be transmitted genetically?

While there are still proponents of the idea that archetypes are transmitted genetically (see for further information the review by Roesler [1]), many consider discussions of nature versus nurture to be obsolete and stress the interactionist nature of human development $[1,4,9,17,25,31]$ or point out psychological factors in evolution in the argumentation against a purely genetically transmitted innateness [32]. The innate aspect of the archetype can also be looked at as predisposition to a genetic condition which needs certain environmental cues to find expression in the sense of epigenetics as described by Roesler [1,9] and Rosen [31,33]. In the light of new discoveries it might well be the case that this epigenetic process which provides the link between environment and genome and determines which genes are being active and which are deactivated might even be more important than the genes themselves and may provide the link between biological substrates - genome and cultural heritage — behavior, habits etc. [34]. The Jungian scholar Pietikanen [35] suggested a radical departure from the discussion about innateness and proposed that with the help of a Cassirerian 
approach archetypes could be understood as "culturally determined functionary forms organizing and structuring certain aspects of man's cultural activity" ([35], p. 325).

Regarding inborn behavior and archetypes there appears to be empirical support for innateness in experimental psychology for a range of phenomena including the deep structure of language [36], early attachment patterns [37], the idea of "basic emotions", language acquisition mechanisms, and a face recognition program [1,9]. Roesler [1] points out Seligman's concept of "preparedness to learn" as a further example of innateness that can be applied to archetypal theory. Similarly, Erik Goodwyn [8,38] uses in defense of innateness findings from evolutionary psychology and neuroanatomy.

We can also say that controversies concerning innateness and the archetype reflect broader controversies in psychology at large. While approaches such as the dynamic systems approach, cognitive semantics, embodiment and enacted cognition as approaches in the study of cognitive processes enjoy widespread popularity, there are also many scholars who conduct experimental work in connection with innate mechanisms. The experimental work of developmental psychologists such as Spelke provides data which supports the hypothesis of multiple innate mechanisms with which infants are equipped at birth. Spelke suggests that "perception, thought, value and action depend on domain-specific cognitive systems" and "each system has its own innate foundations and evolutionary history" ([39], p. 204). For example, in a recent study Izard, Sann, Spelke and Steri [40] report findings that support the assertion that infants at birth are equipped with abstract, numerical representations. Yet other cognitive scientists do not readily accept the notion that there are innate foundations for cognitive capacities, particularly for certain capacities, such as language. It, thus, seems that cognitive science at large is still grappling with questions concerning innateness.

The debate around the nature of the archetype is further enriched by archetypal psychology which sees the place of the archetype in imagination and stresses the transcendental nature of the archetype [1,9]. Although this approach to the archetype might not resonate with many mainstream psychologists, there are tendencies in contemporary studies of consciousness which are compatible with the ideas of archetypal psychology. The Hameroff and Penrose quantum theory of consciousness [41], the idea that consciousness "emerges as natural processes" that involve quantum phenomena "unfold[ing]" [42], and the hypothesis that the brain does not produce consciousness but serves the purpose of receiving and transmitting information which exists from beyond it [43] can all be seen to resonate with some of the basic ideas of archetypal psychology concerning the archetype. Furthermore, the notion of synchronicity-meaningful coincidences-based on an acausal connection principle, which Jung developed in exchange with Wolfgang Pauli and Albert Einstein, and which can be seen as an expression of a constellated archetypal field at work [6,44], finds in recent days, support through discoveries in complexity theory and the dynamics of complex adaptive systems [7].

Given all these ideas how are we to understand the archetype? Are archetypes transmitted biologically or are they transmitted by culture as Roesler [1] asks? Can we understand the collective unconscious in terms of subliminal transmission and inter-individual neuronal format as Roesler [1] proposed or is it a form of archetypal memory as Rosen et al. [2] suggested? However we reformulate the theory of the archetype and the collective unconscious most Jungian scholars would agree that the basis of the archetype and the collective unconscious is both innate and environmental. The differences are more in terms of degree and the role of each of the two factors. 
While the above developments in psychology provide much food for thought, finding a way to test notions about archetypes, however this notion is formulated, would be instructive. We thus turn to two previous empirical studies which attempted such a test and found empirical support in favor of the existence of something akin to archetypes, henceforth termed the archetype hypothesis.

\subsection{Previous Research}

Apart from the above mentioned theoretical discussions concerning the nature of the archetype a few scholars have sought to empirically test the hypothesis of archetypes and archetypal memory. As mentioned above, Rosen et al. [2], as well as Huston, Rosen and Smith [45], Bradshaw and Storm [12] and Maloney [10] examined this in the domains of memory and preferences.

Maloney [10] asked a community sample of 151 participants to rate their preferences to images containing archetypal themes and factor analyzed the responses. The images included the archetypal themes of the mother and the hero in both anthropomorphic (e.g., woman gazing lovingly at a child for the positive mother, Hercules for the positive hero) and non-anthropomorphic (e.g., the cave as a symbol of the Great Mother, the heraldic lion as a symbol of the hero) form. Both positive and negative aspects of these themes were examined. The study used an unconstrained Q-sort method. Participants were presented with sets of six images and asked to rate their responses to three questions in respect to the images using a limited set of possible answers. The analysis demonstrated a stable three-factor structure underlying responses to the question "If I were to keep this image with me forever, I would be". Factor 1 contained images related to a quest theme- the positive hero, the non-anthropomorphic hero, the non-anthropomorphic mother, according to the author. Factor 2 was reported to contain images related to an attachment theme-positive mother. Factor 3 was interpreted as being related to a conflict theme. The author thus concluded that "archetypal structure underlies adult affective responses" ([10], p. 110). Furthermore, Maloney concluded that the images alone were not enough to evoke an archetypal structure, they had to be viewed in a certain way so that the structure was triggered which in the design of his study was achieved through the question that the subjects had to answer. Only the question which required most active participation on the part of the participants in assessing the images yielded significant results.

A different experimental paradigm was developed by Rosen, Smith, Huston and Gonzales [2]. Rosen and colleagues argued that a natural extension of Jung's own early studies with the Word Association Test would be the study of associations on the basis of symbols. They developed an inventory of forty symbols and forty associated words which were intended to correspond to the symbol's archetypal meanings-The Archetypal Symbol Inventory (ASI). Furthermore, they designed a cognitive psychological experimental paradigm to test the hypothesis that archetypal symbols were strongly associated to these proposed underlying meanings and that the association lies beyond conscious retrieval under ordinary conditions. Rosen et al. conducted a series of three experiments with undergraduate students in psychology at a large university in southwestern U.S. The first two experiments tested participants' conscious knowledge of the symbols and their meanings. When they were shown each of the ASI symbols, and asked to guess the meaning of each symbol, American participants could not come up with the designated meaning of the symbols. Even more surprisingly, when they were given the 40 ASI symbols with a randomly ordered list of the meanings, participants were unable to match symbols to their correct meanings above the level of 
chance. These results show that participants were not consciously aware of the meanings of the symbols. The third experiment was a paired-associate learning task in which students (divided into two groups) were first shown all forty symbols. Each group was given half of the symbols matched with the proposed associated meanings and the other half with symbols and meanings mismatched (the particular pairings were counterbalanced across the two groups). After a one minute rest participants were shown only the symbols and were asked to remember and write down the word they initially saw paired with the symbol. It was found that students learned and recalled significantly better the words whose meanings corresponded to the proposed meanings of the archetypal symbols than those that were unrelated to the purported meaning of the symbols. From the list-learning research literature (e.g., $[46,47])$ it is known that pairs of strongly associated words are learned better than less associated pairs. This gave ground to the authors of the study to conclude that archetypal symbols are strongly associated to the proposed related meanings and that the association is unconscious.

Huston, Rosen and Smith [45] proposed a mechanism to explain the observed effects in the original Rosen et al. study and a second variation of the research [11]. They suggested that when a symbol was presented paired with its associated "archetypal" meaning priming occurs which facilitates later recall. The correctly paired symbol with its proposed related meaning also triggers an emotional response which contributes to the "activation and constellation of an archetypal image" ([45], p. 147). The constellated archetypal image and the associated meaning presented to participants together led to priming of memory for the association and facilitated later recall. The mechanism proposed by the above authors is still in the realm of hypothesis and needs to be experimentally tested.

In a recent study Bradshaw and Storm [12] conducted three experiments based on the Rosen and Smith paradigm using 30 out of the original 40 symbols from the ASI in a sample of 237 students and members of the general public in the state of Victoria, Australia. The sample consisted of predominantly Australian/New Zealander citizens (81\%) and was predominantly English native speaking (around 86\%). The other countries/regions represented were respectively, Britain (3\%), Europe (4\%), Asia (7\%), America (North and South 2\%) and Other 3\%. The authors replicated the results of Rosen and Smith in the free association task (Experiment 1) and detected in the forced association task (Experiment 2) seven out of 30 symbols which could be consciously known by the participants. For the rest of the symbols there was no statistical evidence in the forced association task for conscious knowledge. The authors modified the paired-associate learning task used in the third experiment of the paradigm. To additionally control for intermediate effects they presented four randomized versions of symbol-word sets, i.e. instead of two counterbalancing conditions they had four. Furthermore they modified the timing in the list learning task giving participants 8 seconds in the learning phase as opposed to 5 seconds in the original paradigm and 20 seconds in the recall phase as opposed to 8 seconds in the original paradigm. As stimuli the authors used a set of pictures and drawings of the symbols predominantly downloaded from Internet instead of the original images from the ASI. There was no explanation given for the above modifications. The results replicated the findings of Rosen et al. [2] and Huston [11]. Matching words with the symbol that they are associated with, benefitted learning and subsequent recall of the words. The authors reported a statistically significant difference between the different versions of the main experiment. There was a statistically higher recall rate for both matched and mismatched recall in one of the versions. This 
was partially explained by the age difference between the participants in this version $(M=23$ years) and one of the other versions ( $\mathrm{M}=30$ years). No information is available about the mean age in the other groups, as well as the means and standard deviations for matched and mismatched recall in the different groups. Furthermore, the authors detected increased difficulty in learning and recall of mismatched pairs with increased age in their sample (mean age $27, \mathrm{SD}=11$ years). No significant interaction between country and ethnicity and performance was found on any of the tasks in all three experiments. This is not surprising since as noted above the sample consisted of predominantly Australian/New Zealander citizens (81\%). The number of participants from other countries of origin was very small. As such it could be argued that the sample size of the individual ethnic groups (distributed across the 6 different conditions) was too small to detect any meaningful difference. There is also no information available about how the different ethnic groups or counties of origin were represented across the different experimental conditions. Furthermore, the experiment was carried out in English. All participants, even those who were not native English speakers (14\% or less since the authors did not control for language which the participants consider to be their native language) used English as the experimental language. In this sense, it cannot be ruled out that the effect which the authors report (no difference in performance between the different ethnic groups, as well as the significant effect of matching on learning and recall) can be explained by characteristics specific to the English language.

Following its publication the Rosen et al. study led others to wonder how robust or generalizable the findings were. Jill Gordon [48] posed the question whether the images used by the team could be considered to be archetypal before additional, cross-cultural, research is conducted using the same paradigm. Similarly, Gordon stressed the importance of conducting cross-cultural studies to determine whether the images used really had the qualities of archetypal images, namely, whether these were "forms that provoke more or less similar or even identical associations from a majority of people" ([48], p. 229). Raya Jones argued in a similar fashion that the results observed by Rosen et al. could be explained either in terms of "cultural convention" or as "artifacts of the statistical procedure" ([49], p. 707).

\section{Present Study}

Motivated by the question of whether the findings of Rosen et al. [2] are replicable in a different language and in a different cultural context we decided to conduct the same experiment in another context. We chose for the setting of our study the German-speaking part of Switzerland; although English and German are related languages, there are sufficient cultural differences between the southwestern region of the United States and Switzerland that we felt justified in considering the latter to be a sufficiently different cultural environment. We reasoned that if the results observed by Rosen and colleagues were related to the archetypal nature of the symbols used in the experiments then these results should be replicable in cross-cultural studies conducted in a different language and a different cultural context.

Thus we hypothesized that if the "archetype hypothesis" has merit, then symbols representing archetypes and their proposed German meanings would also be significantly better learned and recalled than mismatched pairs. The Archetypal Symbol Inventory is composed of forty symbols with occurrence in different cultures and their accepted meanings, that is, the associated accepted 
meaning of the symbols across cultures. Since the main idea of the present study was to test the replicability of the results from the initial Rosen et al. [2] study in a different cultural and linguistic context, it was agreed to apply exactly same procedure for the present experiment.

\subsection{Participants}

A total of 412 college students were recruited for the experiment. They included two different groups of randomly assigned first and second year students from the Medical School at the University of Bern, as well as 14 randomly assigned psychology students from the University of Basel. None of the students had studied archetypal symbolism. Ten students' data were excluded from the analysis due to incomplete completion of the protocols. Thus the total number of participants in the subsequent analysis was 402.

The experiment was conducted in two groups (counterbalancing conditions where the participants were assigned randomly). There were 221 students in counterbalancing condition 1 (CB1) and 181 students in counterbalancing condition 2 (CB2). The average age of participants was 21 years; one participant did not indicate her age. Overall 224 women and 178 men took part in the experiment.

In terms of language background, a total of 366 participants indicated that their primary language was German. An additional 35 participants indicated having a native language other than German; one participant did not indicate native language. The first languages of these participants included Hindi (1), Spanish (2), Serbian (1), French (6), Czech (1), Romansh (3) (the fourth official language of Switzerland), Italian (6), Dutch (1), Tamil (3), Bosnian (1), Croatian (1), Portuguese (1), Turkish (2), Bulgarian (1), English (2), Polish (1), Albanian (1), and Slovenian (1). However, since all participants were studying in fields which required passing a highly competitive entrance exam in German and subsequently took classes and exams in the German language, the research team assumed that the level of language proficiency of these participants is close to that of German speaking native speakers.

\subsection{Materials}

The original English Archetypal Symbol Inventory (ASI) was translated into German (for a description of the process of development of the ASI see Rosen et al. [2]). For this purpose the first three authors individually translated the forty items from English to German and then through a process of inter-rater agreement arrived at the final set of German translation equivalents for the forty symbols. An external expert from the Baumann Foundation (Basel) with long experience as a Jungian analyst, supervisor and training analyst, was asked to proof read the translations as well [50].

\subsection{Procedure}

Following Rosen et al. [2], a paired-associate learning task was devised. Each group of participants was presented the whole set of forty symbol-word pairs, however, twenty of these were matched with their related meanings and twenty were mismatched, that is, paired with unrelated meanings. The matched pairs in the first counterbalancing condition were presented mismatched in the second counterbalancing condition and vice versa. Furthermore, in counterbalancing condition 2 
(CB2) the images were shown in reverse order from the order of presentation in counterbalancing condition 1 (CB1) to control for any residual effects related to the order of presentation, as done in the original study. Students were instructed to try to remember the pairs they were shown and received no explanation as to the relationship between the image and the word.

The participants in each group initially saw each image-word pair for 5 seconds and after a 1- minute rest they were shown the images in the same order as in the beginning. This time each image was presented without the word for 8 seconds on the screen. During this time the participants had to try to recall the word they saw initially paired with the image and write it in the respective field of the test protocol. The stimuli were presented using Microsoft Power Point.

Finally, participants were asked to fill out a subjective report consisting of four questions after the end of the experiment. The questions were as follows:

(1). Were any of the image-word pairs familiar to you already before the experiment? If yes, which ones?

(2). Were there among the image-word pairs, ones that you found particularly intriguing? If yes, which ones?

(3). Did you use any particular strategy to be able to learn better the image-word pairs? If yes, then what was it?

(4). Do you have any other comments about the experiment?

\section{Results}

The responses given by participants were scored using a strict criterion. Only words which were the same as the stimulus words or their word forms were coded as "correct", no synonyms or association words to the stimuli were allowed. Three stimulus words proved to be particularly difficult for the participants-Unbewusstes (unconscious), Vervollständigung (completion) and Schöpfungskraft (generativity). Among the answers there were a small number of word forms such as for Unbewusstes-Unterbewusst(sein) (34 in CB1 and 14 in CB2), for Vervollständigung - Vollständigkeit (6 in CB1 and 3 in CB2) and for Schöpfungskraft-Schöpfung (57 in CB1 and 35 in CB2) which needed special attention since these were rather distant word forms of the stimulus words. These word forms appeared as answers in both conditions independent of the fact whether the stimulus word was correctly matched with the symbol whose meaning it represents or not. The subsequent analysis demonstrated that the manner of coding of these answers did not affect significantly the results and it was decided to code the word forms as "correct".

Furthermore, a technical mistake in the power point presentation of CB2 was discovered. The slide with the mismatched pair-square with the word 'Wohltätigkeit' (charity), had appeared sizably shorter on the screen which had prevented the participants from learning the pair, therefore both symbols affected by the mistake the Square (No. 7) and the Heart (No. 5) were removed from the subsequent analysis in both conditions.

A repeated measures factorial ANOVA with one within-subjects variable (Stimulus Type-matched vs. mismatched symbol-meaning pair) and one between subjects variable (Counterbalancing - CB1 vs. CB2) was conducted to analyze the data. The means and SD of the recall rates for matched and mismatched pairs in each counterbalancing condition are summarized in Table 1. 
Additionally percentages of correctly recalled matched and mismatched words were calculated for each group following the procedure of Rosen et al. [2]. The total number of correctly recalled matched words in each condition was divided by the total possible number of correctly matched responses in the condition and the same procedure was repeated for the mismatched pairs in both conditions. Overall percentages of correctly recalled matched and mismatched words for both conditions were calculated as well. The results are summed in Table 1. In both groups, and for all subjects, the percentage of correctly recalled matched words was higher than the percentage of correctly recalled mismatched words.

Table 1. Means, SD and percentage correct answers for both conditions.

\begin{tabular}{crrrrrr}
\hline & \multicolumn{3}{c}{ Matched } & \multicolumn{3}{c}{ Mismatched } \\
\cline { 2 - 7 } & $\%$ & Mean & SD & $\%$ & Mean & SD \\
\hline $\begin{array}{c}\text { Counterbalance 1 (CB1) } \\
(\mathrm{N}=221)\end{array}$ & 70 & 12.59 & 2.66 & 60.27 & 12.05 & 3.29 \\
$\begin{array}{c}\text { Counterbalance 2 (CB2) } \\
(\mathrm{N}=181) \\
\quad \text { Total } \\
(\mathrm{N}=402)\end{array}$ & 64.72 & 12.94 & 3.3 & 59.48 & 10.71 & 3.2 \\
& 67.47 & 12.75 & 2.97 & 59.93 & 11.45 & 3.32 \\
\hline
\end{tabular}

The main effect of stimulus type was significant, $F(1,401)=125.83, p<0.001$, MSE $=3.047$, effect size $\omega^{2}=0.22$; indicating a significantly higher recall accuracy for matched pairs than for mismatched pairs (see Table 1). Matching the symbols with their proposed associated meanings benefited learning and the subsequent recall.

\subsection{Item Analysis}

We also conducted analysis of the individual items of the ASI following the model of Rosen et al. [2]. Our intention was to compare the ranking of the symbols in our study to the ranking which symbols had in the original study. Rosen and team demonstrated that not all symbols were equally useful in their study through calculating an ASI Index for each symbol. The ASI Index was calculated taking into consideration the percentage of correct responses when the symbol and the word were correctly matched and the percentages of correct responses for respectively the symbol and the word when each appeared in a mismatched combination with another word (for the symbol) and another symbol (for the word). For each item the percentage of correct responses when the symbol was mismatched and the percentage correct responses when the word was mismatched were subtracted separately from the percentage correct responses when symbol and word were correctly matched, the two differences were added and divided by two to obtain the ASI index. We conducted the same analysis for all items and the results are presented in Table 2.

Table 2. Archetypal Symbol Inventory (ASI) Summary of item analysis: rank-ordered ASI.

\begin{tabular}{cccccc}
\hline \multirow{2}{*}{ Symbol G/E } & ASI & $\begin{array}{c}\text { \% correct } \\
\text { answers } \\
\text { match }\end{array}$ & $\begin{array}{c}\text { \% correct } \\
\text { answers } \\
\text { mismatch symbol }\end{array}$ & $\begin{array}{c}\text { \% correct } \\
\text { answers } \\
\text { mismatch word }\end{array}$ & $\begin{array}{c}\text { ASI } \\
\text { Index }\end{array}$ \\
\hline
\end{tabular}




\begin{tabular}{|c|c|c|c|c|c|}
\hline Zorn/Wrath & 40 & 96.13 & 33.03 & 43.44 & 57.9 \\
\hline Geburt/Birth & 3 & 97.73 & 34.81 & 74.59 & 43.03 \\
\hline Schönheit/Beauty & 2 & 96.83 & 41.99 & 73.48 & 39.1 \\
\hline Böse/Evil & 9 & 82.81 & 22.65 & 70.72 & 36.13 \\
\hline Rettung/Salvation & 29 & 90.6 & 62.44 & 46.61 & 36.08 \\
\hline Möglichkeit/Possibility & 21 & 72.38 & 43.44 & 33.03 & 34.15 \\
\hline Einheit/Unity & 37 & 74.66 & 70.72 & 22.65 & 27.98 \\
\hline Männlich /Masculine & 17 & 83.43 & 24.89 & 88.24 & 26.87 \\
\hline Macht/Power & 23 & 83.71 & 54.14 & 64.64 & 24.32 \\
\hline Schlaf/Sleep & 31 & 70.59 & 35.36 & 58.56 & 23.63 \\
\hline Schutz/Protection & 25 & 80.54 & 75.14 & 40.88 & 22.53 \\
\hline Leben/Life & 16 & 83.71 & 65.19 & 61.88 & 20.18 \\
\hline Unbewusstes/Unconscious & 36 & 58.56 & 39.37 & 48.87 & 14.44 \\
\hline Gesundheit/Health & 14 & 72.38 & 67.42 & 51.13 & 13.11 \\
\hline Mut/Valor & 38 & 86.74 & 74.21 & 74.21 & 12.53 \\
\hline Geist/Spirit & 33 & 72.4 & 59.67 & 60.22 & 12.46 \\
\hline Potenzial/Potential & 22 & 69.23 & 64.64 & 54.14 & 9.84 \\
\hline Ewigkeit/Eternity & 8 & 63.35 & 74.59 & 34.81 & 8.65 \\
\hline Wissen/Knowledge & 15 & 57.46 & 42.08 & 57.92 & 7.46 \\
\hline Synthese/Synthesis & 34 & 64.09 & 51.13 & 67.42 & 4.82 \\
\hline Aufstieg/Ascent & 1 & 92.27 & 92.76 & 83.71 & 4.04 \\
\hline Reinigung/Purification & 26 & 65.19 & 66.52 & 62.44 & 0.71 \\
\hline Weiblich/Feminine & 10 & 87.85 & 83.71 & 92.76 & -0.39 \\
\hline Ursprung/Origin & 18 & 62.9 & 61.88 & 65.19 & -0.64 \\
\hline Perfektion/Perfection & 20 & 52.04 & 40.88 & 75.14 & -5.97 \\
\hline Rationalität/Rationality & 28 & 40.27 & 58.56 & 35.36 & -6.69 \\
\hline Zentrum/Center & 4 & 56.91 & 62.44 & 66.52 & -7.57 \\
\hline Virilität/Virility & 39 & 80.54 & 89.5 & 87.29 & -7.86 \\
\hline Fruchtbarkeit/Fertility & 11 & 65.75 & 74.21 & 74.21 & -8.46 \\
\hline Paradox/Paradox & 19 & 64.09 & 64.25 & 81.9 & -8.99 \\
\hline Seele/Soul & 32 & 64.09 & 81.9 & 64.25 & -8.99 \\
\hline Schöpfungskraft/Generativity & 12 & 33.7 & 48.87 & 39.37 & -10.42 \\
\hline Fortschritt/Progress & 24 & 40.33 & 46.61 & 62.44 & -14.2 \\
\hline Verwandlung/Transformation & 35 & 42.99 & 60.22 & 59.67 & -16.96 \\
\hline Harmonie/Harmony & 13 & 32.6 & 57.92 & 42.08 & -17.4 \\
\hline Suche/Quest & 27 & 39.37 & 73.48 & 41.99 & -18.37 \\
\hline Selbst/Self & 30 & 65.61 & 87.29 & 89.5 & -22.79 \\
\hline Vervollständigung/Completion & 6 & 9.95 & 88.24 & 24.89 & -46.62 \\
\hline
\end{tabular}

Items that were recalled better when correctly matched than in any of the other two conditions were ranked the highest. Items that were recalled better when incorrectly matched in both conditions were ranked lowest.

Although there was a partial overlap of the ranking of items in both the Rosen et al. [2] study and our German-speaking study such as having the symbols for power (Macht), unity (Einheit), birth (Geburt), masculine (Männlich) and protection (Schutz) rank among the top third of the ASI index as best recalled when in the matched condition, there were also notable differences. The summary of the comparison of the ranking of the ASI symbols according to their ASI Index for both studies is given in Table 3. Surprisingly symbols as the ones for soul (Seele) and feminine (Weiblich) dropped to the lowermost third of the ranking in the German study while ranking in the topmost third in the US 
study. Similarly, the symbol for ascent (Aufstieg) that ranked highest in the rank-order of the US ASI study was in the lower end of the middle group of the rank-order in the Swiss study. The ranking of the symbols in the Swiss study was topped by the symbol of wrath (Zorn).

Table 3. Swiss-German ASI Index and US-English ASI Index Comparison.

\begin{tabular}{cccccc}
\hline \multirow{2}{*}{ Symbol } & & \multicolumn{2}{c}{ German ASI } & US ASI Index \\
G/E & ASI No. & \multicolumn{2}{c}{ Index } & & \\
\cline { 3 - 6 } & & Ranking & Value & Ranking & Value \\
\hline Aufstieg/Ascent & 1 & 21 & 4.04 & 1 & 54 \\
Schönheit/Beauty & 2 & 3 & 39.1 & 17 & 11.5 \\
Geburt/Birth & 3 & 2 & 43.03 & 8 & 22 \\
Zentrum/Center & 4 & 27 & -7.57 & 2 & 47 \\
Vervollständigung/Completion & 6 & 38 & -46.62 & 25 & 0 \\
Ewigkeit/Eternity & 8 & 18 & 8.65 & 19 & 10.5 \\
Böse/Evil & 9 & 4 & 36.13 & 24 & 1.5 \\
Weiblich/Feminine & 10 & 23 & -0.39 & 10 & 19.5 \\
Fruchtbarkeit/Fertility & 11 & 29 & -8.46 & 26 & 0 \\
Schöpfungskraft/Generativity & 12 & 32 & -10.42 & 31 & -9 \\
Harmonie/Harmony & 13 & 35 & -17.4 & 30 & -8 \\
Gesundheit/Health & 14 & 14 & 13.11 & 22 & 7.5 \\
Wissen/Knowledge & 15 & 19 & 7.46 & 20 & 10 \\
Leben/Life & 16 & 12 & 20.18 & 23 & 7.5 \\
Männlich/Masculine & 17 & 8 & 26.87 & 12 & 15 \\
Ursprung/Origin & 18 & 24 & -0.64 & 34 & -15 \\
Paradox/Paradox & 19 & 31 & -8.99 & 11 & 19 \\
Perfektion/Perfection & 20 & 25 & -5.97 & 14 & 14 \\
Möglichkeit/Possibility & 21 & 6 & 34.15 & 15 & 14 \\
Potenzial/Potential & 22 & 17 & 9.84 & 36 & -24.5 \\
Macht/Power & 23 & 9 & 24.32 & 5 & 33 \\
Fortschritt/Progress & 24 & 33 & -14.2 & 27 & -4 \\
Schutz/Protection & 25 & 11 & 22.53 & 9 & 20 \\
Reinigung/Purification & 26 & 22 & 0.71 & 35 & -17.5 \\
Suche/Quest & 27 & 36 & -18.37 & 37 & -38 \\
Rationalität/Rationality & 28 & 26 & -6.69 & 33 & -11.5 \\
Rettung/Salvation & 29 & 5 & 36.08 & 28 & -4.5 \\
Selbst/Self & 30 & 37 & -22.79 & 29 & -5 \\
Schlaf/Sleep & 31 & 10 & 23.63 & 21 & 9.5 \\
Seele/Soul & 32 & 30 & -8.99 & 4 & 38 \\
Geist/Spirit & 16 & 12.46 & 18 & 11 \\
\hline & & & & &
\end{tabular}

Table 3. Cont.

\begin{tabular}{cccccc}
\hline $\begin{array}{c}\text { Symbol } \\
\text { G/E }\end{array}$ & ASI No. & $\begin{array}{c}\text { Germa } \\
\text { n ASI } \\
\text { Index }\end{array}$ & $\begin{array}{c}\text { US ASI } \\
\text { Index }\end{array}$ & $\begin{array}{c}\text { Symbol } \\
\text { G/E }\end{array}$ & ASI No. \\
\hline Synthese/Synthesis & 34 & 20 & 4.82 & 38 & -39 \\
Verwandlung/Transformation & 35 & 34 & -16.96 & 6 & 33 \\
Unbewusstes/Unconscious & 36 & 13 & 14.44 & 32 & -11
\end{tabular}




\begin{tabular}{cccccc} 
Einheit/Unity & 37 & 7 & 27.98 & 3 & 46.5 \\
Mut/Valor & 38 & 15 & 12.53 & 13 & 14.5 \\
Virilität/Virility & 39 & 28 & -7.86 & 7 & 33 \\
Zorn/Wrath & 40 & 1 & 57.9 & 16 & 12 \\
\hline
\end{tabular}

The observed differences can possibly be explained by the different contexts of the samples in the two studies, i.e., socio-cultural factors might have exerted an influence on the results. These may include, for example, cultural value systems, cultural complexes, and/or current culturally specific social, economic and political issues. Central themes for the participants at the time of the experiment might have also affected the results (e.g., the nearing of exam session for the medical students). Among the psycholinguistic factors that could have affected the observed results are word length and frequency of use in daily speech for the respective word-stimuli used in the experiment. As stated earlier some of the verbal stimuli in German presented a significant challenge for the participants (e.g., Unbewusstes (unconscious), Vervollständigung (completion) and Schöpfungskraft (generativity)).

\subsection{Subjective Report}

A total of 184 out of 221 participants in CB1 and 108 out of 181 participants in CB2 indicated that they did not know any of the image-word pairs used in the experiment before taking part in it. Among the rest of the participants in both groups there were participants who listed some pairs - both matched and mismatched - as already familiar.

In CB 1 the pairs that were listed by the highest number of people as familiar were Taube-Geist (pigeon — spirit) named by 14 participants and Ring — Ewigkeit (ring — eternity) written by 8 participants. This is not surprising since both pairs are culturally well-known. The participants in CB2 listed as familiar the combinations Schlange-Gesundheit/ Medizin (snake-health/medicine) named by 29 people, Treppe-Aufstieg (stairs - ascent) named by 18 participants, Mond-Weiblich (moon-feminine) listed by 12 people, Sonne-Männlich (sun-masculine) written by 11 people, Arche-Rettung (ark - salvation) named by 9 participants and Apfel - Wissen (apple - knowledge) written by 6 participants. In this case as well, most of the symbols, listed as familiar from before the experiment, are well culturally known symbols. We can also say that the association between the snake and health/medicine is related to the major of the participants in our study (medicine).

To control for previous conscious knowledge of the above pairs listed by the participants in their subjective report, we identified and excluded from the analysis all correct answers which corresponded to the pairs listed by the respective participants as familiar from before the experiment. The data were then reanalyzed. There was no change in the results. The effect of matching on learning and recall was still significant, $F(1,401)=55.78, p<0.001$. Thus we can say that even after controlling for previous knowledge the appropriate matching of the symbols with the associated meaning benefited learning and subsequent recall of the words and the associations were not considered to be consciously familiar by the participants.

Almost all pairs - both matched and mismatched - in both groups were listed by some participants as intriguing. Some participants indicated that the intriguing pairs were the ones that they listed as familiar. These answers are particularly interesting since they raise the question about the subjective experience of the participants during the experiment and the personal associations of 
participants. While this was outside the scope of the present study it is worthwhile investigating in subsequent studies.

A total of 41 participants in CB1 and 12 participants in CB 2 answered that they used no strategy in learning the pairs in the experiment. However, many participants listed a number of strategies they used to learn better the image-word pairs. Among these the most common ones were: making associations between image and word, mentioned by 71 participants in CB1 and 48 in CB2, constructing stories/sentences with the image and the word, named by 61 participants in CB1 and by 74 participants in $\mathrm{CB} 2$, building associations to previous experiences or known facts, given by 23 participants in $\mathrm{CB} 1$ and 18 in $\mathrm{CB} 2$, finding a personal meaning or associating to a personal memory (memory aid) by 12 people in $\mathrm{CB} 1$ and 14 in CB2, connecting image and word with emotions, named by 2 people in $\mathrm{CB} 1$ and 5 in $\mathrm{CB} 2$, constructing scenes or pictures with the image and the word, listed by 13 people in $\mathrm{CB} 1$ and 9 in $\mathrm{CB} 2$. It is of particular interest that participants note the use of personal experience or associations related to the image-word pairs, as well as emotion. The last strategy relates to the mechanism proposed by Huston et al. [45] which explains the observed effect of matching where the constellated archetypal image evokes an affective response and the affect facilitates the later recall of the word through building association with personal experiences. However, these subjective reports do not suffice as proof of the mechanisms and further research is necessary before any definite statements can be made.

Among the more common remarks about the experiment were suggestions for improvement of the experimental design such as including numbers on the slides with the images in the second part, showing the image-word pairs longer on the screen, reducing the number of images. Some included comments concerning the fit of image and word (these did not fit together) or mentioned being able to recall the associations but not the words. These remarks are not surprising and demonstrate the difficulty which the experiment presented for the participants.

\section{Discussion}

The cross-cultural study of the associations between archetypal symbols and their proposed meanings in a German-speaking sample of Swiss students replicated the findings of Rosen et al. [2] and demonstrated that there was a highly significant effect of matching on learning and subsequent recall of words correctly matched with the archetypal symbols whose meaning they represent. These results extend to Swiss German speakers the findings of Rosen and colleagues [2] reported in a sample of English speaking students. Being able to replicate the findings of superior memory for related than unrelated pairs in a German speaking sample provides further evidence that archetypal symbols are truly associated with their accepted meanings. The fact that even after excluding the pairs which were listed by the participants as familiar from before the experiment the effect of matching on learning and recall was still highly significant supports the hypothesis that the associations between symbols and their meanings are not conscious. Furthermore, this cross-cultural evidence of the association between archetypal symbols and their meanings demonstrates that it is less likely that the observed effect is related to cultural context or is a linguistic artifact. In this sense, it can be said that our results provide more evidence that the collective unconscious and archetypes as hypothesized by C. G. Jung might have a universal nature. 
The differences in the rank-order of the archetypal symbols in the US study and in the Swiss-German study suggest that it is likely that depending on circumstances some archetypes come to the fore and affect stronger conscious life than others. As mentioned earlier, according to Jungian scholars, we all have the potential or predisposition to recognize the archetypal image, however, our environment influences our experiences. The differences in the rank-order of the items in both the US and the Swiss-German ASI studies empirically support such reasoning. It is highly interesting that some symbols which at first glance seem to have an obvious association to their proposed meaning were not ranked high as would be expected-e.g., Ascent (Aufstieg). Also symbols that were highly culturally bound such as the symbol for soul (Seele), for example, dropped in the lowermost third of the ranking against our expectations. Since we do not know how exactly the symbol-word pairs represent the archetypes and how the archetype enhances memory, as Bradshaw and Storm [12] point out as well, the index and the comparison between the different studies can potentially hint to processes which are at work. It might well be that this Symbol Association Test which Rosen and Smith first proposed functions similar to the Word Association Test used by Jung, in the work with which Jung first came across the phenomenon of the archetype. More research is needed on the personal associations of participants involved in the paired associate task and cross-sample comparison of the indexes for each item to be able to make definite conclusions.

Furthermore, some participants indicated in their subjective report that there were pairs they knew from before the experiment. It is of course possible that the participants were familiar with the indicated pairs, since most of the pairs mentioned as familiar were culturally known symbols. However, it is also noteworthy that this was an experiment where archetypal associations were investigated and it is known that often an archetypal experience, correlating the presentation of an archetypal image and meaning, is followed by a strong feeling of having already known the experience or familiarity [51]. Regardless it is clear that among the pairs listed as familiar there were some mismatched pairs. While from a Jungian point of view this must indicate strong personal associations reflecting the activation of a complex, it would also be interesting to research this phenomenon in the context of illusions of competence in monitoring one's won knowledge as done by Koriat and Bjork [46].

Although our empirical investigation demonstrated that archetypal symbols are strongly associated in two different cultures and two different languages, English and German are languages from the same language group and share many similarities. Therefore, to convincingly demonstrate the universality of these findings, future research should attempt to replicate the experiment in non-Indo-European languages such as Japanese, Chinese, Turkish, Hebrew, Arabic, etc. or other Indo-European languages which are less related to English and German, such as Slavic languages for example. Furthermore, it would be of interest to conduct the paired associate learning task with the archetypal symbols from the ASI and their associated meanings in a larger sample of bilingual participants to test if bilingual participants will demonstrate the same pattern of learning and recall.

Although the cross-cultural replication of the original study with the Archetypal Symbol Inventory replicated the findings, there still are many questions that deserve further research. A question raised by a reviewer of this article and addressed by Bradshaw and Storm [12] is whether the observed significant effect of matching cannot simply be explained by the fact that meaning-words demonstrate a degree of descriptive similarity to the visual images of the symbols 
from the ASI. To control for a possible effect of descriptive similarity between the image and its associated meaning-word on the observed results, symbols and meaning-words were presented also mismatched to the participants. As already noted by Rosen et al. [2] some words were better learned and recalled when mismatched as reflected in the calculation of the index in item analyses. A similar phenomenon was observed by Bradshaw and Storm [12] as well. These authors reported having identified six words which were recalled better when mismatched. They argued that this memory enhancement could be based on descriptive similarity. The question is whether this phenomenon is not better explained as resulting from the personal associations of the participants and the complexes which were triggered rather than descriptive similarity. The very fact that there is such variability of learning and recall of the words from the ASI in the different samples as demonstrated by the comparison of the indexes in the item analyses of the US study and the Swiss study would seem to support such a hypothesis. However, further research on the associations of people using symbols from the ASI is necessary to be able to have a better understanding of the processes involved.

Furthermore, whereas there is clearly a strong association between the archetypal symbols and their proposed meanings independent of linguistic and cultural context, it still is not exactly clear how this can be explained. Are the observed results due to the effect of embodiment on cognition in terms of the dynamic system's approach to cognition and action and the theory of image schema? The embodied cognition approach proposes that "cognitive processes are deeply rooted in the body's interactions with the world" ([52], p. 625). What is more, this approach argues that "we represent our knowledge together with the sensory and motor features that were activated during its acquisition" ([53], p. 161), and which in part constitute the image schemas as neuronal activation patterns that underlie even abstract knowledge and concepts [19]. As pointed out earlier, the dynamic systems approach to the development of cognition and action suggests that as a result of experience attractor states are formed in the infant's brain; these correspond to particular neuronal activation patterns which encode the experience resulting from the interaction of the organism and the environment where the environment has to be understood both as social and physical. These patterns underlie also conceptual understanding and are associated with feelings which have accompanied the respective experience. These basic patterns of neuronal activation form the basis of most of our cognitive and emotional functioning. In this sense it seems worthwhile experimentally investigating the hypothesis that the associations between archetypal symbols and their meanings can be explained in terms of encoding the same sensory-motor experience in a different form. Testing this hypothesis experimentally can also provide evidence in favor of or against the assertions that the archetype-as-such can be understood in terms of image schema.

Do our results, on the other hand, support the debated innateness of the archetype? Although our study found out that in different language and cultural contexts archetypal (presumably universal) symbols are strongly associated to their accepted meanings and the nature of this association is unconscious, the question still remains whether this memory effect can be explained as a result of innate mechanisms and predispositions or as Roesler points out using Seligman's term "preparedness to learn" as an innate factor, or if the observed memory effect can be viewed as resulting from the quality of the brain as a system to form stable attractor states based on accumulated experience in the environment both physical and social (image schemas). We could demonstrate the presence of unconscious implicit memory of the associations between symbols and their proposed meanings in 
the absence of conscious awareness of the associations, but the source and quality of this form of memory needs further investigation. It would be particularly interesting to conduct functional brain imaging of participants involved in the main experiment to be able to delineate the activation pattern which underlies the performance on the cognitive tasks involved in the main study. Furthermore, comparing the activation pattern observed in such a study to the activation pattern underlying a constellated complex from the brain imaging study of Bechtel [54] could shed more light as to the neural correlates underlying the complex and the archetype.

Although we could demonstrate that participants from two different language and cultural backgrounds could more easily learn and recall matched archetypal symbol-meaning pairs, the question remains whether these associations are moderated by age. Bradshaw and Storm [12] demonstrated a significant correlation between age and learning and recall of mismatched pairs in a sample of 154 participants with mean age of 27 years $(\mathrm{SD}=11$ years). However, the question still remains whether the results are replicable among the elderly and/or children. Demonstrating that in a large enough sample of children or elderly presenting the symbols together with their archetypal meanings benefits learning and subsequent recall of words would be a further argument supporting the proposed by Jung universality of the archetype and is a necessary further step in this line of research. Furthermore, it would be of interest to conduct the experiment with patients who have amnesia, as suggested by Huston, Rosen and Smith [45]. Results from such a study would be revealing as to the type of memory involved in the mechanisms which underlie the observed effects.

Given the answers of the participants to the questions in the subjective report it seems also worthwhile to investigate the subjective experience of the participants when they are presented the symbol-word pairs and in this sense to systematically use symbols in the study of personal associations in a manner similar to the studies conducted using the Word Association Test. Thus developing a symbols association test would be a further important step in the study of the complex and the archetype.

Furthermore, all the studies based on the Rosen and Smith paradigm until now were conducted in samples of students or the general public. In this sense, it would be interesting to conduct studies using the ASI with Jungian analysts. It would also be particularly valuable to test the model validity of the ASI in a study with trained Jungian analysts and or Jungian scholars to test the degree to which this model of presentation of the archetype is acceptable to the general Jungian community.

Finally, it is important to acknowledge that although our findings are consistent with the framework of archetypes that there may be other underlying factors that may have made the matched pairs easier to learn and recall than the mismatched pairs. Possible stimulus-related characteristics to screen in additional research would be word length and frequency of daily use for the verbal stimuli.

\section{Conclusions}

To conclude, our study demonstrated that presenting symbols matched with their accepted meanings exerts a statistically significant effect on learning and recall independent of language and culture, even though participants lack conscious awareness of the associations. Our findings which replicated the initial findings of Rosen et al. [2], suggest that there is indeed an "archetypal memory 
advantage". However, there is need for further experimental work to be able to answer many of the questions concerning the nature of the archetype and the collective unconscious.

\section{Acknowledgments}

The authors wish to express their deep gratitude to the 1st and 2nd year medical students, the University of Bern, Switzerland, for their participation in the experiment! Special thanks go also to the Stefanie and Wolfgang Baumann Foundation, Basel, Switzerland, for the scholarship given to the first author.

\section{Conflicts of Interest}

The authors declare no conflict of interest.

\section{References}

1. Roesler, C. Are archetypes transmitted more by culture than biology? Questions arising from conceptualizations of the archetype. J. Anal. Psychol. 2012, 57, 223-246.

2. Rosen, D.H.; Smith, S.M.; Huston, H.L.; Gonzalez, G. Empirical Study of Associations between Symbols and Their Meanings: Evidence of Collective Unconscious (Archetypal) Memory. J. Anal. Psychol. 1991, 36, 211-228.

3. Knox, J. Archetype, Attachment, Analysis: Jungian Psychology and the Emergent Mind; Routledge: New York, NY, USA, 2003.

4. Knox, J. From archetypes to reflective function. J. Anal. Psychol. 2004, 49, 1-19.

5. Knox, J. Mirror neurons and embodied simulation in the development of archetypes and self-agency. J. Anal. Psychol. 2009, 54, 307-323.

6. Cambray, J. Synchronicity and emergence. Am. Imago 2002, 59, 409-434.

7. Cambray, J. Synchronicity: Nature and Psyche in an Interconnected Universe, 1st ed.; Texas A\&M University Press: College Station, TX, USA, 2009.

8. Goodwyn, E. The Neurobiology of Gods: How Brain Physiology Shapes the Recurrent Imagery of Myth and Dreams, 1st ed.; Routledge: New York, NY, USA, 2012.

9. Roesler, C. Analythische Psychologie Heute: Der Aktuelle Stand der Forschung zur Psychologie C. G. Jungs (in German); Karger Verlag: Basel, Switzerland, 2010.

10. Maloney, A. Preference rating of images representing archetypal themes. J. Anal. Psychol. 1999, 44, 101-116.

11. Huston, H. Direct and indirect tests of archetypal memory. Master's Thesis, Texas A\&M University, College Station, TX, USA, 1992.

12. Bradshaw, S.; Storm, L. Archetypes, symbols and the apprehension of meaning. Int. J. Jungian Stud. 2013, 5, 154-176.

13. Barnes, H.E. Neoplatonism and analytical psychology. Philoso. Rev. 1945, 54, 558-577.

14. Jung, C.G. The Psychological Aspects of the Mother Archetype. In The Collected Works of C.G. Jung, 2nd ed.; Read, H., Fordham, M., Adler, G., McGuire, W., Eds.; Princeton University Press: Princeton, NJ, USA, 1968; Volume 9-I. 
15. Jung, C.G. On the Nature of the Psyche. In The Collected Works of C.G. Jung, 2nd ed.; Read, H., Fordham, M., Adler, G., McGuire, W., Eds.; Princeton University Press: Princeton, NJ, USA, 1969; Volume 8.

16. Merchant, J. The developmental/emergent model of archetype, its implications and its application to shamanism. J. Anal. Psychol. 2006, 51, 125-144.

17. Merchant, J. A reappraisal of classical archetype theory and its implications for theory and practice. J. Anal. Psychol. 2009, 54, 339-358.

18. Sotirova-Kohli, M.; Rosen, D.H.; Smith, S.M.; Henderson, P.; Taki-Reece, S. Empirical study of kanji as archetypal images: Understanding the collective unconscious as part of the Japanese language. J. Anal. Psychol. 2011, 56, 109-132.

19. Johnson, M. The Meaning of the Body; The University of Chicago Press: Chicago, IL, USA, 2007.

20. Thelen, E.; Smith, L.B. A Dynamic Systems Approach to the Development of Cognition and Action; MIT Press: Cambridge, MA, USA, 1994.

21. De Vega, M., Glenberg, A.G., Graesser, A.G., Eds. Symbols and Embodiment: Debates on Meaning and Cognition, 1st ed.; Oxford University Press: New York, NY, USA, 2008.

22. Binder, R.J.; Desai, R.H. The neurobiology of semantic memory. Trends Cogn. Sci. 2011, 15, 527-536.

23. Hampe, B., Ed. From Perception to Meaning: Image Schemas in Cognitive Linguistics; Mouton de Gruyter: New York, NY, USA, 2005.

24. Varela, F.J.; Thomson, E.; Rosch, E. The Embodied Mind: Cognitive Science and Human Experience; MIT Press: Cambridge, MA, USA, 1991.

25. Hogenson, G.B. Archetypes as action patterns. J. Anal. Psychol. 2009, 54, 325-337.

26. Hogenson. G.B. The Self, the symbolic and synchronicity: Virtual realities and the emergence of the psyche. J. Anal. Psychol. 2005, 50, 271-284.

27. Saunders, P.; Skar, P. Archetypes, complexes and self-organization. J. Anal. Psychol. 2001, 46, 305-323.

28. McDowell, M.J. Principle of organization: A dynamic-systems view of the archetype-as-such. J. Anal. Psychol. 2001, 46, 637-654.

29. Van Eewynk, J.R. Archetypes: The strange attractors of the psyche. J. Anal. Psychol. 1991, 36, $1-25$.

30. Van Eewynk, J.R. Archetypes and Strange Attractors: The Chaotic World of Symbols; Inner City Books: Toronto, Canada, 1997.

31. Rosen, D.H.; Mascaro, N.; Arnau, R.; Escamilla, M.; Tai-Seale, M.; Ficht, A.; Sanders, C.; Henderson, P.; Hoang, U.; Stevenson, K. Depression in medical students: Gene-environment interactions. Ann. Behav. Sci. Med. Educ. 2010, 16, 8-14.

32. Hogenson, G.B. The Baldwin effect: A neglected influence on C. G. Jung's evolutionary thinking. J. Anal. Psychol. 2001, 46, 591-611.

33. Rosen, D.H. Inborn basis for the doctor-patient relationship. Pharos 1992, 55, 17-21.

34. Remark added following suggestion by a reviewer of the article.

35. Pietikainen, P. Archetypes as symbolic forms. J. Anal. Psychol. 1998, 43, 325-343.

36. Haule, J.R. Jung in the 21st Century: Evolution and Archetype, 1st ed.; Routledge: New York, NY, USA, 2010; Volume 1. 
37. Stevens, A. Archetype Revisited: An Updated Natural History of the Self; Inner City Books: Toronto, Canada, 2003.

38. Goodwyn, E. Approaching archetypes: Reconsidering innateness. J. Anal. Psychol. 2010, 55, 502-521.

39. Spelke, E. Innateness, Choice and Language. In Chomsky Notebook; Frank, J., Bricmont, J., Eds.; Columbia University Press: New York, NY, USA, 2010; pp. 203-210.

40. Izard, V.; Sann, C.; Spelke, E.S.; Streri, A. Newborn infants perceive abstract numbers. Proc. Natl. Acad. Sci. USA 2009, 6, 10382-10385.

41. Hameroff, S.; Penrose, R. Conscious events as orchestrated space-time selections. NeuroQuantology 2003, I, 10-35.

42. Satinover, J. The Quantum Brain: The Search for Freedom and the Next Generation of Man; John Wiley \& Sons, Inc.: New York, NY, USA, 2001.

43. Beauregard, M. Neuroscience and Spirituality_Findings and Consequences. In Neuroscience, Consciousness and Spirituality; Walach, H., Schmidt, S., Jonas, W.B., Eds.; Springer: New York, NY, USA, 2011; pp. 57-74.

44. Jung, C.G. Synchronicity: An Acausal Connecting Principle. In The Collected Works of C. G. Jung, 2nd ed.; Read, H., Fordham, M., Adler, G., McGuire, W., Eds.; Princeton University Press: Princeton, NJ, USA, 1969; Volume 8.

45. Huston, H.L.; Rosen, D.H.; Smith, S.M. Evolutionary Memory. In Evolution of the Psyche; Rosen, D.H., Luebbert, D.C., Eds.; Praeger: Westport, CT, USA, 1999; pp. 139-149.

46. Koriat, A.; Bjork, R.A. Illusions of competence in monitoring one's knowledge during study. J. Exp. Psychol. Learn. 2005, 31, 187-194.

47. Thomson, D.M.; Tulving, E. Associative encoding and retrieval: Weak and strong cues. J. Exp. Psychol. 1970, 86, 255-262.

48. Gordon, J. Comment on paper by David H. Rosen et al. J. Anal. Psychol. 1991, 36, 229.

49. Jones, R. On innateness: A response to Hogenson. J. Anal. Psychol. 2003, 48, 705-718.

50. The Archetypal Symbol Inventory (ASI) is published in the article of Rosen et al. See: [2].

51. Hunt, H.T. A collective unconscious reconsidered: Jung's archetypal imagination in the light of contemporary psychology and social science. J. Anal. Psychol. 2012, 57, 76-98.

52. Wilson, M. Six views of embodied cognition. Psychon. B. Rev. 2002, 9, 625-636.

53. Fischer, M.H. A hierarchical view of grounded, embodied and situated numerical cognition. Cogn. Process. 2012, 13, 161-164.

54. Bechtel, P. The Effect of Complex Stimulus Words Determined by Means of the Word Association Test on Functional Magnetic Resonance Imaging; C. G. Jung Institute: Zürich, Switzerland, 2013. 


\title{
Chapter 11
}

\section{Evidence for the Effectiveness of Jungian Psychotherapy: A Review of Empirical Studies}

\author{
Christian Roesler $^{1,2}$
}

1 Clinical Psychology, Catholic University of Applied Sciences, Karlsstraße 63, 79104 Freiburg, Germany; E-Mail: christian.roesler@kh-freiburg.de; Tel.: +49-761-200-1513;

Fax: +49-761-200-1496

2 Faculty of Psychology, University Basel, Switzerland

\begin{abstract}
Since the 1990s several research projects and empirical studies (process and outcome) on Jungian Psychotherapy have been conducted mainly in Germany and Switzerland. Prospective, naturalistic outcome studies and retrospective studies using standardized instruments and health insurance data as well as several qualitative studies of aspects of the psychotherapeutic process will be summarized. The studies are diligently designed and the results are well applicable to the conditions of outpatient practice. All the studies show significant improvements not only on the level of symptoms and interpersonal problems, but also on the level of personality structure and in every day life conduct. These improvements remain stable after completion of therapy over a period of up to six years. Several studies show further improvements after the end of therapy, an effect which psychoanalysis has always claimed. Health insurance data show that, after Jungian therapy, patients reduce health care utilization to a level even below the average of the total population. Results of several studies show that Jungian treatment moves patients from a level of severe symptoms to a level where one can speak of psychological health. These significant changes are reached by Jungian therapy with an average of 90 sessions, which makes Jungian psychotherapy an effective and cost-effective method. Process studies support Jungian theories on psychodynamics and elements of change in the therapeutic process. So finally, Jungian psychotherapy has reached the point where it can be called an empirically proven, effective method.
\end{abstract}

Reprinted from Behav. Sci. Cite as: Roesler, C. Evidence for the Effectiveness of Jungian Psychotherapy: A Review of Empirical Studies. Behav. Sci. 2013, 3, 562-575.

\section{Introduction}

Jungian Psychotherapy has long been accused of not giving any empirical proof of its effectiveness. In the early 1990s, the first meta-analyses of empirical studies investigating the effectiveness of psychotherapy were published. Following this, several researchers claimed that 
there were no studies investigating the effectiveness of Jungian psychotherapy and therefore it should be excluded from the field of psychotherapy. This motivated several Jungian training institutes, namely Zurich, Berlin and San Francisco, to design the first empirical studies in the field of Jungian psychotherapy. Prospective, naturalistic outcome studies and retrospective studies using standardized instruments and health insurance data as well as several qualitative studies of aspects of the psychotherapeutic process were conducted mainly in Germany and Switzerland. The results of these studies will be summarized and critically reviewed in this article.

In empirical research there is a differentiation between different levels of studies, which is described in the Handbook of psychotherapy and behavior change [1]. The highest level or Gold Standard is the Randomized Controlled Trial (RCT), with an experimental and a control group and a randomized distribution of the participants to the groups. Only RCTs can give proof of the efficacy of a psychotherapy method, which means that the effects on the patients are a result of the method alone (and of no other extra-therapeutic factors; this is equivalent to the term: internal validity). In general, only RCTs are accepted as a proof for the efficacy of the psychotherapy method. In recent years though, there has been a discussion about the validity of RCTs, since their internal validity is high but the external validity, its applicability to every day practice, is low [2]. Several researchers have argued for naturalistic prospective outcome studies which are conducted in every day practice and therefore are much more applicable to real-life conditions. Several of the Jungian studies have used this method. Generally speaking prospective data are more valid than retrospective data. Even though two Jungian studies described below applied a retrospective design, they reached a high validity through careful design.

\section{Overview of Jungian Empirical Studies}

\section{Prospective, naturalistic outcome studies}

- Praxisstudie Analytische Langzeittherapie (PAL) Schweiz (Naturalistic study on analytical long-term psychotherapy in Switzerland) [3,4]

- San Francisco Psychotherapy Research Project [5]

- PAP-S Naturalistic study on outpatient psychotherapy in Switzerland [6]

Catamnestic/retrospective studies

- $\quad$ Berlin Jungian Study [7]

- Konstanz Study_A German consumer reports study [8]

$\underline{\text { Small sample and case studies }}$

- On Jungian sand play therapy [9], psychosomatic disorders [10,11], integration of shadow aspects [12]

Qualitative and process studies

- On complex theory [13], picture interpretation method [14] 
A group of researchers at the Jung Institute Zurich participated in a larger German study on analytical long-term psychotherapy [4] conducted by the University of Heidelberg and applied the elaborated research design. The design was a naturalistic prospective outcome study, which means that therapists and patients were monitored from the beginning of therapy in the usual everyday practice context (no control group). Twenty-six therapists and their patients, totaling 37 cases, were chosen as representatives for Jungian psychotherapy in Switzerland. Fifty-seven percent of these patients suffered from depressive disorders and with $47 \%$ of the patients diagnosed with personality disorders the sample had a considerably high burden of disease. The mean duration of treatment was 35 months with a mean of 90 sessions, which is equivalent to a low-frequency treatment. This was a realistic sample representation for Jungian therapy in Switzerland.

There were three different perspectives applied: researchers, therapists and the patients themselves. On each level a set of objective and self-evaluation measures were used.

\subsubsection{Researchers}

Operationalized psychodynamic diagnostics (OPD), Jungian adaptation [15]: OPD is a complex set of dimensions systemizing and operationalizing psychoanalytic diagnostic interviews, e.g., types of unconscious conflicts, maturity of personality (ego) structure, etc. This was adapted to Jungian theoretical concepts (e.g., complex theory) for the PAL-study.

Psychodynamic focuses (two interviews): focus means the main unconscious conflicts (e.g., attachment vs. autonomy) identified via OPD that are treated in analysis.

Changes in personality structure (Heidelberger Umstrukturierungsskala): measures changes in the maturity levels of personality/ego functions identified via OPD.

Therapeutic alliance and transference (SGRT: spontane gefühlshafte Reaktion, TAB: therapeutische Arbeitsbeziehung): external rating of quality and character of the therapeutic relationship, working alliance and transference.

Interpersonal problems (Interpersonal Problems Inventory, IIP)

Changes in life conduct (research interview)

\subsubsection{Therapists}

Physical and psychological symptoms:

Severity of symptoms score (Beeinträchtigungsschwereskala, BSS): measures the impairment the patient suffers through the symptoms.

Status and process ratings:

ICD10 (International Classification of Diseases, chapter 10: psychological disorders)-diagnosis

\subsubsection{Patients}

Psychological and interpersonal symptoms: Symptom Checklist 90 Revised Version (SCL-90-R), the most widely used clinical measure in psychotherapy research; psychological/social/communicative competencies measure (PSKB-Se-R);

Interpersonal Problems Inventory (IIP); 
Trier Personality Inventory (TPF);

Health insurance data (use of health care services, visits to primary care physicians, days in hospital etc.)

\subsubsection{Results}

(The term effect size describes the impact the therapy method has in moving the patient sample from an area of disorder to an area of normal health.)

Researchers:

- Positive restructuring of patient's personality, effect size: 0,94.

- Positive changes in everyday life, very high effect size: 1,48 .

Therapists:

- Global rating of results positive or very positive for $75 \%$ of therapies

- Cost-effectiveness good, very good or maximum for $55 \%$ of therapies

Patients:

- Global Severity Index (the global measure of the SCL-90-R) reduced highly significant, very high effect size: 1,31 , normal level at end of therapy

- Significant reduction of interpersonal problems (IIP), medium effect size

- Rating of results over $90 \%$ positive, very positive or maximum

- Cost-effectiveness $80 \%$ good, very good or maximum, $20 \%$ satisfying

All these reported results were significant (5\%-level) or highly significant (1\%-level).

\subsubsection{Follow-up}

All results remained stable after one year and three years. An interesting point is that there are findings for further positive effects between the end of therapy and follow-up, which would mean that some effects of the therapy show only after the end of therapy; this is an effect that psychoanalysis has always claimed. The use of healthcare services was already low during the course of therapy and remained on a low level until the follow-up.

This study could give proof for very positive effects of Jungian psychotherapy in a prospective design that remains stable over three years after the end of therapy. Jungian therapy leads not only to a significant reduction of symptoms and of interpersonal and other problems, but also to a restructuring of the personality with the effect that the patients can deal with upcoming problems much better after the end of therapy. The satisfaction of the patients with the results was extremely high even though most of the patients had to pay for their therapy themselves. The limitation of the study is the lack of a control group which poses the question whether the sample may be an especially highly motivated group of patients, even though the severity of symptoms was high and representative for the population of patients in Switzerland.

\subsection{San Francisco Psychotherapy Research Project}


Originally this study conducted by the San Francisco Jung Institute was designed as a prospective outcome study with four points of measurement (start of therapy, end of therapy, one-year and five-year follow-up). In many aspects the design of the San Francisco psychotherapy research project is similar to that of the Zürich study. The measures applied were: SCL-90-R; IIP, GAF (Global Assessment of Functioning Scale, rated by external experts); an additional instrument designed by the Institute asking for demographic data, therapy motivation and subjective experience with the therapy; the therapists had an instrument also designed by the Institute called "Portrait of my practice" (POMP), which asked for structural aspects as well as the personal style and background of the therapist. The participants of the study were patients of the outpatient clinic of the San Francisco Jung Institute; of 100 patients in the clinic, 57 participated in the study. The participating therapists were 23 professional analysts of the Institute as well as 17 candidates in training and seven psychology interns.

Because of the low participation of analysts from the Institute, the project had to be terminated early. Because of these problems, the original design had to be collapsed into a one-group pretest-posttest-design. This included 39 of the original 57 patients and only part of these completed follow-ups. The internal validity of the study could not be secured and the statistical results have to be interpreted on that background. Only data from the start and end of therapy could be compared. Bearing these limitations in mind, the study still points in the direction of proving effectiveness of Jungian therapy; there were significant reductions in SCL-90-R and IIP.

\subsection{Berlin Catamnestic Study}

In the early 1990s the Empirical Psychotherapy Research Group in Analytical Psychology Berlin conducted a nationwide catamnestic, retrospective study [16,17]. Former patients of Jungian psychotherapies were asked to participate and were tested via questionnaires and interview. All members of the German Society for Analytical Psychology (DGAP) were asked to participate in this retrospective study: $78 \%$ responded, $24.6 \%$ participated. In retrospective studies there is always the danger of a bias in the sense that only successful patients (or therapists) are willing to participate, which would give no realistic picture of the results. So the reasons for refusal to participate were documented and no bias was found. The participating therapists documented all cases terminated in $1987 / 1988$ and gave a comprehensive evaluation of the success of therapy. In Germany, psychotherapy is financed quite generously by the health insurance companies (up to 300 hours of analysis); at the beginning of therapy the therapist has to apply for financing. These applications contain numerous data about the health state and symptoms of the patient, the personality, the social context, the psychodynamics and diagnosis. This information is stored by the health insurances for decades and the Berlin study made use of these data. Additionally, other health insurance data about the patients could be used, for example, their use of healthcare services, days in hospital, etc. The distribution of symptoms and their severity in the sample were as follows: $46 \%$ affective disorders, $24 \%$ other neurotic and psychosomatic disorders, and $17 \%$ personality disorders.

The problem with catamnestic studies is the risk of biases through selection effects, but these were tested in the study: of 353 documented cases 111 participated in the study; a bias was found concerning the number of therapy drop-outs which was higher in the sample than in the population; 
apart from that the sample was representative for the population. The mean duration of treatment was 162 sessions with a frequency of one to two sessions per week.

Results: of $60.4 \%$ of patients reporting their well-being as very poor (severe set of diagnoses) prior to therapy, $86.6 \%$ rated their global well-being at follow-up as very good, good or moderate (well-adjusted close to normal reference group on all scales of psychopathology). Six years after the termination of treatment $70 \%-94 \%$ reported good to very good improvements in: psychological distress, general well-being, life satisfaction, job performance, partner and family relations, and social functioning. The global health state of $88 \%$ could be described as "normal health". Patients were better off than any of the clinical groups with which they shared diagnoses prior to therapy. Regarding the SCL-90-R Jungian therapy could move the sample of severely disturbed patients close to a standardization sample of normal subjects where one can speak of psychological health (see Figure 1 below).

Figure 1. Mean SCL-90-R measures on follow-up compared to standardization samples (Figure taken from Keller et al. 1997 with kind permission from the author).

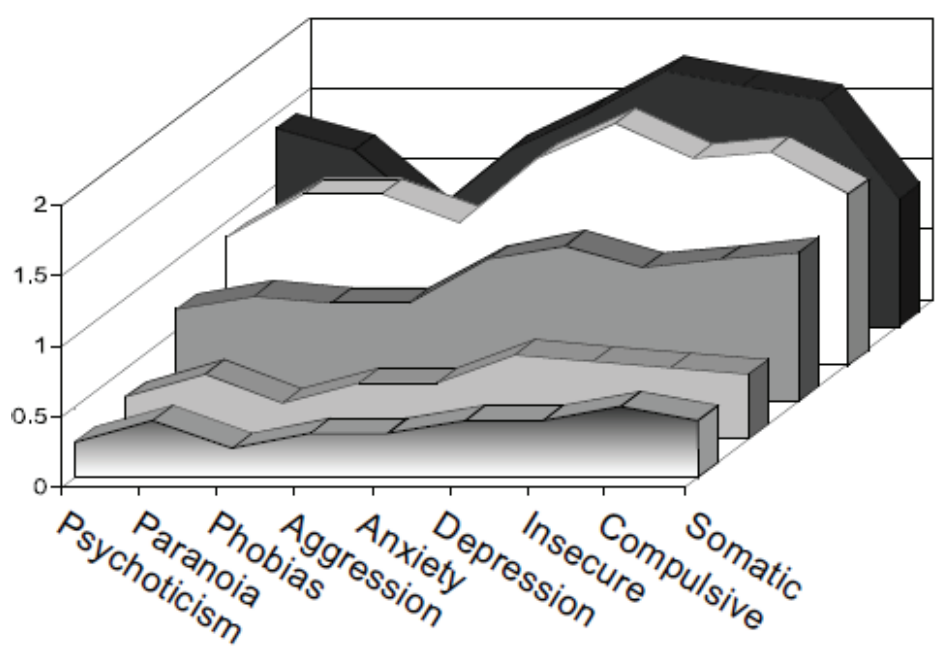

- Normal subjects

$\square$ Jung study sample

$\square$ Psychosomatic disorders

$\square \quad$ Neuroses

- Personality disorders

All of these results were statistically highly significant. There was also a significant reduction of health insurance claims: the mean number of days lost due to sickness, the mean number of days of hospitalization, the intake of psychotropic drugs and the number of visits to primary care physicians were all significantly reduced even below the level of the average German member of the health insurance system (see Figures 2 and 3 below). 
Figure 2. Mean number of days lost per annum due to sickness (Figure taken from Keller et al. 1997 with kind permission from the author).

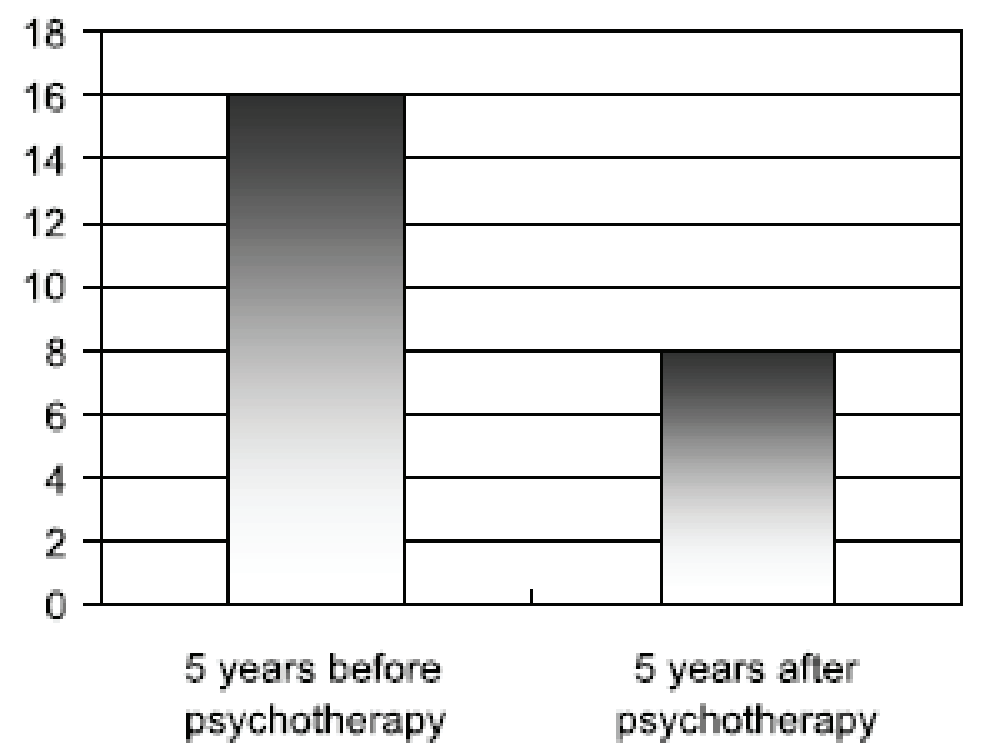

Figure 3. Mean number of days of hospitalization (Figure taken from Keller et al. 1997 with kind permission from the author).

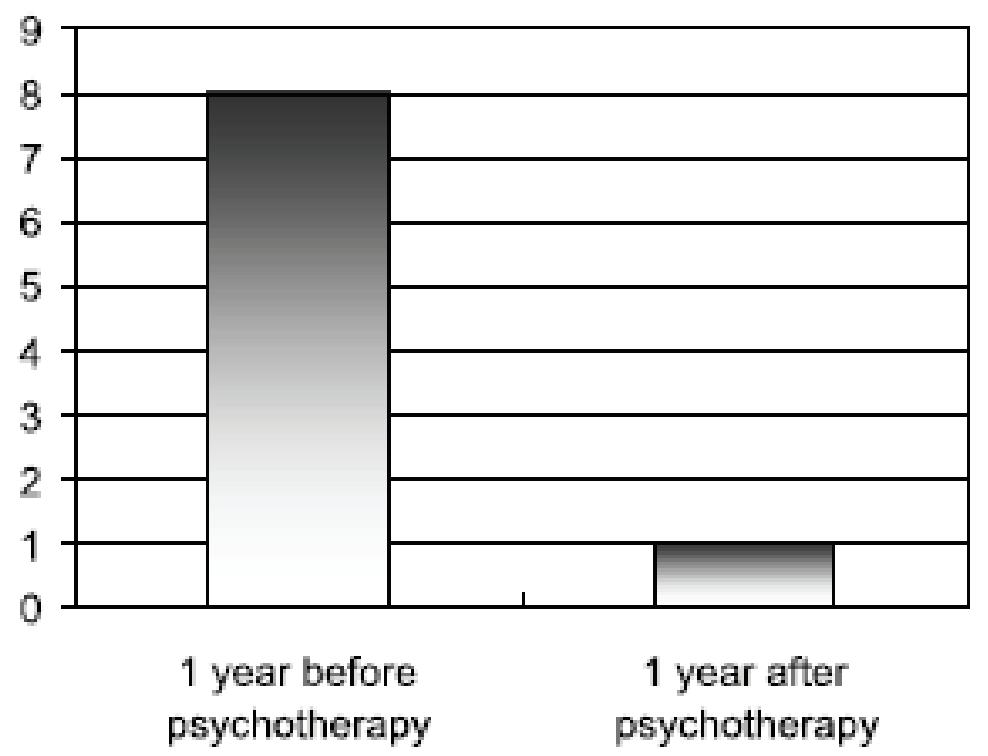

Other interesting findings are seen in the relationship between improvement and treatment length and again there are indicators for further improvements after termination of therapy (between post- and follow-up).

Summarizing the results it can be said that there was not only a high satisfaction of the patients with the Jungian psychotherapy but there was also a reduction in symptoms, which moved the patients into the area of normal health. The effects of psychotherapy were long-lasting and touched all areas of the life of the patients so that even the use of healthcare services was so drastically reduced that Jungian therapy was also cost-effective in the long run. These results have to be 
interpreted against the background of limitations of the design even though the study made great efforts to control biases and secure the representativeness of the sample.

\subsection{Konstanz-Studie-A German replication of Seligman's Consumer Reports Study}

The study conducted in Constance/Germany is a replication of the famous Consumer Reports Study done by Seligman [8] applied to therapies from several psychodynamic schools and in its design comparable to the above-mentioned Berlin study. Ninety psychotherapists distributed 979 questionnaires to former patients of whom $66 \%$ participated in the study. There were no systematic biases found in the sample. About a fifth of the participating therapists had a Jungian background and it could be shown that there are no systematic differences between this subgroup and the overall sample so that the study is representative for psychoanalytic practice in Germany in general and for Jungian psychotherapy.

The results are very much comparable to those of the above-mentioned Berlin study, in all dimensions the study found significant benefits in health and well-being. There were again significant changes between end of therapy and follow-up. As in the Berlin study health insurance data were used and there was found to be a highly significant reduction in health utilization parameters. All of these, results remained stable in a six-year follow-up. A special aspect of this study is the carrying out of a cost-benefit computation: there were significant savings accrued as a result of individual and group psychotherapy in the first two years after therapy (see Table 1 below). These were significantly higher in relation to the severity of the health status of the patient at the beginning of therapy.

Table 1. Savings accrued as a result of individual and group psychotherapy in the first two years after completion of therapy (table taken from Breyer et al. 1997 with kind permission from the authors).

\begin{tabular}{ccc}
\hline & Individual therapy & Group therapy \\
\hline $\begin{array}{c}\text { Savings through expected reduction in } \\
\text { health care events (doctor visits, days } \\
\text { sickness, days in hospital) }\end{array}$ & $8,477.80 \mathrm{DM}$ & $14,330.00 \mathrm{DM}$ \\
Costs of treatment & $33,235.00 \mathrm{DM}$ & $4,305.00 \mathrm{DM}$ \\
Savings/costs ratio & $0.255: 1$ & $3.32: 1$ \\
\hline
\end{tabular}

As this study is a retrospective study the results have to be interpreted against the background of risk of biases but these were controlled for as far as possible.

\subsection{Praxisstudie Ambulante Psychotherapie Schweiz (PAP-S)_Practice Study Outpatient Psychotherapy Switzerland}

This study realized a quasi-experimental design, which is the highest level of all the studies described here. The design is comparable to that of the Zurich Jungian study but additionally it has a parallel control group. In Switzerland, all of the different psychotherapeutic schools are organized in the Charta for Psychotherapy and this was the organizer of the PAP-study. The choice of measures applied followed the recommendations given by the Society for Psychotherapy Research and 
includes outcome as well as process variables. Measures for the patients included: self rating of therapy outcome (Outcome Questionnaire OQ 45), symptoms (Brief Symptom Inventory BSI-the short version of SCL-90-R), depression (Beck Depression Inventory BDI), Sense of Coherence (SOC-9), congruence (K-INK - means self congruence as defined by Carl Rogers), and therapy motivation (FMP). For the researchers: Standardized Clinical Interview for DSM (SKID), Global Assessment of Functioning Individual (GAF) and Relationships (GARF), and Operationalized Psychodynamic Diagnostics (OPD). The study ran seven years (2006-2012) including therapies and follow-up.

The participating psychotherapists mainly utilized psychodynamic and experiential approaches. The problem was that even though the Swiss Jungian Association paid the largest part of the study there were only four Jungian cases participating in the study; which is far too small a number to compute a result for Jungian therapy alone. Even though all the Swiss Jungians were asked to participate; the majority was reluctant.

Nevertheless, the study produced some interesting findings. Generally all the participating schools were successful in improving the health status of the patients significantly and effectively. A part of the study consisted in describing the interventions in detail that are applied by the different schools. In the study, therapies were videotaped and external raters evaluated which of the described interventions were practically applied. This may be the most interesting finding of the whole study: in every school the majority of interventions applied was not school-specific but either general or stemming from a different school. Only about $15 \%$ of the interventions came from the specific background of the therapist. This is a finding that other studies produced that were also investigating the question of the school specificity of interventions applied. Already in the so-called generic model of psychotherapy by Orlinsky [18] it was assumed that there are common factors applied in all schools of psychotherapy that make the greatest part of the impact of psychotherapy. Keller [19] has compared the common factors model with the central interventions used in Jungian psychotherapy and has found many parallels. This of course automatically puts the question whether there even is specificity in the practical therapeutic work of Jungian therapists and what that would be. After so many studies certified the so-called "Dodo-verdict" showing that all schools seem to be equally effective, the current trend in psychotherapy research is to look at differences between therapists and investigate what they actually do when they "do therapy".

\subsection{Small Sample Studies, Case Studies and Qualitative Process Research}

At the Pontifica Universidade Catolica de Sao Paulo, Brazil, there has been a clinical psychology department with an explicitly Jungian orientation for many years. In the Master and Doctoral program, a couple of empirical research papers were produced. Just a few of them will be summarized now. A group of papers investigated the effectiveness of sand play therapy and other explicitly Jungian interventions in different psychosomatic diseases [9-11]. In general, the application of Jungian methods, especially that of sand play therapy, had a very positive effect on the well-being of the patients and in some cases even lead to remission of the physical symptoms. Additionally the papers could show that the psychodynamics behind the psychosomatic disorder clearly influenced the symbolism in the sand pictures and that there was a parallel development between the symbols in sand play therapy and improvements in the well-being of the patients. 
Other investigations attempted to catch other aspects of Jungian psychotherapy interventions and make them accessible for empirical research. Krapp [14] has developed a systematic method for interpretation of pictures from psychotherapeutic processes. Kleeberg [12] investigated the development of shadow symbols in several psychotherapy processes and could show that the unconscious symbols pictured important aspects of the therapeutic relationship. In a single case study on complex theory [13], Heisig investigated the development of complexes in the course of an analytical psychotherapy and could show that in the first phase of the therapy the complexes were reproduced in the transference relationship, whereas towards the end of therapy the ego complex could slowly separate from other complex patterns which can be understood as a process of ego strengthening.

\section{Discussion}

When we put the studies on Jungian therapy in the matrix of evidence-based therapy we get the following:

Level I (randomized controlled trials): no studies

Level II (quasi-experimental studies; prospective naturalistic outcome studies): PAL-Study, San Francisco Research Project (with limitations); PAP-S Study (with control group)

Level III (retrospective studies): Berlin Jungian Study and Constance Study with very high methodological level

Level IV (case studies etc.): positive effects through sand play therapy, in psychosomatic disorders etc.

As there are, up to now, no level I studies (RCTs) there is no proof of efficacy of Jungian psychotherapy, but the effectiveness of Jungian psychotherapy is now empirically proven on the base of the above-mentioned studies; the same can be said for the cost-effectiveness. As most of the studies are naturalistic designs it can be assumed that they give a realistic picture of Jungian therapy in every day practice. All of the studies report positive effects in a wide variety of disorders with good or very good effect sizes on: symptom reduction, well being, interpersonal problems, change of personality structure, reduction of health care utilization, and changes in everyday life conduct. All of these effects are stable in follow-ups up to six years after therapy. There are even further positive changes between termination and follow-up. With an average of only 90 sessions, Jungian therapy is a very time- and cost-effective form of psychodynamic psychotherapy. All the studies realized a high methodological standard with objective measures, different research perspectives (patient, therapist, researcher), and control of biases. The most convincing result concerning the effectiveness of Jungian psychotherapy in the overview of all studies is that their results all point in the same direction even though they had quite different patient samples and applied very different methodologies. Nevertheless, the efficacy of Jungian psychotherapy is still to be proven in a randomized controlled trial design.

A very interesting point is that in all the studies that realized a follow-up, further improvements were found after the end of therapy. In the theoretical model of analytical psychology it was always assumed that some effects would emerge only after the therapeutic relationship has ended. The empirical studies described here give proof of this assumption. This can also be interpreted as 
evidence for the fact that analytical psychotherapy not only changes symptoms but also the structure of personality in a deeper sense which leads to a better adaptation to life contexts and relationships but needs some time to unfold. Therefore, future research should always include a follow-up to catch this effect of analytical psychotherapy.

On the other hand, the overview of the studies indicates some recurrent problems. We have to note that in all studies $10 \%-20 \%$ of patients did not profit from Jungian therapy. This is a common finding also in other studies investigating other schools of psychotherapy. Nevertheless, this should be subject to further research aiming at finding markers for personalities expected to profit from Jungian psychotherapy.

Another severe problem that comes to light in the overview of the studies is the fact that Jungian analysts tend to be very reluctant in participating in empirical studies to the extent that leads almost to the breakdown of studies. From the beginning there were difficulties in recruiting enough practicing analysts to participate in the studies, which is still a problem today as can be seen in the latest example, the PAP-study Switzerland. One of the main arguments against participating in empirical studies was the assumption that the research process would interrupt or at least influence the analytic process and the therapeutic relationship in an unfavorable way. Also it was argued that empirical instruments would never be able to catch the complexity of the analytic process. From my point of view these critical positions are based on false ideas about the research process, its capacities and its limitations. Of course any research design to investigate psychotherapy has its limitations and can only analyze certain aspects of the complex interactions taking place in the process of psychotherapy. However, empirical research methods offer the possibility to get an insight into the psychotherapeutic work and its effects from a more objective position. We have to consider that the perspective of practicing psychotherapists on their own processes is, and has to be, mainly subjective and is subject to interpretation and also to the possibility of error. On the other hand, empirical research can never claim to tell the whole truth about psychotherapy. We also have to consider that the work of psychotherapy has a major impact on the lives of the clients and therefore it is an ethical requirement to install quality management processes of which psychotherapy effectiveness research is one.

From my point of view this should be a point of discussion in the Jungian community. At least it can be said now that the point that was often made from critics of empirical research in the Jungian community - that empirical methods would interfere with the special situation of the analytical relationship - has been falsified by the above studies: in no study there was any hint of a negative interference into the psychotherapeutic process; some studies made great efforts to adapt or even develop research measures which catch aspects specific to the Jungian background, for example, changes in personality or the adaptation of psychodynamic diagnostics [15]. On the other hand, Jungian psychotherapy can now offer empirical results about the effectiveness of its method and is no longer subject to the critique that the method is not effective or empirically proven. For a more detailed description and discussion of research in Jungian psychology see the German publication by Roesler [20]. 


\section{Prospects: Currently Ongoing Studies in Germany}

The German Association of Analytical Psychology has formed a research platform (www.cgjung.de/forum), which is currently planning to conduct several studies in the field of Jungian psychotherapy. The training institutes are working on an agreement that future training candidates will have to apply a set of empirical measures (symptoms, life satisfaction, Operationalized Psychodynamic Diagnostics) to their training cases in order to form a database and to make ongoing quality management possible. In the long run this aims at creating a more open attitude to empirical research in the coming generations of Jungian analysts. On the other hand this process aims at stabilizing the currently comfortable position Jungian therapy has in the German healthcare system for the future, by delivering empirical results on the effectiveness of the methods and applying standard quality management processes.

Structural dream analysis: The author has developed a narratological qualitative research method for analyzing dream series from analytical psychotherapies and extracting the core process of change in the course of the psychotherapy [21]. At the moment a number of dream series from Jungian psychotherapy processes are being analyzed using this method in a research project at the University of Basel, Switzerland. After the Structural Analysis of a dream series is completed, the results are compared with the report from the psychotherapist about the process of the therapy. This project aims at building a corpus of cases, which would make it possible in the long run to show that the unconscious produces therapeutic change via dreams in the course of an analytic therapy.

In another research project, a documentation scheme for systematic documentation of synchronistic events taking place in psychotherapy is applied [22]. This documentation scheme is now distributed in the German Jung Association and practicing analysts are invited to document relevant events to build up a corpus of cases, which will be subject to further analysis. This project aims at building an empirically based theory of synchronicity in psychotherapy.

In general, these projects and attempts aim at generating a more research open attitude in the Jungian community and a more evidence-based foundation of the theoretical models of Analytical Psychology.

\section{Conflicts of Interest}

The author declares no conflict of interest.

\section{References}

1. Lambert, M.J. Bergin and Garfield's Handbook of Psychotherapy and Behavior Change, 5th ed.; Wiley: New York, NY, USA, 2004.

2. Westen, D.; Morrison, K. A multidimensional meta-analysis of treatments for depression, panic, and generalized anxiety disorder: An empirical examination of the status of empiricially supported therapies. J. Consult. Clin. Psychol. 2001, 69, 875-899.

3. Mattanza, G.; Jakobsen, T.; Hurt, J. Jung'sche Psychotherapie ist effizient. In Seele und Forschung. Ein Brückenschlag in der Psychotherapie (in German); Mattanza, G., Meier, I., Schegel, M., Eds.; Karger: Basel, Switzerland, 2006; pp. 38-82. 
4. Rudolf, G.; Dilg, R.; Grande, T.; Jakobsen, T.; Keller, W.; Krawietz, B.; Langer, M.; Stehle, S.; Oberbracht, C. Effektivität und Effizienz psychoanalytischer Langzeittherapie: Die Praxisstudie analytische Langzeittherapie. In Psychoanalyse des Glaubens (in German); Gerlach, A., Schlösser, A., Springer, A., Eds.; Psychosozial: Gießen, Germany, 2004; pp. 515-528.

5. Rubin, S.I.; Powers, N. Analyzing the San Francisco Psychotherapy Research Project. Available online: http://www.sirseth.net/doc/SFresearch.pdf (accessed on 27 July 2013).

6. Tschuschke, V.; Crameri, A.; Koemeda, M.; Schulthess, P.; von Wyl, A.; Weber, R. Fundamental Reflections on Psychotherapy Research and Initial Results of the Naturalistic Psychotherapy Study on Outpatient Treatment in Switzerland (PAP-S). Int. J. Psychoth. 2010, 14, 247-256.

7. Keller, W.; Dilg, R.; Westhoff, G.; Rohner, R.; Studt, H.H. and the Empirical Psychotherapy Research Group in Analytical Psychology Berlin. On the efficacy of outpatient Jungian psychoanalyses and psychotherapies. In Proceedings of the 13th International Congress for Analytical Psychology, Zürich, Switzerland, 17-23 August 1995; Mattoon, M.A., Ed.; Daimon: Einsiedeln, Switzerland, 1997.

8. Breyer, F.; Heinzel, R.; Klein, T. Kosten und Nutzen ambulanter Psychoanalyse in Deutschland. (Cost and benefit of outpatient analytical psychotherapy in Germany). Gesundheitsökonomie und Qualitätsmanagement 1997, 2, 59-73.

9. Tavares, M.L. The Patient's Psyche in Cancer Terminal Phase. Ph.D. Dissertation, Pontifica Universidade Catolica de Sao Paulo, Sao Paulo, Brazil, 2002.

10. Muller, M. A Psychosomatic Study of Patients with Vitiligo from an Analytical Approach. Ph.D. Dissertation, Pontifícia Universidade Católica de São Paulo, Sao Paulo, Brazil, 2001.

11. Yoshika, M.L. A Psychosomatic Study of Women with Polycystic Ovary Syndrome (PCOS) through Sandplay Therapy. Ph.D. Dissertation, Pontifica Universidade Catolica de Sao Paulo, Sao Paulo, Brazil, 2002.

12. Kleeberg, A.; Schreiber, S.; Schwinger, T. Symbole als Ausdruck der therapeutischen Beziehung. Eine empirische Untersuchung zur Schattensymbolik in einer jungianischen Psychotherapie. Anal. Psych. 2003, 34, 266-297 (in German).

13. Heisig D. Wandlungsprozesse durch die therapeutische Beziehung. Anal. Psych. 2001, 32, 230-251 (in German).

14. Krapp, M. Pictorial-hermeneutic, qualitative methods. In Open Questions in Analytical Psychology; Mattoon, M.A., Ed.; Daimon: Einsiedeln, Switzerland, 1997; pp. 581-586.

15. Junghan, M. Die Anwendung der Strukturachse der OPD in der Analytischen Psychologie. In Die Struktur der Persönlichkeit (in German); Rudolf, G., Grande, T., Henningsen, P., Eds.; Schattauer: Stuttgart, Germany, 2002; pp. 90-114.

16. Keller, W.; Dilg, R.; Westhoff, G.; Rohner, R.; Studt, H.H. and the Empirical Psychotherapy Research Group in Analytical Psychology Berlin. The Berlin Jungian Study: on the effectiveness and efficacy of outpatient (Jungian) psychoanalysis and psychotherapy-a catamnestic study (BJS). In An Open Door Review of Outcome Studies in Psychoanalysis; Report prepared by the Research Committee of the IPA at the request of the President 1999; Fonagy, P., Ed.; International Psychoanalytic Association: London, UK, 1999. 
17. Keller, W.; Westhoff, G.; Dilg, R.; Rohner, R.; Studt, H.H. and the study group on empirical psychotherapy research in analytical psychology. Efficacy and cost effectiveness aspects of outpatient (Jungian) psychoanalysis and psychotherapy — a catamnestic study. In Longer-Term Psychoanalytic Treatment: Perspectives for Therapists and Researchers; Leuzinger-Bohleber, M., Target, M., Eds.; Whurr: London, UK, 2002.

18. Orlinsky, D.E.; Grawe, K.; Parks, B.K. Process and Outcome in Psychotherapy. In Handbook of Psychotherapy and Behaviour Change, 4th ed.; Garfield, S.L., Bergin, A.E., Eds.; Wiley: New York, NY, USA, 1994; pp. 270-376.

19. Keller, W.; Stehle, S.; Dilg, R.; Grande, T.; Rudolf, G.; Oberbracht, C.; Mattanza, G.; Junghan, M.; Krapp, M. Empirical Research in Psychoanalysis and Analytic Psychotherapy. In Destruction and Creation: Personal and Cultural Transformations; Mattoon, M., Ed.; Daimon: Einsiedeln, Switzerland, 1999; pp. 556-586.

20. Roesler, C. Analytische Psychologie heute. Der aktuelle Stand der Forschung zur Psychologie C.G.Jungs (German); Karger: Basel, Switzerland, 2010.

21. Roesler, C.; Götz, N. Manual zur Strukturalen Traumanalyse (in German). 2012, unpublished paper. Available online: http://www.cgjung.de/forum/index.php?page=Thread\&postID=37\#post37 (accessed on 22 September 2013).

22. Roesler, C. A Research Frame for Investigating the Appearance of Synchronistic Events in Psychotherapy. In The Pauli-Jung Dialogue and Its Impact Today; Atmanspacher, H., Fuchs, C., Eds.; Imprint Academic: Exeter, UK, 2013, in print. 
MDPI AG

Klybeckstrasse 64

4057 Basel, Switzerland

Tel. +41616837734

Fax +41613028918

http://www.mdpi.com/

Behavioural Sciences Editorial Office

E-mail: behavsci@mdpi.com

http://www.mdpi.com/journal/behavsci 


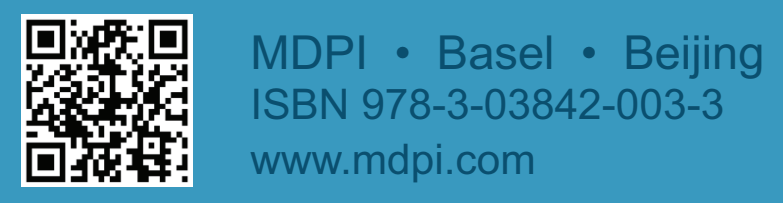

